\title{
The Role of Play in Children's Health and Development
}

Edited by

Ute Navidi

Printed Edition of the Special Issue Published in Children 
Ute Navidi (Ed.)

\section{The Role of Play in Children's Health and Development}

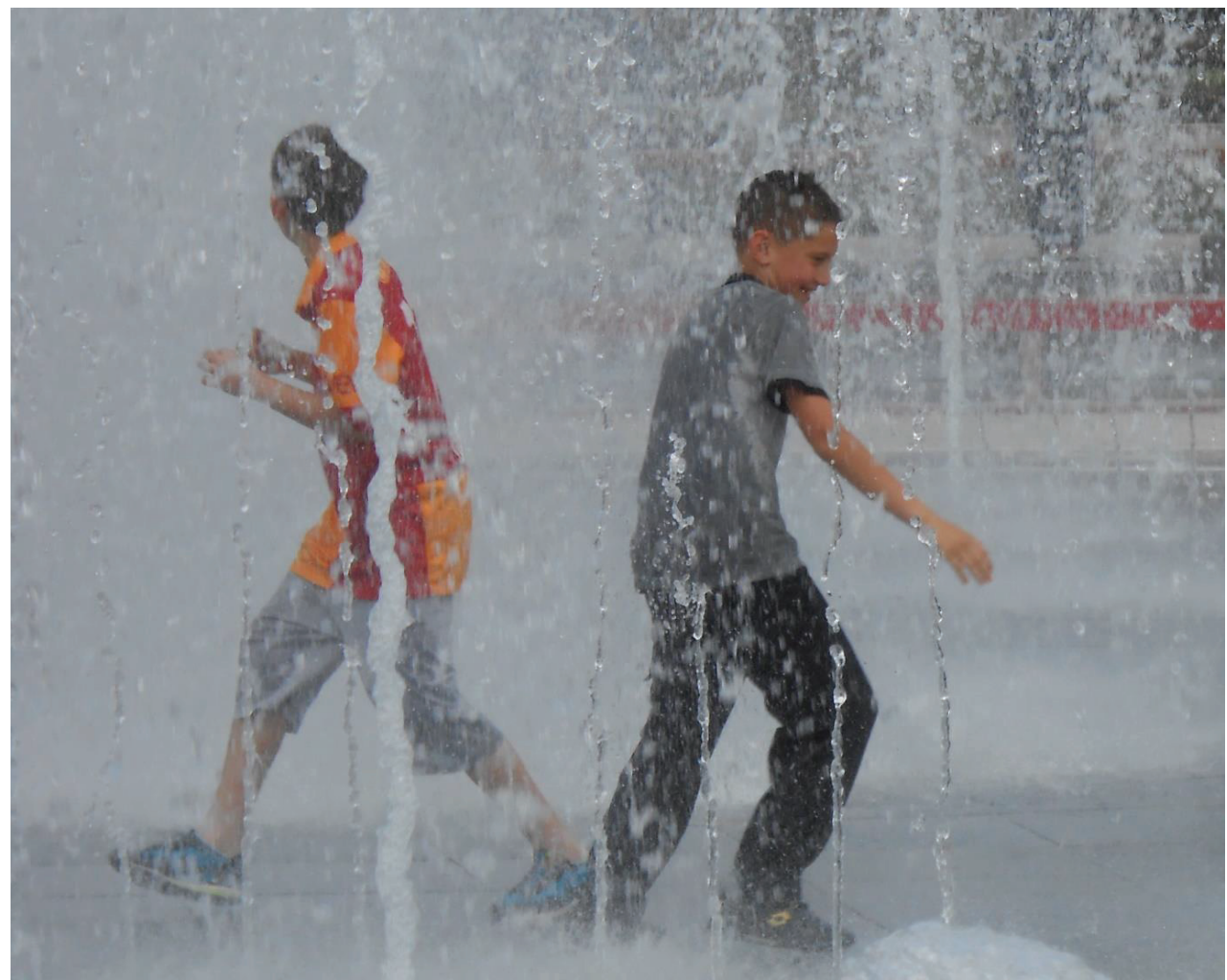

Photo credit: Ute Navidi

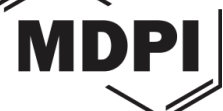


This book is a reprint of the special issue that appeared in the online open access journal Children (ISSN 2227-9067) in 2014 (available at:

http://www.mdpi.com/journal/children/special_issues/play_children_health).

\section{Guest Editor}

Dr. Ute Navidi

Independent International Consultant

formerly Regional Vice President (Europe),

International Play Association

Editorial Office

MDPI AG

Klybeckstrasse 64

Basel, Switzerland

Publisher

Shu-Kun Lin

Managing Editor

Delphine Guérin

\section{Edition 2016}

MDPI • Basel • Beijing • Wuhan

ISBN 978-3-03842-181-8 (Hbk)

ISBN 978-3-03842-182-5 (PDF)

(C) 2016 by the authors; licensee MDPI, Basel, Switzerland. All articles in this volume are Open Access distributed under the Creative Commons License (CC-BY), which allows users to download, copy and build upon published articles even for commercial purposes, as long as the author and publisher are properly credited, which ensures maximum dissemination and a wider impact of our publications. However, the dissemination and distribution of physical copies of this book as a whole is restricted to MDPI, Basel, Switzerland. 


\section{Table of Contents}

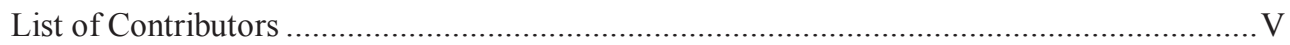

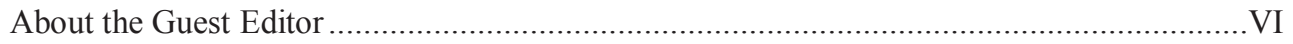

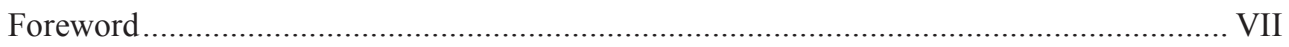

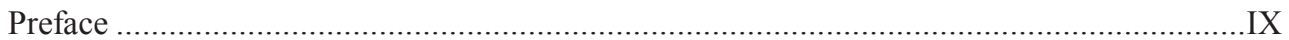

\section{Chapter 1: Play: Promoting Children's Physical and Mental Health and} Well Being

\section{Stuart Lester and Wendy Russell}

Turning the World Upside Down: Playing as the Deliberate Creation of Uncertainty Reprinted from: Children 2014, 1(2), 241-260

http://www.mdpi.com/2227-9067/1/2/241

\section{Perry Else}

Teenagers and Playing: Are Pastimes Like Neknominate a Usual Response to Adolescence?

Reprinted from: Children 2014, 1(3), 339-354

http://www.mdpi.com/2227-9067/1/3/339

\section{Jane Hewes}

Seeking Balance in Motion: The Role of Spontaneous Free Play in Promoting Social and Emotional Health in Early Childhood Care and Education

Reprinted from: Children 2014, 1(3), 280-301

http://www.mdpi.com/2227-9067/1/3/280

\section{Lis Mathiasen}

Prevention is Better than Cure: A Hands-On, Play-Based, Innovative, Health and Well-Being Program in Remote Australia

Reprinted from: Children 2014, 1(3), 318-338

http://www.mdpi.com/2227-9067/1/3/318 


\section{Chapter 2: Coping with Illness and Getting Better through Play}

\section{Fraser Brown}

The Healing Power of Play: Therapeutic Work with Chronically Neglected and

Abused Children

Reprinted from: Children 2014, 1(3), 474-488

http://www.mdpi.com/2227-9067/1/3/474

\section{Laura Anes and Marianne Obi}

Hospital Clowning as Play Stimulus in Healthcare

Reprinted from: Children 2014, 1(3), 374-389

http://www.mdpi.com/2227-9067/1/3/374

\section{Lino de Macedo, Gláucia Faria da Silva and Sandra Mutarelli Setúbal}

Pediatric Hospital: The Paradigms of Play in Brazil

Reprinted from: Children 2015, 2(1), 66-77

http://www.mdpi.com/2227-9067/2/1/66 116

\section{Sue Boucher, Julia Downing and Rise Shemilt}

The Role of Play in Children's Palliative Care

Reprinted from: Children 2014, 1(3), 302-317

http://www.mdpi.com/2227-9067/1/3/302

\section{Chapter 3: Restorative Powers of Play}

\section{Isami Kinoshita and Helen Woolley}

Children's Play Environment after a Disaster: The Great East Japan Earthquake

Reprinted from: Children 2015, 2(1), 39-62

http://www.mdpi.com/2227-9067/2/1/39

\section{Laleh Taheri and Golshan Chahian}

Restoration of Traditional Children's Play in Iranian Nomadic Societies (Case Study of

Kohgilouyeh and Boyer Ahmad

Reprinted from: Children 2015, 2(2), 211-227

http://www.mdpi.com/2227-9067/2/2/211 


\section{List of Contributors}

Laura Anes: RED NOSES Clowndoctors International, Wattgasse 48, A-1170 Vienna, Austria.

Sue Boucher: International Children's Palliative Care Network (ICPCN), Assagay 3610, South Africa.

Fraser Brown: Leeds Beckett University, City Campus, Leeds LS1 3HE, UK.

Golshan Chahian: Ecology and sustainable landscape planning and designer, CENESTA, Shiraz, Iran.

Gláucia Faria da Silva: Hospital Infantil Sabará, Fundação José Luiz Egydio Setúbal, Av. Angélica, 1987, 17o. Andar, 01.227-2000-São Paulo/SP, Brazil.

Lino de Macedo: Instituto Pensi, Fundação José Luiz Egydio Setúbal, Av. Angélica, 1987, 17o. Andar, 01.227-2000-São Paulo/SP, Brazil.

Julia Downing: International Children's Palliative Care Network, Assagay, 3610, South Africa.

Perry Else: Sheffield Hallam University, UK; International Play Association - England, Wales and Northern Ireland (IPA-EWNI). Sadly, Dr. Perry Else passed away on 1 June 2014. It stands as a tribute to his work, passion and dedication that he managed to complete the article whilst very ill.

Jane Hewes: Early Learning and Child Care, Faculty of Health and Community Studies, MacEwan University, Edmonton AB T5J4P2, Canada.

Isami Kinoshita: Department of Landscape Architecture, Chiba University, Matsudo 271-8510, Japan.

Stuart Lester: Faculty of Applied Sciences, University of Gloucestershire, Oxstalls Campus, Oxstalls Lane, Gloucester GL2 9HW, UK.

Lis Mathiasen: Association for the Welfare of Children in Hospital WA Inc., Princess Margaret Hospital for Children, BOX D184, Perth 6840, Western Australia, Australia.

Marianne Obi: RED NOSES Clowndoctors International, Wattgasse 48, A-1170 Vienna, Austria.

Wendy Russell: Faculty of Applied Sciences, University of Gloucestershire, Oxstalls Campus, Oxstalls Lane, Gloucester GL2 9HW, UK.

Sandra Mutarelli Setúbal: Hospital Infantil Sabará, Fundação José Luiz Egydio Setúbal, Av. Angélica, 1987, 17o. Andar, 01.227-2000-São Paulo/SP, Brazil.

Rise Shemilt: Paediatric Palliative Care Service, Gaddum Centre, Manchester, M15 4AX, UK.

Laleh Taheri: Architect, from the nomadic tribe of Boyer Ahmad, CENESTA, Shiraz, Iran. Helen Woolley: Department of Landscape, The University of Sheffield, Sheffield S10 2TN, UK. 


\section{About the Guest Editor}

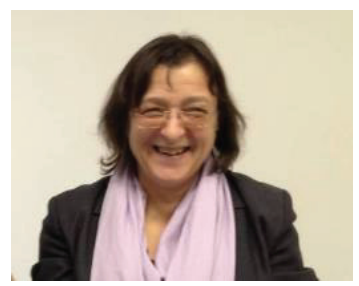

Dr. Ute Navidi is an Independent International Consultant and External Expert, for the European Commission. Her recent history includes roles as the CEO of London Play, Regional Vice President (Europe) of International Play Association, and Consultant Director of the Hillingdon Play Association.

E-Mail: ute.navidi_europe@yahoo.co.uk

Skype: uteipa 


\title{
Foreword
}

\author{
Play is the only way the highest intelligence of humankind can unfold. \\ -Joseph Chilton Pearce
}

This compilation of contributions from around the globe is both compelling and eye-opening. I am particularly struck by the fundamental, yet often under-recognized, relationship of child wellness to play. As the different perspectives given in this culturally-diverse compilation demonstrate, the psychological, developmental and physical rewards of play for children can neither be overstated nor overemphasized. It is easy to discern through the perspectives provided by these authors how play significantly enhances a child's social competence, cognitive functioning, motor skills, and resiliency to combat anxiety, fear, and hopelessness. Moreover, it is also evident that forms of play evolve and yet continue to be bound by societal values and culture. Thus, they remain susceptible both to the impositions brought about by new technology (and its related sedentary behavior), as well as to the boundaries created by caregivers and their environmental, cultural and socioeconomic surroundings.

Through my own personal experiences, first as a child raised in the midst of the long civil war in Lebanon, and later as a father and a pediatrician involved in the care of children for over 25 years, I have witnessed first-hand how play, laughter, and imagination can mitigate a child's internalization of helplessness and loss of control. Even through the struggle to comprehend physical pain, uncertainty, and disquieting environments, children use play as a coping mechanism to negotiate meaning and understanding. As demonstrated in this book, the healing and therapeutic benefits of play greatly assist in offsetting a myriad of impediments to achieving healthy child development.

Dr. Ute Navidi has dedicated her career to advocating for children's rights both in England and throughout the globe. She has fearlessly tackled the status quo by speaking out against Westernized societies that have blindly become so entrenched in risk-aversion, as playgrounds are dismantled and outside play is plagued by a trend of fear. She has additionally challenged our traditional understanding of what factors affect healthy development in a child, maintaining that risk and the opportunity to take risk are significant ingredients to raising self-reliant and well-equipped members of society. I applaud her for her insightfulness and for her continued advocacy for the most vulnerable members of society. 
Our editorial team greatly values Dr. Navidi as a guest editor, her initial proposal for this special issue of Children, and her dedication to bringing it all together. The response to this special issue was overwhelmingly positive. I hope readers find this publication as inspiring and relevant as I do.

Sari Acra, MD, MPH

Professor and Division Chief D. Brent Polk Division of Pediatric Gastroenterology, Hepatology and Nutrition Vanderbilt University School of Medicine, Nashville, Tennessee, USA 


\section{Preface}

The importance and benefits of play for the holistic development of children are not always appreciated by professionals working in fields such as child welfare, health, education, and housing. Whilst earlier generations of children often played freely outdoors, today's children around the globe face many barriers to play, not least because of the "toxic" environments humankind has created. Yet play "heralds the beginning of civilisation by imposing routines, rituals, and rules upon the expression of the universal primary and relentless adaptive emotions (loneliness, anger, fear, shock, disgust, and apathy)" (Brian Sutton-Smith). Play research has progressed our knowledge, but has yet to reach wider audiences and influence practice. Many aspects of, and assumptions surrounding play — and even definitions - remain controversial and subject to debate.

Play benefits all children, and has protective and preventative functions. With a focus on health, this special issue addresses: the benefits of play for children's physical and mental health; play at different developmental stages; and the therapeutic power of play. "Opportunities for play can help children to work through difficult experiences, to make sense of life around them, to cope better with changes that have happened in their lives and sometimes to restore and heal them, as well as to provide fun, friendship and support positive relationships" (Theresa Casey). This collection of papers from around the world provides unique insights from play-related research and practice. It is based on the corresponding MDPI online resource which intended to provide a space where academics and practitioners can discuss, share knowledge and case studies, and find partners for joint projects and further studies with a focus on play and children's well-being. We hope this book serves as a stimulus for continuing the sharing.

As guest editor, I would like to thank all authors for their thoughtful and thought-provoking contributions (and their translators, as appropriate), and all people associated with this publication at the MDPI Children Editorial Office, in particular Delia Costache, then Managing Editor (succeeded by Franziska Vogel), and Dr. Sari A. Acra, Editor in Chief, who together had the vision to support this special issue of Children on play, Martyn Rittman, Editorial Director, as well as Wenchao Zhu and Zhenfang Zhao, Assistant Editors, and Laura Wagner, Manager of the Monographs Program.

Special thanks are due to the anonymous peer reviewers from around the globe who gave of their time and wisdom and made constructive comments, and helped to steady the bridge between papers from social sciences and practitioners' perspectives, and the journal's clinical/medical and natural sciences character.

Dr. Ute Navidi

Guest Editor 



\section{Chapter 1:}

Play: Promoting Children's Physical and Mental Health and Well Being 



\title{
Turning the World Upside Down: Playing as the Deliberate Creation of Uncertainty
}

\author{
Stuart Lester and Wendy Russell
}

\begin{abstract}
Risk is big business. It has assumed almost universal acceptance as an ever-present reality of life, something out there waiting to cause harm (most notably to political, economic and health systems). It commands vast resources to develop preventative measures that are the preserve of experts issuing often contradictory advice and warnings. Children's play is caught up in this account. No longer something that children just do, it is subject to adult scrutiny that simultaneously and paradoxically attempts to manage risk and promote "risk-taking" for its perceived instrumental benefits, primarily the development of risk assessing skills. Adults thus guide children's play, rendering children passive and needy recipients of expertise. This article takes a broader perspective to consider how this contemporary understanding of risk plays out in material discursive practices in relation to childhood, play, health and wellbeing. It then draws on conceptual tools of relationality, materiality and performativity to reconfigure playing as an emergent co-production of entangled bodies, affects, objects, space and histories in ways that make life better for the time of playing. Such moments produce health-affirming potential as an intra-dependent phenomenon rather than an individual achievement. Finally, it considers implications for "health promotion" and health enabling environments.
\end{abstract}

Reprinted from Children. Cite as: Lester, S.; Russell, W. Turning the World Upside Down: Playing as the Deliberate Creation of Uncertainty. Children 2014, 1, 241-260.

\section{Introduction}

One summer afternoon, some children had been investigating around the edges. One boy emerged with the red plastic slide from the kit house that is scattered around. He said "Look what I found! What can I do with it?" Several other children followed him. They decided to take it up the water tower structure. They worked together to lift the slide up the structure. They got to the level where the rope hangs over the sand pit. The group of 4-5 boys involved were all very competent climbers so I decided to watch from a distance what happened next. They pushed the slide out over the end of the structure above the sand and two of them sat on the slide, stopping it from falling over the edge with their weight. Then after a countdown, the boy at the back got off and the slide dropped with one boy still on it. He grabbed the rope just in time to stop himself falling along with the slide. The level of excitement was something I've not seen before on the playground. He climbed down. The other boys congratulated him on surviving. He said "That was sick! That was sick you know!" One of the other boys said "We could do this every day!" The first boy said "I didn't know I was going to make it! I thought I was going to die!" (Research participant's blog [1]). 
We can make sense of this extract from a blog in a recent action research project on an adventure playground in a number of ways. The aim of this article is to present a perspective on playing that challenges and extends the current common-sense understanding of "play" and its instrumental application in policy and practice settings, using this extract as an illustration. The endeavor here is to turn conventional wisdom on its head in pretty much the same fashion as children do when playing. In performing this task, the intention is not merely to critique and deconstruct, but to reconfigure, by drawing on a different set of conceptual tools and approaches from those traditionally employed in the study of play and by doing so attempt to forge some new connections. It is a generative and additive piece, assembling ideas that are intended to multiply rather than subtract [2] and to open what appears to be taken-for-granted assumptions and relationships to more critical scrutiny to see what more might be revealed. In undertaking this task, the article:

- considers contemporary perspectives on risk and how they play out in material discursive practices in relation to childhood;

- explores the entanglement of play, risk and health;

- introduces another perspective on playing; and

- considers implications for "health promotion" and health enabling environments.

\section{Risky Childhoods}

Pre-modern meanings of risk largely portray it as existing outside of human affairs; humans could do little against these potential dangers other than estimate their likelihood and take steps to limit their impact [3]. Its origins in modern usage can be attributed to principles of maritime insurance as a way of describing the balance between opportunities for profit and potential dangers [4]. This suggests a relatively neutral position on risk, implying there are potential benefits as well as losses. However with the advancement of "modernity" (the rise of an industrialized, scientific, technical, rational and liberal state), risk is commonly equated with threats and adverse outcomes. While definitions and applications may be contested, in the context of this article it is used as a generic concept that denotes "a family of ways of thinking and acting that involve calculations about probable futures in the present followed by interventions into the present in order to control that potential future" [5] (p. 70). The risks apparent in the opening scenario therefore might include serious injury on the part of the child, or allegations of negligence on the part of the adult observer (perhaps in the form of legal action), both of which require an intervention to reduce or remove this possibility. It is this interventionist and utopian discourse that is central to the discussion here. First, we propose an opening position, drawing on and extending Foucault's [6] concepts of biopower/biopolitics and governmentality, tracing this through more contemporary thinking that engages with "risk" [3,5,7,8]. It considers how complex and multiple disciplinary forces, coalescing around notions of risk and enshrined in so many socially legitimated powers and authorities, seek to shape and fashion the lives of individuals $[8,9]$.

Risk is a defining feature of modern society and pervades all aspects of everyday life, filling it with perceived physical, moral, psychological, social, technological, economic, geopolitical and 
environmental dangers [10]. Scientific advancements have unveiled numerous previously unknown risks, bringing them to our attention thereby also creating demand for action against them. Risk has become the lens through which activities are judged, yet such judgments are now largely beyond the lay-person [11]. The science of risk calculation, assessment and evaluation has become the hallmark of modernity's progress by rationalization and calculation; "from the actuarial tables of life insurers to the risk analysis of those in the business of risk: the movers and shakers of capitalism" [12] (p.12). The technology of risk-assessment is entangled with knowledge, instruments, bodies, institutions and spaces to form assumptions about life itself [5] and to shape patterns of governance. The biopolitical drive to minimize risks to human health extends, for example, to control of environmental pollution, reduction of accidents (including falling off the plastic slide in the opening scenario), maintenance of body health and nurturing of children.

A key feature of the biopolitics of risk is the governing of conduct [9]; people are placed under constant surveillance while at the same time increasingly encouraged to monitor themselves. It marks a political and ethical field where individuals are obliged to assess, make responsible choices and to take control over their lives, to monitor inputs (food, sleep, alcohol, nicotine, etc.) and outputs (exercise, time-management, body shape, etc.) with the intention of minimizing exposure to health hazards [8]. Failure to do so labels individuals as "risky", generating both societal disapproval and also potentially feelings of personal shame, despair or disengagement [13]. Rose calls this the "responsibilization" of life, or what Beck refers to as "individualization", in which more and more aspects of behavior are subject to self-reflection and self-management. Thus, for example, family support networks are replaced by reliance on individual ingenuity to develop personal support mechanisms and economic self-responsibility [10]. Evaluating risk establishes a moral dimension to bodily behavior, creating a hierarchy between those who choose to use the advice on "safe" ways to manage their bodies and those who do not. Individuals are encouraged to "care for the self" and blame may be attached to those who fail or who choose not to take responsibility for their own health.

This "modern" conception of risk inevitably contributes to the formation of childhood, marking it as a period of the life-course in which the vulnerable innocence of the child needs protecting from the multiple risks that lie in wait to cause harm [14]. There is an inherent presumption that children's vulnerability and immaturity render them more susceptible to risks than adults who are better positioned to make informed judgments [15]. Returning to the opening scenario, the observing adult is understood as being responsible for making judgments about the likelihood of serious injury, evident in her comment about the boys being competent climbers. The construction of the innocent child imbues children with their own form of "specialness", [15]. Adult nostalgia for times spent playing outdoors, in a carefree state away from adults, provokes a sense of loss for more innocent times. Perceived contemporary social ills threaten this state of innocence and promote ever-increasing levels of risk-anxiety and fear (for example, child abuse, children's access to information technologies and the commodification and sexualization of childhood). In minority world countries, contemporary childhood has become the most intensely governed period of life [16]. (We use the terms "minority" and "majority" here to refer to what are often termed "developed" and "developing" countries respectively. This format is preferred as it acknowledges that much 
power resides in the few countries whose economic, political and cultural activities affect the majority of the world. We are also aware that the use of these terms may suggest a dichotomy that elides the multiple and diverse contexts and contestations that ebb and flow between such a simple division.) Children's lives are increasingly subject to measuring and monitoring to provide "more accurate measures of the conditions children face and the outcomes various programs achieve" [17] (p. 21), giving rise to high levels of surveillance in which the "child has become the target of social, political, educational and legal regulations that constitute children as the powerless and dependent Other in relation to adults in society" [18] (p. 5) and as such in need of protection. The discourse of protection, generally framed within the well-intentioned notion of acting in the best interests of the child (who would not want children's lives to be better?), impacts in multiple and complex ways to shape how children are perceived and acted upon in the family, school and in wider society [18].

Not only are children's positions fixed; adults, as the protectors of children, need to be scrutinized and made accountable, carefully regulated to avert any threat to children's innocence [19]. The regime of risk management acts as a regulatory technology that determines what is desirable and acceptable. It is enacted through a series of judgments and comparisons (policies and standards) and associated practices of symbolic and material rewards and sanctions that come to represent the worth and value of individuals and organizations. Professional practice becomes framed in an over-riding sense of prevention:

We used to have the kids out running around clothed only in their suntan [lotion], naked under those on a hot day. Now we wouldn't do that. We are aware of cultural issues, cultural safety, some cultures don't like them naked, but also sun safety, and of course the safety from voyeurs [20] (p. 242).

Thus, the discourse of risk has material consequences and is played out and negotiated in everyday relationships and spaces; parental anxieties and responsibilities may delimit children's ability to negotiate time/space away from adults [21-23]; practitioners are guarded in their contact with children [20,24].

The governance of children is not just about maintaining the discourse of childhood innocence. Childhood represents a projection of adults' desires, hopes and fears, rendering children redemptive agents who hold the promise of becoming better and who need careful investment in order to realize the utopian vision [25]. It has become a state project of control through particular configurations of language, institutions, materials and space, or what Deleuze and Guattari [26] term "molar assemblages". These seek to shape children's minds and bodies in order to ward off any possible risk to this progression towards the compliant and consuming citizens of tomorrow. The responsibility for safe progression falls to the institutions of childhood (primarily family, school, nursery and health centers) which combine to form a "plane of organization" [26], or blueprint of ideal development, where technical accounts of well-being are increasingly applied to measure progress. These institutions are the conduit through which lives are governed [27].

Health and education institutions have co-emerged as central pillars of this project and have increasingly spread their regimes and accounting procedures into other sectors [28]. The foundations of biomedical accounts of health, (generally seen as the absence of disease) and 
development (generally seen as teleological progression) are deterministic or reductionist in establishing cause-effect relationships [8]. Universal norms are drawn from limited studies to generalize solutions for a range of biomedical, psychological and social risks and problems. The continuous refinement of accounting systems ensures that children can be measured and monitored in systematic ways.

A biomedical perspective also assumes a particular construction of "the body", as a relatively stable thing that is pre-social and pre-discursive, ready to be over-coded by adult calculations and interventions aimed at normalizing "health consciousness". Western philosophical underpinnings of thought, in which cognition is held to be superior to the unruly body, dominate approaches to education and health; the mind is something to be cultivated, and by making conscious, informed, "right" choices the body and its affects are to be controlled, policed, subdued and got out of the way [29]. Such an approach privileges rationality and autonomy; it becomes "an instrumental, calculating and totalizing reason and a scientific knowledge that is unified and claims to reveal an objective and universal truth about humanity, history and nature" [30] (p. 230) producing a biomedical account of the body as "both the object of risk and the subject of risk-reduction" [13] (p. 123).

Children's play is caught up in this future-focused, bio-political, technical yet nostalgic and redemptive project, and the following section considers how it has become entangled in the material discursive practices of risk, health and well-being.

\section{Play, Health and Well-Being}

In minority world countries play is held to be a defining feature of childhood, largely valued for the contribution it makes to "healthy" development. Traditional accounts portray development as a maturation process achieved by the progression through universal stages from simple to increasingly complex, or from "immature" to "mature". The framework of development as progress proposes scenarios in which the future is known, and thus pre-exists the unfolding of life [31]; development becomes a process of "achieving full potential" or becoming filled with what a child needs to become adult. In a desire to avoid uncertainty and risk, uncritical, accepted wisdom and conventions assume a "taken-for-granted sense that harbors given solutions that correspond to given problems and given answers that correspond to given questions" [32] (p. 82). This common-sense, or orthodoxy of materials, codes, practices and discourse, presents a certain view of childhood that informs judgments about progress, distinguishing between a series of binary relationships such as right/wrong or good/bad, carried out with good intentions and in the best interest of all.

Play can be commandeered to support this progression [33] thereby assuming an instrumental value that promotes desirable play behaviors - those that clearly contribute to growing up — while at the same time censuring apparently purposeless, trivial and other undesirable play forms. Play is held to be beneficial for developing physical, cognitive, social and emotional skills, a "deferred benefits" approach in which play serves something outside of playing [34,35]. In this account, play is defined and classified as an activity, subsumed into the plane of organization, ordered, structured, and situated in dedicated time/spaces and for specific purposes. For example, a discourse of play and learning purports to welcome children's freedom to discover and explore through play, but 
such freedom is held in check by pedagogical gaze and scrutiny; children's freedom to discover is strictly monitored and controlled as it is essential that children are discovering the right things [36].

This reified, instrumentalized progress narrative extends to two interrelated aspects of interest to the discussion in this article, namely those of health (as the absence of illness) and safety (as the management of risk). Much of the focus for this is on physical, outdoor play as a particularly promoted category. One example of the growing interest in the instrumental value of play from public health institutions and health promotion units is the promotion of play as a tool to combat obesity [37,38], now given the status of an epidemic in minority world health agendas and increasingly seen as a global issue [39]. The discourse of obesity, from the normative position established by biomedicine, emphasizes the causal relationship between inactivity, poor diet, obesity and poor health; "obese and 'at-risk' (i.e., overweight) bodies are constructed as lazy, expensive, and in need of expert control" [40] (p. 228).

The intention is not to present a critical examination of the obesity discourse; what is at issue here are the ways in which play gets caught up in this account. As Alexander et al. [37] note, it becomes a serious activity that requires deliberation and planning to ensure it achieves its intended purpose. The promotional literature on children's play and obesity constructs play as a health activity, not only seeking to delimit valuable forms of play (and by implication undesirable forms, which in this context generally means sedentary) but also holding adults to account for children's participation in such activity [37,38]. Yet by doing so such policies largely ignore how children co-create moments of play anywhere and everywhere [41]:"where children are is where they play" [42] (p. 10). Playing with the slide on the "water tower" in the opening scenario was not a deliberately planned activity aimed at promoting participation in physical activity.

Alongside the instrumentalization of "physical play" as a tool for combatting obesity is the value attributed to "risky play" and the proposed contribution this makes to children's development of risk-assessment competencies [43]. This position is somewhat problematic and ambiguous. Under the general rubric of the protection of innocence, children's risk-taking is seen as threatening and children are required, as a measure of increasing competence, to avoid risk; injuries and lifestyle-related illnesses are largely attributed to poor risk-management on the part of adults [44]. At the same time, a degree of risk-taking is advocated as beneficial. The development of a risk-benefit approach seeks to adopt a balanced attitude, particularly in UK:

those responsible for play provision can develop an approach to risk management that takes into account the benefits the provision offers to children and young people as well as the risks. It aims to help providers achieve two objectives that are fundamental in any play provision: to offer children and young people challenging, exciting, engaging play opportunities, while ensuring that they are not exposed to unacceptable risk of harm [45] (p. 8).

While this is seen as countering the excessive risk-aversion seen to permeate the institutions of childhood, it is still couched in the (necessary) language of technical risk management processes, placing responsibility on adults to control what is perceived to be irrational behavior. The enactment of this is entangled in a much wider discourse already discussed of adult accountability 
and regulation, childhood as innocence, protection, best interests and future-citizen, with accompanying discursive effects that create the "problem" and by doing so implicitly set limits upon what can be said and done [46]. Thus, adults may often make assessments of children's play based on a literal and risk-focused reading of its content rather than an appreciation of the symbolic, "as if" nature and vivid emotional dimensions. From a protection perspective, the possibility of any injury is undesirable, presenting the potential for harm not only to children but also to adults themselves for failing in their task of keeping children safe [34]. This thinking can readily be applied to the opening scenario. The children's behavior can be understood as risky, in that there is a risk of serious injury; the adult has to make a judgment about the likelihood of injury, which she does by saying she knows them to be competent climbers. The children could be understood to be developing risk assessment skills, as they undoubtedly are; however, what the observation also describes is the affective vitality of the experience for the children (and intimations of this for the adult), and this aspect is picked up later.

There is growing interest in play from public health and education institutions, and the concept of "well-being" has become an adjunct to issues of health and health promotion. Accompanying this is an assumed relationship between children's health and development, actualized in such terms as "healthy development" as shorthand for normative measurements of children's well-being. However, concepts are poorly defined: various terms such as well-being, positive health, quality of life, and happiness are often conflated, vague, lacking definition, and used inconsistently in the literature [47,48], and have become widely critiqued [49,50]. Well-being is a highly political concept that seeks to adopt an objective, normalizing account of what it is to be "well". When it comes to accounting for children's well-being, measurements adopt a deficit approach: children's well-being is measured by a "lack of" education, physical and mental health. Such a stance reinforces the needs agenda in which the identity and trajectory of children is pre-ordained and applied to determine what may be missing from being "normal", constructing an emphasis on children as "well-becomings" rather than well-beings [51]. Morrow and Mayall [50] (p. 227) conclude that the focus on well-being "is ultimately an individualistic, subjective approach that risks depoliticizing children's lives"; studies isolate children from their everyday worlds and experiences. Measures of "well-being" say more about the priorities and ideology of political parties than lived experiences and general definitions of well-being and happiness elide the messy, complex and contingent context of people's everyday lives.

Children's play is increasingly implicated in this process through a range of strategic promotions designed to inculcate values about appropriate behaviors to support progress towards economically productive and healthy adults. The issue at stake here is not so much the value of these interventions but more about the ways in which they produce a certain understanding of the relationship between children and play:

...by regulating children's play to be healthy and active, and thus normalising the ways in which children are encouraged to play, other relative qualities of play may be neglected. Indeed, while playing simply for fun (that is, frivolous pleasure) is considered a common experience of childhood, it appears to be less important than the more productive and explicitly active play for health [37] (p. 14). 
Returning to the opening scenario, such an account would foreground the benefits of the physical activity and the development of risk assessment skills but pay less attention to the significance of the final few sentences:

He said "That was sick! That was sick you know!" One of the other boys said "We could do this every day!" The first boy said "I didn't know I was going to make it! I thought I was going to die!"

However, of course, even in such situations, while children might be regulated there are always opportunities for moments of spontaneous, unpredictable, and pleasurable acts of co-creation that enable children, and sometimes adults, to escape from the demands that others seek to impose on their behaviors and movements. In addition, it is to this perspective on playing that we now turn.

\section{Playing Differently}

So far, we have looked at the ways in which play is a matter of increasing concern in the biopolitical project of childhood, assuming significance as a form of organization of bodies. In doing so, it reduces complex and lively behavior to narrow instrumental purpose, based on a biomedical model that reflects and perpetuates a series of binary relationships: adult/child, active/sedentary, work/play, safe/risky, purposeful/frivolous, health/illness, rational/irrational, etc.; the first of each of these being the ideal conditions for the development of healthy identities, their binary opposites sites of concern. Life begins with a pre-established endowment (genetic predispositions) and moves, through a process of cultural acquisition, towards "terminal closure, a gradual filling up of capacities and shutting down of possibilities" [31] (p. 4). The creation, identification, measurement and classification of needs is a driving force of neoliberalism (control, commodification, consumption), reducing behavior to measurements (children need 60 minutes of physical activity each day) and feeding off these for its own purpose. It produces a metanarrative that positions childhood as risky and needy, a condition defined by multiple and omnipresent threats that are analyzed with little regard for the multiple and complex ways in which children feel about, negotiate and act upon them in their everyday lives [52]. Life itself is rarely given attention; theorists have treated it as merely consequential, the derivative representation of patterns, codes, structures or systems variously defined as genetic/cultural or natural/social, and thereby expunging life from their accounts [31]. The force and vitality of life, its exuberance and suppleness ("I didn't know I was going to make it! I thought I was going to die!") becomes over-coded by the reactive demands and discursive/material effects of such representations [27]. Attention is given to assessing, valuing and normalizing the properties of bodies rather than seeing what they can do ("I decided to watch from a distance what happened next").

A number of studies of risk and health [40,44,52] and broader studies of childhood [53-56] counter dominant biomedical accounts, noting little attention is given to the everyday ways in which children go on with their lives. The intention here is to develop this in order to think playing differently, to turn the world upside down, by drawing on a different set of conceptual tools that may be arranged under interwoven themes of relationality, materiality, and performativity to "explore ways of engaging affirmatively with the present, accounting for some of its features in a 
manner that is empirically grounded without being reductive and remains critical while avoiding negativity" [57] (p. 5). It assembles a range of diverse concepts including, but certainly not limited to, strands of materialist philosophy $[26,57,58]$, [post] human and children's geographies $[55,59,60]$, hybrid studies of childhood [53,56], life and physical sciences [8,61-63], critical early years and education [27,32,64], and anthropology [31]. This complex entanglement offers new ways of accounting for the world, "to take a leap forward into the complexities and paradoxes of our times" [57] (p. 54). At its core is a move away from anthropomorphism and humanism, that is, the idea that humans have a privileged place in and are set apart from the world and each other. Rather it adopts a position that presents life as emergent, multi-layered, non-linear and in a state of constant constitutive and interactive flux; "individuals do not pre-exist their interactions, rather individuals emerge through and as part of their entangled intra-relating" [61] (p. ix). This perspective on emergence offers a different viewpoint on development where time, space, bodies, materials and meanings come into co-existence and are "iteratively reconfigured through each intra-action, thereby making it impossible to differentiate in any absolute sense between creation and renewal, beginning and returning, continuity and discontinuity, here and there, past and future" (ibid.). It is through this process that life takes shape; there is no fixed self-contained identity but it is always creatively and actively assembled. The concern then is not about function and structure, cause and effect, but about the process of desire, that is the productive and creative force of life itself to exist and become something more [8], to realize what else bodies can do. To ask what a body can do is to pursue a line of enquiry into what particular intra-actions human and non-human bodies, materials and so on can compose [63] to produce the best possible state that conditions allow. Following Deleuze's reading of Spinoza [65], desire marks the ability of a body to affect and be affected; affect in this sense is an expression of a body's power to act:

[it is] more than a feeling or an emotion it is also a potential for action, a dispositional orientation to the world. In each sense, affects are an inevitable by-product of encounters in that every encounter subtly transforms a body's affective capacities [63] (p. 627).

This brief introduction sets the foundations for thinking differently about playing and at this stage a brief observation of two children playing is introduced [66] (p. 22):

Two young children, a boy and a girl, are sitting playing with some "gooey" like stuff, when the following conversation occurred:

Boy: What about if everything was made out of gooey?

Girl: Well, hmm, we would actually have all goo on our bums and stuff and we'd be all gooey and pooey and booey

The boy laughs

Boy: What if everything was made out of poo eugh!

Girl: Err, we would all have poo on our bums

Boy: And what about poo people?

Girl: Yuck

Boy: And what about poo willies! 
Girl: No [boys name], no

Boy: What about poo trees

Girl: Yuck

Boy: What about, this is the worsest thing, what about poo leaves!

Girl: Why would you want to make poo leaves?

Boy: What if everything was made out of poo?

Girl: I dunno.

A relational and performative perspective suggests bodies and materials are continually and inextricably responsive to local conditions. It decenters the human individual as the locus of agency while acknowledging the power of things, as vibrant materials, to affect other bodies, enhancing or weakening their collective power to act [58]. These moments are singular events; a world made from poo will not occur in this manner again; it cannot be a signifier of anything other than itself as it only relates to itself as a novel formation. However the micro-details from this observation matter as they open up the possibility to look closer at this event and pose further questions and digressions [67]. The focus is on process and not codification or positionality that cuts the co-creation apart, reducing it to individual components and imposing fragmentary analysis. In this sense, playing is a phenomenon with a certain style and force (pleasurable, "as if", indeterminate, emergent), although the very description of the event as play potentially isolates it from the flow and movement of life. A world made from poo is not a separate text [33] but is inherently situated in the environments and interwoven with and created from the materials that children encounter moment-by-moment in their everyday lives.

This restores playing as a process over the identification of a distinct and final form. It allows for more fluid, discontinuous, contingent and multiple forms of expression that pervade and persist across life [68]. No longer an exercise in accuracy or attribution of some utilitarian or instrumental developmental purpose that occurs outside of playing, attention switches to the performance of the moment. Playing has no original identity, but is emergent, and gaze is brought to bear on bodies and things co-joined in situated action [68]. Even in an apparently mundane game such as rock, paper, scissors, which appears to be a simple matter of making random arbitrary choices between three symbols, there is much more going on [69]. For example, minds/bodies may become attuned to each other to try and predict actions, and as players build experience, they may start to discern patterns. It is performative guessing and second-guessing (and third, fourth) through attending to movements, patterns, affects:

Where is the uncertainty in Rock/Paper/Scissors? That should be obvious. It is in the unpredictability of opposing players. In fact, that is all there is in Rock/Paper/Scissors Rock/Paper/Scissors is a game of player unpredictability in its purest form, for this single factor is the sole determinant of the game's uncertainty, its raison d'être, and its cultural continuance [69] (p. 32).

Playing is a precarious achievement in which the material and social are entangled in all kinds of "promiscuous combinations" [70] (p. 4). It also denotes an anticipatory readiness to the environment [71], alert to the possibilities that any moment may contain for being and becoming 
different. The concept of becoming, in this sense, differs from the fixed trajectory of developmental psychology that children must successfully travel along to achieve maturity. Rather, following Deleuze and Guattari [26] the concept of becoming denotes a dynamic and continuous transforming relationship with the world; becoming is always a temporary combination or assemblage of heterogeneous parts each with their own intensive force that enables the emergence of new formations and affects. Attention is drawn to the ways in which mundane materials (gooey stuff), bodies (human and non-human), affects, and actions compose a moment of "what if", a questioning of all of these elements to see what more might be done with them. Life is always in process, relational and open-ended; attention is given to pre-conscious, embodied movements and affective intensities that occur anywhere and everywhere [35,72].

This is far removed from a contemporary and increasingly pervasive disenchanted version of "what if" currently evident in approaches to risk and security, and which track through childhood, that assumes a precautionary and pre-emptive anticipatory logic [73,74]. Here "what if" questions are designed to create current solutions to perceived future social risks (the rhetoric of early intervention). However, this is problematic in ethico-political terms; projective risk mediations are based on worse case, dystopic futures and have real consequences, not simply on the individuals involved, but also "because the application of pre-emptive rationality is driving a culture in which risk scaling of people, places, and products and legal states of exception are being normalized" [74] (p. 58). Making worlds from poo may be fraught with potential dangers that may engender adult concerns: disgusting, age inappropriate, sexualized, unhygienic, and purposeless behaviors, a reductive and rational reading of irrational, irreducible and indeterminate behavior.

Yet what this fails to realize is moments of playing are affirmative and productive desires, different connections, actualizing the unexpected and by doing so temporarily breaking away from the plane of organization to become different. Bodies have a desire or incentive to be restless, moving towards the things that will increase well-being and avoiding those that decrease this state. Pursuing this, Massumi [67] notes that bodies may be distinguished by two complementary forces: they move and they feel. Thus, a body:

...moves as it feels and it feels itself moving. Can we think of a body without this: an intrinsic connection between movement and sensation whereby each immediately summons the other [67] (p. 1).

From this, the slightest movement of a body instigates a qualitative difference: movement evokes feelings and sensations that fold into each other, resonate, interfere, intensify in unquantifiable (non-representational) ways to unfold again in movement "felt and unforeseen" (ibid.). It marks an "accretion of feelings, capacities, opportunities and interactions" [75] (p. 149) in a particular and singular moment/event, a continuous process of dynamic change. All this can be seen in the opening scenario of the slide on the water tower structure. The following edited account from field notes from a recent action research project with an adventure playground [1] also reveals this performative process:

Two boys (aged about 10/11) were playing a game of tag, using the circular platforms that surrounded a rope swing. It was evident that these two were part of a larger group 
of players, the rest safely ensconced in the hut at the top of a tower. It was also apparent that the game had a rule of not going on the ground, which constrained the two adversaries to the platform and other structures. There was also another implicit rule which meant that these two could engage in reciprocal bouts of tagging. This led to the two children standing facing each other, in very close proximity, but not touching. The person who was "it" would tag, and immediately receive a tag back from the other, often increasing the force of the contact in an attempt to push each other away and create a moment to flee; and then there were brief moments when both stood poised ready to tag without actually doing anything. There was a restless dance between the two, as one looked to retreat the other followed; it was almost balletic in the choreography of action, bodies and affects, tensions and laughter and so on. But this was also situated; the platforms were an integral part of this dance, and there was only one way out from the circular platform i.e., the walkway that led to the tower, and so the space had strategic meaning within the context of this play. Both children sought to maneuver the game to the part of the circular platform closest to the "escape" route and then one child decided he was going to make a break, tagged the other child and turned to run away but was pushed/tagged in return, diverting the child beyond the escape, and the other child seized the moment to run along the platform and up into the next level.

This brief moment illustrates the sensational/motivational behaviors found in playful encounters "the ongoing, underlying process of off-balancing, loosening, bending, twisting, reconfiguring" [76] (p. 42) between bodies, things and their affects. Bodies emerge as an assemblage, connected in extensive ways and composed in recursive encounters [63], or "milieus", composed of discontinuous movements without a beginning or end but "always a middle from which it grows and overspills" [26] (p. 23). As Duff comments [76], such milieus are important sources of developmental capabilities; intra-actions constitute affective and relational repertoires of response-abilities. They appear as ordinary events, but as Lester and Russell [34], drawing on Masten's study of resilience [77], note, they contain properties which augment the power to act and by doing so maintain and strengthen the capacity to co-create more playful moments in the near future.

There is a growing body of research that suggests playing may contribute to the enhancement of adaptive systems, mind and body capabilities that enable life to thrive, building the capacity to cope better with uncertainty through refining stress response pathways and building a network of strong attachments to other bodies, spaces and materials. The fun and pleasure of playing generates positive affect, which has considerable health benefits and the ability to affect and be affected in a joyous manner leads to ever widening connections and greater possibilities for further connections across multiple levels of organization. Playing has been described as the deliberate creation of uncertainty [78] and as a state of "being in control of being out of control" [79] (p. 216), something that can be seen in the opening scenario, the world of poo and the balletic performance on the swing platforms. A focus on uncertainty offers a different perspective on "risky play" [80]. This generation of moderate and desirable stress which is under the control of the players may serve to 
prime stress response systems so there is something to draw on when faced with non-playful stress, referred to as "stress inoculation" [34].

These potential playful developmental capabilities can be understood as much more than developing skills of risk assessment, or developing resilience as an individual achievement. They become reduced when prized apart and utilized in a highly instrumental manner largely focused on the psychological and biomedical profile of resilient children and associated practices of promoting resilient capabilities. The focus on resilience as an individual capacity in an objective and measurable world relegates it to health/identity politics and the development of self-regulation [81]. The perspective on playing introduced here presents resilient capabilities in terms of desire, as a force that flows between bodies, materials and their affects "experienced in those moments of connection with life that defy common-sense, resist dominant cultural interests and power relations and in an untimely manner unsettle the identity of individuals" [81] (p. 40). MacKinnon and Derickson's critique of the contemporary discursive effects of resilience through state agencies and expert knowledge [82] offers an alternative viewpoint that highlights its ecological, contingent and dynamic nature and brings a socio-political dimension to the discussion:

Put another way, if alternative social relations are to be realized democratically and sustainably, and in ways that are wide-reaching and inclusive (as opposed to uneven or vanguard driven), then uneven access to material resources and the levers of social change must be redressed. To that end, we offer resourcefulness as an alternative concept to animate politics and activism that seek to transform social relations in more progressive, anti-capitalist and socially just ways. In contrast to resilience, resourcefulness as an animating concept specifically seeks to both problematize and redress issues of recognition and redistribution [82] (p. 255).

The everyday environments that children share with adults are produced, regulated and over-coded with "a vast array of practices, habits, technologies, symbols and so on that constitute the maintenance routines that keep them operational" [83] (p. 45). At the same time, these generally taken-for-granted spatial orderings have exclusionary effects. As outlined in the opening section of this article, the dominant constructions and productions of risky childhood have significant influence in shaping, in contingent, complex and entangled ways, the conditions which children encounter in their everyday lives. The concept of resourcefulness switches attention from the needy and deficient child to the forces that underlie the inequitable distribution of resources and subject these to critical scrutiny, a political-ethical consideration that will be addressed in more detail in the following section.

\section{Political-Ethical Imaginations and Health-Enabling Environments}

While the forces that assemble worlds made from poo are constituted from everyday materials they are thoroughly entangled with macro forces that shape spaces and spatial practices. Moments of playfulness are not set apart from these; they work with the "real" by reconfiguring, subverting and inverting the world as it is generally given by adults to "intensify the vital productivity of daily life" [84] (p. 243). This requires consideration of adult response-ability to pay attention to equitable 
distribution of resources that might create the conditions in which playfulness can thrive: in other words, it is a political-ethical endeavor.

Deleuze [65] reads Spinoza's ethics as the accumulated repertoire present at any given moment by which individuals organize their encounters to produce and maximize the experience of joyful affects, the power to live one's life actively [85]. Ethical instances are not located or confined within the self-regulating subject but are always situated in a set of interrelations with both human and non-human materials. Ethics, in this reading, implies the ability to "cultivate, establish and sustain empowering relations as well as the commitment to the production of social conditions that are conducive to transform the negative instance into affirmative and productive ethical relations" [86] (pp. 174-175). Health, therefore, is a relational process rather than a fixed state, constituted from specific moments of connection and association of bodies, affects and materials [75]. The following observation [87] (p. 24) provides an illustration of an "ethical maneuver" carried out in a museum:

\section{A Visitor Services Assistant (VSA) approaches a small group of children and presents them with a precious and fragile dinosaur egg (a blown goose egg) and asks them if they would take it to the VSA on another gallery. The children smile as one of them takes the egg and they carefully climb the stairs, whispering and giggling amongst themselves. At some point they find the VSA and hand over the egg. A short while later, this VSA passes the egg to another child and it starts over again.}

The intention within this simple promotion is to see what more bodies and materials might do. It is a micro-political experiment from the VSA that animates the possibility of temporary escape from the molar assemblage; children are no longer passive observers of cultural artifacts, the gallery assistant no longer a supervisor of children's behavior, the egg becomes a rare "thing" that demands care. It is an intra-active entanglement, a shared desire to simply be and become well by increasing affective capacities to act differently, a singular episode of enchantment when disciplinary power, rationality and scientific calculations are set to one side and the world is a "lively flow of molecular events, where matter is animate without necessarily being animated by divine will or intent" [71] (p. 14).

In 2013 the UN Committee on the Rights of the Child issued General Comment 17 in recognition that children's right to play, expressed in Article 31 of the Convention, is poorly recognized by States, resulting in "lack of investment in appropriate provision, weak or non-existent protective legislation and invisibility of children in national and local level planning". The General Comment also highlights the importance of creating time and space for spontaneous play and the promotion of societal attitudes that support and encourage playing. The Comment offers a valuable range of justifications, considerations and recommendations for improving the conditions to support children's play [88]. However, it also implicitly contains an ethical responsibility. Responsibility in this sense means paying closer attention to the everyday movements between bodies and things and being responsive to the possibilities they contain that might help life to flourish [61]. It is a question of what can be done here and now to affect something or someone in a different way [64] to create possible futures by mobilizing resources 
and materials that have hitherto been overlooked or used to privilege the needs of the few over the multitude [57]. Playing reminds adults that the desire to affect and be affected "exceeds attempts to make it into an object-target for forms of power" [73] (p. 34). It presents a different version of "hope", no longer a form of discipline and control to ensure a safe, utopian and distant future but rooted in the ordinary micro-practices of everyday life.

Such an ethical perspective challenges current biomedical accounts of health, and the ways they are played out in health promotions that seek to encourage self-regulation, a decontextualized individualization of life. The position presented here is not indifferent to the human condition, quite the opposite: "it rather implies a new way of combining ethical values with the well-being of an enlarged sense of community which includes one's territorial or environmental interconnections" [57] (p. 10). The ideas here suggest that rather than targeting individuals, attention is given to the conditions that constitute "health enabling spaces" [75], that is, the relational, affective and material processes that intra-actively and indeterminately produce moments of care and reciprocity. The museum gallery can, through a minor experiment and for a short period of time, become a place where bodies and materials actualize different ways of being and moving beyond that of "visitor", promoting different affects and encounters. It also opens up the possibility that there may be more of these moments to come, to actively seek out other ways of affecting and being affected.

There are no blueprints for this; ethical practices are relational, emergent and specific, but without these practices well-meaning policy/promotional prescriptions become blunt instruments. While there may be no a priori foundations, attention needs to be given to exploring the ways in which affects, relations, things and encounters constitute such processes; "it requires an empiricism not of identities, structures and essences but of events, processes and relations" [75] (p. 155). While the limitations of this article prohibit a detailed examination (see [83]), it is worth highlighting here the significant step taken by the Welsh Government in placing children's play as a central component of social policy and the statutory duty for local authorities to assess and, as far as is reasonably practicable, secure a sufficiency of play opportunities. The vagueness of the term "sufficiency" defies dominant outcomes-driven policy formulation and associated technical measuring devices and calculations, providing a degree of indeterminacy that allows for the possibility of creative and experimental approaches in order to appreciate the multiple and complex processes that constitute moments of play, to build collective wisdom in order to act more responsibly with these [83].

\section{Conclusions}

This paper critiques the well-intentioned but fragmented interpretation and instrumental application of playing in biomedical and developmental psychology accounts of health and well-being and presents a counter position where playing becomes a collective self-protecting mechanism that thrives when children can create momentary time/space within their daily lives [89]. Playing (including what is sometimes called "solitary" play) is an intra-active milieu, co-creating moments in which, for the time of playing, life is simply more vibrant and there is greater satisfaction in being alive [90]. This presents a more affirmative and potentially valuable 
perspective in which play is not a specialized activity but rather may be seen as a creative force or desire of life itself:

Play is the condition for the possibility of new possibility itself. To be human is to inhabit a dynamic world of not only what is but what could be Play is tension (used in this sense as a stretching out-authors note) turned toward new possibility without play there would be no world of meaning at all [91] (p. 53).

We have a long standing and cherished recognition of individual rights, freedoms and responsibilities. Yet such a position may be untenable in the face of research from physical and life sciences that suggests all matter is lively and contains unlimited potential $[58,61]$. We are entwined and entangled in a complex world; there is no escape to an individual self to be viewed above or outside of this world. Our politics are constructed from the same vulnerability as the rest of life, and "to refuse to experiment is to resign oneself to the intolerable, to abandon both the struggle to change the world and the opportunity to celebrate living within it" [92] (p. 529). The issue becomes, then, one of asking what more can be done, from this perspective, to create the conditions for such affirmative "what if?" moments of health-enabling playfulness where adults can watch in wonder (and perhaps also anxiety) as children "walk the plank" on the plastic slide high up on the water tower, or co-create their balletic performances in a game of chase on the American swing, or discuss disgusting worlds of poo, or where a Visitor Services Attendant in a museum can enchant the space with a dinosaur egg.

\section{Acknowledgments}

Acknowledgements go to Sarah Wilson and Emma-Louise Simpson for their observational notes.

Thanks are also extended to the two anonymous referees for their insightful and detailed feedback on the first draft of this article.

\section{Author Contributions}

SL and WR conceived and wrote this article.

\section{Conflicts of Interest}

The authors declare no conflict of interest.

\section{References}

1. Lester, S.; Fitzpatrick, J.; Russell, W. Co-creating a Play Space: Reading Playwork Stories, Practices and Artifacts; University of Gloucestershire: Gloucester, UK, 2014.

2. Latour, B. Why Has Critique Run Out of Steam? From Matters of Fact to matters of Concern. Crit. Inq. 2004, 30, 225-248.

3. Lupton, D. Risk; Routledge: London, UK, 1999.

4. Mythen, G. Sociology and the Art of Risk. Soc. Compass 2008, 2, 299-316. 
5. Rose, N. The Politics of Life Itself. Biomedicine, Power, and Subjectivity in the Twenty-First Century; Princeton University Press: Princeton, NJ, USA, 2007.

6. Foucault, M. The Birth of Biopolitics: Lectures at the College de France, 1978-1979; Palgrave: London, UK, 2008.

7. Wright, J., Harwood, V., Eds. Biopolitics and the "Obesity Epidemic”; Routledge: London, UK, 2009.

8. Fox, N. The Body; Polity Press: Cambridge, UK, 2012.

9. Miller, P.; Rose, N. Governing the Present; Polity Press: Cambridge, UK, 2008.

10. Beck, U. World Risk Society; Polity Press: Cambridge, UK, 1999.

11. Alaimo, S. Bodily Natures; Indiana University Press: Bloomington, IN, USA, 2010.

12. Fox, N. Beyond Health: Postmodernism and Embodiment; Free Association Books: London, UK, 1999.

13. Fullager, S. Governing Healthy Family Lifestyles through Discourses of Risk and Responsibility. In Biopolitics and the "Obesity Epidemic”; Wright, J., Harwood, V., Eds.; Routledge: London, UK, 2009; pp. 108-126.

14. Faulkner, J. Negotiating vulnerability through "animal" and "child". Angelaki 2011, 16, 73-85.

15. Jackson, S.; Scott, S. Risk anxiety and the social construction of childhood. In Risk and Sociocultural Theory: New Directions and Perspectives; Lupton, R., Ed.; Cambridge University Press: Cambridge, UK, 1999; pp. 86-107.

16. Rose, N. Powers of Freedom; Cambridge University Press: Cambridge, UK, 1999.

17. Ben-Arieh, A.; Goerge, R.M. Measuring and Monitoring Children's Well-Being: The policy process. In Indicators of Children's Well-Being: Understanding Their Role, Usage and Policy Influence; Ben- Arieh, A., Goerge, R.M., Eds.; Springer: Dordrecht, The Netherlands, 2006; pp. 21-30.

18. Robinson, K. Innocence, Knowledge and the Construction of Childhood; Routledge: Abingdon, UK, 2013.

19. Fenech, M.; Sumision, J. Promoting high quality early childhood education and care services: Beyond risk management, performative constructions of regulation. J. Early Child. Res. 2007, 5, 263-283.

20. Jones, A. The Monster in the Room: Safety, pleasure and early childhood education. Contemp. Issues Early Child. 2003, 4, 235-250.

21. Karsten, L. It All Used to be Better? Different generations on continuity and change in urban children's daily use of space. Child. Geogr. 2005, 3, 275-290.

22. Veitch, J.; Bagley, S.; Ball, K.; Salmon, J. Where Do Children Usually Play? A qualitative study of parents' perceptions of influences on children's active free-play. Health Place 2006, 12, 383-393.

23. Ramstetter, C.; Murray, R.; Garner, A. The crucial role of recess in schools. J. Sch. Health 2010, 80, 517-526.

24. Piper, H.; Smith, H. "Touch" in Educational and Child Care Settings: Dilemmas and responses. Br. Educ. Res. J. 2003, 29, 879-894.

25. Kraftl, P. Young People. Hope and Childhood-Hope. Space Cult. 2008, 11, 81-92. 
26. Deleuze, G.; Guattari, F. A Thousand Plateaus; Continuum: London, UK, 1988.

27. Dahlberg, G.; Moss, P. Ethics and Politics in Early Childhood Education; Routledge Falmer: London, UK, 2005.

28. Prout, A. Culture-nature and the construction of childhood. In The International Handbook of Children, Media and Culture; Drotner, K., Livingstone, S., Eds.; Sage: London, UK, 2008; pp. 21-35.

29. Paechter, C. Reconceptualizing the Gendered Body: Learning and constructing masculinities and femininities in school. Gend. Educ. 2006, 18, 121-135.

30. Moss, P. Meeting across the paradigmatic divide. Educ. Philos. Theory 2007, 39, 229-240.

31. Ingold, T. Being Alive. Essays on Movement, Knowledge and Description; Routledge: London, UK, 2011.

32. Olsson, L. Movement and Experimentation in Young Children's Learning; Routledge: Abingdon, UK, 2009.

33. Sutton-Smith, B. The Ambiguity of Play; Harvard University Press: Cambridge, MA, USA, 1997.

34. Lester, S.; Russell, W. Play for a Change. Play, Policy and Practice: A Review of Contemporary Perspectives; National Children's Bureau: London, UK, 2008.

35. Woodyer, T. Ludic Geographies: Not merely child's play. Geogr. Compass 2012, 6, 313-326.

36. Lester, S. The pedagogy of play, space and learning. In Fritidshemmet; Pihlgren, A., Ed.; Studentlitteratur: Lund, Sweden, 2011; pp. 243-282.

37. Alexander, S.; Frohlich, K.; Fusco, C. Active Play May Be Lots of Fun, but it's Certainly not Frivolous: The emergence of active play as a health practice in Canadian public health. Soc. Health Illn. 2014, 1-17, doi:10.1111/1467-9566.12158.

38. Fusco, C. "Healthification" and the Promises of Urban Space: A textual analysis of place, activity, youth (PLAY-ing) in the city. Int. Rev. Soc. Sport 2007, 42, 43-63.

39. Wright, J. Biopower, Biopedagogies and the Obesity Epidemic. In Biopolitics and the "Obesity Epidemic”: Governing Bodies; Wright, J., Harwood, V., Eds.; Routledge: London, UK, 2009; pp. 1-14.

40. Rail, G. The Birth of the Obesity Clinic: Confessions of the flesh, biopedagogies and physical culture. Soc. Sport J. 2012, 29, 227-253.

41. Ward, C. The Child in the City; Penguin: Harmondsworth, UK, 1979.

42. Opie, P.; Opie, I. Children's Games in Street and Playground; Oxford University Press: Oxford, UK, 1969.

43. Department for Children, Schools and Families. In The Play Strategy; DCSF Publications: Nottingham, UK, 2008.

44. Christensen, P.; Mikkelsen, M. Jumping off and Being Careful: Children's strategies of risk management in everyday life. Soc. Health Illn. 2008, 30, 112-130.

45. Ball, D.; Gill, T.; Spiegal, B. Managing Risk in Play Provision: An Implementation Guide; DCSF Publications: Nottingham, UK, 2008.

46. Bacchi, C. Introducing the "What's the Problem Represented to be?" Approach. In Engaging with Carol Bacchi: Strategic Interventions and Exchanges; Bletsas, A., Beasley, C., Eds.; Adelaide University Press: Adelaide, Australia, 2012; pp. 21-24. 
47. Galloway, S. Well-Being and Quality of Life: Measuring the Benefits of Culture and Sport. A Literature Review; Scottish Executive: Edinburgh, UK, 2006.

48. Cameron, E.; Mather, J.; Parry, J. "Health and Well-being": Questioning the use of health concepts in public health policy and practice. Crit. Public Health 2006, 16, 347-354.

49. Camfield, L.; Streuli, N.; Woodhead, M. What's the Use of "Well-Being" in Contexts of Child Poverty? Approaches to research, monitoring and children's participation. Int. J. Child. Rights 2009, 17, 65-109.

50. Morrow, V.; Mayall, B. What is Wrong with Children's Wellbeing in the UK? Questions of meaning and measurement. J. Soc. Welf. Fam. Law 2009, 31, 217-229.

51. Fattore, T.; Mason, J.; Watson, E. When Children are Asked About Their Well-being: Towards a Framework for Guiding Policy. Child Indic. Res. 2003, 2, 57-77.

52. Pain, R.; Panelli, R.; Kindon, S.; Little, J. Moments in Everyday/Distant Geographies: Young people's fears and hopes. Geoforum 2010, 41, 972-982.

53. Prout, A. The Future of Childhood; Routledge Falmer: London, UK, 2005.

54. Lee, N. Childhood and Human Value; Open University Press: Maidenhead, UK, 2005.

55. Horton, J.; Kraftl, P. "What Else?" some more ways of thinking and doing "Children's Geographies". Child. Geogr. 2006, 4, 61-95.

56. Kraftl, P. Beyond "Voice", Beyond "AZgency", Beyond "Politics"? Hybrid childhood and some critical reflections on children's emotional geographies. Emot. Space Soc. 2013, 9, 13-23.

57. Braidotti, R. Posthuman; Polity Press: Cambridge, UK, 2013.

58. Bennett, J. Vibrant Matter. A Political Ecology of Things; Duke University Press: Durham, NC, USA, 2010.

59. Thrift, N. Non-Representational Theory; Routledge: Abingdon, UK, 2008.

60. Anderson, B., Harrison, P., Eds. Non-Representational Theories and Geography; Ashgate: Farnham, UK, 2010.

61. Barad, K. Meeting the Universe Halfway; Duke University Press: Durham, NC, USA, 2007.

62. Jablonka, E.; Lamb, M. Evolution in Four Dimensions; MIT Press: Cambridge, MA, USA, 2005.

63. Duff, C. Towards a Developmental Ethology: Exploring Deleuze's contribution to the study of health and human development. Health 2010, 14, 619-634.

64. Lenz-Taguchi, H. Going beyond the Theory-Practice Divide in Early Childhood Education; Routledge: London, UK, 2011.

65. Deleuze, G. Spinoza: Practical Philosophy; City Lights Books: San Francisco, CA, USA, 1992.

66. Lester, S. Rethinking Children's Participation in Democratic Processes: A right to play. Soc. Stud. Child. Youth 2013, 16, 21-43.

67. Massumi, B. Parables for the Virtual; Duke University Press: Durham, NC, USA, 2002.

68. Harker, C. Playing and Affective Time-Spaces. Child. Geogr. 2005, 3, 47-62.

69. Costikyan, G. Uncertainty in Games; MIT Press: Cambridge, MA, USA, 2013.

70. Whatmore, S. Hybrid Geographies; Sage: London, UK, 2002.

71. Bennett, J. The Enchantment of Modern Life; Princeton University Press: Princeton, NJ, USA, 2001. 
72. Lorimer, H. Cultural Geography: The busyness of being more-than-representational. Prog. Hum. Geogr. 2005, 29, 83-94.

73. Anderson, B. Affect and Biopower: Towards a politics of life. Trans. Inst. Br. Geogr. 2011, $37,28-43$.

74. Mythen, G.; Walklate, S. Agency, Reflexivity and Risk: Cosmopolitan, neurotic or prudential citizen? Br. J. Soc. 2010, 61, 45-62.

75. Duff, C. Networks, Resources and Agency: On the character and production of enabling places. Health Place 2011, 17, 149-156.

76. Schechner, R. The Future of Ritual: Writings on Culture and Performance; Routledge: London, UK, 1993.

77. Masten, A. Ordinary Magic: Resilience processes in development. Am. Psychol. 2001, 56, 227-238.

78. Spinka, M.; Newberry, R.; Bekoff, M. Mammalian Play: Training for the Unexpected. Q. Rev. Biol. 2001, 76, 141-168.

79. Gordon, G.; Esbjorn-Hargens, S. Are we having fun yet? An Exploration of the transformative power of play. J. Hum. Psychol. 2007, 47, 198-222.

80. Lester, S.; Russell, W. Tell Your Mum I Saved Your Life. Play Rights 2008, 2/08, 4-10.

81. Jenkins, A. Becoming Resilient: Overturning common sense-Part 1. Aust. N. Z. J. Fam. Ther. 2011, 32, 33-42.

82. MacKinnon, D.; Derickson, K. From Resilience to Resourcefulness: A critique of resilience policy and activism. Prog. Hum. Geogr. 2013, 37, 253-270.

83. Lester, S.; Russell, W. Leopard Skin Wellies, a Top Hat and a Vacuum Cleaner Hose: An analysis of Wales' Play Sufficiency Assessment duty; Play Wales: Cardiff, UK, 2013.

84. Gardiner, M. Everyday Utopianism: Lefebvre and his critics. Cult. Stud. 2004, 18, 228-254.

85. Colebrook, C. Gilles Deleuze; Routledge: London, UK, 2002.

86. Braidotti, R. Nomadic Ethics. In The Cambridge Companion to Deleuze; Smith, D., Somers-Hall, H., Eds.; Cambridge University Press: Cambridge, UK, 2012; pp. 170-197.

87. Lester, S.; Strachan, A.; Derry, C. A More Playful Museum: Exploring issues of institutional space, children's play and well-being. Int. J. Play 2014, 3, 24-35.

88. Lester, S.; Russell, W. Children's Right to Play. In The Sage Handbook of Play and Learning in Early Childhood; Brooker, E., Blaise, M., Edwards, S., Eds.; Sage: London, UK, 2014; pp. 294-305.

89. Lester, S.; Russell, W. Children's Right to Play: An Examination of the Importance of Play in the Lives of Children Worldwide; Bernard Van Leer Foundation: The Hague, Netherlands, 2010.

90. Sutton-Smith, B. Play as a Parody of Emotional Vulnerability. In Play and Educational Theory and Practice, Play and Culture Studies; Lytle, D.E., Ed.; Praeger: Westport, CT, USA, 2003; pp. 3-17.

91. Wall, J. Ethics in the Light of Childhood; Georgetown University Press: Washington, DC, USA, 2010.

92. May, T. To Change the World, to Celebrate Life. Philos. Soc. Crit. 2005, 31, 517-531. 


\section{Teenagers and Playing: Are Pastimes Like Neknominate a Usual Response to Adolescence?}

\section{Perry Else}

Abstract: While "outside of society" for much of the last sixty years, adolescents have attracted attention in recent times because of perceptions of their anti-social and, in some cases, violent behaviour. Teenagers face many challenges on their journey to adulthood; growth spurts, hormone developments and changes in the structure of the brain. These biological challenges have been affected since around 1990 by the impact of technology and the subsequent cultural changes. Activities, like the technology-driven, socially-networked pastime, Neknomination, amongst others, meet basic drives that gym-based activities do not. Adults are increasingly concerned about unhealthy patterns of behaviour that suggest that this coming generation of adults will not live as long as their parents, causing misery and putting additional economic pressures on families and society if the expected standards of living and health are to be maintained. The pressures facing teenagers are many, but a concerted effort by adults to change their attitudes towards children and young people to help rather than instruct may assist with meeting their needs and those of society.

Reprinted from Children. Cite as: Else, P. Teenagers and Playing: Are Pastimes Like Neknominate a Usual Response to Adolescence? Children 2014, 1, 339-354.

\section{Background: Healthy Development of Children and Young People}

Changes in society and human environments over the last thirty years have been faster than at any time in recorded history, yet are no less profound for that. Almost every aspect that impacts on a human's life has changed in the post-modern world: domestic and global polices, social cohesion, protection of personal and property rights and invested wealth, investments in research and development and infrastructure, the development of human capital through education, healthcare and child care and the protection and stewardship of natural capital [1].

While these issues may seem remote to children and young people, they will have profound impacts on the support and choices available to them, and it is recognised that the context of a person's life is as important as the environment and physical resources supporting that person [2]. Most children are born with a wide range of abilities that will become manifest if given the appropriate type of experience and support, yet different environments will profoundly affect those life chances.

When looking at healthy development for children and young people, there is often a focus on physical development and the correlating avoidance of obesity [3]. The engagement of young people in physical activity programmes has gained prominence, as adults are increasingly concerned about unhealthy patterns of teenage behaviour that suggest that this coming generation of adults will not live as long as their parents [4]. The adult solution around the world has been shown to be the provision of organised sports and activity sessions aimed at lowering obesity levels and establishing a life-long habit to exercise. 
Regarding physical health and obesity, research carried out in the U.K. in 2008-2009 [5] revealed that primary school children were sedentary for over six hours a day, with girls being particularly inactive (nearly four out of ten). Similar figures were reported in 2010-2011 with children getting heavier, especially in urban and deprived areas [6].

Reports on health tend to focus on the cost of programmes e.g., obesity in the U.K. costing over $£ 5$ bn per year [7], yet as will be shown, it is motivation and quality of life that ultimately will change young people's behaviour. The guidance offered by the U.K.'s National Health Service, while well intentioned, may not be the answer needed, as it focussed on gym-based activities, such as sit-ups, push-ups, gymnastics, resistance exercises, weight machines, rock climbing and sports, such as football, basketball and tennis [8]. Twelve- to sixteen-year-olds do not stop playing through lack of knowledge about fitness and obesity; more information about diet and exercise is not needed. Games, like Neknomination (see below), meet basic drives that gym-based activities do not. Adults and policy makers should understand more of the pressures on and desires of young people in order to help support and help change activities and behaviours.

Some understanding is emerging; research in Australia showed that young women aged 12-16 years equated dissatisfaction with their body image to the perception of poorer health and related health behaviours, such as low physical activity levels, dieting and external physical activity motivators [9]. The research team concluded that adult-led interventions were needed to promote the young women's positive body image and increase intrinsic motivation for physical activity before physical activity levels would rise among adolescent girls in the cohort. "Intrinsic motivation - the drive to do something because it is interesting, challenging and absorbing" [10] is necessary if individuals are to feel motivated to engage in new activity or change their behaviour; targets set by others - extrinsic motivators unless linked to collective benefits - are increasingly failing in the modern world.

Another example from the U.K., the Women's Sport and Fitness Foundation (WSFF) [11], looked at the views held by young women and men about physical activity, sport and PE (physical education) lessons. They reported that only 12 percent of young women aged 14 get enough physical activity each week; roughly half that of young men at the same age. The WSFF found that young women want to be active, take part in physical activity and remain healthy, but the researchers attribute the lack of participation to young women feeling they do not have a suitable outlet for their activity. In earlier times, young people would have been busy with adult-directed activities at home or in school, yet in the twenty-first century, they feel it essential to fit physical activities into their cultural framework.

Finally, a study from Denmark [12] revealed that there was no relationship between families' socio-economic position and the amounts of general physical activity in children and young people; though organised sports showed an increase in young peoples' activity, which was attributed to the economic and social capitals held by the family. Therefore, when activities are supported and paid for by parents, adolescents will take part, but their own self-chosen activities are hardly different from the rest of the young population; other pressures must be at work. 


\section{Playful Activity Is Good for All Aspects of Being Human}

All humans, but children and young people especially, experience life holistically and with integrated experiences; it is not possible to isolate physical actions from the space in which they occur. The growth in social media amongst young people shows that the desire to link with others is vital, yet the thousands of messages sent every day are about personal activities, what is happening, what was done, what excites them. The integral four quadrant model [13] demonstrates how the primary activities of humans link together to satisfy most human desires and needs. The model has been adapted and amended as the Integral Play Framework [14] to link to play activities for children and young people.

The balance of physical activities with cultural interests brings together the objective reality of exercise and bodies in space with the subjective opinions of those "operating" the bodies; humans are not just robots carrying out mechanical motions, nor are they cultural identities remote from the world. The actions of the body impact on the feelings of the person and the feelings change the way the body is used/operated. When living in the world, humans also use their cognition to make decisions about the world and, when interacting with others, will be aware of their status in that social framework, whether they are a leader of the group, a partner or a follower. These four ways of interacting with others and the ecology are described by the Integral Play Framework [15]; see Figure 1.

The circle represents the individual young person and the four quadrants within that circle the four main ways that humans interact with others; two "internal" and mind based, two "external" in the physical realm, yet all interacting and affecting the others. Using the example of physical activity, sport and PE lessons, it may be seen that exercising the body is only part of the motivations for undertaking such a task. If there is a group status or role to be gained from the activity, then the activity may be undertaken in order to fit in or form good links with others; or the activity may be carried out if there are enough cognitive or emotional arguments to motivate the person-e.g., feeling good as a result of exercise or understanding that a limit on calorific intake may affect body shape and weight. Finally, a shared culture could influence the type and range of activities an individual undertakes with others; a strong motivator, especially for adolescents. Each of these quadrants could be a prime motivator or actions could be a combination of two of more of the quadrants. The framework describes the actions and choices of individuals, yet those choices may be affected and influenced by others in the environment or the opportunities in the environment itself. This in part explains why Neknomination was a more popular craze than gymbased activities for a time with some young people. 
Figure 1. The Integral Play Framework.

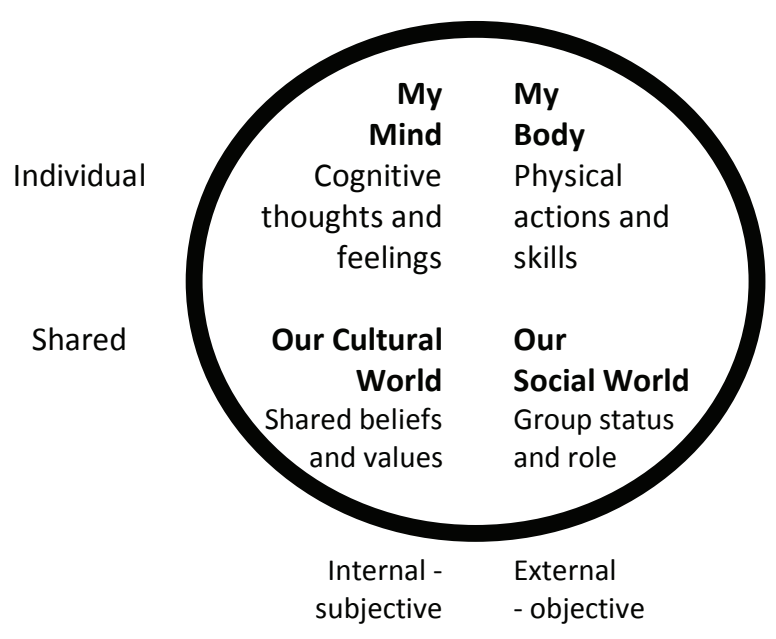

A human being is a time-sample of human nature. The whole person is physical if viewed from one angle; psychological if viewed from another. There are the soma (the body of an organism) and psyche (the human mind, conscious, and unconscious) [16].

\section{Cultural Frameworks}

Young people are very aware of contemporary culture, the effect it has on them and the impact they have through cultural behaviours, such as social media, socialising and rebelling, whether overt or passive, against the dominant traditions. The complexity of cultural transmission and the resultant changes in society were explained by Konner: "The issue with cultural evolution is that it is quite different from biological evolution, and one of its meanings is the succession from hunting and gathering to horticulture and/or pastoralism, to full-scale agriculture, to industrial and post-industrial modes of subsistence - a succession that entails changes in social and political complexity... Transmitting culture to children and young people is more complex and much less well understood than genetic inheritance" [17]. The early stages of this continuum would have required young people to learn the rules of the culture in order to survive; for example, a lack of understanding of food acquisition would eventually lead to death. Yet, in many societies in the minority world over recent years, food has been unreservedly available, leaving young humans to create their own cultures and belief systems. As Edelman put it, "Consciousness is not a thing; it is a process"; human minds are not determined by genetics, but by the interaction of chosen activities with the environments and opportunities available [18]. Genetics alone do not determine a human's behaviour; culture plays a major part in shaping an individual's behaviour, beliefs and attitudes. 


\section{Brain Growth and the Playful Development of Consciousness}

There is now strong evidence that one reason for the evolution of playing is to help develop more efficient brains by enhancing cortical connections; that when humans play, the nerve signals that bodies generate create pathways in the brain that help with brain development $[18,19]$. The brain expands in volume four times from birth to the teenage years, and the brain structure and function in adults is a product of both evolution and individual development [20]. Research has shown that the first eight years of a human's life are critical for facilitating brain development, with ages from birth to three years being especially crucial. The more children play in this period, the more connections are made between the various parts of the brain and especially through the corpus callosum, the band of cells that connect the left and right sides of the brain and that help integrate what are often two completely different views of the world. When children play cognitively, they develop mental wellbeing, brain elasticity, autonomy, as well as resilience [21]. Yet, a second critical phase of brain growth emerges when humans enter adolescence.

There is evidence that the cerebellum continues to change throughout adolescence; it is one of the last structures of the brain to develop in adulthood. It still needs to experience flexibility and stimulation. The way to make a better brain is not through hours of homework and training, what the brain wants is play; it grows best when it is allowed to play [22]. Smith quotes Panksepp as saying, "Play is quintessentially capable of activating the very best that the (brain) is capable of" [23]. Additionally, as brain functions increase, the variety and complexity of play increases; is it any wonder that the animals with the largest brains are also amongst some of the most playful? [19].

The brain remains flexible during pubescence and adolescence and only as adulthood approaches does it start to fully consolidate its structure (through myelination). If the brain were totally organised and set in its structure too early, human beings would never be able to learn the things they need to survive [24]. Myelination is a process of insulating neuron cell bodies, keeping the brain's electrical signals on their intended paths and increasing their speed. This process in the developing teenage brain has good and bad consequences. After neurons are completely myelinated, they are more efficient and twice as fast, a desirable trait in adults who may need to respond quickly to challenges in the environment, but the brain cells also become rigid and less flexible. This is why, for instance, an adult reports finding it harder to learn new languages or new skills, hence the proverb about teaching old dogs new tricks. Adults can learn facts faster than children, they understand the methods and have models to assimilate new ideas into; however, the related skills of word pronunciation or understanding of sounds is much harder to grasp, and lack of confidence prevents most adults revealing their deficit to others, a reluctance that most children and many teenagers do not experience in certain contexts. There are many changes during adolescence that teenagers go through and help them enter a phase of risk taking and exploration that fades as they reach adulthood. 


\section{Teenagers Are Naturally Changing}

There are key changes that young people go through, starting on average at 12 for girls and 14 for boys. Anecdotal and media claims state that these ages are dropping, yet research supports the traditional ages and suggests that cultural appearances are what explain the impression of lower ages for maturity and one or two highly reported media stories; most young women still wait for physical maturity and security before starting a family [25]. Evolutionary changes do not take place in one generation, but over a much longer period.

The physical changes during adolescence include growth spurts of 200-300 mm over a period of two or three years; increasing weight, height, heart size, lung capacity, muscular strength and giving teenagers ravenous appetites. Bone growth in adolescence is faster than muscle development, which can result in their lack of coordination and clumsiness. Puberty can be revealed by voice changes, emergence of body hair, growth of internal and external reproductive organs, production of female and male hormones and acne. Sex characteristics show in young women with breasts enlarging and menstruation beginning and erection and ejaculation for young men [26].

During the teenage years, loyalty for many shifts from parents to peers, who become sources for standards and models of behaviour, influenced in recent years by media advertising. Adolescents copy and display fads of extremes in clothing, speech and mannerisms, which have cycled faster and faster since the middle of the twentieth century. Young adolescents (as their parents before them did) believe their experiences are unique and dramatic. This is demonstrated in the adolescent's search for independence, which frequently results in conflict with anyone in an authoritative positions [26].

Mentally, cognitively, the adolescent is able to participate in abstract thinking (Piaget's formal operational stage), enabling them to process and group ideas; adolescence also brings egocentrism, where individuals believe everything centres on their appearance, thoughts and behaviours, and that critical thinking emerges from taking a firm position and arguing their point of view. Teenagers are curious and exhibit a strong willingness to learn things they consider useful, adding to the belief that they are invincible and incapable of experiencing anything harmful, leading to engagement in risk-taking or reckless behaviours [26].

Teenagers and their need for diversity and new experiences are also models for Gardner's theory of multiple intelligences, which argues that logico-mathematical and linguistic intelligences, though valued in most modern societies, are not the only forms of intelligence. Varied forms of intelligence that are clear within teenagers and children (and some adults) are bodily-kinaesthetic, spatial, naturalist, musical and moral, amongst others [27]. Certainly, much teenage behaviour may have its evolutionary roots in the basic drive to mate, rather than a desire to fit into the social order or traditional norms [24].

\section{Risk Taking in the Econiche}

As well as the influences of others and genes on the teenager, the impact of the environment has a significant sway on growing adolescents. Research on rats' brains revealed that a complex 
environment with lots of stimulus made the rats' brains grow and change; toy-playing rats were also shown to be quicker at complex tasks [28].

Edelman [18] made a similar statement when talking about the environment that children grow and play in: "The econiche in which animals must survive has an enormous number of signals to which an individual must adapt". In the modern world, human brains still need these signals in order to adjust to the planet; there is a danger that as environments are increasingly controlled and "made safe" for humans (especially in the industrialized world), the necessary richness and diversity are lost and so is the teenagers' ability to develop and adapt.

Fortunately, it has been shown that play contributes to coping with stress, resilience and problem solving [19, 29]. Connecting with others, learning the rules and developing physical skills all help most animals fit into their "gang" and become skilled at the incidents that life throws at them. Playing in challenging environments also aids recovery when stress hormones are released to help animals change or evade challenges they face; animals not used to such exposure take longer to calm down and so remain stressed for longer [19].

In humans, the confidence learned and developed though experience aids the emergence of positive emotions, which can help with both physical and psychological health issues by promoting resilience, endurance and optimism [30].

\section{Neknominate and Other Modern Risks}

Risk taking is a normal tool of development, and teenagers often define their identity through risk [31]. However, there is a threat that modern worlds, while still varied in their stimuli, offer reduced access to developing humans, who choose not to expose themselves to the chances on offer, but follow fads and crazes. As Strauch put it, "Modern rebels are lazy... There are too few outlets for normal risk-taking these days; the paths toward success are too limited" [24].

Such limits lead in part to the rise of social network games, such as Neknominate, the drinking game that started in Australia before spreading around the touch-screen, mobile-device carrying world. The game involves people (often teenagers) filming themselves drinking excessive amounts of alcohol (prohibited for those under 18 and under 21 in various countries), often while doing outlandish activities before posting images on friends' sites and then nominating someone else to continue with another activity or drink. In the U.K., Neknominate has been linked to several deaths, prompting calls for social networking sites, such as Facebook and Twitter, to introduce warnings in an attempt to curtail or stop the activity [32]. In spite of that advice, the behaviour will only change when participants see value in other activities that meet their needs and desires. If adults are to work with teenagers in supporting healthier behaviour, they will need to consider the motivations and pressures on young people at the current time.

Other forms of play that adolescents have participated in since the millennium include extreme forms of the risky children's game "chicken" (a form of deep play), such as street running or parkour, tomb-stoning, jumping into the unknown, buildering or building climbing, base jumping, bungee jumping, extreme ironing, off-piste snowboarding and skiing and modern skydiving, skimming just meters above the ground, sometimes with fatal consequences. Media reports of these activities also reveal that many of them add further challenges to social norms by being carried out 
naked, with no safety equipment, in ultimate conditions or even while participants get married. Many of these activities are intense forms of deep play [33] that allow young people to encounter risky or even potentially life-threatening experiences, testing the participants' physical and mental reserves, while aiming to be satisfying, pleasurable and thrilling, with a deep sense of being alive.

\section{So What Is Play?}

There are many definitions of play, but a recent meta-analysis of authors' views [15] suggests that play must be a self-chosen, engaging and satisfying activity or the player will stop playing. The pleasure of play has been recognised as contributing to many things; feeling good helps with "flexible thinking and problem solving, mastery and optimism" [34].

While play is self-chosen, nonetheless play is never fully free, as some definitions claim - children and young people cannot really fly; they can never get everyone to play "my" game, and so on. For play to be self-chosen, the player has to feel sufficiently safe, physically and psychologically, i.e., not threatened excessively by others or the environment [21]; though certainly, there are exceptions, hence the "sufficiently". For example, locomotor play, movement in all directions, will be different for a toddler and a teenager; the skill needed, the type of activity and the point of the play will vary across the ages and between individuals; and of course, older children may be socialising and problem-solving while running around. In some parts of the U.K. (and with similar activities across the world), children still do door-knocking, usually around Halloween. This is a fairly harmless activity of knocking on a series of doors and then running away before the occupants catch you; a bit of fun and no one should get harmed, though it is likely these days that they do not knock on the doors showing pictures of dangerous dogs and the legend "I live here" on the front door. Therefore, play is self-chosen with willing participation from the player.

Active engagement is necessary to sustain the play, responding to feedback from the environment and from other players: Are the tree branches still strong enough to hold me if I go higher? What role do I have in this game; do we need to change it? Playful engagement often leads to players losing track of time as they become immersed in their activity, which is usually a whole mind and body experience, with the player getting stimulation and satisfaction throughout while the activity still has the opportunity for newness or new experiences. The love of new things is called neophilia: Pink explained it thus: "Our basic nature is to be curious and self-directed"- and if as adults we are, "passive and inert, that's not because it's our nature. It's because something flipped our default setting" [35]. Play is often described as "fun", though five minutes watching children playing helps us realise that fun does not describe fully the rewards of play for them. Playing may be fun, but it can also be pleasurable, rewarding, satisfying, done for its own sake to experience the crossing of a boundary, done for the exuberance of it just to experience a feeling (jumping in a river, breaking rules, saying "no"); it is much more than just "fun".

Playful activity is important for social, physical and intellectual development, but also for another theme, which may be the most important from an evolutionary perspective-cultural development. Playful activity, while benefitting the individual, is usually a group activity, where the rules and activities are defined by those playing - how far to roam, what the rules are to be 
"on", how to move (often with self-limiting motions), how to get free, and so on. Many games involve movement whether using large muscle groups for running and climbing or fine movement, such as collecting, weaving or pattern-making; while moving around children and young people will be developing tactics to win, stay with their friends, outwit the chaser; this is the beginning of cognitive or intellectual development, alongside the symbolic recognition that leads to language development. Most playful activity involves leaders and followers, whether "real" or "pretend"; through play, children learn about social rules and who is in charge, who' is fair, who picks on you when no one is looking. Additionally, children and young people learn about their culture, the dominant beliefs and values, how to behave in the street and school, but also how to behave in the mosque and minster. Of course, when children grow older, they will learn the games that are not allowed in certain cultures; for a time, they will comply, though the braver ones will begin to play with the systems and ask "why?" Teenagers will search for independence, exploring the rules in their immediate econiche and challenging those in positions of authority. Some adults will try to constrain this activity, describing it as anti-social, or try to teach the "right way" to behave through play.

As Grieshaber and McArdle stated, "The trouble with the idea that play is children's natural way of learning is that ideas about what is natural in children are selective. They are a conglomeration of science, tradition, history, culture, and other ideas. And they vary across time and place." [36]. Some modes of play will be affected by what is happening in those worlds; when a child states to a playmate, "I know the rules-I am a Muslim/I am a Catholic, etc.," is that a fully conscious thought or a learned reaction from adults? Adolescents will begin to challenge these attitudes in their journey to independence, and this will bring them into conflict with the grownups. While very exceptional, think of Ms. Malala Yousafzai, the Pakistani student who was shot by the Taliban after speaking out about girls' education. Fortunately, most teenagers do not endure such dire consequences when they start saying "no" to adults. Naturally, not everything that young people do on their way to adulthood may be considered play or playful, yet playful approaches still have their benefits.

The evidence is clear that play has a role in improving physical and social health, psychological wellbeing, creativity and divergent thinking, attention and cognitive functioning, child development and educational achievement and conduct [37]. Yet, not all young people access play on a regular basis.

\section{The Not-Play Function of Play Type Activities}

With the growing global trend to reduce obesity, agencies and settings are introducing what they consider to be playful sports and games with the stated outcome of burning up calories and reducing weight. The prompt for this type of programme is supported by research, such as that by Dehghan et al:: "It is more difficult to reduce excessive weight in adolescents and adults once it becomes established; therefore, it may be helpful to initiate obesity prevention interventions during early childhood" [38]. On the other hand, these programmes may not be playful, involving as they do adult-led activities conforming to adult-planned curricula, which, in part, explains why children and young people become frustrated with them and give them up when they can. 
As playful activity often "wastes energy" or time, exposes the playful to noisy, aberrant behaviour and displays weakness until mastery is gained, animals must have had other purposes for play-type activities that conferred benefits through evolution. The not-play function of play states that simple locomotor play as exhibited by reptiles is about survival; being agile and adept on their legs helps them get away from predators more rapidly than less adept animals or helps them get to their own food faster. However, locomotor play is also good for physical wellbeing, contributing to muscular growth, flexibility/agility, and coordination; all activities shown in playful activity. The not-play function of play as exhibited by social mammals, such as monkeys, apes, dogs and meerkats, is connection: individuals may not "like" each other, but when the big cat comes around, they all stick together to chase it away or minimise loss in the group. Social play also helps with social wellbeing, belongingness, social connections, and acceptance. Additionally, the not-play function of emerging neural networks is resilience, problem solving, emotional regulation and flexibility. Therefore, it is possible to participate in playful-type activities without them being playful-self-chosen, engaging and satisfying; this may be one of the reasons that adolescents choose not to participate in sport and games as they move into secondary or high school.

In an effort to address reducing levels of activity, the "Girls on the Move" programme in Scotland set up community-based projects with the aim of improving girls and young women's (aged from 11 to 18 years) engagement in physical activity, building on the desire for activity with peer groups and away from other distractions. The programme was reported in 2013 and showed that six-out-of-ten girls maintained their involvement in the projects and that four-out-of-ten girls had high levels of attendance. However, the conclusion of the report was that, while such short-term community-based projects can contribute to daily activity, organised sessions need to be supplemented with other forms of physical activity (e.g., physical education, active living) if girls and young women are to attain the U.K. government recommended 60 min of moderate-to-vigorous physical activity per day [39].

\section{Play Deprivation}

If it is recognized that play is good for making connections in a child's brain, good for muscular growth and coordination, for socialisation, making friends and cognitive development and creativity [34]; then, not playing or being deprived of play opportunities would have a detrimental effect on the child or young person. The effects of play deprivation are complex, as there are many factors that affect the growing child, and there are always exceptions to the rule: children who will play and thrive in extreme conditions; however, the three main causes of play deprivation are the child, the environment and others (usually adults).

It may seem strange that children limit their own play, but looking at the characteristics of play, being in a sufficiently safe place, physically and psychologically, is a necessary factor [15]. Children under stress will do what they can to survive before they begin to play; if the stress factors continue long enough, the child experiences severe play deprivation. Most self-imposed play deprivation will come from feelings of fear or insecurity prompted by others or by the environment, whether those concerns are real or imagined. Though rare, there are instances in the modern world of carers who lock up their children, isolating them from contact with others and play spaces; the 
child's response on being freed is to seek nourishment and other basic needs for survival rather than play. Work with animals has shown that if the play deprivation is short-lived, the animals bounce back and play more, almost as if they were trying to catch up; however, if the deprivation goes on too long, then brain structures and systems will be affected [40,41].

The extreme effects of adults' actions on children may be seen in the extended play deprivation experienced by a large group of Romanian orphans that came to the attention of a wider community after the fall of the Communist government in 1989. As a result of government policies, the number of orphans rose during the regime, while the support to orphanages fell as a result of economic savings. After the fall of the regime it was discovered that some children were treated as subhuman by several of their carers and had been tied to their cots for the majority of their early childhood, unable to interact with others.

In a small-scale study measuring the brains of Romanian orphans who had been maltreated in their early years, Chugani et al. found that the orphans were "metabolically less active" in parts of the brain, especially the inner limbic area, linked to recognition of faces and emotions, two crucial components of bonding and attachment [42].

Some of the children were adopted by families from the USA and U.K. and were the subject of later research. When Beckett et al. [43] reported on the progress of the Romanian adoptees in the USA (compared to English adoptees), they found that the early effects of institutionalized care had lasting effects on the cognitive ability of the children, though there was good improvement shown by some of the most affected after intervention. This finding was consistent with the outcomes of the Therapeutic Playwork project [44], which did intense playwork with orphans in Romania and found that some of the children who were limited in size (compared to active peers) and considered by their carers to be brain damaged were able to respond positively when offered a stimulus and appropriate play cues [45].

The effects of play deprivation caused by the environment have already been touched on, though it follows that if an environment is impoverished (i.e., lacking balanced stimulation opportunities), then children and young people will not be able to play to the extent of their abilities and desires. Additionally, the longer this environmental deprivation goes on, the more "normal" it may be considered by the adults and children who use that environment. The simple fact is that children need to be able to exercise their bodies, minds and emotions, exploring varied environments that give them access to others in those environments. While it is true that children and young people will play in the spaces they are in, the more stimulating those spaces are, the more they will be able to play.

The arguments for play and the explanations of not-play and play deprivation show how "play is critically important to human development and evolution" [33]; the drive to play while serving physiological, biological ends also contributes to children and young peoples' mastery of the environment and their bodies and their development of higher level thinking and imagination. The loss of play opportunities in children and young people's lives is potentially having a more profound impact on them than being overweight, as important as the ramifications of that may be on them and society. 


\section{Technology and Play}

The impact of technology has affected humans for the last 200 years, but has escalated dramatically in the last thirty with the increase in available energy and computer-based technology; how this is affecting children's play in all quadrants needs to be fully explored.

Play is what children get up to in their own lives, in their own way, every day. There is no agenda to what they do; they do it if they find it engaging and satisfying. The opportunities to play in the twenty-first century are quite varied from earlier generations, but carry the same interests for children; finding out about each other, exploring the world and beginning to make a difference in it. Yet, there has been an exponential growth in access to technology based activity and "play" in recent years. In addition to playing at home and in the street, children and young people may play everywhere in the real and virtual worlds; they will be healthier if they have the chance to balance these activities in their daily lives. As well as technology facilitating games, such as Neknomination, there is growing concern that violent video games leave teenagers "morally immature" [46] with weakened empathy for others; and so, perhaps, one of the reasons why drinking games are seen as playful and "fun" rather than dangerous.

Canadian-based research [47] working with a small cohort carried out an in-depth exploration of teenagers' behaviour playing video games. More than half of the gamers were found to play video games between one and three hours every day, with violent games the most common activity; "violent" games were defined as those where players acted out the killing, decapitating or mutilating of other human characters. Concerns arose with teenagers who spent more than three hours every day in front of a screen, continuously playing violent games without any other real-life interaction. Empathy, trust and concern for others were found to be delayed in those who played these games excessively. The adult research team then suggested that a possible solution was for parents to place the teenagers in social situations, such as working for charities, where they get to see other people's perspectives or needs. With all of the evidence of intrinsic motivation and self-chosen activity being critical to positive engagement, it may soon be considered impractical to try to overcome biological and culture motivators for adolescents' behaviour with such adult-directed programmes.

\section{Adult Roles and Attitudes}

In recognising the effects of play deprivation and the benefits of self-chosen and engaging play, adults should do all that is possible to help children and young people access a variety of environments, with natural and unpredictable elements. These spaces should feel safe, psychologically and physically, for children and young people, and adults should understand the value and benefit, so that they encourage more play and experimentation. In the twenty-first century, too many children are being denied stimulating places to play because of the changes in the environment away from bio-diverse landscapes into designed spaces or indoor provision (with computers, videos and multi-media) that only meet limited interests. This is because too many adults believe that such "modern" environments are preferable to less comfortable ones without access to constant heat, hot water and every modern gadget. Children and young people will do 
what they have done for millennia; they will play, thrive and adapt in the environments in which they find themselves. It is adults who control those environments, and who try to control children and young people, who need to change. "For all sorts of reasons our society has restricted children's and young people's play; to remove restrictions and reverse a potentially damaging trend requires a change in attitudes across adult society" [48].

\section{Summary}

This paper has explored the motivations, personal, biological and cultural, that impact on teenagers' play and choice of playful pastimes. It has shown that humans and particularly teenagers, due to the changes they experience in adolescence, need a multiplicity of varied stimuli and the opportunity to engage with them for extended periods from an early age; six-month programmes, while showing progress, are not enough to change underlying behaviours. Ideally, these opportunities should be a balance carried out with peers and supported by adults with an understanding of the drivers motivating young people. Teenagers continue playing beyond early childhood, though the play activities change and meet new needs. While pastimes, like Neknominate, parkour and buildering, are not recommended activities for teenagers, they may be understood as a response to adolescence and a desire for deep play, denied in other parts of the teenagers' lives through the well-intentioned acts of parents and other adults. As reported, attitudes across adult society need to change, just as adults have radically changed the econiches that children and young people find themselves playing in throughout recent decades. The biological and cultural influences need to be considered and balanced, with the roles of policy makers and media reporters given particular attention alongside the impact of new technology.

\section{Conflicts of Interest}

The author declares no conflict of interest.

\section{References}

1. Gore, A. The Future; Random House: New York, NY, USA, 2013.

2. Bronfenbrenner, U. The Ecology of Human Development; Harvard University Press: Cambridge, MA, USA, 1979.

3. WHO. Why Does Childhood Overweight and Obesity Matter? Available online: http://www.who.int/dietphysicalactivity/childhood_consequences/en/2014 (accessed on 16 May 2014).

4. WHO. Obesity and Overweight. Available online: http://www.who.int/mediacentre/factsheets/ fs311/en/2014 (accessed on 16 May 2014).

5. Griffiths, L.J.; Cortina-Borja, M.; Sera, F.; Pouliou, T.; Geraci, M.; Rich, C.; Cole, T.J.; Law, C.; Joshi, H.; Ness, A.R.; et al. How active are our children? Findings from the Millennium Cohort Study. BMJ Open 2013, 3, e002893, doi:10.1136/bmjopen-2013-002893. 
6. NHS. Physical Activity Guidelines for Children and Young People. Available online: http://www.nhs.uk/livewell/fitness/pages/physical-activity-guidelines-for-young-people.aspx (accessed on 25 April 2014).

7. GOV.UK. Reducing Obesity and Improving Diet. Available online: https://www.gov.uk/ government/policies/reducing-obesity-and-improving-diet (accessed on 16 May 2014).

8. NHS. Physical Activity Guidelines for Children and Young People. Available online: http://www.nhs.uk/Livewell/fitness/Pages/physical-activity-guidelines-for-young-people.aspx (accessed on 16 May 2014).

9. Symons, C.; Polman, R.; Moore, M.; Borkoles, E.; Eime, R.; Harvey, J.; Craike, M.; Banting, L.; Payne, W. The relationship between body image, physical activity, perceived health, and behavioural regulation among Year 7 and Year 11 girls from metropolitan and rural Australia. Ann. Leisure Res. 2013, 16, 115-129.

10. Pink, D.H. Drive: The Surprising Truth about What Motivates Us; Canongate Books: London, U.K., 2009; p. 46.

11. Women's Sport and Fitness Foundation (WSFF). PE Lessons Put Girls off Exercise. Available online: http://www.nhs.uk/news/2012/05may/Pages/girls-put-off-exercise-school-sport.aspx 2012 (accessed on 25 April 2014).

12. Nielsen, G.; Grønfeldt, V.; Toftegaard-Støckel, J.; Andersen, L.B. Predisposed to participate? The influence of family socio-economic background on children's sports participation and daily amount of physical activity. Sport Soc. 2012, 15, 1-27.

13. Wilber, K. The Eye of Spirit; Shambhala: Boston, MA, USA, 1997.

14. Else, P. Practical Applications of the Psycholudic Model for Play Work. In Therapeutic Playwork Reader One 1995-2000; Common Threads: Eastleigh, U.K., 1999.

15. Else, P. Making Sense of Play: Supporting Children in Their Play; Open University Press: Maidenhead, U.K., 2014.

16. Winnicott, D.W. Human Nature; Free Association Books: London, U.K., 1988; p. 11.

17. Konner, M. The Evolution of Childhood; Belknap Press: Cambridge, MA, USA, 2010; p. 687.

18. Edelman, G.M. Second Nature: Brain Science and Human Knowledge; Yale University Press: Boston, MA, USA, 2006; p. 41.

19. Pellis, S.; Pellis, V. The Playful Brain: Venturing to the Limits of Neuroscience; OneWorld: Oxford, U.K., 2009.

20. Johnson, M.H. Brain Development in Childhood: A Literature Review and Synthesis for the Byron Review on the Impact of New Technologies on Children; 2008. Available online: http://www.eyepat.org/login/uploaded/JohnsonBrainDevelopmentLiteratureReviewfortheByro nReview.pdf (accessed on 13 October 2014).

21. Else, P. The Value of Play; Continuum: London, U.K., 2009.

22. Giedd, J.N.; Blumenthal, J.; Jeffries, N.O.; Castellanos, F.X.; Liu, H.; Zijdenbos, A.; Paus, T.; Evans, A.C.; Rapoport, J.L. Brain development during childhood and adolescence: A longitudinal MRI study. Nat. Neurosci. 1999, 2, 861-863.

23. Smith, P.K. Children and Play; Wiley-Blackwell: London, U.K., 2010. 
24. Strauch, B. Why Are They So Weird? What's Really Going on in a Teenager's Brain; Bloomsbury: London, U.K., 2003.

25. Family Planning Association. Teenage Pregnancy Factsheet. Available online: http://www.fpa.org.uk/factsheets/teenage-pregnancy (accessed on 16 May 2014).

26. Nevid, J.S.; Rathus, S.A. Psychology and the Challenges of Life: Adjustment in the New Millennium, 9th ed.; John Wiley \& Sons: Hoboken, NJ, USA, 2005.

27. Gardner, H.E. Intelligence Reframed: Multiple Intelligences for the 21st Century; Basic Books: New York, NY, USA, 1999.

28. Diamond, M.C.; Krech, D.; Rosenzweig, M.R. The effects of an enriched environment on the histology of the rat cerebral cortex. J. Comp. Neurol. 1964, 123, 111-120.

29. Sutton-Smith, B. Play as a Parody of Emotional Vulnerability. In Play and Educational Theory and Practice, Play and Culture Studies; Roopnarine, J.L., Ed.; Praeger: Westport, CT, USA, 2003; Volume 5.

30. Mayer, J.D.; Salovey, P.; Caruso, D. Models of Emotional Intelligence. In Handbook of Intelligence; Sternberg, R.J., Ed.; Cambridge University Press: Cambridge, U.K., 2000.

31. Ponton, L.E. The Romance of Risk; Basic Books: New York, NY, USA, 1997.

32. BBC News. "Up to Five Deaths" Caused by Drinking Game Neknominate. Available online: http://www.bbc.co.uk/news/health-26302180 (accessed on 16 May 2014).

33. Hughes, B. Evolutionary Playwork, Reflective Analytic Practice, 2nd ed.; Routledge: London, U.K., 2012.

34. Lester, S.; Russell, W. Play for a Change; National Children's Bureau: London, U.K., 2008; 128.

35. Pink, D.H. Drive: The Surprising Truth about What Motivates Us; Canongate Books: London, U.K., 2010; p. 89.

36. Grieshaber, S.; McArdle, F. The Trouble with Play; Open University Press: Maidenhead, U.K., 2010; p. 29.

37. Matthews, N.; Kilgour, L.; De Rossi, P.; Crone, D. Literature Review to Investigate the Evidence Underpinning the Role of Play for Holistic Health: Final Report; University of Gloucestershire: Gloucester, U.K., 2011.

38. Dehghan, M.; Akhtar-Danesh, N.; Merchant, A.T. Childhood obesity: Prevalence and prevention. Nutr. J. 2005, 4, 24.

39. Taylor, J.; Hughes, A.R. ; Koufaki, P. The impact of community based physical activity projects on girls' and young women's engagement in physical activity: Findings from an evaluation of the "Girls on the Move" programme. Manag. Leisure 2013, 18, 46-60.

40. Vieira, M.L.; Garcia, M.P.; Rau, D.D.; Prado, A.B. Effects of different opportunities for social interaction on the play fighting behavior in male and female golden hamsters (Mesocricetus auratus). Dev. Psychobiol. 2005, 47, 345-353.

41. Cui, M.; Yang, Y.; Yang, J.; Zhang, J.; Han, H.; Ma, W.; Li, H.; Mao, R.; Xu, L.; Hao, W.; et al. Enriched environment experience overcomes the memory deficits and depressive-like behavior induced by early life stress. Neurosci. Lett. 2006, 404, 208-212. 
42. Chugani, H.T.; Behen, M.E.; Muzik, O.; Juhász, C.; Nagy, F.; Chugani, D.C. Local brain functional activity following early deprivation: A study of post-institutionalised Romanian orphans. Neuroimage 2001, 14, 1290-1301.

43. Beckett, C.; Maughan, B.; Rutter, M.; Castle, J.; Colvert, E.; Groothues, C.; Kreppner, J.; Stevens, S.; O’Connor, T.G.; Sonuga-Barke, E.J. Do the Effects of Early Severe Deprivation on Cognition Persist Into Early Adolescence? Findings from the English and Romanian Adoptees Study. Child Dev. 2006, 77, 696-711.

44. Webb, S.; Brown, F. Playwork in Adversity: Working with abandoned children in Romania. In Playwork Theory and Practice; Brown, F., Ed.; Open University Press: Buckingham, U.K., 2003.

45. Sturrock, G.; Else, P. The playground as therapeutic space: playwork as healing. In Therapeutic Playwork Reader one; Else, P., Sturrock, G., Eds.; Common Threads: Southampton, U.K., 2005.

46. Coughlan, S. BBC News. Available online: http://www.bbc.co.uk/news/education-26049333 (accessed on 16 May 2014).

47. Bajovic, M. Violent Video Game Playing, Moral Reasoning, and Attitudes Towards Violence in Adolescents: Is There a Connection? Ph.D. Thesis, Brock University, St Catharines, ON, Canada, 2012.

48. Cassidy, T.; Rushe, J. Childplay Patterns and Opportunities as a Factor in Adult Health; Conference Poster Presentation, British Psychological Society, annual conference 2010, Stratford-upon-Avon, U.K., 2010. http://abstracts.bps.org.uk/app_templates/bpsapps/conf_ abstracts/googleGW.cfm?\&resultsType $=$ Abstracts\&ConferenceID $=5526 \&$ google $=$ No\&Result Set_ID $=5587 \&$ FormDisplayMode=view $($ accessed on 13 October 2014) 


\title{
Seeking Balance in Motion: The Role of Spontaneous Free Play in Promoting Social and Emotional Health in Early Childhood Care and Education
}

\section{Jane Hewes}

\begin{abstract}
There is accumulating scientific evidence of the potential of play and playfulness to enhance human capacity to respond to adversity and cope with the stresses of everyday life. In play we build a repertoire of adaptive, flexible responses to unexpected events, in an environment separated from the real consequences of those events. Playfulness helps us maintain social and emotional equilibrium in times of rapid change and stress. Through play, we experience flow-A feeling of being taken to another place, out of time, where we have controlled of the world. This paper argues that spontaneous free play, controlled and directed by children and understood from the child's perspective, contributes to children's subjective experience of well-being, building a foundation for life-long social and emotional health. The paradoxical nature of young children's spontaneous free play is explored. Adaptability, control, flexibility, resilience and balance result from the experience of uncertainty, unpredictability, novelty and non-productivity. These essential dimensions of young children's spontaneous free play typically produce play which is experienced by adults as chaotic, nonsensical and disruptive. The article concludes with a preliminary discussion of the challenges and possibilities of providing for spontaneous free play indoors, in early childhood care and education programs.
\end{abstract}

Reprinted from Children. Cite as: Hewes, J. Seeking Balance in Motion: The Role of Spontaneous Free Play in Promoting Social and Emotional Health in Early Childhood Care and Education. Children 2014, 1, 280-301.

\section{Introduction}

Any discussion of young children's health would be incomplete without some reference to the role of play. Early childhood development is a determinant of health [1]. There is compelling neuroscientific evidence of the significance of early experience to life-long mental, as well as physical health [2], and accumulating evidence of the adaptive value of play and playfulness in the development of social competence, emotional resilience, and flexibility in response to unpredictability and stress [3,4]. The child is a citizen with the right to play [5]. There is an urgent need to articulate the conditions that ensure the young child's right to spontaneous free play in the increasingly formal environments in which early childhood experience unfolds.

Profound changes in the physical and social environments of early experience in the western world are constraining opportunities for spontaneous free play in early childhood [6]. Changes in the demographics of family life are accompanied by an institutionalization of free play: young children are spending long hours in non-parental group care [7]; the majority of families now lives in cities, where traffic and urban land-use patterns have changed the natural play territory of childhood and children are less likely to have access to outdoor play spaces in natural 
environments; families are increasingly concerned about neighborhood safety, and are choosing to enroll young preschool children in structured education, recreation, and organized sports programs, leaving little time for self-initiated play [6]. There is growing concern amongst academics, professionals, policy makers and community leaders alike that the decline in free play opportunities may be a contributing factor to increasing rates of childhood obesity, and to the alarming increase in the incidence of anxiety, stress and depression in young children [8-14].

Neuroscientific evidence of the significance of early experience not just to individual health, but also to the long term social and economic prosperity of society as a whole $[1,15]$ is driving a new public policy agenda in early childhood development. The evidence highlights the interconnectedness of physical, intellectual, social and emotional development [16], and of physical and mental health. There is powerful evidence about the impact of excessive stress and adversity in the early years on the incidence of a range of chronic diseases in adulthood [17], creating a new emphasis on the importance of social and emotional health in early childhood [2] and growing public policy interest in early intervention with children living in families coping with the stresses of poverty, violence, mental illness, and substance abuse. Early childhood is on the public policy agenda, and the environments where children spend time in their pre-school years are under intense scrutiny [18].

The focus of the public policy agenda in Canada and much of the Western world is on combatting sedentary lifestyles and childhood obesity, increasing self-regulation and impulse control, and ensuring school readiness, particularly for young children whose development may be compromised by social and environmental factors. This agenda is instrumentalizing $[19,20]$ and pedagogizing [21] children's play in the service of adult goals. Taking a playful approach to learning can be very effective, however it frequently takes control of the play away from the players, changing the experience for the player. However well-intentioned, the intensity of the adult agenda for early childhood, in combination with the changing social reality of early childhood experience, is crowding out children's opportunities for spontaneous free play, an approach that undermines the benefits of play, and ultimately limits its potential to contribute to health [18]. Even very young children are now losing the opportunity to play for their own purposes and with this, essential opportunities to build the foundation of play, and playfulness, which determine in large part their subjective sense of well-being and belonging in childhood and may well affect their physical and mental health long into the future.

This paper explores the potential of spontaneous free play controlled and directed by children themselves, to contribute to children's experience of a healthy childhood and subjective well-being in the present, as well as to the foundation of life-long social and emotional health. The paper argues that opportunities for spontaneous free play, in particular spontaneous free play that allows young children to explore those dimensions of play which may appear to be chaotic, nonsensical and disruptive to adults, is key to their health and well-being. The barriers, challenges and possibilities of providing for these kinds of spontaneous free play opportunities in group early childhood care and education settings are explored. 


\section{Spontaneous Free Play and Health}

Article 31 of the United Nations Convention on the Rights of the Child (UNCRC) challenges us to understand play from the perspective of the child, as a positive factor in children's lives, and from their perspective, as a "necessity of life" [22] (p. 469). This section of the paper discusses the foundation for viewing young children's spontaneous free play as necessary to their subjective sense of well-being in childhood, and considers the evidence that it also contributes to a foundation for social and emotional health and resilience over the life-span.

Section 2.1 considers both recent and established theoretical and conceptual writing defining the nature and characteristics of spontaneous free play, in order to distinguish it from other play-based approaches. Understanding play from the perspective of the player and children's purposes in play is critical to understanding its benefits to social and emotional health. Section 2.2 looks more specifically at the disruptive dimensions of play in relationship to the emerging evidence about the role of spontaneous free play in developing flexibility and adaptability, building the capacity to cope with everyday stress and anxiety. The body of knowledge coalescing around the value of rough and tumble play in healthy social and emotional development in early childhood provides a focus for understanding how children play with the ongoing social and emotional self-balancing that is fundamental to successful participation in social life.

\subsection{The Nature of Play and Spontaneous Free Play in Early Childhood}

"Play is a thing by itself" [23] (p. 45). The recognition of play as a distinct conceptual category and an irreducible concept in human culture rings true nearly 75 years after the publication of Homo Ludens: A Study of the Play Element in Culture. Huizinga emphasizes that play cannot be reduced to other terms or understood by connecting it to a functional purpose that is not play, arguing that to be understood, play must be seen as the player(s) sees it [23] (p. 21). Seeking always to understand the perspective of the player - the child's purposes in playing - is critical to understanding the social and emotional benefits of spontaneous free play in early childhood. For purposes of this paper, it is important to consider some of the defining characteristics of spontaneous free play in childhood, in order to distinguish it clearly from notions of "educational play", "guided play", and "purposeful play", which have crept into recent academic and policy literature, and to highlight some of the key features of spontaneous free play that speak to its value in promoting social and emotional health in early childhood.

The defining characteristic of spontaneous free play is the control of the play by the players. This is the source of some of its unique benefits for children, and most enduring challenges for adults. Children, particularly young children, are never really in control of their everyday lives. Nonetheless, the experience of being in control and making decisions in play can contribute to children's understanding of themselves as social actors and active participants in determining the course of their daily lives. Although play is not the only experience that affords children an opportunity to make their own decisions, in spontaneous free play controlled by the players, children can explore what it means to be in control of themselves and others, without the full responsibility of being in control. Importantly, play also offers a context where children can 
explore being out of control, in ways that are often unacceptable outside of the play context. For the child, play and playing is fundamentally about agency, power, and control. In play, children actively explore their own social and physical power, in relationship to the world, and to other children. As each child participates with other children in the social contexts of play, exploring and testing and making decisions at the edges of their own possibility, they come to understand what it means to be in control, and what it means to be out of control. When left to control their own play, they do explore what it means to exert their own power over others, and they do take chances and physical risks. These are essential dimensions of spontaneous free play that present critical ethical challenges for adults. It is worthy of note that the notions of participation and control are deeply embedded in the language of health promotion [24]. Active participation in community and in particular in the decisions that affect us contributes to a sense of control over the multiple factors that influence not just our physical and mental health, but also our subjective sense of well-being and belonging.

The question "What is play?" both plagues and fascinates researchers, writers, philosophers, poets, parents and educators. Children, arguably the experts on play and playing, seem to know exactly what it is and are unconcerned with trying to call it anything else. As play theorist Brian Sutton-Smith observes, "We all play occasionally, and we all know what playing feels like. However, when it comes to making theoretical statements about what play is, we descend into silliness" [25] (p.1).

Play has a pervasive and ubiquitous presence in human culture and across multiple animal species. We tend to associate play and playfulness with the young of a species. While the play of children, kittens, puppies, and monkeys is familiar, animal play researchers have also observed playful behavior in birds, turtles, fish and even some insects [26]. Despite its variability and remarkable social complexity in the animal world, play seems to be more clearly identifiable as a distinct behavior in animals than it does in humans. The message "this is play" [27] as well as the invitation to play, is behaviourally clear in many animal species. When a puppy wants to play, it assumes a characteristic pose, lowering on its front legs and wagging its tail. The invitation to play in young children is often much more ambiguous, requiring subtle interpretation of social communication, as well as a certain kind of emotional resiliency, as the following example of two boys meeting on a public playground for the first time, illustrates:

Boy \#1 (opening the conversation and for no apparent reason): You're $a$ baby

Boy \#2: No, you're a baby

Boy \#1: You're a ridiculous baby

Boy \#2: You're a poop stick!

Boy \#1: Do ya wanna play [28]?

Human play is arguably more varied and complex than animal play. There are many forms of childhood play and an equally diverse array of functions of human play as are emerging in the study of animal play. It is this sheer diversity of types and functions of play that make it difficult to define. Burghardt notes that the diversity "obscure[s] the commonalities of all forms of both human 
and animal play" [29] (p. 341). Play defies definition and eludes categorization at every turn; the more we try to pin it down, the more it moves - play is playful — it is a "hobgoblin" [23].

Traditional play classification schemes fall apart in the face of a sustained episode of young children's spontaneous free play, which is by nature combinatorial [30], and may exhibit multiple forms, types and stages simultaneously. A recent observation of a group of five year old boys deeply engaged together in block play confirms that children continually slip in and out of solitary, onlooker, parallel, associative and cooperative play [31] as it suits their purposes, developing their own ideas and seeking out the possibilities and fun that results when their playfulness intersects with the play narratives and constructions of other players. Their play embraces aspects of object play, sensory-motor play, construction play, symbolic play, and games with invented rules [32]. The disruptive dimensions of play that are the subject of this paper-the rowdy, rambunctious, nonsensical, irrational, elements of rough and tumble, and order and disorder, both physical and verbal - are characteristic of spontaneous free play. These are better understood as dimensions and qualities of the spontaneous free play experience rather than forms of play, dimensions that coexist simultaneously and fluidly, forming, reforming, appearing and disappearing spontaneously, as any free play episode unfolds.

In early childhood education, children's play is often described using some variation of the characteristics of play identified by Rubin, Fein and Vandenberg in 1983 [33], based on a review of psychological research on play. Play is variously described as voluntary, freely chosen and intrinsically motivated; controlled and directed by the players; possessing a non-literal, "as if" quality; being free of externally imposed rules, taking place 'to the side of' or 'outside of' the rules of ordinary life; undertaken for no immediate goal or purpose, and focused on means rather than ends; characterized by active engagement, deeply absorbing and satisfying for the players; and, generally speaking, producing a positive, pleasurable affect for the player. While this definition of play is in many ways explanatory, it does not capture essential elements and nuances of spontaneous free play from the perspective of the player. For example, the idea that play is free of externally imposed rules suggests, quite rightly, that children are able to make their own rules in play. What it does not adequately describe or explain is the meaning of play and playing that pushes the edges, challenging and even breaking the rules of ordinary life. The popular YouTube video [34] of a wild polar bear returning night after night to play with a husky sled dog is a stunning example of play that breaks the rules of ordinary life. Young children routinely challenge the rules in play, for example climbing up the slide rather than sliding down it is a playful approach which breaks the rules of how young children are expected to use slides in most early childhood care and education programs. The notion that children play to experience pleasure is also limited; when children play they feel powerful. Jumping from a playground platform is a total body encounter with gravity and an experience of the power of flying.

Stuart Brown, a psychiatrist and play advocate, adds depth to our understanding of the nature of spontaneous free play from the player's perspective. He lists the following as properties of play: "apparently purposeless, voluntary, inherent attraction, freedom from time, diminished consciousness of self, improvisational potential, [and] continuation of desire" [35] (p. 17). The notion of a diminished sense of self is echoed in Csikzentmihalyi's discussion of play as the "flow 
experience par excellence", a "the merging of action and awareness" [36] (p. 37-38). A similar notion appears in Gadamer's philosophical treatise on play: "Play fulfills its purpose only if the player loses himself in play" [37] (p.102). Along with the idea of being free from time in play, this notion may speak to the role of play in reducing stress, by taking the player outside of him/herself, into another reality, even for brief periods of time. The improvisational nature of play is thoroughly explored by Keith Sawyer in his study of preschool pretend play [38], a quality of play may be linked to its capacity to enhance adaptability and flexibility in response to rapid change.

Brown's notion of the players' "apparent" purposelessness in play and their desire to continue the play is essential in understanding young children's purposes in spontaneous free play, particularly as it challenges the commonly held notion that spontaneous free play is goalless or purposeless. The players do have one key purpose, and that is to keep the play going, particularly if it is accompanied by pleasurable affect and feelings of power. Keeping the play going is the source of incredible creativity and spontaneous innovation in play. We observe young children introducing surprising novelty into story lines and character roles, in order to sustain the play or include more players or combine their play narrative with another group. Sutton-Smith proposes that these "quirky twists" are characteristic of play and may be connected to its potential to contribute to "adaptive variability" [25] (p. 229). Spontaneous free play can only take place in an environment where spontaneity is possible. It must be possible for play to "erupt" and take off in unusual directions, for metal pots to be hats in one moment and drums in a marching band in the next. It is common in young children's play that these spontaneous narrative directions are non-linear, irrational and difficult for adults to follow. The phenomenon of group glee [39] in toddlers and preschoolers is another spontaneously disruptive and common feature of free play, one which produces a strong sense of social bonding and belonging. The shared humor of very young children is not obvious to adults and other outsiders. For the player, these experiences nourish feelings of subjective well-being in the here and now, and are now acknowledged as some of the immediate social and emotional benefits of children's spontaneous free play [4] (p. 114).

In an attempt to distinguish play from nonplay behaviour in animals, Burghardt [29] (pp. 345-346) identifies several dimensions of play that shed further light on understanding spontaneous free play in early childhood. He describes the voluntary nature of play as being intentional, which further complicates our understanding of play as purposeless. Burghardt notes that the purposelessness of play in the animal world is specific to immediate survival needs. The purposelessness that adults observe in children's play may not be shared by the child(ren). The players may be pursuing purposes that are neither immediately obvious nor purposeful from an adult perspective. Burghardt goes on to describe the exaggerated, novel, repetitive and incomplete behavioral patterns characteristic of animal play, which are reminiscent of young children's playful ways of moving. While an adult will walk efficiently, a small child walking from the house to the car will adopt a gait that includes elements of hopping, skipping, and galloping. This expressive and playful approach to movement has been aptly described as "galumphing" [30], and is characterized by exaggeration, reordering and repetition of sequences of behaviour. Spontaneous free play frequently involves intentional, systematic and novel complication of behavioural patterns, building 
a combinatorial freedom and flexibility in the behavioural repertoire, arguably rendering both animals and humans more adaptable [40].

The following description of free play introduces the notion that some of the more disruptive qualities of play may be defining features of the spontaneous free play experience from the players' perspective, whose main purpose in play quickly becomes to keep playing.

In spite of the complexity and diversity of play behaviour, there is general agreement by specialists in the field that play is controlled by children rather than by adults, and that it is undertaken for its own sake and not for prescribed purposes. The term "free play" is often used to distinguish this from organized recreational and learning activities, which also have important roles in child development. However, the characteristics of free play-control, uncertainty, flexibility, novelty, and non-productivity - are what produce a high degree of pleasure and, simultaneously, the incentive to continue to play [41] (p. 25). These qualities of free play produce the affect that the player is seeking, and which have the potential to contribute positively to children's health and sense of well-being. They are also the qualities that lead to play that is frequently suppressed by adults because it tends to be disruptive [4] (p. 17). Interestingly, these are also the qualities of animal play that are understood to contribute to its adaptive value [42].

Children value play. It is significant in their lives. The awareness that children may have purposes in their spontaneous free play that are neither readily apparent, nor important to adults, is key to understanding the potential of play to contribute to the subjective experience of well-being in childhood. A critical difference between spontaneous free play and other play based approaches lies in the participation of the adult. Children make a very clear distinction about what is and is not play based on how adults participate [43]. In spontaneous free play, the locus of control remains with the players. Adult efforts to guide and direct play-either out of necessity or in the service of a developmental or learning agenda - generally interrupt the flow of the play for the player(s). The idea that the benefits of play accrue most directly from play where the frame is both set and sustained by the players themselves presents significant challenges to adult sensibilities and to the expectations of early childhood educators. For children, play must be spontaneous free play in order to be experienced as play. This means it is controlled and directed by children, even when adults are playing. Other kinds of play based approaches are neither experienced as play by children, nor defined by them this way.

\subsection{Promoting Social and Emotional Health: Making a Case for Disruptive, Disorderly,} Dizzy Play

A theoretical explanation of what exactly is important about play, how its associated benefits are realized and what dimensions of play produce which benefits is almost as difficult as defining it. There is an extraordinary array of developmental and learning benefits that are associated with young children's play, but the evidence linking these benefits to play remains largely correlational [44]. The benefits of animal play are most often linked with the rehearsal of behaviours that serve no immediate survival purpose, but, in the words of Karl Groos "will later be essential to life" [45]. Recent evidence from neuroscience suggests that play may have more important social, emotional, and affective benefits in the immediate context of living than were previously understood [4] (p. 15). 
As Pellis et al. note, [46] (p. 279), the multifunctional nature of play in animals and humans contributes to the difficulty in articulating a coherent explanatory theory as to its adaptive value. Nonetheless, researchers and play theorists alike maintain that there must be some adaptive value to play, given its pervasiveness, its ubiquity and its evolutionary resilience.

This section of the paper looks specifically at the potential of play to contribute to social and emotional health in early childhood, building a case for the idea that the power of play to make us resilient, flexible, and strong-emotionally, socially, physically, intellectually, and perhaps spiritually - may lie in its propensity to invert and subvert the order of things. In particular, it is argued that those dimensions of young children's spontaneous free play and playfulness that experiment with ordering, disordering, and reordering, rough and tumble, and all forms of dizzy, chaotic, nonsense play may provide critical opportunities for children to experience a sense of social belonging, well-being and participation in the culture of childhood, as well as to develop social and emotional awareness, control and resilience. Play helps children learn to "roll with the punches" of everyday life $[42,47]$, and to experience the ongoing social and emotional balancing of self that is fundamental to successful participation in social life.

The similarities between health promotion action strategies - strengthening social relationships, personal control and participation [24] and the characteristics of spontaneous free play, support the notion that play can be understood as a contributing factor to health in its broadest sense. Participation in the peer culture of play is foundational to the child's sense of well-being and belonging in childhood; play creates the possibility of control, motivating and challenging the player to explore the dimensions of their own agency, and thereby experiencing the emotional reality, the thrill, and the risk of making decisions, in an environment that is buffered from the real consequences of those decisions. Play is behavior in the "simulative mode" [48]. In a recent analysis of the decline of free play in childhood, Peter Gray reviews the evidence linking the loss of a sense of personal control and the lack of social connectedness to the increasing incidence of depression and anxiety in children and young adults [12] (p. 449). These are critical dimensions of health promotion action strategies and also key features of spontaneous free play. Play promotes health in early childhood.

The impact of vigorously active spontaneous free play on young children's physical health —on their strength, coordination, spatial awareness and balance - is readily observable. Less obvious, but now quite compelling, is the thought that this same kind of playful exploration of balance and balancing that characterizes so much of young children's physical play, might also be going on in relationship to the emotional realities and social relationships that are so much a part of the play material of childhood, and that there might be similar benefits to emotional resilience, social awareness, the coordination of self with others [49], and the ability to maintain social and emotional equilibrium when things are changing.

\subsubsection{Spontaneous Free Play Alleviates Stress}

Young children use play to cope with stress in situations of extreme trauma as well as everyday events. There is considerable concern with the impact of stress and adversity in early childhood on the developing brain, primarily with the profound impact that extreme adversity or toxic stress in 
early childhood (resulting from violence, neglect, or abuse), has on life-long physical as well as mental health [17]. The evidence is suggesting that the developing brain needs just the right amount of the right kind of stress; there is concern about the impact of removing all stress from children's lives, as well as the supports that should be in place for young children to cope with every day or tolerable stress, for example, with the stress of moving to a new home, or beginning school. There is some common sense in the notion that playing, similar to other forms of recreation, alleviates stress.

The player's experience of play is often associated with freedom. Play is freeing; it frees us temporarily from the cares and stresses of everyday life. As noted previously, and importantly, play is a place where the player feels in control of the world, even for a brief time. It is a hopeful place. Play is about possibility, and for a time, anything can be possible in play. Sutton Smith asserts that the opposite of play is depression [25] (p. 198). Gadamer argues that play is experienced by the player as being effortless and without strain [37] (p.105); the result, he claims, is relaxation. The common sense is that play helps the player to relax, which can be beneficial in coping with stress. The notion of playfulness is important to consider, in addition to play. As illustrated in the fable of the oak and willow, the flexibility that characterizes playfulness can also be adaptive.

However, the relationship between play and stress and how each impacts the other appears to be much more complex than common sense would have it, and like other aspects of play, is informed by multiple disciplinary perspectives. Animal neuroscience [50] is enhancing our understanding of the relationships between stress, adversity, brain development and play. Play is impacted by stress, i.e., situations of anxiety and threat reduce play and playfulness, but play also appears to be resilient to stress, with some evidence that some stress may facilitate play [29]. The research on play in psychotherapy reveals its considerable power as a cathartic and expressive outlet for young children who are coping with overwhelming, confusing, traumatic emotions and life events. In play therapy, children replay and/or play out fearful or stressful situations, often repeatedly, in order to gain control over the emotions. Play has been used effectively to help children cope with hospital stays [51] and surgery, as well as to cope with the aftermath of natural disasters [52].

Young children frequently use play to work through everyday stresses and anxieties. Finding out that daddy is going away for a few days, that grandma is picking you up today instead of Mom, or that your brother will not be coming to child care today because he is sick, are common examples of the everyday stresses that young children gain emotional control of through play. Interestingly, there is some research that suggests that children use solitary play to work through these emotions more often than social play, and that this kind of play can be quite repetitive [53]. Noticing the child's reality and protecting the time and space needed for this kind of play in a busy early childhood program can be challenging. There is a tendency to intervene in play that is repetitive, without first asking what the purpose of the repetition might be. The repetitiveness of this kind of play is arguably linked to establishing a sense of predictability and control. A recent play scenario of a toddler whose father was going away for a few days was captured on video and serves as an interesting example of the everyday potential of play to help children cope with stress and work through normal anxieties. Shortly after her father dropped her off at child care, the child sat down to play at a dollhouse. She played by herself, quite contentedly, inventing conversations between the family figures for well over 15 minutes, which many might consider an unusual length of time 
for a child of this age. What is audible on the video is her repetition of the phrase "You ok? You ok?" A follow-up conversation with the child care educator confirms that this was part of the conversation she had with her father at drop off. The child is actively seeking to balance her emotional reality through the expressive medium of play. After Geertz, she is using play to tell herself a story about herself [54] (p. 674).

\subsubsection{The Social and Emotional Value of Disruptive, Disorderly, Dizzy Play}

Play works in fundamentally paradoxical ways, and it is not always what it seems. Young children have a preponderance for dizzy play, most obvious in their persistent pursuit of vertigo — spinning, whirling, swiveling, twirling, somersaulting and tumbling - turning the world upside down and inside out, and creating considerable tumult in the process. Callois called the pursuit of vertigo in play ilinx, describing it as one of the four major categories of play, in which the player "gratifies the desire to temporarily destroy his bodily equilibrium, escape the tyranny of his ordinary perception, and provoke the abdication of consciousness" [55] (p. 44). Physically, this kind of play results in an increased sense of spatial awareness, vestibular and proprioceptor strength, physical coordination and balance. What is fascinating is that balance is strengthened through the deliberate exploration and experience of imbalance. According to Sutton-Smith, it is the player's deliberate intent to create and experience this imbalance, to create nonsense out of sense, not necessarily to resolve the opposition, rather in an effort to experience it fully [56]. The deliberateness of children's intent is echoed in the recent work of Lester and Russell on players' exploration of risk in play as the deliberate creation of uncertainty [57] (p. 8).

Locomotor-rotational play involving jumping, leaping, twisting, swinging and running is common in the play of many animal species [29] (p. 340). Spinka et al. interpret the function of this kind of play as "training for the unexpected" [42], creating novel behavioural patterns and rehearsing the flexibility of response needed in a rapidly changing environment. While it is also common in young children, it is not generally regarded as beneficial or significant. There are varying levels of adult tolerance for the tumult that is created by dizzy play or chaotic play [58], particularly in indoor environments. Young children's dizzy play also includes elements of verbal nonsense (which may be rude as well as inappropriate), spontaneous fantasy, and group glee, mentioned previously. These kinds of play are often shut down or only allowed in the outdoor environment.

Gadamer [37] (p. 106), speaks to the freedom of decision-making that characterizes play for the player and to playing as the exercise of free impulse, a notion that contrasts with emerging evidence in neuroscience about the role of play in refining the executive functions in the prefrontal cortex of the brain, and specifically, with our ability to control impulses [59]. Ironically, it is through the experience of exercising free impulse in play that young children improve impulse control. One of the durable insights from the research on rough and tumble playfighting is that it does not tend to lead to real fighting [44]. It is fascinating that play that looks aggressive actually builds social empathy and emotional self-control, and may prevent the development of aggression [60]. Studies of rough and tumble play in young children reveal that it is an expression of caring and friendship [61]. It is tempting to theorise that play works by providing an experience of the opposite, however this does not explain its generative power. In play, the players explore the 
dynamic space - the play — between order and disorder, reordering and rebalancing themselves in relationship to the experience and to other players, finding just the right balance in the moment. Sometimes order becomes disorder; sometimes disorder becomes a new order. As Sutton-Smith points out, order and disorder in play are not opposites; they are ambiguities [25]. The power of play is in the moment and the ongoing resolution of imbalance is dynamic, unique to the player(s) and often fleeting and momentary. A crawling infant playing with a ball is motivated by its unpredictability and rewarded by its responsiveness. The infant experiences a sense of agency, power and influence, simultaneously with unpredictability, uncertainty and lack of control of the movement of the ball. The result is fun.

It is significant that play is behavior in the "simulative mode" [48], separated from its real consequences. Playing creates an intense and immediate emotional reality, one that provides an opportunity for the player(s) to experience and respond to the real feeling of terror for example, without the reality of a predatory threat. This dimension of play is observable in mother-infant play across species, where, as Jerome Bruner observes "the mother seems able to bring the young, so to speak, to the edge of terror" [62] (p. 48). This quality of play makes it safe to take a chance: "When we play, we prod the world - and ourselves - to discover our limits. We willfully put ourselves in precarious situations so that we can experience the emotions that attend success and failure, danger and security. In so doing, we see more clearly the spectrum of our own possibilities" [63] (p. 1).

The experience of joy and freedom and thrill that many of us associate with our memories of childhood play are the possibilities that draw children into play, possibilities that frequently involve disorderly, disruptive elements of risk, uncertainty and unpredictability-social and emotional, as well as physical. The player is taking a chance that the risk might connect them to the world and others in new ways, and when it does, the player feels powerful. The understanding emerging from neuroscience that "playing is a way of building and shaping the emotion, motivation and reward regions of the brain" [4] (p. 15) resonates.

There is a body of knowledge coalescing around the social and emotional value of the rough and tumble dimensions of spontaneous free play. Rough and tumble play is common in children, adolescents and across many animal species. While there is now a substantive body of evidence pointing to the benefits of playful aggression in young children [64], it remains one of the most challenging kinds of play to support in group environments. Many do not recognize that rough and tumble playfighting is social play. Gender does appear to play a role; rough and tumble playfighting is more common amongst boys than girls and it is more difficult for women (particularly women who have not experienced rough and tumble play themselves) to distinguish this kind of play from aggression [65]. Research with animals, as well as children, confirms that the signs and behavioural action patterns of rough and tumble playfighting are distinct and recognizable. Maintaining reciprocity is essential and this requires that players exercise self-restraint and engage in continual role reversals and self-handicapping actions. Players actively seek to balance the relationship in order to keep the play going.

The recent work of Pellis et al. $[46,49,60,66]$ on rough and tumble play in rats adds compelling new dimensions to our understanding of this pervasive form of play. Their close and systematic observation of rough and tumble playfighting in juvenile male rats, accompanied by neuroscientific 
analysis of its impact on the brain, reveals that in rats, the experience of peer to peer play fighting in the juvenile period "can lead to organizational changes in the brain, especially in those areas involved in social behavior" [49] (p. 95). They demonstrate that rats deprived of play fighting in the juvenile period display significant deficits in social competence as adults. They conclude that the significant contribution of rough and tumble play fighting to the normal social development of juvenile rats is the opportunity it provides for rats to "co-ordinate their movements" with a peer. One of the remarkable insights from this research is what it reveals of the subtlety and complexity of the social communication and social cues that characterize rough and tumble play. Recently, when confronted with the ambiguity and subtlety of the social communication in rough and tumble play, young children in our child care lab school agreed that "stop-for real" meant that the play was going too far, while "stop" was considered necessary to the playful exchange and did not indicate that you really wanted to stop playing [67]. This kind of nuanced co-ordination of self with others is, in some sense, the basis of participation in social life. That children might learn to do this through full body contact with others in what may appear to be aggressive behaviour, is a significant insight.

Pellis and Pellis [49] (p. 97) argue that there is now sufficient evidence of continuity between playfighting in human and non-human animals to support the notion that rough and tumble play may promote the development of social competence in children. This finding confirms earlier research with children which established a correlation between social competence and children who frequently engage in rough and tumble play [68]. There is growing interest in looking at the implications of these findings for early childhood care and education [69], and new research is emerging. A recent study of rough and tumble play in Norwegian preschools [70] builds on the notion of affordances in the environment - physical, social, and relational affordances - that invite or inhibit, condone or prohibit rough and tumble play. Freeman and Brown argue that it is time to reconceptualize rough and tumble play in early childhood education, to "ban the banning," and intentionally welcome consensual rough and tumble play [71] (p. 230).

To summarize, in early childhood, spontaneous free play promotes social and emotional health and a subjective sense of control, agency, well-being and belonging - in the here and now. Burdette et al. provide an alternative conceptual framework for describing the immediate benefits of spontaneous free play in health, arguing that spontaneous free play contributes to attention (self-control), affiliation (friendship), and affect (happiness) [19]. The improvisational nature of spontaneous free play builds flexibility and resilience in emotional and social responses, contributing to adaptability in the moment. The simulated, intense and immediate reality of play provides a unique vantage point from which children can explore the social and emotional world, one that invites them to appreciate and experience serendipitous joy, as well as become comfortable with unpredictability and uncertainty. The experience of rewarding, successful and satisfying participation in social play with friends, initiated, directed and sustained by young children themselves, and including the disruptive, rambunctious rowdy dimensions of full body social play contributes to a robust and resilient sense of social connectedness that is essential to long term physical and mental health. 


\section{Spontaneous Free Play in Early Childhood Care and Education}

Spontaneous free play promotes social and emotional health in early childhood. There is an urgent challenge before us in early childhood care and education to clearly identify and then consistently create the conditions that allow spontaneous free play to flourish in early childhood care and education programs. What enhances spontaneous free play? As Kalliala notes:

Supporting children's play is more active than simply saying you believe that it important. When children's play culture is taken seriously, the conditions which make it flourish are carefully created. Children's play culture does not just happen naturally. Play needs time and space. It needs mental and material stimulation to be offered in abundance [72] (p. 139).

Group settings in early childhood may offer young children new opportunities to explore and develop spontaneous free play, however they present significant challenges. The spontaneity of spontaneous free play is critical to its health benefits, as is the control of the play by the players. Is it possible to support spontaneity in free play in a formal early childhood environment, bound as it is by regulations, occupational and accreditation standards, and early learning outcomes? How do early childhood educators plan for spontaneous free play? How do we create the conditions that make it possible for three-year-olds to control and direct their own play? Is a pedagogy of play possible without destroying play [73]? These are critical questions right now in early childhood pedagogy.

Notions of child-centred care and education, the centrality of play and "learning through play" have become deeply embedded in the philosophical foundation and professional practice of early childhood care and education. Based in developmental science, play is understood to be essential to development, and to have universal and naturally occurring benefits, illustrating what play scholars have labelled as the "play ethos" [3,25]. This theoretical foundation is criticized in early childhood pedagogy for its tendency to romanticize all play as innocent, pure, and positive, ignoring or shutting down common play experiences that explore more complex and problematic dimensions of our humanity, like social power, gender roles, and racial diversity [74-77]. Many early childhood scholars argue that it is time to reflect more critically on the taken-for-granted approaches to play that have evolved in early childhood care and education, defining an intentional pedagogy of play that considers these complex issues and clearly articulates the rationale for a continued pedagogical focus on spontaneous free play, as well as the conditions that support and enhance it in formal early childhood care and education programs [78-80].

What does it look like when early childhood educators focus intentionally on providing opportunities for children to play on their own terms and for their own purposes? How does it change the role of the educator? What conditions create the possibility of extended episodes of spontaneous free play, controlled and directed by young children? With these questions in mind, I have been following the work of Anne and Brittany, two early childhood educators in a university child care laboratory school, whose collaborative focus over the past several years has been to understand the meaning of the child as a citizen, with a right to play for their own purposes. Each has become deeply involved in reflecting on the meaning of play from the perspective of the young child. Their work draws on new thinking in early childhood pedagogy, connected to the image of 
the child as a strong, resourceful, capable learner and citizen, and the role of the early childhood educator as a co-learner and co-researcher alongside children and families, in a democratic play and learning community [81]. Following is a preliminary discussion of the possibilities that emerge when educators critically reconsider taken-for-granted practices of provisioning the environment for indoor play, refocussing their participation on co-creating the relational space and time for spontaneous free play alongside children.

\subsection{Towards a Pedagogy of "Organized Chaos"}

The notion of play as a pedagogy of organized chaos is borrowed from Somerville and Green's study of outdoor learning in primary schools in socio-economically disadvantaged rural communities in Australia [82]. Building on the ideas of ecological learning and place-based education, as well as other critical pedagogies, the authors conceptualize that deep ecological learning results from a pedagogy of organized chaos, one that calls upon the educator to be "responsibly uncertain," and "willing to risk the unknown." The experiences that inform the pedagogy of organized chaos were founded on children's "immense pleasure with an impromptu, chaotic and random 'jungle' adventure," in the outdoors, where a "sense of imagination and impulsiveness that enables a liberating interaction with the more wild aspects of a school ground landscape" (p. 22) led to rich pedagogical encounters.

Though these ideas are developed in relationship to the exploration of a natural outdoor learning environment, they resonate both with the characteristics of spontaneous free play and its potentially disruptive, chaotic elements, and with the stories of practice that follow. Thinking about play as a pedagogy of organized chaos may open up new possibilities for honoring children's purposes in play and their unique ways of organizing themselves in play.

\subsubsection{Citizenship and Community are Critical Conditions for Spontaneous Free Play}

Spontaneous free play does not just happen; it thrives when children have strong and trusting relationships with one another. Based on her multiyear research on children's citizenship in early childhood programs [83] and her abiding belief in the value and capacity of children to control their own play, Anne speaks about notions of citizenship and community as critical conditions for spontaneous free play to flourish. The environment for play is much more than a physical reality for children. There is a cultural environment that supports young children's play, one that requires intentional work on the part of early childhood educators and that takes time to develop in group settings. Anne describes her role in providing rich materials and resources for children's play, "firing up their imaginations" with stories and new information. The group of children she works with this year have been fascinated by superhero play; after careful thought, she brought in a children's story book about Achilles to stimulate children's thinking about superheroes in new ways, beyond their experience with TV and movies. Anne puts a lot of energy into building a repertoire of social strategies with children, which allow them to enter and leave play, and to participate actively. Anne and Brittany emphasize the importance of working with children to create an environment of strong social relationships, where each child can trust that their ideas will 
be taken seriously by the group. Taking the time to build trusting social relationships in each group of children enhances the capacity of young children to engage deeply in extended and continuing episodes of spontaneous free play that they can control and direct independently. Anne emphasizes that they must be able to trust one another before they can play together. Creating a community that values each child as a citizen requires careful listening on the part of the educators and ongoing attunement to how children are negotiating their friendships and play relationships with one another. It does not mean that all children have to play together all the time. And it is not always smooth.

Both Anne and Brittany maintain that there is a subculture of play that emerges and develops in each group of children. In contrast to a formal school environment, where children move up the grades as a cohort, Brittany comments that in child care "things linger." On average children will spend three years in a preschool room, entering as three-year-olds and leaving as five-year-olds. Children learn to play from other children; multiage groupings support spontaneous free play by feeding the peer to peer transmission of play culture. Childcare programs create the possibility of multiage play. Recent experimentation at the lab school involved toddlers joining the preschool group for several hours each day. This reinforced the educators' understanding of the possibilities of multiage groupings to support spontaneous free play, not only stimulating the toddlers' sociodramatic play in new ways, but also reminding the preschoolers of the pleasure they experienced in sensory play as toddlers [83] (p. 27). As the sense of place and belonging in community is strengthened, so too are the opportunities for rich and varied spontaneous free play experiences.

\subsubsection{Co-Creating Places for Play}

Both Brittany and Anne maintain that the spaces and places for play must be co-created by the children, and further, that the building and transforming of the space is continual, evolving and changing along with the play. Brittany's pedagogical teacher research over the past year has been focused on understanding how preschool children create a sense of place through their play and how this sense of place in turn influences their play. Through critical reflection on ongoing documentation of children's play, Brittany observed a common story line in all of the children's play narratives early in the year. Whether the play characters were dinosaurs or meerkats or superheroes or human beings, the stories were always about family relationships, and the action primarily centred on going places - for example, to and from child care, or to and from the grocery store-common experiences in children's everyday lives that they were playing and replaying together, creating shared meaning. This is another example of Geertz' notion that play is a "story that the players tell themselves about themselves" [54] (p. 674).

After reflecting on this observation with a faculty mentor in an effort to identify possibilities for extending this play, an interesting idea emerged, one that sustained a series of connected play experiences over several months. The idea was to build and add a simple wooden door frame to the playroom, thinking that it might support the comings and goings of children's play narratives. The doorway has been in the playroom for several months now. Initially, the children did not do much with it, but over time, they began to use it intentionally, not just in the literal sense of defining their movement from one place to another, but also as a portal to another world and even to another 
identity. The doorway was draped with fabric that began to have specific meanings for this group of children. For example, when children drape the doorway with sparkly material, they use it to enter a fantasy world.

The practice in many early childhood programs has been to organize the environment for spontaneous free play by providing play centres, for example a house play centre, a dress up centre, a block play area, a quiet play area, and a gross motor play area-provisioned with suitable loose parts, play props and other materials. Although this organization of the environment does offer free play opportunities for children, it also constrains the serendipitous aspects of spontaneous free play, which tends to combine multiple forms and narratives simultaneously. Structuring spontaneous free play in these ways communicates specific messages to children about what to play-in the house centre children are expected to engage in dramatic or sociodramatic family role play-and how to play - rough and tumble play is not acceptable in the house centre; it belongs in the gross motor play area. Through critical reflection on how these environments both invite and limit spontaneous free play, Brittany and Anne have begun to explore a different organization of space, one that values and invites continual transformation. Brittany's immediate observation was that in this kind of environment children begin to use the whole room to develop and sustain their play. It means that children can negotiate the use of space for different and perhaps unusual purposes. For example, recent family play led to the creation of a sleeping area in the entrance to the playroom. Typically, this would be restricted to the house corner.

These are preliminary reflections. Further theoretical insight on co-creating the space for play with young children may lie in Russell's recent writing on "co-producing" the space for play in adventure playgrounds [84], Sawyer's study of the "polyphony" of play that unfolds in an early childhood playroom [38], and Marg Sellers' fascinating Deleuzian interpretation of the multiple and intersecting "lines of flight" that emerge in children's spontaneous free play [85]. As Anne describes it, children begin to "see possibilities" in one another's play and they actively seek to connect their play narratives, sometimes in very creative ways. Sometimes these intersections emerge as a result of a social problem, for example, the need to share space or materials with one another. Anne and Brittany gave me numerous example of this kind of intersecting play — one was about a group of children playing out a narrative of being a film crew, who came upon a group of players who were playing at being cooks and invited themselves for lunch, giving flight to a more elaborate play narrative.

Young children's spontaneously occurring play sometimes does not look like much to an adult — it is often repetitive and the narrative sequence is not particularly logical—which makes it difficult to know when it is meaningful to participate. Brittany reflects on the times when the multiple intersecting episodes of spontaneous free play taking place simultaneously in the whole room have become chaotic creating "uncertainty" and "unknowing," for her as an educator. She has found it sometimes difficult to follow the storyline even when she is listening closely. She can see when it makes sense to the children, but it is not always understandable to her. Anne says we have to trust children to play. We have to wait and listen and try not to interrupt. Lester et al. recently proposed that we rethink the role of the participant observer in children's play, becoming instead an "observant participant" [86] (p. 8). The notion of an observant participant makes clear the 
impossibility of observing without influencing, drawing attention to the idea that young children's play spaces are always and inevitably co-produced, and to some degree, controlled by adults. The notion of the observant participant also suggests observing carefully before participating more actively, intentionally seeking a deeper understanding of the meaning of the play for the player before interrupting or redirecting it. This shift in role may open up a legitimate space for recognizing and valuing the disruptive dimensions of children's play in early childhood programs.

\subsubsection{Honoring Children's Purposes: Keeping the Play Going}

Even very young children have a right to play for their own purposes. Spontaneous free play is enhanced when adults actively seek to understand, acknowledge and respect children's purposes in play and participate intentionally in ways that keep the play going. Brittany speaks to the importance of children being free to choose an identity in play. In order to support spontaneous free play, she has been exploring the possibilities of honoring that identity though the transitions and routines of the day, and not just during free play time. If a child arrives in the morning announcing that he/she is Batman, she honors this identity at the lunch table and when the child wants to wear a cape outdoors.

Many of the family play narratives in Brittany's playroom this year revolved around animal families. In particular, one group of children spent several weeks returning frequently to a pretend play scenario where they became kittens, rolling around on the floor with one another, and rubbing up against the legs of the child care educators, looking to be stroked and petted. This play involved boys and girls in repetitive episodes of very gentle, full body rough and tumble floor play, similar to the gamboling play of kittens. The mama cat appropriated a box of Q-Tips from the art table nearby, which spontaneously became the kitty food. She brought bowls from the house play corner to fill with the Q-Tip food, and the kittens pretended to eat the food by picking up the Q-Tips with their teeth and dropping them back in the bowl. An issue arose for Brittany when the children began to pick up Q-Tips from one another's bowls. Thinking quickly on her feet, she asked if anyone thought the kittens might get sick from sharing their food in this way. A response came immediately and spontaneously from one of the players, who suggested to all the others that the kittens could eat with their feet instead of their mouths. And the play continued, albeit with a new and "quirky twist" [25] on kitten behavior. What mattered to the children was finding a way to keep the play going. Brittany's recognition of this purpose and children's ongoing enjoyment of their play is significant. Much of her reflection this year was about situations like this one, where the participation of the adult can easily interrupt the rhythm and flow of the play, breaking the play frame. In this case she participated as a player might, contributing her thought within the metacommunicative structure of spontaneous free play, where children slip in and out of character roles to shape and direct the ongoing action.

\section{Conclusions}

The UN Convention on the Rights of the Child calls upon us, individually and collectively, to honor and uphold the image of the child as a participating and contributing citizen, with a right to 
play, a right "that is most distinctly children's" and that "defines, almost, the right to be a child" [4] (p. 8). There is good evidence now to support the notion that spontaneous free play contributes positively to mental as well as physical health in early childhood. These benefits are linked to spontaneous free play that is controlled and directed by children themselves; to critical new understanding of the role of rough and tumble play in the development of healthy social relationships; to the capacity of sustained involvement in socio dramatic play to enhance emotional and social self-control; and to the significance of the disruptive dimensions of spontaneous free play in enhancing children's flexibility and adaptability in response to change and unpredictability. This kind of play is often shut down by adults who experience it as noisy, messy, silly, chaotic, risky, uncivilized, dangerous and annoying.

Creating and sustaining the conditions for spontaneous free play in the increasingly formalized environments in which early experience unfolds presents significant challenges for early childhood educators. It is essential that we honor children's purposes in play, and reflect critically on taken-for-granted assumptions and practices in provisioning indoor as well as outdoor play environments for young children in early childhood care and education. Increased time in peer groups at a young age may also create new possibilities for spontaneous free play in early childhood. Ensuring young children's right to play will take intentional effort on the part of early childhood educators and families, with the support of and policy makers and allied professionals.

\section{Acknowledgments}

I am indebted to my conversations with Anne Grove and Brittany Atkinson, Early Childhood Educators, MacEwan University Child Care Lab School, in developing the final section of the paper. Their intentional and deeply thoughtful reflection on the relational time and space for spontaneous free play inspires hope for the possibilities that group early learning and care might have for children's play. I also acknowledge the essential contribution of the children whose play stories are shared here.

\section{Conflicts of Interest}

The author declares no conflict of interest.

\section{References}

1. Keating, D.P.; Hertzman, C. Developmental Health and the Wealth of Nations: Social, Biological and Educational Dynamics; Guildford Press: New York, NY, USA, 1999.

2. National Scientific Council on the Developing Child. Establishing a Level Foundation for Life: Mental Health begins in Early Childhood: Working paper 6; Centre on the Developing Child at Harvard University: Boston, MA, USA, 2012.

3. Smith, P.K. Children and Play; Wiley-Blackwell: West Sussex, UK, 2010.

4. Lester, S.; Russell, W. Play for a Change. Play, Policy and Practice: A Review of Contemporary Perspectives; Play England: London, UK, 2008. 
5. United Nations Human Rights. United Nations Convention on the Rights of the Child. Avaliable online: http://www.ohchr.org/en/professionalinterest/pages/crc.aspx (accessed on 22 September 2014).

6. Hewes, J. The value of play in early learning: Towards a pedagogy. In Several Perspectives on Children's Play: Scientific Reflections for Practitioners; Jambor, T., VanGils, J., Eds.; Garant: Antwerp, Belgium, 2007; pp. 119-132.

7. Unicef Innocenti Research Centre. The Child Care Transition: A League Table of Early Childhood Education and Care in Economically Advanced Countries; Unicef: Florence, Italy, 2008.

8. Wenner, M. The serious need for play. Sci. Am. Mind 2009, 20, 22-29.

9. Ginsburg, K. The importance of play in promoting healthy child development and maintaining strong parent-child bonds. Pediatrics 2007, 119, 182-191.

10. Miller, E.; Almon, J. Crisis in the Kindergarten: Why Children Need to Play in School; Alliance for Childhood: College Park, MD, USA, 2009.

11. Henig, R.M. Taking play seriously. Avaliable online: www.whywaldorfworks.org/ 03_newsevents/documents/takingplayseriously.pdf (accessed on 22 September 2014).

12. Gray, P. The decline of play and the rise of psychopathology in children and adolescents. Am. J. Play 2011, 3, 443-463.

13. Modern life leads to more depression among children. Avaliable online: http://www.telegraph.co.uk/news/1528639/Modern-life-leads-to-more-depression-amongchildren.html (accessed on 22 August 2014).

14. Rosin, H. The overprotected kid. Avaliable online: http://www.theatlantic.com/features/ archive/2014/03/hey-parents-leave-those-kids-alone/358631/ (accessed on 22 August 2014).

15. McCain, M.N.; Mustard, F. Reversing the Real Brain Drain: The Early Years Study; Canadian Insitute for Advanced Research: Toronto, Canada, 1999.

16. Diamond, A. Interrelated and interdependent. Dev. Sci. 2007, 10, 152-158.

17. National Scientific Council on the Developing Child. Excessive Stress Disrupts the Architecture of the Developing Brain: Working Paper 3; Center on the Developing Child at Harvard University: Boston, MA, USA, 2014.

18. Organisation for Economic Co-operation and Development (OECD). Starting Strong II: Early Childhood Education and Care. Final Report of the Thematic Review of Early Childhood Education and Care; OECD: Paris, France, 2006.

19. Burdette, H.L.; Whitaker, R.C. Resurrecting free play in young children: Looking beyond fitness and fatness to attention, affiliation and affect. Arch. Pediatr. Adolesc. Med. 2005, 159, $46-50$.

20. Alexander, S.A.; Frohlich, K.L.; Fusco, C. Playing for health? Revisiting health promotion to examine the emerging public health position on children's play. Health Promot. Int. 2012, 29, $155-164$.

21. Rogers, S. The pedagogization of play in early childhood. In Varied Perspectives on Play and Learning: Theory and Research on Early Years Education; Lillemyr, O.F., Dockett, S., Perry, B., Eds.; Information Age Publishing: Charlotte, NC, USA, 2013.

22. Hodgkin, R.; Newell, P. Implementation Handbook for the Convention on the Rights of the Child; United Nations Children's Fund (UNICEF): Geneva, Switzerland, 2007. 
23. Huizinga, J. Homo Ludens: A Study of the Play Element in Culture; The Beacon Press: Boston, MA, USA, 1950.

24. World Health Organization. Ottawa Charter for Health Promotion; WHO: Geneva, Switzerland, 1986.

25. Sutton-Smith, B. The Ambiguity of Play; Harvard University Press: Cambridge, MA, USA, 1997.

26. Burghardt, G.M. The Genesis of Animal Play: Testing the Limits; MIT Press: Cambridge, MA, USA, 2005.

27. Bateson, G. A theory of play and fantasy. In Play: Its Role in Development and Evolution; Bruner, J.S., Sylva, K., Jolly, A., Eds.; Viking Penguin Inc: New York, NY, USA, 1976; pp. 119-129.

28. Hewes, J. Early Learning and Child Care, Faculty of Health and Community Studies, MacEwan University, Edmonton AB T5J4P2, Canada. Play anecdote from parent, as recalled by child care educator. Personal communication, 2010.

29. Burghardt, G.M. The comparative reach of play and brain: Perspective, evidence, and implications. Am. J. Play 2010, 2, 338-356.

30. Miller, S. Ends, means and galumphing: Some leitmotifs of play. Am. Anthropol. 1973, 75, 87-98.

31. Parten, M. Social participation among preschool children. J. Abnorm. Soc. Psychol. 1932, 27, 243-369.

32. Piaget, J. Play, Dreams and Imitation in Childhood; Routledge: London, UK, 1951.

33. Rubin, K.H.; Fein, G.G.; Vanderberg, B. Play. In Handbook of Child Psychology; Hetherington, E.M., Ed.; Wiley: New York, NY, USA, 1983; Volume 4, pp. 693-774.

34. A Talk by Stuart Brown. On Being with Krista Tippett. Avaliable online: https://www.youtube.com/watch?v=iHj82otCi7U (accessed on 22 September 2014).

35. Brown, S. Play: How it Shapes the Brain, Opens the Imagination and Invigorates the Soul; Avery/Penguin Group: New York, NY, USA, 2009.

36. Csikzentmihalyi, M. Beyond Boredom and Anxiety; Jossey-Bass: San Francisco, CA, USA, 1975.

37. Gadamer, H.-G. Truth and Method, 2nd revised ed.; The Continuum Publishing Company: New York, NY, USA, 1994.

38. Sawyer, R.K. Pretend Play as Improvisation: Conversation in the Preschool Classroom; Lawrence Erlbaum Associates: Mahwah, NJ, USA, 1997.

39. Sherman, L.W. An ecological study of glee in small groups of preschool children. Child Dev. 1975, 46, 53-61.

40. Miller, S.N. The playful, the crazy, and the nature of pretnse. Rice Univ. Stud. 1974, 60, 31-51.

41. Fronczek, V. Article 31: A "forgotten right of the UNCRC". Realising Rights Young Child. Progr. Chall. Early Child. Matters 2009, 113, 24-28.

42. Spinka, M.; Newberry, R.C.; Bekoff, M. Mammalian play: Training for the unexpected. Q. Rev. Biol. 2001, 76, 141-168.

43. Howard, J.; Jenvey, V.; Hill, C. Children's categorization of play and learning based on social context. Early Child Dev. Care 2006, 176, 379-393.

44. Smith, P.K.; Pellegrini, A. Learning through play. In Encyclopedia on Early Childhood Development (online); Tremblay, R.E., Boivin, M., Peters, R., Eds.; Centre of Excellence for Early Childhood Development and Strategic Knowledge Cluster on Early Childhood Development: Montreal, QC, Canada, 2013; pp. 1-6. 
45. Groos, K. The Play of Animals; D. Appleton and Company: New York, NY, USA, 1898.

46. Pellis, S.M.; Pellis, V.; Bell, H.C. The function of play in the development of the social brain. Am. J. Play 2010, 2, 278-296.

47. Siviy, S.M. Neurobiological substrates of play behavior: Glimpses into the structure and function of mammalian playfulness. In Animal Play: Evolutionary, Comparative, and Ecological Perspectives; Bekoff, M., Byers, J.A., Eds.; Cambridge University Press: Cambidge, MA, USA, 1998; pp. 221-242.

48. Reynolds, P. Play, language and human evolution. In Play: Its Role in Development and Evolution; Bruner, J.S., Jolly, A., Sylva, K., Eds.; Viking Penguin Inc: New York, NY, USA, 1976; pp. 621-635.

49. Pellis, S.M.; Pellis, V. Rough-and-tumble play and the development of the social brain. Curr. Dir. Psychol. Sci. 2007, 16, 95-98.

50. Siviy, S. Play and adversity: How the playful mammalian brain withstands threats and anxieties. Am. J. Play 2010, 2, 298-314.

51. Patte, M. The therapeutic benefits of play for hospitalized children. In Play as Engagement and Communication (Play and Culture Studies, volume 10); Nwokah, E.E., Ed.; University Press of America: Lanham, MD, USA, 2010; pp. 3-22.

52. Fearn, M.; Howard, J. Play as a resource for children facing adversity: An exploration of indicative case studies. Child. Soc. 2012, 26, 456-468.

53. Barnett, L. The adaptive powers of being playful. In Diversions and Divergences in Fields of Play. Play and Culture Studies; Duncan, M.C., Chick, G., Aycock, A., Eds.; Ablex: Greenwich, CT, USA, 1998; volume 1, pp. 97-120.

54. Geertz, C. Deep play: A description of the Balinese cockfight. In Play: Its Role in Development and Evolution; Bruner, J.S., Jolly, A., Sylva, K., Eds.; Viking Penguin: New York, NY, USA, 1976; pp. 656-676.

55. Callois, R. Man, Play, and Games; The Free Press: New York, NY, USA, 1961.

56. Sutton-Smith, B. Towards an anthropology of play. In Studies in the Anthropology of Play: Papers in Memory of B. Allan Tindall; Stevens, P., Ed.; Leisure Press: West Point, NY, USA, 1977.

57. Russell, W.; Lester, S. "Tell your mum I saved your life": The relationship between children's play, uncertainty and risk. Avaliable online: www.ipaworld.org (accessed on 22 September 2014).

58. Lofdahl, A. Preschool teachers' conceptions of children's "chaotic play". In Play: An Interdisciplinary Synthesis; McMahon, F.F., Lytle, D.E., Sutton-Smith, B., Eds.; The Association for the Study of Play: Lanham, MD, USA, 2005.

59. Diamond, A.; Barnett, S.W.; Thomas, J.; Munro, S. Preschool program improves cognitive control. Science 2007, 318, 1387-1388.

60. Pellis, S.M.; Pellis, V. Play-fighting during early childhood and its role in preventing later chronic aggression. In Encyclopedia on Early Childhood Development (online); Tremblay, R.E., Boivin, M., Peters, R., Eds.; Centre of Excellence for Early Childhood Development and Strategic Knowledge Cluster on Early Child Development: Montreal, QC, Canada, 2012; pp. 1-4.

61. Reed, T.; Brown, M. The expression of care in the rough and tumle play of boys. J. Res. Child. Educ. 2000, 15, 104-116. 
62. Bruner, J. The nature and uses of immaturity. In Play: Its Role in Development and Evolution; Bruner, J.S., Jolly, A., Sylva, K., Eds.; Viking Penguin Inc.: New York, NY, USA, 1976; pp. 28-64.

63. Henricks, T.A. Orderly and disorderly play: A comparison. Am. J. Play 2009, 2, 12-40.

64. Hart, J.L.; Tannock, M.T. Young children's playfighting and use of war toys. In Encyclopedia on Early Childhood Development (online); Tremblay, R.E., Boivin, M., Peters, R., Eds.; Centre of Excellence for Early Childhood Development and Strategic Knowledge Cluster on Early Child Development: Montreal, QC, Canada, 2013; pp. 1-6.

65. Pellis, S.M.; Pellis, V.C. Play and the socially competent brain. PlayRights 2009, 2, 4-7.

66. Pellis, S.; Pellis, V. The Playful Brain: Venturing to the Limits of Neuroscience; Oneworld Publications: Oxford, UK, 2009.

67. Hewes, J. Early Learning and Child Care, Faculty of Health and Community Studies, MacEwan University, Edmonton AB T5J4P2, Canada. Play anecdote shared by Brittany Atkinson, child care educator. Personal communication, 2014.

68. Pellegrini, A. A longitudinal study of popular and rejected childre's rough-and-tumble play. Early Educ. Dev. 1991, 2, 205-213.

69. Tannock, M. Rough and tumble play in early childhood settings: Challenges for personnel training. In Play as Engagement and Communication (Play and Culture Studies); Nwokah, E.E., Ed.; University Press of America: Lanham, MD, USA, 2010; volume 10, pp. 143-164.

70. Storli, R. Characteristics of indoor rough-and-tumble play (R\&T) with phsycial contact between players in preschool. Nord. Early Child. Educ. Res. J. 2013, 6, 1-15.

71. Freeman, N.K.; Brown, M.H. Reconceptualizing rough and tumble play: Ban the banning. In Social Contexts of Early Education, and Reconceptualizing Play (II); Reifel, R.S., Brown, M.H., Eds.; Elsevier JAI: Oxford, UK, 2004; volume 13, pp. 219-234.

72. Kalliala, M. Play Culture in a Changing World; Open University Press: New York, NY, USA, 2006.

73. Rogers, S. Play and pedagogy: A conflict of interests? In Rethinking Play and Pedagogy in Early Childhood Education: Concepts, Contexts and Cultures; Rogers, S., Ed.; Routledge: New York, NY, USA, 2011; pp. 5-18.

74. Cannella, G.S.; Viruru, R. Privileging child-centred, play-based instruction. In Deconstructing Early Childhood Education: Social Justice and Revolution; Cannella, G.S., Ed.; Peter Lang: New York, NY, USA, 2008; pp. 117-136.

75. Brooker, L. Taking play seriously. In Rethinking Play and Pedagogy in Early Childhood Education; Rogers, S., Ed.; Routledge: New York, NY, USA, 2011; pp. 152-164.

76. Ailwood, J. Governing early childhood education through play. Contemp. Issues Early Child. 2003, 4, 286-299.

77. Grieshaber, S.; McCardle, F. The Trouble with Play; Open University Press: Berkshire, UK, 2010.

78. Brooker, L.; Edwards, S. Engaging Play; Open University Press: Maidenhead, Berkshire, UK, 2010.

79. Rogers, S. Rethinking Play and Pedagogy in Early Childhood Education: Concepts, Contexts and Cultures; Routledge: New York, NY, USA, 2010.

80. Lillemyr, O.F.; Dockett, S.; Perry, B. Varied Perspectives on Play and Learning: Theory and Research on Early Years Education; Information Age Publishing: Charlotte, NC, USA, 2013. 
81. Makovichuk, L.; Hewes, J.; Lirette, T.; Thomas, N. Play, Participation and Possibilities: An Early Learning and Child Care Curriculum Framework for Alberta. Avaiable online: www.childcareframework.com (accessed on 22 September 2014).

82. Somerville, M.; Green, M. A pedagogy of "organized chaos": Ecological learning in primary schools. Child. Youth Environ. 2011, 21, 14-34.

83. Grove, A.; Lirette, T. Children and citizenship. In Leading the Way: Recognizing the Role of Early Learning Lab Schools in Canadian Universities and Colleges; Langford, R., DiSanto, A., Eds.; School of Early Childhood Studies, Ryerson University: Toronto, ON, Canada, 2013; pp. 22-28.

84. Russell, W. Towards a spatial theory of playwork: What can Lefebvre offer as a response to playwork's inherent contradictions? In The Philosophy of Play; Ryall, E., Russell, W., McLean, M., Eds.; Routledge: Oxon, OX, USA, 2013; pp. 164-174.

85. Sellers, M. Young Children Becoming Curriculum: Deleuze, Te Whariki and Curricular Understandings; Routledge: Abingdon, Oxon, UK, 2013.

86. Lester, S.; Russell, W.; Fitzpatrick, J. Co-creating an Adventure Playground (CAP): Reading Playwork Stories, Practices and Artefacts. Report from an Action Research Project; University of Gloucestershire: Gloucestershire, UK, 2014. 


\title{
Prevention is Better than Cure: A Hands-On, Play-Based, Innovative, Health and Well-Being Program in Remote Australia
}

\section{Lis Mathiasen}

\begin{abstract}
A key to improving the quality of life in remote communities is the empowerment of children who are at health and educational risk. Between 2002 and 2009, at a remote Aboriginal school, students and community members participated in an innovative, play-based health and well-being program aimed at helping children to become self-determining and responsible for their own health and well-being. Holistic in its approach, and broad in its scope, the multi-faceted program encompassed the fundamentals of personal hygiene; understanding of body systems; the importance of nutrition, hydration, sleep and exercise; brain care; the biology of emotions, with particular emphasis on anger management and the critical interplay between emotions and behavior; the impact of substances of abuse on the brain; as well as the Hospital Familiarization Program (HFP) which prepares children for planned and unplanned hospitalization. Program outcomes included improved school attendance and student engagement; increased community awareness of the importance of a healthy lifestyle; improved self-concept, self-esteem and self-confidence; as well as increased respect and caring for self and others. A reduction in children's fear and anxiety when facing hospitalization and visits to the doctor was also evident. Each year, 12,500 children throughout Western Australia enjoy the benefits of the HFP.
\end{abstract}

Reprinted from Children. Cite as: Mathiasen, L. Prevention is Better than Cure: A Hands-On, Play-Based, Innovative, Health and Well-Being Program in Remote Australia. Children 2014, 1, 318-338.

\section{Introduction}

This paper describes the rationale, theoretical underpinnings and the process of the implementation of a play based, hands on health and well-being program in a remote community. The program was three-fold, featuring the key elements of physical health, social and emotional well-being and a hospital familiarization program that featured role-play as an important component.

The article is based on my experience as a teacher and principal, working in a small Aboriginal community school in the Ngaanyatjarra Lands, over a period of eight years (2002-2009). Approximately, 150 students aged from five to 16 years attended the school over this period of time. Located in the Gibson Desert, $2000 \mathrm{~km}$ north east of Perth, the Ngaanyatjarra Lands is home to a cluster of the most isolated communities in Western Australia. The community is situated approximately $30 \mathrm{~km}$ west of the Northern Territory border and lies to the south east of Lake Hopkins on the Sandy Blight Road, see Figure 1. The nearest major town in Western Australia is Kalgoorlie, $1300 \mathrm{~km}$ southwest and Alice Springs, in the Northern Territory $980 \mathrm{~km}$ to the east. The community population is small, approximately 80 residents clinging to their traditional, 
culturally orientated activities in harsh yet beautiful countryside ([1], pp. 9-11, 28-29). There is a shop, a school, a clinic and an air strip.

Figure 1. Ngaanyatjarra Lands.

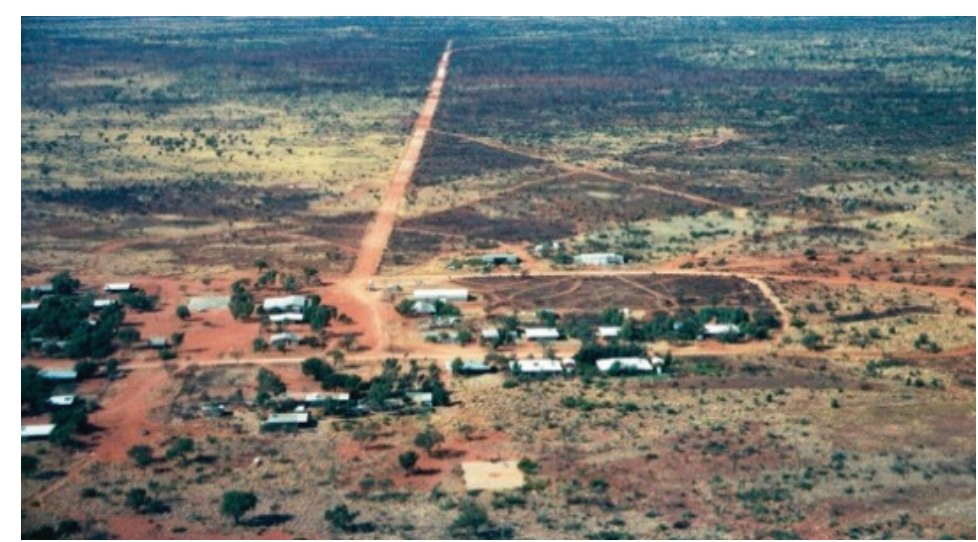

Written from an action research/practitioners perspective, this article argues that there is a real need for preventative health and well-being education programs in remote communities in Australia. The results of the integrated, play based, hands on program, conducted in a small remote community school, clearly demonstrate how students became motivated and engaged in their own learning. In addition, anecdotal evidence showed significant evidence of learning outcomes in areas such as health and well-being, English and mathematics. Furthermore, findings of the effectiveness of a Hospital Familiarization Program (HFP) showed a reduction in children's fear and anxiety of medical procedures. An increase in children's knowledge of medical equipment was also evident. Moreover, community members became empowered to take a positive and proactive role in their children's and their own education, promoting physical, social and emotional health.

To facilitate sustainable delivery of this program to a wider audience of students in Australian rural and remote schools, recommendations were made collaboratively with elders from the remote community.

\section{Cultural Background}

Cultural activities such as hunting, traditional secret men's and women's business, funerals and major sporting events take precedence over education, and the children are allowed the autonomy of making their own decision about attending school [2]. A death in the community also affects the attendance. The bereaved relatives move out of their home into a "sorry camp" a short distance away from the community and relatives from distant communities may travel to the sorry camp and remain there until after the funeral. For a period of time after the death, that person's name will no longer be referred to and instead the "no name" Kunmarnu will be substituted [3].

Traditionally, Aboriginal children learn by observation and by trial and error. They have their own particular understandings based on their experiences, often within a traditional foundation ([4], pp. 1-14). Aboriginal children also learn their own limits and they are not 
disciplined until they reach teenage years. Eye contact, particularly between a child and adult is considered disrespectful, and walking away in the middle of a conversation is considered acceptable [3]. These are cultural influences that teachers need to accept and adapt to when working in and with indigenous communities. It is very much a two way learning process ([1], pp. 9-11, 28-29).

\subsection{The Ngaanyatjarra Language}

The majority of people speak Ngaanyatjarra as their first language. Others are speakers of closely-related Western Desert dialects. Ngaanyatjarra has historically only been a verbal language but, in the past decade an increasing amount of written vernacular has been produced in an attempt to retain the language. However, less than $20 \%$ of adult Ngaanyatjarra speakers are able to read Ngaanyatjarra, because it has not been taught in schools [5].

Historically, language is the mediator of learning in Western education. However, in the Aboriginal culture and context some people rely on observation and approximations and repeated passing of the unchanged stories and songs about knowledge, wisdom and lore [6]. This practice was clearly an important part of the students' culture as singing and telling stories in the sand was spontaneously carried out during the school day. The importance of two-way learning was acknowledged and an emphasis placed on socio-dramatic play, storytelling, music, drama and art as an integral part of the health and well-being program.

\subsection{Community Health Background}

The Ngaanyatjarra Lands of 3.1 million sq km have a population of approximately 2500 Indigenous people. The level of poverty in the remote communities has significant implications for health and well-being as it acts as a hindrance to affordability of nutritional food. In addition, the lack of availability of healthy foods is profound and the higher cost in the more remote areas of Australia is significant ([7], pp. 189-218). Fresh fruit and vegetables are transported a long distance and are extremely expensive to buy. For example, the price of one piece of poor quality fruit is around $\$ 5$ and potatoes cost 50 cents each. According to Burden (2001), this poses a serious problem as many Aboriginal children are failing to thrive ([7], pp. 189-218).

Several communities have no permanent doctor or nursing sister and medical evacuations are not uncommon ([1], pp. 9-11, 28-29). Moreover, the mortality of Indigenous people is 13 times higher than mainstream society and Aboriginal children are rated a one in four chance of developing serious emotional or behavioral difficulties [8]. Chronic Suppurative Otitis Media (CSOM) is a common disease in Aboriginal children [9]. The World Health Organization has indicated that a prevalence rate of CSOM greater than $4 \%$ in a defined population of children is indicative of a massive public health problem ([10], pp. 177-178). Alarmingly, CSOM affects up to 10 times this proportion of children in many Aboriginal communities. The associated hearing loss has a life-long impact, as it occurs during the years of speech and language development and the early school years ([10], pp. 177-178). Infectious diseases such as head lice, scabies and tinea (ringworms) are all too common. Some diseases still prevalent in Aboriginal children are virtually 
non-existent in the non-Aboriginal community, for example rheumatic fever causing significant life-long morbidity [9].

Furthermore, Princess Margaret Hospital for Children, Perth West Australia statistics for 2009 revealed that $13.3 \%$ of outpatients, and $17 \%$ of inpatients come from rural and remote areas [11]. Timmins (2010) stated that the medical care such as hospitalization and medical treatment may be foreign and frightening for Indigenous people who live in remote communities [12]. They may fear the unknown; being transported thousands of kilometers away from their familiar environment; flying; dying; bad spirits, which many believe reside in hospitals; isolation and lack of family support. Timmins (2010) cites the following case, which clearly illustrates the need for education about hospitalization and medical treatment:

A 17-year old boy from a remote community was evacuated to Alice Springs $(980 \mathrm{~km}$ away) because of a fractured elbow. I next saw him two weeks later and discovered that on arriving in Alice Springs for the first time ever, became so terrified by this "metropolis" that he immediately set about finding ways to return to his community rather than attend hospital care. He now lives with a permanently dysfunctional elbow. [13].

In addition, research suggests that for many young children, hospital admission provokes feelings of considerable anxiety. This is particularly so in the case of emergency admission to hospital and treatment by invasive procedures. Adding to the child's distress, the withdrawal of the child's familiar routines and surroundings, which are replaced by an environment filled with unfamiliar people, sights, sounds and smells [13]. For some children the ensuing stress may be relatively minor. However, other children have been found to suffer negative psychological effects such as withdrawal, depression, aggression and phobias, sleeping disorders, hyperactivity and erratic control of bodily functions, both during and after hospitalization [14-16].

\subsection{Rationale}

To address the poor state of health and the fear of hospitalization, it was decided to implement a three-fold multi-faceted, holistic health and well-being program, featuring the Hospital Familiarization Program (HFP) as a key component [17]. It was concluded that the most important principle would be to ensure that the students and their parents were made to feel welcome and valued; that the school environment was student centered in terms of being interesting, fulfilling, enjoyable, relevant to the culture, safe and empowering.

In 2002 an integrated health and well-being program was developed in consultation with community elders, the Aboriginal and Islander Education Officer, (AIEO) and the local community health worker. In 2008 this program was revised, enhanced and consequently implemented and offered to students and to the local community members [17].

The impetus for this health program development came from the finds of Calmas (2007) who stated that it is our responsibility to improve the social and emotional well-being for our children, families and communities [18]. Consistent with this view, Burden (2001) proposed that if significant improvement is to occur in the health status of Aboriginal people a preventative, holistic approach needs to be adopted ([7], pp. 189-218). Burden recommend that the Department of 
Education and Training provide significant preventative health programs in schools as part of the health and physical education program and that health programs are developed in conjunction with community members, Aboriginal health workers, clinical staff and allied health agencies. Furthermore, regular meetings should be held between school and local clinic staff to discuss relevant cases and health education within the community context [19]. In addition, this view was supported from 2002-2009 by the Circuit doctors, touring the 11 communities in the Ngaanyatjarra Lands. They stated that the health and well-being program should be part of every remote community school's curriculum.

\section{Program Pedagogy}

\subsection{Empowerment}

Community involvement in class activities such as art, music and health lessons was encouraged and fostered. Provision was made for informal and formal meetings with parents/caregivers who are acknowledged as first teachers of their children [20] and were therefore encouraged to take a positive and proactive role in their children's education. The educational task was to enhance the competence of parents/caregivers so that they would use both their resources and their control over family processes to, in turn, enhance the competence of their child.

Health promotion is the process of enabling individuals and communities to increase control over the determinants of health and thereby improve their physical, emotional and community health. It assumes direct involvement of community members in the achievement of change. It also involves political action towards better health for people living in remote communities ([21], p. 187).

Educator Paulo Freire's (1986) sociological philosophy of empowerment states that the goal of empowerment is not to achieve power and control over others but it aims at giving power to make changes collectively [22]. It is a social action process that promotes participation and dialogue between community members. Empowerment encompasses prevention, self-determination and social justice ([23], pp. 738-739) giving individuals a greater locus of control over their own lives, within their communities and in the wider society. Empowerment education can be an effective health education and prevention model that promotes physical, social and emotional health.

\subsection{Student Centered Education}

It is well known that students who have been part of decision making processes about their own learning, are more likely to feel valued, to be more self-motivated and engaged in any learning process. It is critical, however, that the learning experiences offered are real, concrete and relevant to students, reflecting their world and experiences [24].

Crowther (2005) postulates the significance of a student centered environment with three dimensions: child/adult, structured/directed/explicit teaching and student initiated [25]. Furthermore, students should be challenged through learning experiences that vary in length and complexity, including culturally appropriate methods. Given that Australian Aboriginal children learn by observing and by trial and error [4], the program focused on play-oriented hands on activities. The 
program included role play about cultural activities such as hunting, music and dancing, hospital play and "telling stories in the sand", see Figure 2.

Figure 2. Telling stories in the sand.

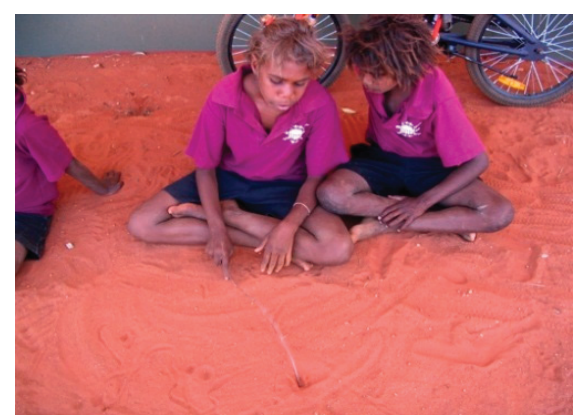

\subsection{Play}

Seeing family members airlifted out of the community because of illness was a familiar experience for these children. While some of the children had actually been the patient requiring emergency treatment, for those who had watched a plane carry a community member over the horizon, where the patient was taken and what happened during their absence remained a mystery. In addition to familiarizing children with medical procedures, participation in the HFP helped the children make some sense of what ill community members experienced during their absence ([1], pp. 9-11, 28-29).

Sebastian-Nickell (1992) described play as "one of the most important activities in a young child's life", adding that it is "valuable to every aspect of development: physical, social, intellectual and emotional" [26]. Play is a context for learning that enhances children's thinking so that they become inquisitive, wanting to know and to learn, solve problems and engage in critical thinking. They actively construct their own understanding and contribute to others' learning. Children become aware of their capacity to initiate and lead learning, and their rights to be part of decision making processes concerning their own learning [27].

Indigenous Elder, Aunty Irene McBride (2008), stated that young Indigenous children should be encouraged to role play more because it is vital to their development as well as to their education [28]. Furthermore, students who have difficulty expressing their feelings and ideas using language are given the opportunity to demonstrate understandings through socio-dramatic play [29]. While engaged in socio-dramatic play children's ability to self-regulate: to monitor and modify emotions, control impulses, tolerate frustrations, delay gratification and co-regulate in social interactions is significantly enhanced ([30], pp. 899-911).

Through socio-dramatic medical play, children can create their own world, where they are free to act out new roles as they master new situations. Smilansky and Shefatya (1990) point out that the roles taken on by children in play are significant because rather than being the recipients of someone else's activity, the children are now in control [31]. For example, being the doctor treating the patient, rather than being the patient receiving treatment. 
Socio-dramatic medical play also enables children to explore in a non-threatening and safe environment. By exploring unknown medical equipment, such as a drip or a stethoscope they are able to hold, feel, examine and manipulate the object. As a result, a relationship is developed with each object ([32], pp. 687-708), and simultaneously any anxiety associated with the unknown object is reduced [33-35].

Gaining control over potentially fearful events may in turn enhance a child's confidence and feeling of self-worth and hence, the ability to cope better with medical procedures [36,37]. Socio-dramatic medical play may also be therapeutic in the healing process, where children have the opportunity to act out feelings about medical procedures; for example by re-enacting a traumatic event, previously experienced involuntarily ([38], pp. 23-26).

It is important to respect the integrity of socio-dramatic play by protecting the children from adult interference, providing the appropriate space and props, and permitting the children to choose and decide how long they will play [39]; thus, enabling them to come to terms with reality in their own way and in their own time.

Traditionally, Aboriginal children rely heavily on observation and imitation to learn new skills ([4], pp. 1-14). Given that young Aboriginal children living in remote areas of Australia may have limited understanding of the English language, it is important to provide opportunities to develop understanding through engagement in concrete learning experiences, where children can adopt roles and rules that have a culturally appropriate base. As role play has no language barriers, children from diverse language backgrounds will readily participate, acting out what they have learned.

\subsection{Collaboration}

Collaboration with the Aboriginal and Islander Education Officer (AIEO) ensured provision of cultural understanding and appropriate learning experiences. Aboriginal children are used to a higher degree of autonomy at an early stage, and their learning style is based on modeling and trial and error [29]. Acknowledgement that English is the student's second or third language was inherent in the program's design and consideration was given to the fact that it is tiring for students to translate and respond to another language [6].

Consistent with the findings of Malcolm et al. (1999) and the Deadly Ideas resources [29,32,40] the health and well-being program was underpinned by negotiation, collaborative group work, problem solving, acknowledgement of the students' home language, integration of curriculum areas and hands-on learning experiences.

Collaboration with doctors, nurses, allied health workers, other related agencies, families/caregivers and specialist teaching staff assisted in achieving better outcomes. This collaboration included frequent informal and formal meetings with all relevant stakeholders.

\section{The Health and Well-Being Program}

As shown in Figure 3, a to h, the integrated health and well-being program encompassed the curriculum areas of health, science, English, mathematics, technology and enterprise, society and environment and the arts. Its aim was to increase students' awareness of healthy living; promote 
healthy self-concept; self-esteem; self-confidence; respect and caring for self; others; the community and the environment. To achieve this, the dual components of physical and emotional well-being were included.

\subsection{Program Content}

Self-management skills, interpersonal skills and basic physiology about the human body, such as the skeletal, muscular, cardiovascular, respiratory, renal, digestive and nervous system were taught. Furthermore, simple research skills and report writing were integral elements of the program, which focused on developing awareness of how to achieve and maintain a healthy lifestyle through personal hygiene, safety, nutrition, sleep and visits to the doctor, dentist and the hospital, The program was differentiated to meet the needs of multiple age groups and individual students' abilities. Individual learning styles, multiple intelligence and cultural diversity were taken into consideration [17].

Figure 3. (a) Science: Learning about the skeletal system; (b) Music: Singing a skeleton song; (c) Science and Math's: Making a plaster cast; (d) Art: Painting torsos; (e) Art: Painting a skeleton; (f) Health: Learning about healthy food groups.

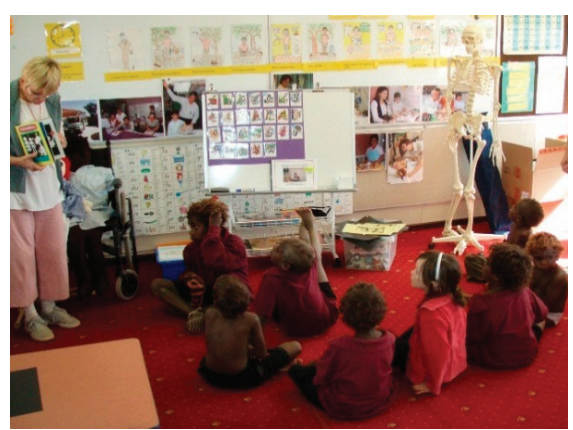

(a)

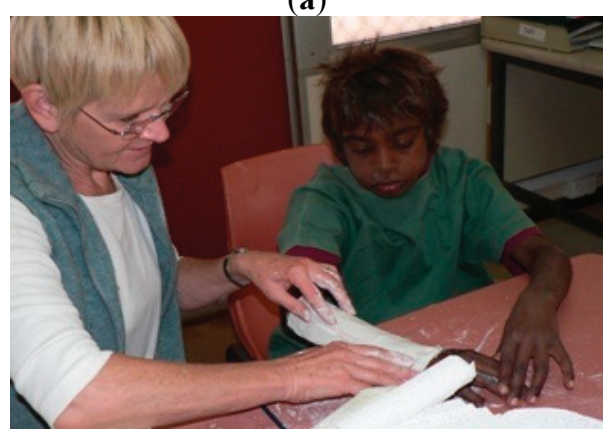

(c)

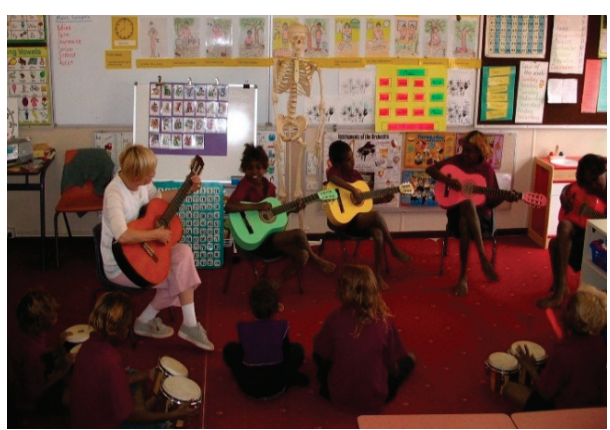

(b)

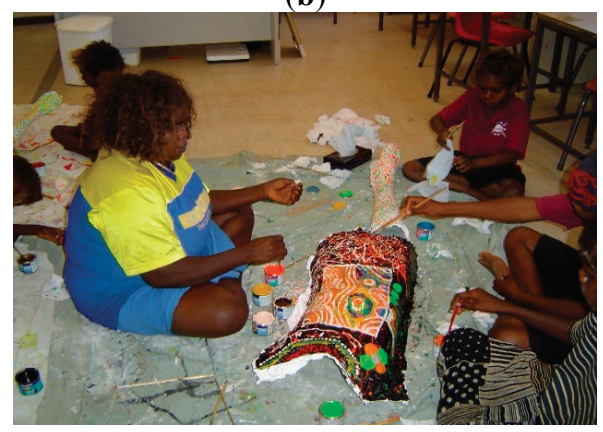

(d) 
Figure 3. Cont.

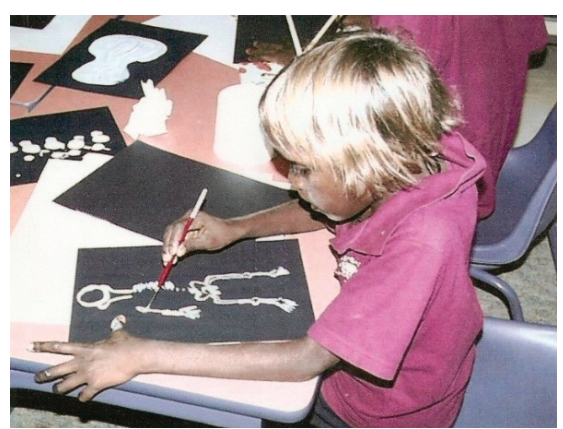

(e)

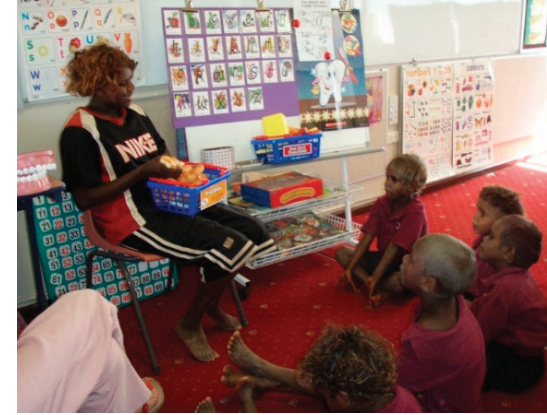

(f)

\subsection{Implementation}

The daily routine of the health and well-being program began in the morning. On arrival, the students immediately went to the bathroom, where they had a shower and then dressed in freshly-laundered uniforms. This was followed by eating a healthy breakfast; oral hygiene and the breathing blow and cough (BBC) procedures. Healthy morning tea, lunch and filtered boiled water were provided. A $15 \mathrm{~min}$ rest or meditation session after lunch was also part of the program.

\section{Findings}

Case studies were made of each individual child and portfolios of the students' work were compiled, displayed where appropriate, and shared with parents. Following are some snapshots of student's progress:

In the beginning of 2008, a year two student who had poor listening skills, no knowledge of the alphabet, no phonological awareness, unable to form letters and no knowledge of numbers became a motivated and engaged learner, who accelerated beyond all expectations. By June this student wrote a simple question and answer about the length of the esophagus. In addition, he developed a real passion for reading and mathematics. By the end of the year, the student was able to read more complex text and operate with numbers over a thousand, making additions, subtractions, divisions and multiplications. Another student wrote a simple question and answer about the length of the small and large intestines. Once he had found the answer, he decided to demonstrate to the class what it meant. Using strings he measured the length of the small and large intestines and displayed his findings on the board.

\subsection{Knowledge of Health Issues}

A year six student who researched the respiratory system, wrote about having two healthy lungs because she does not smoke. People who smoke, she wrote, have black lungs and if they keep smoking they may develop cancer and die. She stated that she is not going to smoke, because she wants to live for a very long time, see Figure 4, a - b. 
Figure 4. (a) English/science: Researching the human body; (b) Science: Researching the respiratory system.

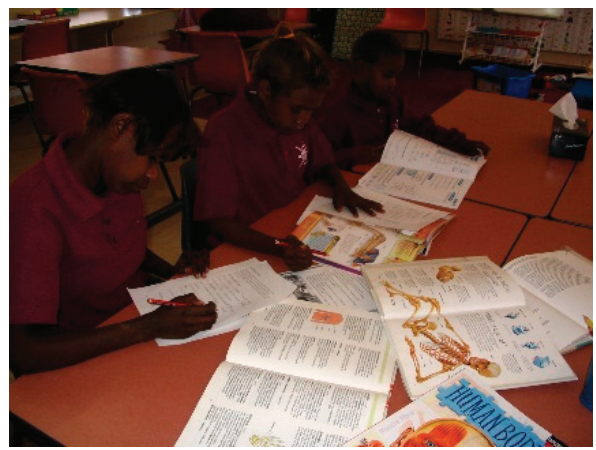

(a)

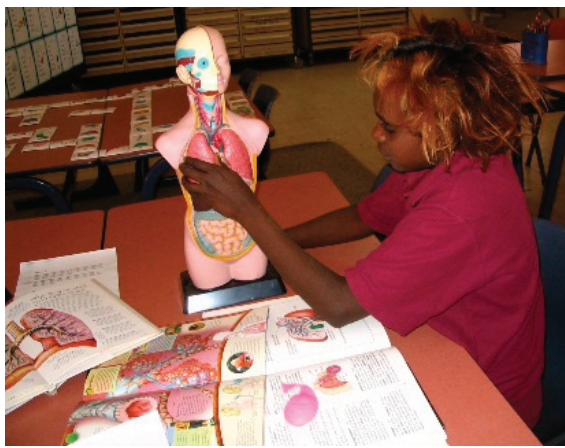

(b)

During a large influx of students from other communities, living in the local sorry camp, one of the year two students decided to demonstrate oral hygiene to the visiting students, while talking about the importance of looking after the teeth, see Figure 5a. This was followed by another year two student who proceeded to demonstrate how the digestive system works, explaining the importance of eating healthy food and keeping the teeth clean. He strongly emphasized how rotten teeth have a bad effect on the digestive system, see Figure 5,b.

Figure 5. (a) Demonstrating oral hygiene; (b) Explaining the digestive system.

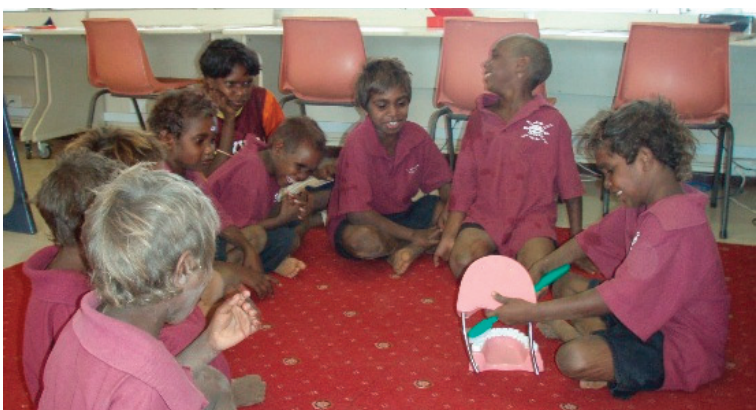

(a)

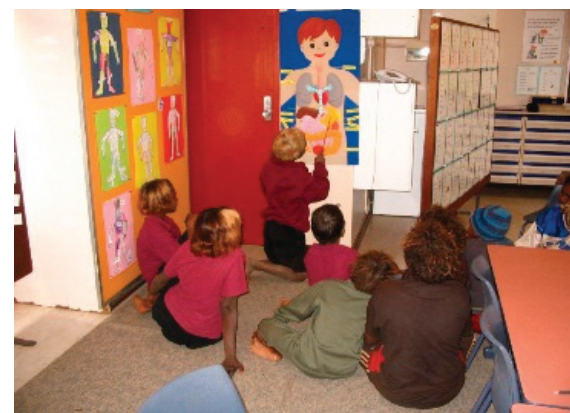

(b)

\subsection{Changes of Community Policy}

During this time, and in consultation with the advisor and a dietician, local community members decided to develop and implement a new Healthy Store Policy. This included a significant reduction in ordering unhealthy foods for the community store, which contain high levels of salt and fat and drinks, which contain high levels of sugar. 


\section{The Social and Emotional Well-Being Program}

The second component of the health and well-being program, designed to support students in developing healthy concepts about themselves as individuals and about themselves as learners, was facilitated through a series of lessons in which the students investigated the brain structure and function, the importance of sleep and exercise; the impact of substances of abuse on the brain; the biology of emotions, with particular emphasis on anger management and critical interplay between emotions and behavior.

Informed by neuroscience research and based on the principals of brain compatible learning [41-43], this component of the program provided a range of hands-on multi-sensory learning experiences that fostered alternative learning pathways to meet the specific learning needs of these students. Activities included: dissection of sheep's brains to explore the brain parts that are responsible for balance, coordination and movement; thinking; learning; emotion; relaying information and sleep; construction of model brains and neurons, see Figure 6, a - c creative movement; music; mind mapping and role play.

Figure 6. A local community member translating. (a): Science: A student explaining;

(b) Science: Dissecting sheep brains. The anatomy of the brain into the local dialect.

(c) The anatomy of dendrites.

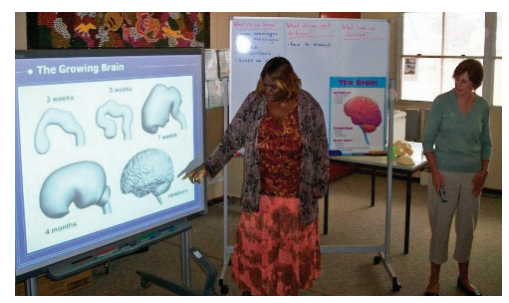

(a)

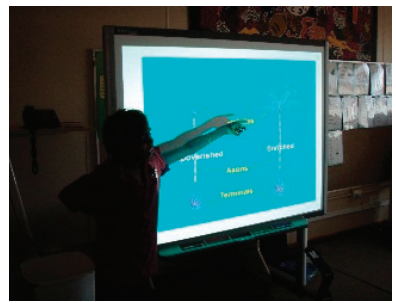

(b)

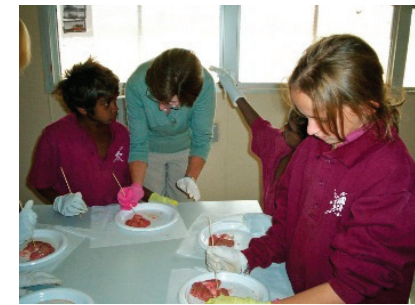

(c)

Students explored the concept of self-talk and rehearsed strategies for taking control of their inner voice and thus maintaining balance between the emotions and the intellect. This was achieved through a range of role play scenarios, through which students explored feelings such as joy, optimism, creativity, loneliness, anger, fear or despair, and developed a vocabulary to describe feelings and emotions. Wright (2006) postulates that through drama, where students take on the roles of others; their social, emotional and intellectual abilities are enhanced [44]. He further reports that role play has been found to improve vocabulary and self-concept.

Role play experiences enable children to develop an understanding that when the emotions are allowed to override the intellect impulsive, volatile behavior is likely to occur. They learned to apply reasoned thought and analysis to situations to avoid habituating to impulsivity and aggression and were encouraged to extend this understanding to the playground and circumstances beyond school. By empowering students with a language to describe feelings, the propensity to react impulsively to situations was clearly minimized. 
Students further created a mind map, see Figure 7 a, and learned about neurons and dendrites and understood that dendritic growth occurs as a result of all new learning. Each student was provided with a "dendrite chart", see Figure 7, b, on which they recorded new growth when they mastered a new skill. These included academic, social, emotional and intellectual skills.

This segment of the program also dealt with confronting but relevant issues of substance abuse and petrol sniffing. Animated computer graphics were used to guide students' understanding of the impact of substances on brain function, along with an introduction to the physiology of addiction. Cartoon graphics were used to demonstrate the pathway of substances through the brain to activate the brain's reward system so that feelings of pleasure experienced in relation to the substance convince the user to want to repeat the experience. Students learned that with each repetition of use of the substance the momentum towards addiction is accelerated.

Figure 7. (a) Science/English: Making a mind map; (b) Recording of new dendrite growth.

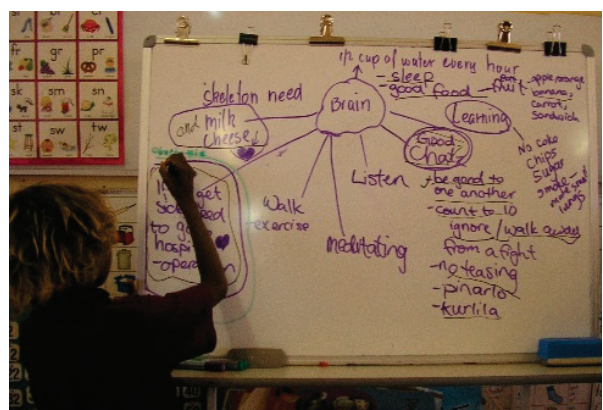

(a)

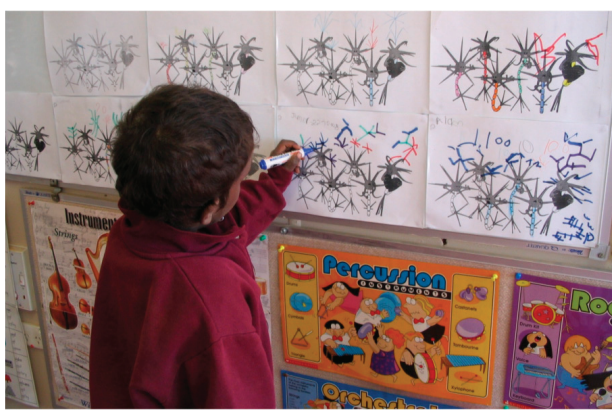

(b)

Students further understood that when a foreign substance is introduced to the brain, the balance between the brain's chemicals and hormones is upset. This can lead to erratic behavior, loss of cognitive function, loss of appetite, disruption to sleep cycles and breathing.

\subsection{Findings}

Observations of students' behavior indicated that the social and emotional well-being program was successful. As students internalized the hands-on learning experiences, they became more confident, motivated and aware of their own learning processes. The role play, creative movement and puppetry activities were introduced to support the concept of "self-talk", providing structures to help them make better choices. They were more confident to resolve issues using dialogue instead of fighting; to listen to others' viewpoints and to put themselves in the other person's shoes. There was a significant reduction in aggressive behavior from term one to term four.

Students spoke of new learning in terms of "growing dendrites". At the end of each day student recorded, on an individual "dendrite chart" provided, how many dendrites they estimated they had grown that day. 


\section{The Hospital Familiarization Program}

\subsection{Introduction}

In order to reduce the anxiety of the students about medical intervention and going to hospital, the Hospital Familiarization Program was presented to them. This innovative, play-based program is typically twofold; to inform young children about medical procedures and to teach them effective coping strategies [45]. It has three key elements:

- The first is an interactive group session where children are shown various items of medical equipment and have the opportunity to participate in discussion about their own hospital experiences.

- The second element is the viewing of a DVD in which a child, who has suffered a broken arm, is admitted to hospital and taken through common procedures of hospitalization, including anesthesia and surgery.

- The third, and arguably most significant element, is free socio-dramatic play where children are given the opportunity to dress up as doctors, nurses, surgeons and ambulance drivers in replica, child-sized uniforms. Alternatively, children may elect to play the role of patient or parent.

A wide range of common medical equipment and large persona dolls enable children to further explore the hospitalization scenario through play. In this context, children are able to express their concerns and fears, ask questions and seek assurance from supportive adults as they familiarize themselves with basic items, including drip equipment, bandages, crutches, wheelchairs, stethoscopes, X-rays, plaster casts, blood pressure monitor, thermometer, name bands, books, puzzles and a miniature toy hospital [46].

The pictures below, Figure $8 \mathrm{a}-\mathrm{f}$, illustrate the role-play children eagerly engage in.

Figure 8. (a) The Hospital Familiarisation Program; (b) A parent being treated at the "hospital"; (c) English: Writing a medical report; (d) Doctors treating the patient;

(e) The consultant and the registrar; (f) Caring for the patient.

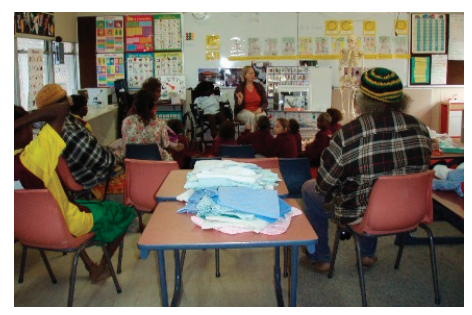

(a)

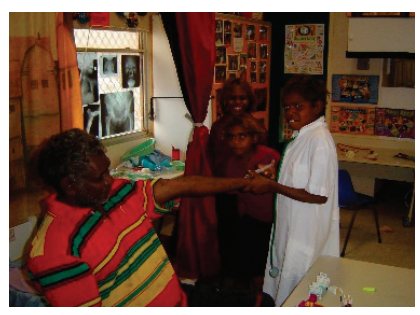

(b)

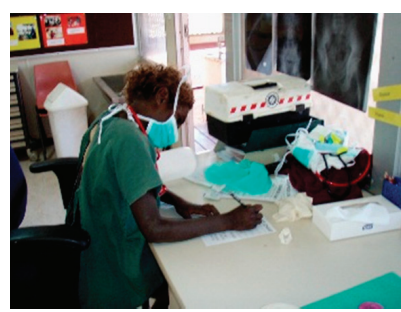

(c) 
Figure 8. Cont.

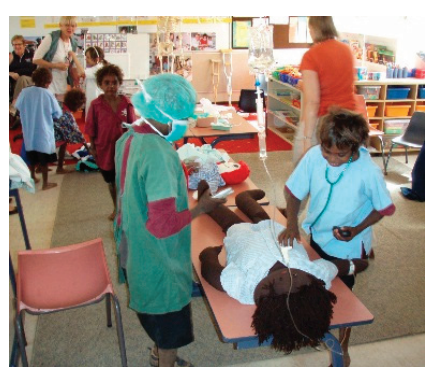

(d)

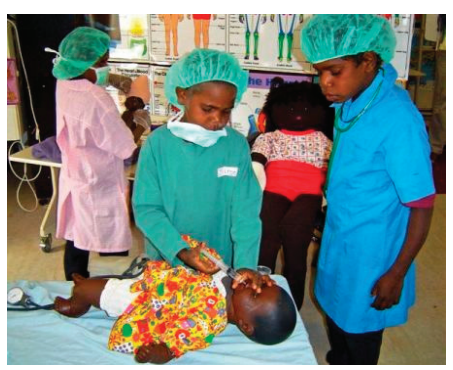

(e)

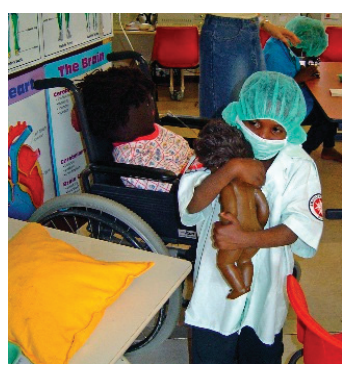

(f)

\subsection{Findings}

A few weeks after the program, in 2008, a six year old child was evacuated to a major hospital with severe burns to her body. She was accompanied by a family member who stayed with her throughout the hospitalization. In addition to being prepared for hospitalization through the HFP at the school, the Association for the Welfare of children in Hospital (AWCH) supplied the child with a doll, which she used to re-enact the traumatic events of her accident and hospitalization. The family, hospital staff and visiting AWCH committee members, all reported how well she coped with hospitalization. However, more importantly, the little girl, on her return to the community, had brought the doll with her. Using the doll, she was able to communicate her experience to her peers and community members.

Observations of the children engaging in medical play revealed that they internalized what they learned about hospitalization and medical procedures, which in turn will prepare them to face the prospect of medical intervention with confidence and resilience, should such a situation arise.

Recordings of the children engaging in spontaneous hospital role-play, shown in Figure 9, a to h, clearly demonstrate a sound understanding of the content of the HFP program: 
Figure 9. (a) The "doctor" tells the patient that he is very sick and that he needs an operation. The "doctor" explains the procedure carefully; assuring the patient that everything is going to be fine; (b) "Jack you are very sick and you need an operation on your brain!" "I need to put you to sleep. I will put magic cream on your hand so that the needle won't hurt you. Before I count to three you will be asleep!"; (c) "One-twothree!"; (d) "His blood pressure is fine!"; (e) The brain surgeon.; (f) "The operation went well Jack, everything is fine, but you need more medication so that you don't get an infection!"; (g) "I am sure that your brother will look after you when you get home!"; (h) "Make sure you look after your brain Jack. Remember it needs healthy food and half a cup of water every hour. Now eat up all the food and drink the water!".

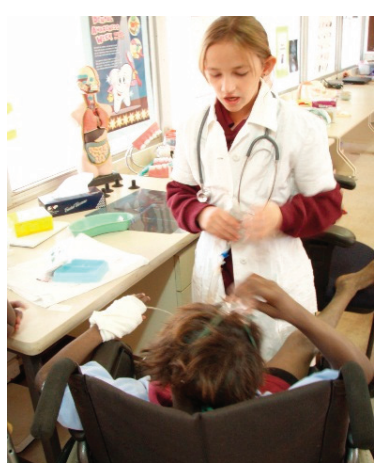

(a)

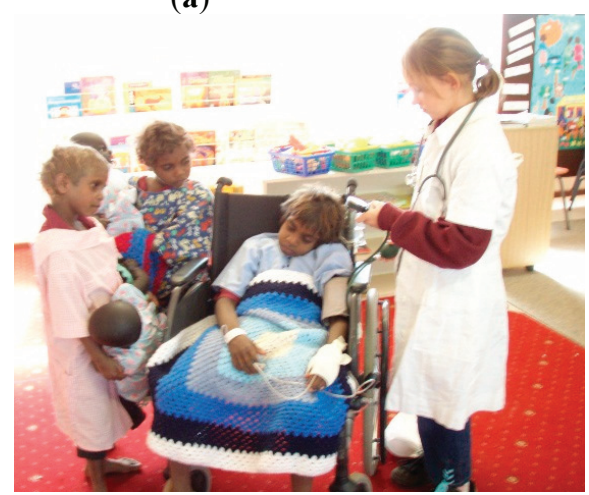

(d)

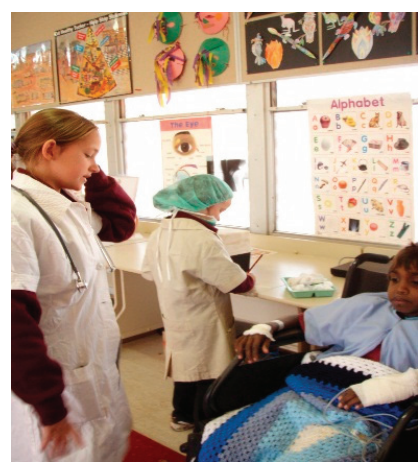

(b)

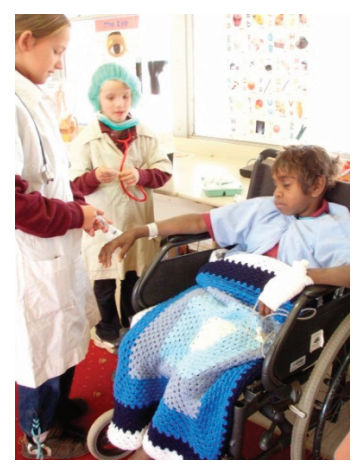

(c)

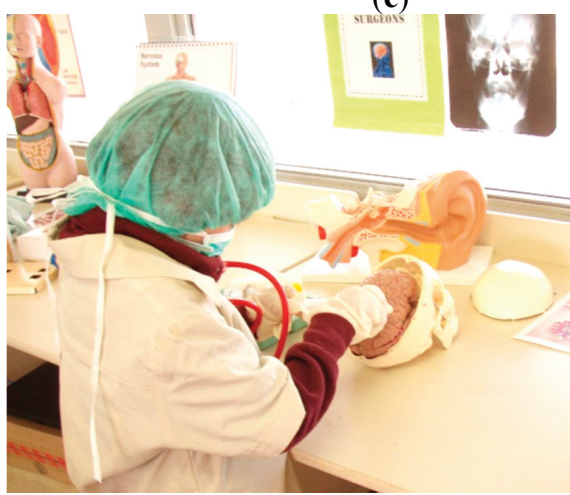

(e) 
Figure 9. Cont.

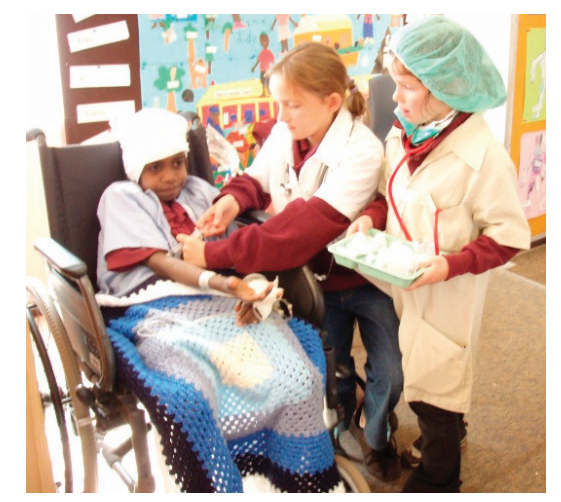

(f)

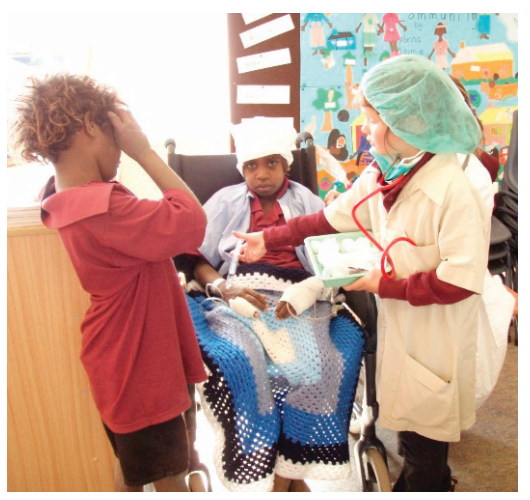

(g)

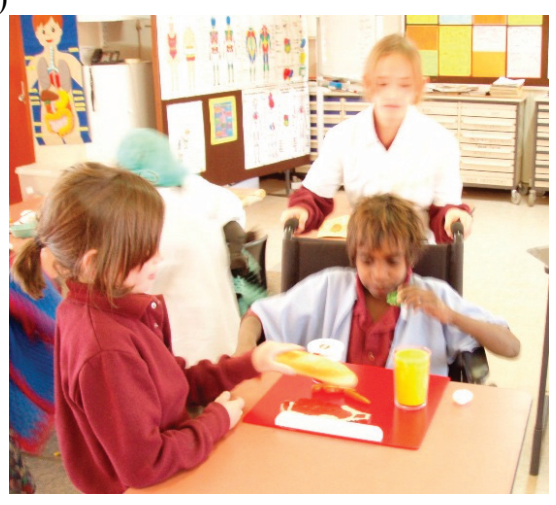

(h)

This story clearly testifies the importance of play in helping children cope with trauma. Therapeutic medical play is a healing process, where children have the opportunity to act out feelings about medical procedures as this young girl did, re-enacting a traumatic event, empowering her to release emotional energy and gain mastery over that event.

An evaluation of the effectiveness of the HFP was carried out in 2003 with 16 children aged from five to 16 to ascertain the effect of providing information about common medical equipment and procedures. This was followed by a socio-dramatic play session to test the students understanding of common items of medical equipment and procedures. This was carried out using the Medical Equipment and Procedures Test (MEPT). In addition, the subjects' feelings towards possible hospitalization and medical intervention were obtained by the use of a Hospital Intervention Feelings Index (HIFI).

An analysis of variance of pre- and post-test measures revealed a significant increase in the children's understanding of medical equipment and procedures ( $\mathrm{F}=16.067$; d.f.1 and 40; $p<0.01)$. Therefore, the provision of information about medical apparatus and procedures in a developmentally and culturally appropriate manner, followed by socio-dramatic play, resulted in increased knowledge and understanding. In addition, positive feelings towards medical equipment and procedures were found $(\mathrm{F}=3.856$; d.f. 1 and $40 ; p=0.06)$ [47]. 
In other words, the HFP was effective in achieving its intended outcomes of increasing the children's knowledge and understanding of common items of medical equipment and procedures and of reducing anxiety regarding possible medical intervention [37,47]. Given that the majority of these children suffer from serious health problems and many are prone to accidents requiring hospitalization away from the community, it is important that they receive a program such as the HFP to minimize anxiety and possible trauma due to medical intervention [48].

\section{Conclusions}

Holistic in its approach, and broad in its scope, this highly successful multi-faceted program encompassed the fundamentals of personal hygiene; understandings of body systems; brain care; the importance of nutrition, hydration, sleep and exercise; the impact of substances of abuse on the brain; and the biology of emotions, with particular emphasis on anger management and critical interplay between emotions and behavior.

Collaboration with local community members and health professionals ensured a well-planned, wide-scaled program offering high quality learning experiences for students, community members and staff alike.

The findings clearly show significant outcomes in improved learning and knowledge of health issues. The impact of how cultural consideration consultation and collaboration can lead to prevention and self-determination is also evident.

The process of the health promotion program enabled individuals and the community to become empowered, increasing control over the determinants of their wellbeing and to improve their physical, emotional and community health. As a result of empowerment, community members collectively became directly involved in the achievement of change.

This program illustrates how empowerment education, through a play based hands on learning environment, can be an effective health education and prevention model that promotes physical, social and emotional health, see Figure 10.

Figure 10. Participants in the program

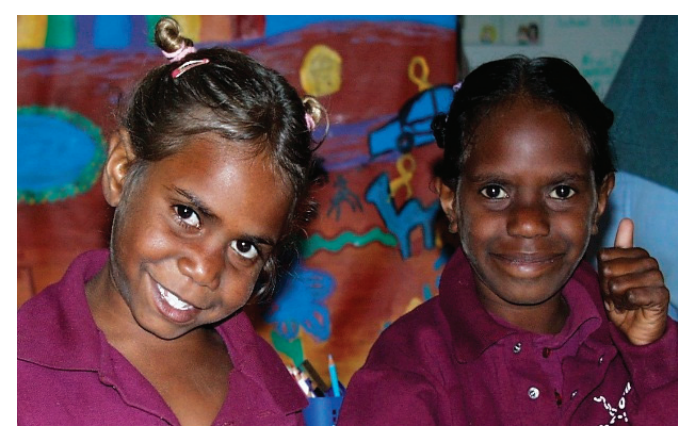

"Tell me and I forget. Teach me and I remember. Involve me and I learn" 


\section{Recommendations}

1. A DVD be produced featuring an Indigenous child from a remote community going to hospital. The DVD would take the child on a tour of the hospital, taking in the admission procedure, the radiology unit, operating theatre, wards and key hospital personal.

2. In order to ensure sustainability the program should be offered to schools throughout Australia including rural and remote community schools.

3. A program, to be produced, features two main animated sections. 1. Educating children about hospitalization. 2. Educating children about the function of the human body systems, along with attention to how illnesses such as diabetics, renal and cardiac vascular diseases affect the body and how they are treated.

4. Publish the health and well-being model for an international audience, with the view of replicating the program in remote locations around the world.

5. Undertake ongoing research to measure the effectiveness of a health and well-being program.

\section{Acknowledgments}

I wish to thank various people for their contribution to this project.

Penny Bingham for her invaluable contribution to the revised health and well-being program, especially the development, delivery and write up of the neuroscience education section.

Kate Casteldine for her strong support and for her valuable delivery of the Hospital Familiarization Program.

Danella Ashwin for her interest in the program and her tireless assistance towards the technological aspects of the paper.

Special thanks should be given to Dawn Butterworth for her professional guidance and valuable support.

Poul Mathiasen for his continual support and encouragement throughout the development of the program.

Last but not least I wish to thank the committee members of the Association for the Welfare of Children in Hospital WA for their generous support which lead to the success of the program.

\section{Conflicts of Interest}

The author declare no conflict of interest.

\section{References}

1. Mathiasen, L. Hospital Play in a remote community in Australia. Play Rights Int. Play Assoc. Promot. Child's Right Play 2012, 1, 9-11, 28-29.

2. Kearins, J. Child-Rearing Practices in Australia: Variation with Life-Style; Education Department of Western Australia: Perth, Australia, 1984. 
3. Overview of Ngaanyatjarra people and culture. In Ngaanyatjarra Cultural Awareness; Ngaawyatjarra Council: Alice Springs, NT, Australia, 2002.

4. Clarke, M. Direction and support for new non-aboriginal teachers in remote aboriginal community schools in the northern territory. Aust. J. Indig. Educ. 2000, 28, 1-14.

5. Glass, A.; Hackett, D. Ngaanyatjarra \& Ngaatjatjarra to English Dictionary; IDA Press: Alice Springs, NT, Australia, 2003.

6. Everyday Strategies for Language and Dialect in Early Childhood Education for Indigenous Students; Department of Education and Training of Western Australia: East Perth, Australia, 2005.

7. Burden, J. Health: A holistic approach. In In Aboriginal Australia: An Introductory Reader in Aboriginal Studies, 2nd ed.; Queensland Press: Queensland, Australia, 2001; pp. 189-218.

8. De Maio, J.A.; Zubrick, S.R.; Silburn, S.R.; Lawrence, D.M.; Mitrou, F.G.; Dalby, R.B.; Blair, E.M.; Griffin, J.; Milroy, H.; Cox, A. The Western Australian Aboriginal Child Health Survey: Measuring the Social and Emotional Wellbeing of Aboriginal Children and Intergenerational Effects of Forced Separation. Curtin University of Technology and Telethon Institute for Child Health Research: Perth, Australia, 2005.

9. Zubrick, S.R.; Lawrence, D.M.; Silburn, S.R.; Blair, E.; Milroy, H.; Wilkes, T.; Eades, S.; D’Antoine, H.; Read, A.; Ishiguchi, R.; et al. The Western Australian Aboriginal Child Health Survey: The Health of Aboriginal Children and Young People; Telethon Institute for Child Health Research: Subiaco, Australia, 2004.

10. Coates, H.L.; Morris, P.S.; Leach, A.J.; Couzos, S. Otitis media in Aboriginal children: Tackling a major problem. Med. J. Aust. 2002, 177, 177-178.

11. Princess Margaret hospital for children statistics. In Medical Records. Princess margaret hospital for children: Subiaco, Australia, 2010.

12. Timmins, P. The Association for the Welfare of Children in Hospital; AWCH: Perth, WA, Australia, 16 August 2010.

13. Jones, W.; Mathiasen, L. Play and its role in the healing process. In International Association for the Child's Right to Play; University of Melbourne: Melbourne, Australia, 1993.

14. Wright, M.C. Annotated behavioural effects of hospitalisation in children. J. Paediatr. Child Health 1995, 31, 165-167.

15. Hagglof, B. Psychological reaction by children of various ages to hospital care and invasive procedures. Acta Paediatr. Suppl. 1999, 88, 72-78.

16. Bar-Mor, G. Preparation of children for surgery and invasive procedures: Milestones on the way to success. J. Paediatr. Nurs. 1997, 12, 252-255.

17. Mathiasen, L.; Bingham, P.; Casteldine, K. REPORT Integrated Health and Well-Being Program at a Remote Indigenous School; The Association for the Welfare of Children W.A. Inc.: Perth, Australia, 2008.

18. Calma, T. Indigenous health: Real solutions for a chronic problem-Social and emotional wellbeing. In 9th Annual Gama Festival of Traditional Culture; Australian Human Rights Commission: Sydney, Australia, 2007. 
19. Re-Thinking the Provision of Education and Training in Remote Communities Project; Department of Education and Training: East Perth, WA, Australia, 2004.

20. Schwab, R.G.; Sutherland, D. Working together for Excellence. Building Indigenous Learning Communities; Department of Education, Government of Western Australia: East Perth, Australia, 2001.

21. Wallersteine, N. Health promotion in action: Practical ideas on programme implementation. Health Promot. 1986, 1, 187-190.

22. Freire, P. A pedagogy for liberation. In Dialogues on Transforming Education; Bergin \& Garvey Publishers: Massachusetts, MA, USA, 1986.

23. Wallerstein, N.; Bernstein, E. Empowerment Education: Freire's ideas adapt to health education. Health Educ. Q. 1988, 15, 738-739.

24. Hattie, J. Teachers Make a Difference. What is the research evidence? In Australian Council for Educational Research Annual Conference Proceedings; Melbourne, Vic, Australia, 19-21 October, 2003.

25. Crowther, F. Parallel leadership-The key that unlocks synergistic school development. In Proceedings of the Western Region Principals' Conference, Victoria, Australia, 3 June 2005.

26. Sebastian-Nickell, P. Care and Education of Young Children; Longman Cheshire: Melbourne, Australia, 1992.

27. Australian Government Department of Education, Employment and Workplace Relations for the Council of Australian Governments. Belonging, Being \& Becoming. The Early Years Learning Framework for Australia; Canberra, ACT, Australia, 2009.

28. McBride, I. Helping Indigenous kids in child's play. In The Koori Mail, Alice Springs, NT, Australia, 2008.

29. Cahill, R. Association of Independent Schools of Western Australia; Catholic Education of Western Australia; Deadly Ways To Learn Consortium; Western Australia Education Department, Perth, W.A. Australia, 2000.

30. Blair, C.; Diamond, A. Biological processes in prevention and intervention: The promotion of self-regulation as a means of preventing school failure. Dev. Psychopathol. 2008, 20, 899-911.

31. Smilansky, S.; Shefatya, L. Facilitating Play: A Medium for Promoting Cognitive, Socio-Emotional and Academic Development in Young Children; Psychosocial \& Emotional Educational Publications: Silver Spring, Maryland, USA, 1990.

32. Bruner, J.S. The nature and uses of immaturity. Am. Psychol. 1972, 27, 687-708.

33. Bolig, R. Play in the health care setting: A challenge for the 1990's. Children's Health Care 1990, 19, 229-233.

34. Klein, C. Preparing of young healthy children for possible hospitalisation. In The Issue; Paediatric Projects Inc.: Santa Monica, CA, USA, 1983; pp. 21-25.

35. Santen, L.; Feldman, T. Teddy bear clinics: A huge community project. Matern. Child Nurse J. 1994, 19, 102-106.

36. Robinson, E.H.; Rotter, J.C.; Fey, M.A.; Robinson, S.L. Children's Fears: Towards a preventative model. Sch. Couns. 1991, 38, 187-203. 
37. Mathiasen, L. Children's Attitudes to a Hospital Familiarisation Program. Master's Thesis, Edith Cowan University: Perth, WA, Australia, 2003.

38. Mathiasen, L.; Butterworth, D. The role of play in the hospitalisation of young children. Neonatal Paediatr. Child Health Nurs. 2001, 4, 23-26.

39. Sawyers, J.K.; Rogers, C.S. Helping Young Children Develop through Play; National Association for the Eduction of Young Children: Washington, DC, USA, 1988.

40. Malcolm, I.; Haig, Y.; Konigsberg, P.; Rochecouste, J.; Collard, G.; Hill, A.; Cahill, R. Two-way English: Towards more User-Friendly Education for Speakers of Aboriginal English; Education Department of Western Australia and Edith Cowan University: Mt Lawley WA, Australia, 1999.

41. Jensen, E. Teaching with the brain in mind. In ASCD; Assn for Supervision \& Curriculum: Alexandria, VA, USA, 1998.

42. Jensen, E. Enriching the Brain: How to Maximise Every Learner's Potential; Jossey-Bass: San Francisco, CA, USA, 2006.

43. Sousa, D.A. How the Brain Learns; Corwin Press: California, CA, USA, 2006.

44. Wright, P.R. Drama education and development of self: Myth or reality? Soc. Psychol. Educ. 2006, 9, 43-65.

45. Salmon, K. Commentary: Preparing young children for medical procedures: Taking account of memory. J. Pediatr. Psychol. 2006, 31, 859-861.

46. Mathiasen, L.; Taylor, A.; Butterworth, D.; Fare, J.; McKinnon, R.; Jones, W. Hospital Familiarisation Programme; The Association for the Welfare of Children in Hospital: Perth, WA, Australia, 1999.

47. Butterworth, D.; Mathiasen, L. Early intervention: A preventative approach to medical procedures with young children. In ECU-Industry Collaborative Grant; Edith Cowan University: Mt Lawley, WA, Australia, 2002.

48. Butterworth, D. Early Intervention: A preventative approach to medical procedures with young Aboriginal children living in a remote community. In ECU-Industry Collaboration Scheme; Edith Cowan University: Perth, WA, Australia, 2003. 


\section{Chapter 2:}

Coping with Illness and Getting Better through Play 



\section{The Healing Power of Play: Therapeutic Work with Chronically Neglected and Abused Children}

\section{Fraser Brown}

Abstract: This article concerns a therapeutic intervention with a group of abandoned children living in a Romanian pediatric hospital. The children, ranging in age from one to ten years old, had suffered chronic neglect and abuse. They had previously spent most of their lives tied in the same cot in the same hospital ward. They were poorly fed and their nappies were rarely changed. Although able to see and hear the other abused children, they experienced little in the way of social interaction. The article focuses on the play-based methods that were employed to aid the children's recovery, while at the same time highlighting the general benefits of this very specific therapeutic approach to children's recovery and development. In particular, there is an exploration of concepts such as symbolic representation, negative capability, joining, and the significance of play cues. However, despite the clear value of these individually focused techniques, the article proposes the tentative hypothesis that the most powerful healing factor was the unfettered playful interaction between the children themselves. In other words, the children in a very real sense may have healed each other while playing.

Reprinted from Children. Cite as: Brown, F. The Healing Power of Play: Therapeutic Work with Chronically Neglected and Abused Children. Children 2014, 1, 474-488.

\section{Introduction}

In the early 1990s, following the overthrow of the Romanian President, Nicolae Ceausescu, (see Deletant [1]) the Western media began to gain access to the former communist state of Romania. They discovered a country whose institutions were largely failing to cope, partly because of the collapse of its financial systems, but substantially because of the legacy of the Ceausescu era. This was one of the poorest countries in Europe, within which lived around two million Roma people - the poorest of the poor, making up around $10 \%$ of the population. Ceausescu's people had been subjected to a raft of bizarre dictums issued by the President. For example, in order to build up the country's industrial base, he had decided there was a need to increase the size of the population. Therefore, contraception was banned for families with fewer than five children, and women were medically "examined" by a special branch of the police to make sure they weren't having abortions [2]. As a result of these and other factors, more than a hundred thousand children were living in orphanages [3]. Many were HIV+, and within days of moving over to full-blown AIDS, they would die. For a short while, the Western media was full of images of dying babies, and the outpouring of charitable aid was enormous. However, interest gradually waned, and by the end of the century there was a widespread assumption that the issue had been addressed. It had not.

This article concerns the impact of a therapeutic playwork project on a group of sixteen abandoned children living in a ward of a Romanian pediatric hospital, ten years after the overthrow of Ceausescu. The project was the subject of a research study that focused on the children's 
development [4]. The article draws on extracts from a research diary kept by Sophie Webb during the early months of the project. A far more extensive version of that diary appears as a chapter in Play and Playwork: 101 Stories of Children Playing [5]. All the children's names have been changed in order to preserve their anonymity.

The children, ranging in age from one to ten years old, had suffered chronic neglect and abuse. They had spent most of their lives tied in a cot; they were poorly fed and their nappies were rarely changed. Although able to see and hear the other abused children, they were unable to leave their cots, and so experienced little in the way of social interaction. Some of the children were from the nearby Roma communities, and it emerged as the project proceeded that some of them had varying degrees of undiagnosed disabilities. The focus of our study was the children's play development, which we assessed using an instrument developed for an earlier study [6]. During a period when nothing changed in their lives, other than their introduction to the playwork project, the children themselves changed dramatically. Their social interaction became more complex; physical activity showed a distinct move from gross to fine motor skills; the children's understanding of the world around them was improved; and they began to play in highly creative ways. They no longer sat rocking, staring vacantly into space. Instead they became fully engaged active human beings. Our conclusion was simple, but striking: The children's developmental progress was clearly identifiable, and apparently made possible through their experience of the therapeutic playwork project.

The therapeutic playwork project began in the summer of 1999 and continues today, albeit in a much changed form. It started as a result of the concern of the newly appointed Director of the Hospitals, Cornel Puscas. Although he was neither a pediatrician nor a psychologist, when confronted with a ward full of disturbed children sitting rocking in their own solitary worlds, he was reminded of one of the most powerful conclusions from the studies of Suomi and Harlow [7]: "play is of utmost importance for the subsequent social well-being of the individual and those around him". In common with most Romanian institutions at that time the hospital had no spare money. Therefore, hoping to help the children recover, he set aside a room to be used as a "playroom" and approached the UK charity White Rose Initiative [8] for funding to employ someone to play with the children. WRI employed Edit Bus as the first Romanian playworker, and brought her to Leeds Metropolitan University [9] for a specially designed training course run by myself. Upon her return to Romania, Edit worked with the children for four months by herself, before being joined by Sophie Webb (a Leeds Met. playwork student) for an extended period, and later by me for briefer periods. Towards the end of the first year, WRI expanded the staff team to four Romanian playworkers.

In the early days of the project, Edit and Sophie had to untie the children in the morning, bathe them, change their nappies and feed them properly, before taking them to the playroom. The two playworkers worked with the children all day, bathing, changing and feeding them as and when necessary, and enabling them to begin the long road to recovery through play. At the end of each day, the children were returned to their hospital ward. As soon as the playworkers left the hospital, the nurses went into the ward and tied the children to their cots for the night. This daily pattern continued for at least the first year of the project. No amount of pleading or persuasion could change the nurses' behavior. I have often been asked for an explanation of this "inhumanity" on the 
part of the nurses. It is of course difficult to understand. Was it rooted in contempt for disabled children, or possibly discrimination towards Roma children? Both prejudices were widespread in Romanian society. Perhaps the nurses were busy and under-resourced, and found the children less troublesome when they were tied up. Possibly they did not see their role in terms of care, but rather more as wardens. Perhaps they were somehow influenced by the general lack of respect for the individual of the Ceausescu regime.

\section{Catastrophic Implications for Development}

The psychiatrist Stuart Brown [10] has shown that when children are deprived of play, the consequences can be catastrophic. The emotions of this group of children were in turmoil, although for much of the time it would be more accurate to describe their emotions as "on standby". Before the project started they just stared vacantly into space, rocking to and fro in that rolling motion so familiar to anyone who witnessed the television images emanating from Romania in the early 1990s. Apart from the overpowering smell of urine and excrement, the most striking thing about entering the ward was the silence, an experience also highlighted more recently by Nathan Fox, Director of the Child Development Laboratory at the University of Maryland, in connection with the Bucharest Early Intervention Project [11]. There was none of the usual noises heard in a typical pediatric ward in the UK, where we might expect to hear a combination of crying, laughing, yelling, etc.

The children generally looked several years younger than their actual age. For example, we worked with a ten year old boy (complete with nappy), who will call Nicolae. He could easily have passed for a three year old toddler in any UK nursery. When first taken out of his cot, he just walked around the room from one cot to the next, all the time holding on to the bars. If we stood him in the middle of the room, he would simply drop down, crawl across the floor and pull himself up with the bars of the cot; after which he would continue walking round the room gripping the bars of the cots. This lack of confidence was fairly typical, and was exacerbated by the fact that the children's gross motor skills were poorly developed compared to what Gallahue et al. [12] suggest would be considered the norm for their age. Those who tried to walk did so in a rather awkward toddler-like fashion, with the result that they often fell and hurt themselves. Their fine motor skills were virtually non-existent.

Although on the surface they appeared to be largely emotionless, the children also exhibited apparently irrational fears, which could pitch them without warning into frantic rocking. This unfortunately caused them to harm themselves, because the violent rocking motion meant their heads contacted the bars of the cot, or sometimes the wall outside the cot. There were also examples of self harm, as defined by the psychotherapist and social work author Steven Walker [13]. For example, one little girl who was punished by a nurse for crying when she had been given an injection, spent the following hour sitting in the cot, banging her head against the wall and scratching at herself. By the time the playworkers arrived the next morning she had damaged her arms badly enough to have drawn blood.

There was minimal meaningful social interaction. Despite living most of their lives in a hospital ward with fifteen other children, they had not formed any relationships with each other. Presumably the fact that their movement was so restricted meant they hardly had the chance to 
interact. Another socially limiting factor was the absence of any verbal exchanges between the nurses and the children. Thus, the children had no opportunity to form an attachment to a sensitive, consistent and emotionally warm carer. According to Bowlby [14] that would be problematic in terms of future relationship building.

The children exhibited little sense of individuality, a fact that was not helped by their hospital records which for example sometimes gave them the wrong name, and also gave many of them the same birthday. We eventually worked out that no-one had kept any records of these children until they were admitted to this particular ward. Their common "birthdays' merely reflected the fact that they had been moved to this ward on the same day. In most cases we managed to find out their real names by virtue of the fact that this was a small town where everyone knew everyone else's business. For example, a passing policeman was able to identify one of the children, because he knew the child had been born in prison.

The classic quote from the developmental psychologist Brian Sutton-Smith [15] sums up the powerful nature of the play experience, and at the same time touches on the awful consequences of a lack of play:

"The opposite of play-If redefined in terms which stress its reinforcing optimism and excitement-Is not work, it is depression. Players come out of their ludic paradoxes... with renewed belief in the worthwhileness of merely living."

The static nature of the children's world meant they had no sense of fun and playfulness, and they initially showed few signs of cognitive functioning. In a remarkably short period of time, all that would change.

\section{Early Developments}

In the early days of the project it was hard to assess which children had been borne with a disability, and which were merely suffering from years of neglect and abuse. However, those distinctions quickly became apparent as the children began to develop. A child who we will call Virgil (a six year old in nappies, looking about two years old) went from silently rocking in his cot to meaningful social engagement, in the form of playful conversation, in the space of six months. He made dozens of new discoveries every day, and excitedly shared them with his new friends. For example, when he worked out how to switch on a torch he toured the playroom tapping his playmates on the shoulder and pointing at the wall where he was shining the beam of light. That single example contains elements of considerable social, physical and cognitive progress in just six months.

On the other hand Olivia, who had been born two months premature and weighing less than two pounds, clearly had serious learning difficulties. She spent much of her time inspecting the toys in great detail, but the next day she would be inspecting the same toys. When Virgil showed her his torch discovery she reacted with enthusiasm, but largely as a result of the social contact, rather than out of any real understanding of what he was showing her. Nevertheless, during the first year she began to walk independently, and was able to join in with a range of simple activities. Perhaps 
most encouraging was the fact she appeared to understand the complex idea that games have rules which apply to everyone.

Although every child made progress, some forged ahead at such a rapid rate that it has forced me to question my previous assumptions about attachment theory, the long term impact of abuse, and the "stages" view of child development suggested by developmental psychologists, such as Erikson [16] and Piaget [17], especially in light of the chaotic way in which development occurred. In fact, the change in the children was so remarkable that a colleague commented to me, "it is almost as if their intellect has been sitting there, waiting to be switched on". Within the first eighteen months, thirteen of the original sixteen children were either adopted or fostered within Romania-Something that would have been extremely unlikely at the beginning of the project, but something that their changed demeanor and behavior almost certainly made possible.

Nevertheless, there were still signs of residual fear, and emotional insecurity, sometimes resulting in the sort of extreme regressive response originally conceptualized by Anna Freud [18] For example, on one occasion the children were playing happily in their "salon", when the hospital's accountant appeared to tell one of the playworkers there had been a problem with her wages this week, and she would not get paid until Monday (instead of Friday as normal). A slightly tense discussion ensued between the playworker and the accountant, albeit at no time did it get heated or aggressive. I looked around the salon and every single child had climbed back into their cot and was sitting rocking! This led me to begin to formulate one of the conclusions summarized later in this article, i.e., that it may not be possible to recover the emotional equilibrium of such children. However, in most other areas of development, the children made remarkable progress.

\section{Some Significant Indicators of Recovery}

There was substantial development in the social skills of all of the children. Within four weeks they all learned how to initiate contact, and generally responded appropriately to contact initiated by another child. This rapid change is illustrated by the following extracts from Sophie Webb's research diary [19]. For example, in the first week we find a complete absence of social skills:

"When I observed the children in the playroom, they were unaware of each other, fixed on their own activities - barely communicating. Some just sat and seemed bewildered and vacant" [20].

However, by Day 22 she recorded the following:

"The way the children sit around the table has proved to be more than just eating together. Olympia started to feed Nicolae today, so they are really interacting with each other so much more. They seem to be enjoying the social event" [20].

All the children's communication skills developed, some more rapidly than others. For example, just sixteen days after Sophie's arrival she recorded two of the children having an imaginary "phone conversation". Another child, whose development was less speedy, was nevertheless sparked into a communication exchange when the playworker repeated a noise that the child made when showing signs of being happy: 
“Today I started to repeat the noises that Elena makes 'waaaaoooo waaaaoooo' and her reaction was amazing! The look on her face was just like someone had spoken her language. It felt like a little break through as you can rarely communicate with her. I started to repeat this noise back to her and she responded by instigating the sequence when she saw me, exploring my face and trying to decide where the noise was coming from. By making myself the play environment Elena was comfortable to allow herself the freedom to communicate and investigate" [20].

Their language skills took longer to develop. At first the children had no language-Except that a couple of them could say "Hiya", which presumably they had learned from the various religious groups who visited the hospital from time to time (but never for more than a couple of hours of largely pointless cuddling). However, once the project had been running for a few months, some of the children began to use words to explain themselves and to express their feelings, for example:

"Virgil especially loved the Lego bricks and we helped him build a house, which is 'casa'. He walked around the room saying 'casa-Casa' in his little voice and he was so proud of it" [20].

Once the project had been running for about 9 months, the children's language skills had developed to such an extent that the UK playworkers were sometimes out of their depth compared to their Romanian colleagues. For example, Edit would be able to stop a child doing something dangerous, with a single word.

Sturrock and Else [20] introduced the idea that the appropriate interpretation of play cues is a key ability in any playworker's skill-set. Indeed it has been suggested that the level of sophistication of a child's play cues can be taken as one indicator of their developmental level [6]. All the children developed cueing behavior, even Nicolae. Despite his clear learning difficulties, I nevertheless recorded him playing a game with one of the playworkers where he was copying her arm and leg movements, and exclaiming as he did so. Between them, they developed a kind of sitting down dance routine. Later in the day he sat down with another playworker and tried to initiate the same game by cueing with his own arms and legs. When she didn't respond, he became quite frustrated, but persevered, and eventually got her to understand and follow his lead, so that they could dance together.

The muscular-skeletal development of the children is perhaps the most remarkable and unexpected of all the indicators of progress. When the project started all the children appeared to have considerably stunted growth, and although they began to get exponentially stronger and more active, we expected that their actual height would be forever damaged by the nature of their early lives. However, that proved to be untrue. Perhaps the most extreme example would be that of Nicolae, whom we have already said was a ten year old child with the build of a three year old. In 2009 I visited a special center in Sighisoara for youngsters with learning difficulties, where I was amazed to find Nicolae, who was now taller than me, and considerably stronger. Clearly, it is not possible to link this specifically to the act of playing, but it certainly raises the possibility that we are genetically programmed at birth with an optimal height. 


\section{Therapeutic Method}

Our basic therapeutic method was to offer the children an environment that was as close as possible to a standard playwork environment, but to apply specific therapeutic techniques to individual children, as and when the need arose. Else [21] has suggested that playwork is characterized by the "three frees": Freedom from payment; freedom of movement; and freedom of choice. Obviously in this unusual setting there was no question of a financial charge. Nor were there any restrictions on the children's choice of activity (other than the limitations imposed by the nature of the playroom and its contents). However, the children were plainly not free to come and go as they pleased. To allow them to do so, would have endangered their safety, so we had to accept that restriction and work within it, albeit I have argued elsewhere [6] that no play environment is ever completely free from externally imposed parameters. In this case, the parameters were particularly unusual and challenging. Nevertheless, at a fundamental level, the key features of our approach were not very different from those applied in most playwork settings. These features are summarized here in no particular order:

\subsection{Removing Barriers to the Play Process}

The playworkers had to untie the children every day, release them from their cots, bathe them, feed them properly, etc. Clearly, the children would not have been able to benefit fully from their play if their movement was restricted, or they felt dirty or hungry or in a state of emotional distress. The very first entry in Sophie Webb's diary illustrates this point:

"Every room was full of children in cots, but it was so quiet. Even when we entered the room there was no sound from the children. They just looked at us. The smell of urine in every room was almost unbearable. The emptiness. Each room had just the cots with plastic mattresses. The children were dirty and wearing clothes that were too big for them. Some were wearing jumpers as trousers, and none of them were wearing shoes. There were rags around their waists, which I later found out were ripped up sheets tied, to keep the nappies in place. These rags were also used to tie the children to the cots. Most children were sitting rocking and others were standing up banging the sides of their cots against the walls. Giving the children a cuddle was strange as they either held on too tightly, or they remained stiff and unfeeling. " [20]

\subsection{Enriching the Play Environment}

In essence enriching the play environment was about ensuring that the playroom had the potential to enable the children to be playful-In other words a place where children are able to engage in non-serious activities for enjoyment, satisfaction and fun [22]. An enriched play environment holds greater potential for child development, but for the playworker this is not about imposing an adult agenda on the play space-Rather the playworker adopts an holistic approach to development; one that respects the idea that children develop while they are playing. There are various ways of enriching the play environment-For example, by providing a large variety of 
artifacts and activities, but leaving the choice of what to do at any particular moment in the hands of the child.

\subsection{The Portchmouth Principle and Nicholson's Theory of Loose Parts}

Nicholson's theory of loose parts [23] holds that "in any environment both the degree of inventiveness and creativity, and the possibility of discovery, are directly proportional to the number and kind of variables in it". Underpinning this idea is the Portchmouth Principle [24] which states, "It helps if someone, no matter how lightly, puts in our way the means of making use of what we find". Taken together these two ideas imply that the playworker's role is to provide the basic tools and materials to enable the children to play. There is no need to tell them what to do. The play environment contains its own inherent stimulation in such circumstances. For example:

"Whilst Alex was sitting in a big yellow box Virgil started to play a game with him, involving an imaginary object. He pretended to receive something from Edit and then took it back to Alex in the box, who took it from him and put it in his lap. The spontaneous interaction between them both was fascinating to watch. Afterwards Virgil continued playing with the yellow plastic box, by putting it on his head and walking around the room, which made me laugh and laugh. He created a sort of obstacle course out of the cots and tables" [20].

\subsection{A Non-Interventionist Approach}

For most children the only time when they are in control of their world is when they are playing. Therefore, if playworkers are to avoid "adulterating" that experience, they have to ensure that wherever possible they are following the child's agenda [21]. This is especially important in a therapeutic setting, where according to Axline [25], children will find a solution to their problems in their play, so long as they are given sufficient time and space. In the case of the therapeutic playwork project in Romania, where the children required a stronger presence over a more extended period, it nevertheless remained the case that most of our interventions were a response to the specific play behaviors of each child.

\subsection{Negative Capability}

According to Fisher [26] it is sometimes by appearing to do nothing that the playworker achieves most. When we rush to intervene we limit our capability and the children's creativity, but she says:

"By actively 'being with' a situation, without trying to change it, influence it, explain it or understand it, we keep all options open-Anything is possible and nothing is closed off. ... the play itself will do what it needs to do, but we need to watch the play carefully with this attitude of negative capability so that we really 'know' what is happening. We will then know intuitively, when or if an intervention is needed." 
Thus, a playworker needs to be open-minded, non-judgemental, and non-prejudiced, and by so doing $\mathrm{s} /$ he provides an environment that encourages imagination, creativity, exploration and experimentation - and hence development.

One day, during the hot summer months we took the children outside for a picnic. Everyone was given a cup of cold water. A little boy, who clearly exhibited learning difficulties, fell over on the rough ground and spilt his drink. He then approached the playworkers to ask for more water. They topped up his cup, whereupon he hurled the contents all over the playworkers.

It is likely that most adults in other professions would have chastised him, or at least given him some moral instruction about not being a naughty boy. However, the playworkers just became really excited, because they recognized real developmental progress in this one act. He had obviously learned from his accident that the water could be tossed from the cup. He had also worked out that he could play a trick on his playworkers. This was quite sophisticated reasoning and remarkably perceptive for a child who had been born with brain damage, and spent most of the subsequent ten years tied in a cot. His sense of achievement was clear, but might have been missed if the playworkers had been adopting a more typically adult (instructional) frame of mind. Indeed, if the playworkers had either chastised him or offered him guidance regarding "good" behavior, they would probably have dampened his enthusiasm to try things out.

\subsection{Using Personal Life Skills}

Sympathy, empathy, mimesis, affective attunement and the sensitive interpretation of play cues, are skills and abilities that are essential for a well-adjusted social being. Children develop these skills while they are playing. They are not skills that can be taught in a classroom. They are all skills that are essential to playworkers if they are not to misread the sort of situations that confront them every day [6]. This was abundantly clear while working in the hospital.

For example, on one occasion a playworker was engaged in a game of chase with one of the children. Although the child was chasing the playworker, he wanted the playworker to chase him. As they were running round the cots he began to issue little cues. First he banged a table with his hand, but the playworker missed the play cue she had just been given. Next, he knocked over a mattress, and clasped his hands to his face in mock horror. This was a more obvious cue, and yet it was also missed. At each missed cue the child was obliged to keep chasing the playworker, even though he didn't want to do so - otherwise the game would have stopped. Finally, he ran past the playworker's coat, which was hanging from a door handle. He put his hand into the coat pocket, pretending to steal something. At last the playworker got the message, and started to chase the child who yelled excitedly, quickly allowing himself to be caught. The pair ended up rolling around on the floor with the child giggling triumphantly.

The fact that the child quickly allowed himself to be caught, once the playworker started chasing him, provides a strong indication of his intended aim, and his new-found ability to reason things out. If the playworker had not been adopting a playful approach, she might have felt obliged to reprimand him for touching her coat, or for trying to steal something from the pocket. However, that would be reflective of an adult agenda, and would be interpreted as such by the child. Of course this is just one example, and it would be wrong to suggest a failure to respond to the child's play cues 
is damaging on every occasion. However, repeatedly failing to understand and respond to the child's real motives would be likely to have negative consequences in terms of that child's development. At best they would become disheartened; at worst it is suggested by Sturrock and Else [21] that children are likely to develop neuroses.

\subsection{Joining the Child's Agenda}

When we first worked with Nicolae he was obsessed with shoes. He spent most of the day trying to take people's shoes off, or putting his shoes onto other people (not just the other children, but anyone who came into the room). He built up collections of shoes, and sometimes had shoes on his hands as well as his feet. In fact, his behavior had similarities to the stereotypic repetitive behavior commonly seen in children with autistic spectrum disorders [27]. However, in line with the approach of the Autism Treatment Center of America [28], we did not try to force him to move away from his obsessive behavior, but instead attempted to use that behavior as a means of initiating contact and building trust. The ATCA calls this approach "joining". In playwork terminology, we were taking the child's agenda as our starting point, and working with it [6].

What did this mean in practice? Sophie played "shoes" with Nicolae over and over again, until he began to interact with her. Very gradually a trusting relationship built up, which Sophie was then able to use to the benefit of Nicolae. As has already been mentioned he was reluctant to walk unaided. Several people had tried persuading him to let go of the bars of the cots and walk independently. However, once Sophie had formed a strong bond with him, she hoped the attraction of a hug from his playworker would over-ride his fear of falling. In the event she was correct. She was able to stand him in the middle of the room and he chose to walk towards her, instead of dropping to the floor and crawling across to the cots. These were the first independent steps of a child who had hitherto been tied to his cot and dismissed as "debil mintal" (mentally deficient), or even worse, "un imbecil".

\subsection{Creating Relationships and Building the Child's Self-Esteem}

One of the most significant elements of the preceding vignette is the way in which the relationship was developed with the child, and the importance of that in helping his development. As we have already seen the playwork approach has unique elements; most especially there is no attempt to take control of the child's agenda. That is unusual for a child to experience, and often leads to the formation of a trusting bond with the playworker. Examples of this process may be seen in several of the vignettes already provided. The non-interventionist, non-judgmental and noncontrolling approach carries with it a powerful message of respect for the child's social, physical and emotional space [6]. Not only does this help the formation of a strong relationship, but it also helps to build the child's self-esteem.

\subsection{Cultural Competence}

Regardless of the setting in which they are working, playworkers need to develop their own cultural awareness-Macro and micro. In other words they need to understand both the culture of 
the local community and also the children's own sub-culture(s). Both will be characterized by their own unique "webs of significance", i.e., a complex intertwined mesh of social, political, economic, philosophical, spiritual and emotional principles that underpins everything that happens within any particular community. In this case, it was necessary for the playworkers to develop an understanding of several communities, i.e., the country, the town, the hospital, the nurses, and as time went on the children's own little community. All these things serve to create the "webs of significance" referred to by Geertz [29], and with which playworkers must aim to feel comfortable.

\section{Longer Term Evidence of Progress}

In an earlier article we reported on our research findings, analyzing the developmental changes identified in the children [30]. These were based on a "play value assessment guide" that focused on eleven distinct categories: Freedom; flexibility; social interaction and socialization; physical activity; intellectual stimulation; creativity and problem solving; emotional equilibrium; self-discovery; ethical stance; child-adult relationships; and general appeal, fun and enjoyment. In every category, for every child, the results showed some development, albeit there were substantial variations from one child to another. However, the findings showed that all the children underwent significant developmental change in the areas of social interaction and socialization, physical activity and general enjoyment of play. Before the input of the Therapeutic Playwork Project each child was isolated, physically weak, lacking in social skills, and generally showing signs of emotional distress. During the first year of the project the children developed a group identity; their gross and fine motor skills moved ahead at a rapid rate; they developed ways of communicating that enabled them to form friendships within the group; and they showed all the "normal" signs of happiness (smiling, laughter, readiness to take risks, the use of make-believe, etc.).

\section{Six Years on}

We have shown our video footage of the children's progress during the first eighteen months of the project in all sorts of settings, and to a wide variety of audiences. The impact of these images remains as strong today as when the original filming took place. In many ways the material is timeless. Maltreatment of children occurs all over the world, albeit not usually in such an institutionalized way. However, the power of the images lies not only in the shocking consequences of neglect, but also in the idea that recovery is possible, even in the most adverse conditions imaginable. Not unreasonably a question we have often been asked is "where are they now, and have they continued to make progress?" Six years after our initial research [31] was presented I attempted to trace the subsequent lives of the original sixteen children.

Three of them were easy to locate, because they were still in the system having been transferred to a children's mental hospital, where the conditions appeared to be extremely restrictive. We were given a permit to visit these children, but were not allowed past the gate-keeper's hut. A nurse brought two of them to the hut to see us, and although there was some evidence of recognition, the children appeared to be in a dream, presumably because they had been given some form of calming 
"medicine". When asked whether the children were given time to play out in the grounds of the hospital, the nurse just said "No!".

The other thirteen children had either been fostered or adopted (all within Romania), which made them far harder to trace. In fact, it was only possible to locate seven of them.

One child, who we shall call Elena, had regressed substantially. I had previously visited Elena soon after she moved into her foster home, and she had formed a strong relationship with her new "grandma". She seemed to be progressing well, and even sang me a nursery rhyme. Soon after that visit Elena was taken into hospital for some tests. While she was away her "grandma" died. Six years on, I found a child who had not spoken a word since coming out of hospital. It is not possible to identify the cause of this. Perhaps she had a bad experience in hospital; perhaps the trauma of losing her "grandma" was simply the last straw in a life of abuse. We shall probably never know.

Although it was not possible to conduct any formal testing, the other six children appeared to be progressing well. For example, one of them had been attending a German speaking nursery, and entertained himself by trying to teach me to count. He even showed himself to be a good mimic when he started to copy my poor attempt at speaking German. Another child was keen to talk about his toys. His foster parents insisted that he also demonstrate his reading skills and some basic arithmetic. I was introduced to several of the children at a special center that aims to help them catch up with their school friends. While talking to one of the workers, I felt a child tugging at my trousers, and a little voice said, "te cunosc" (I know you). Six years previously this was a child who Sophie had discovered tied to his cot, playing with his own feces-presumably for want of something to play with.

We cannot really know whether these seven children are representative of all thirteen adoptees. If they are, then the project appears to have been successful in the longer term on several counts:

- The children are all living in a supportive environment with caring families and a stable home life

- The children who were not born with some form of brain damage appear to have continued the progress made during their experience of the project

- Those children are generally behind in their schooling, but appear to be capable of catching up if given appropriate support

- Of the children who were born with some form of brain damage, all but one has continued to make progress, albeit the level of that progress varies considerably from one child to another

- Apart from Elena and the children who were in the mental hospital, all the children appear to have developed the skills necessary to make friends

- All the children have developed gross and fine motor skills, and appear to be physically healthy, even to the extent of having grown to full adult height

- All the children have developed a strong individual identity

- It was not possible to judge the emotional stability of the children, and in light of our experience during the project I do not feel confident about making any claims in that regard 


\section{Conclusions}

Thankfully the hospital's approach to the children changed dramatically after about eighteen months. Today all children are treated the same, no matter what their reason for being in hospital. They are bathed regularly, properly fed, and their developmental needs are addressed. Staff turnover saw some of the worst offenders move on, but I am convinced the major causal factor was the example provided by the WRI playworkers who were encouraged to treat the children with love and respect at all times.

In less than a year, these chronically abused and neglected children made the sort of progress that many experts assumed would be impossible. During the whole period of the research study when the children were not in the playroom with the playworkers, they were tied back into their cots by the nurses. They were not fed properly; they were not bathed; their nappies were not changed; and no-one gave them any meaningful attention at all. In other words, nothing changed in their lives during that first year except their experience of the playwork project. Therefore, it is sensible to ask what it is about playwork that contributed to the striking changes in the children.

Clearly the children's learning and development resulted substantially from the playworkers' ability to create an enriched play environment that was substantially supportive of the play process. The playworkers' non-judgmental approach, coupled with a determination to take each child's agenda as his/her own starting point, helped to create a good quality playwork environment - in other words, an environment that offered adaptability to the children, and so encouraged the compound flexibility process [31]. Through their empathy, and their ability to interpret the children's play cues effectively, the playworkers were able to create strong trusting relationships, which in turn helps to enhance the children's self-esteem [32].

If such approaches were applied in a typical playwork setting in the UK, we would take it for granted that children would learn and develop naturally. The remarkable thing about our experience in Romania was that this straightforward playwork approach appeared to work just as effectively with some of the most play-deprived children in the world. Given that the playworkers' approach was generally non-interventionist, it is tempting to draw the conclusion that the major healing factor in all this was the children themselves. To substantiate such a claim would require more in the way of comparisons of different types of intervention, including play, to be able to isolate peer-to-peer play as the key causative factor. After all it is also possible that the sensitive interactive input from the playworkers might also have been a trigger and supportive factor in initiating a trajectory towards degrees of recovery. However, to conduct such a comparative experiment would be completely unethical. Therefore, all we can do is draw tentative conclusions, and propose cautious hypotheses. It is clear that the playworkers had an influence, but largely by virtue of the environment they created. It is, therefore, my hypothesis that the remarkable development we witnessed in such a short period of time was substantially stimulated by the children's interaction with each other. 


\section{Acknowledgments}

The author wishes to thank the following:

- Open University Press for permission to reproduce short extracts that first appeared in Brown, F. Play and Playwork: 101 Stories of Children Playing. Maidenhead: OUP. 2014

- Sophie Webb for permission to reproduce extracts from her initial research diary.

- White Rose Initiative, firstly for their permission to conduct the research project referred to in several chapters, and secondly for their permission to report on its remarkable achievements.

- Dr. Cornel Puscas, who at the time of the research was Director of the Sighisoara Paediatric Hospital, for permission to refer to the hospital records, and for allowing us to report honestly on the lives of the children in his hospital. Without his support the Therapeutic Playwork Project would not have existed. I would also like to place on record the fact that the events recorded here took place between 1999 and 2001, and that the hospital completely changed its practice from 2001 onwards.

\section{Conflicts of Interest}

The author declares no conflict of interest.

\section{References and Notes}

1. Deletant, D. Ceausescu and the Securitate: Coercion and Dissent in Romania, 1965-1989; Hurst \& Co. (Publishers) Ltd.: London, UK, 1995.

2. Gloviczki, P. Ceausescu's children: The process of democratization and the plight of Romania's orphans. Crit.: A Worldw. Stud. J. Polit. 2004, 3, 116-125.

3. Nelson, C.; Fox, N.; Zeanah, C. Romania's Abandoned Children: Deprivation, Brain Development and the Struggle for Recovery; Harvard University Press: Cambridge, MA, USA, 2014.

4. Brown, F.; Webb, S. Children without play. J. Educ. 2005, 35, 139-158.

5. Brown, F. Play and Playwork: 101 Stories of Children Playing; Open University Press: Maidenhead, UK, 2014.

6. Brown, F. An Evaluation of the Concept of Play Value and its Application to Children's Fixed Equipment Playgrounds. Unpublished PhD thesis, Leeds Metropolitan University, Leeds, UK, 2003.

7. Suomi, S.; Harlow, H. (1971) Monkeys without play. In Play: Its Role in Development and Evolution; Bruner, J., Jolly, A., Sylva, K., Eds.; Basic Books: New York, NY, USA, 1976; p. 493.

8. For further details, contact White Rose Initiative, 96 Huddersfield Road, Shelley, Huddersfield HD8 8HF, UK.

9. Subsequently renamed as Leeds Beckett University.

10. Brown, S. Play, How It Shapes the Brain, Opens the Imagination and Invigorates the Soul; Penguin: London, UK, 2009.

11. Weir, K. The lasting impact of neglect. Monit. Psychol. 2014, 45, 36-41. 
12. Gallahue, D.; Ozmun, J.; Goodway, J. Understanding Motor Development: Infants, Children Adolescents, Adults, 7th ed.; McGraw-Hill: New York, NY, USA, 2011.

13. Walker, S. Responding to Self-Harm in Children and Adolescents: A Professional's Guide to Identification, Intervention and Support; Jessica Kingsley: London, UK, 2012.

14. Bowlby, J. Attachment and Loss: Volume 1. Attachment; Basic Books: New York, NY, USA, 1969.

15. Sutton-Smith, B. Evolving a consilience of play definitions: Playfully. In Play and Culture Studies, Volume 2: Play Contexts Revisited; Reifel, S., Ed.; Ablex Publishing Corporation: Stamford, CT, USA, 1999; p. 254.

16. Erikson, E. Childhood and Society; W.W. Norton: New York, NY, USA, 1950.

17. Piaget, J. Play, Dreams and Imitation in Childhood; Routledge and Kegan Paul: London, UK, 1951.

18. Freud, A. The Ego and the Mechanisms of Defence (International Psychoanalysis Library); Hogarth Press Ltd.: London, UK, revised edition: 1968

19. Webb, S. Therapeutic playwork project: Extracts from a reflective diary. In Play and Playwork: 101 Stories of Children Playing; Brown, F., Ed.; Open University Press: Maidenhead, UK, 2014.

20. Sturrock, G.; Else, P. The playground as therapeutic space: Playwork as healing. In Proceedings of the IPA/USA Triennial National Conference, Play in a Changing Society: Research, Design, Application, Longmont, CO, USA, 17-21 June 1998.

21. Else, P. The Value of Play; Continuum: London, UK, 2009.

22. Starbuck, W.; Webster, J. When is play productive? Account. Manag. Infor. Technol. 1991, $1,1-20$.

23. Nicholson, S. The theory of loose parts: How not to cheat children. Landsc. Archit. Q. 1971, 62, 30-34.

24. Portchmouth, J. Creative Crafts for Today; Studio Vista: London, UK, 1969; p. 7.

25. Axline, V. Play Therapy, revised edition. Ballantine Books: New York, NY, USA, 1969.

26. Fisher, K. Playwork in the early years: Working in a parallel profession. In Foundations of Playwork; Brown, F., Taylor, C., Eds.; Open University Press: Maidenhead, UK, 2008; p. 178.

27. Baron-Cohen, S. Autism and Asperger Syndrome (The Facts); Oxford University Press: Oxford, UK, 2011.

28. Kaufman, R. Autism Breakthrough: The Ground-Breaking Method That Has Helped Families All Over the World; Vermilion: London, UK, 2014.

29. Geertz, C. The Interpretation of Cultures; Fontana Press: London, UK, 1993; p. 5.

30. Webb, S.; Brown, F. Playwork in adversity: Working with abandoned children. In Playwork Theory and Practice; Brown, F., Ed.; Open University Press: Buckingham, UK, 2003.

31. Brown, F. Compound flexibility: The role of playwork in child development. In Playwork-Theory and Practice; Brown, F., Ed.; Open University Press: Buckingham, UK, 2003.

32. Brown, F.; Webb, S. Children without play. In Complex Trauma and Its Effects: Perspectives on creating an Environment for Recovery; Johnson, R., Maguire, N., Eds.; Pavilion Publishing Ltd.: Brighton, UK, 2012. 


\section{Hospital Clowning as Play Stimulus in Healthcare}

\section{Laura Anes and Marianne Obi}

Abstract: A serious illness, a chronic medical condition or a hospital bed should not deny any child her/his basic right to play, a right essential for children's development and general wellbeing. In fact, it is in these frightening and anxious moments that play and the stimulus that it provides can help the most. This article will focus on the impacts and benefits of professional hospital clowning for the wellbeing and recovery process of ill and hospitalized children. Our experience has shown that through interactive play and humor, "clowndoctors" can create an enabling and supportive environment that facilitates children's adaptation to the hospital setting and improves their acceptance of medical procedures and staff. While moving from bedside to bedside, RED NOSES clowndoctors encourage children's active participation and support their natural instinct to play, fully including them in the interaction, if the children wish to do so. Therefore, clowndoctor performances offer ill children much needed stimulus, self-confidence and courage, elements fundamental to reducing their vulnerability. In this piece, a special emphasis will be put on the various approaches used by RED NOSES clowndoctors to bond and reach out to children suffering from different medical conditions.

Reprinted from Children. Cite as: Anes, L.; Obi, M. Hospital Clowning as Play Stimulus in Healthcare. Children 2014, 1, 374-389.

\section{Introduction}

The use of humor and performing arts as a complementary therapy in the healing process has become widely accepted, and its benefits are increasingly recognized by health professionals and relevant stakeholders [1]. This growing recognition is directly related to the improvements that have been registered in the quality of care offered to patients in the wards where professional hospital clown programs are being implemented. In a feedback session with the Director of the Psychiatric Department, Beit Jala Governmental Hospital, Dr. Salam Al Kamah stated, "We are very grateful that RED NOSES is in Palestine. Their work is tremendously important, especially in the treatment of children with cancer. They accompany them in their suffering; they are a great support and give them love and affection."

While RED NOSES programs have gradually developed to encompass new and diverse target groups, such as the elderly and rehabilitation patients, the main focus of this article will be on chronically and acutely ill children. This piece will explore some of the various approaches used by RED NOSES clowndoctors to reach out to and connect with hospitalized and ill children. It will further shed light on the way these approaches impact and contribute to the recovery process and psychosocial wellbeing of the "little patients".

To meet the needs and characteristics of every specific "audience", clowndoctor performances make use of culturally-appropriated and specially-designed holistic methods that are essential to connect with the children. During the visits, the perception of the children is profusely stimulated, 
and their five senses become the central themes. Their natural instinct to play is brought back to life. This impacts the child's emotional and cognitive development as the clowndoctors provide the space for children to identify and express their emotions, as well as to test and try out their physical capacities in light of certain limitations imposed by their ailment. This is, for example, what is at stake in the Circus Patientus program, where children are provided a stage to express themselves with the assistance of the clowns, as described in Section 2.3.2.

As play is very much about stimulus, during the interaction with the clown, the little patients are encouraged to learn and develop new skills. From the experience of our clowns, detailed in clown reports and regular feedback, as well as supervision sessions, many of the hospitalized children with whom they have contact are, for the very first time, actually exposed to the world of performing arts. In many cases, children take interest in this artistic field and are inspired to learn the tricks performed by the clowns. In the period until the next clown visit, they practice the antics, imagine stories and scenarios that prepare them for the next clown visit. This gives the children in the hospital something to look forward to and allows them to exercise their play predispositions, thus distracting them from the situation of hospitalization that they are in. As described by the Director of Wroclaw Hospital in Poland, Dr. Janusz Jerzak, "Children look forward to every meeting, and for a moment, they forget their illness. The clown visits bring a great deal of positive energy, a great deal of joy and impressions, irrespective of the ages of the children."

This stimulus offered by the performances gives children in the hospital much needed self-confidence and courage, elements fundamental to reducing their vulnerability. The stimulus and playfulness brought into the hospital room further contributes to easing the fear and stress caused by illness, long hospital stays and/or painful treatments. This is possible because during the interaction with their patients, RED NOSES clowndoctors create an enabling and supportive environment that encourages and promotes the children's active participation.

\section{Results and Discussion}

Children are one of the most vulnerable groups and are especially sensitive in the hospital environment. Thus, in this distressing period, special emphasis needs to be placed on the emotional and psychosocial support given to the little patients and their relatives and on the need to create enabling environments that allow for children to be children, even in the face of serious or life-threatening illness.

Even if hospital clowning cannot alter the reality that the children have to face, it can lighten their experience and facilitate their adaptation to the hospital environment. Equipped with an abundance of humor, RED NOSES clowndoctors take on the challenging task of conquering fear and emotional stress, which can be detrimental to the healing process. By turning the performance into a restorative experience and not merely a recreational moment, clowndoctor performances seek to attenuate the tension and vulnerability to which children are exposed, giving them vital psychosocial support by applying a great stress reliever and a powerful pain medicine-laughter!

Therefore, we will start by presenting the main concept behind RED NOSES regular children's programs. This was the first format to be implemented within the group and remains a main pillar of our work. The establishment of RED NOSES Clowndoctors by Monica Culen, Executive 
Director, and Giora Seeliger, Artistic Director, in 1994, brought about the first children's programs to be implemented in Austria. They were developed to address the individual needs of children in the hospital with a two-fold aim: to improve the wellbeing and medical condition of ill children and to assure that all children, regardless of their ailment and/or background, are guaranteed their right to play and to take part in cultural life, as enshrined by Article 31 of the United Nations Convention on the Rights of the Child [2].

The success and positive resonance of this regular program resulted in several spill-overs that shaped new formats addressing hospitalized children's specific needs. That is how programs, such as Circus Patientus, NOS! (Na Operační Sál! ("To the Operation Theatre”)) and others that are the focus in this article, were born. The start of many of these new programs was possible due to the solid collaboration between our clowndoctors and the medical staff in all 187 children's hospitals in the 11 countries where we currently work. After hospital visits and feedback sessions, they together identify the needs and opportunities for the use of hospital clowning, which benefit ill children. Ongoing comments from medical staff in a major hospital in New Zealand reported that clown visits are not only great for staff morale, but they also made a huge difference to the treatment of the patients.

Based on the different format designs, the article will outline how the various approaches influence children's recovery processes and how they open opportunities to play and stimulus in an environment that often does not favor the children's basic instinct to play. Our clowndoctors' task is to create an enabling, participatory and creative environment that reduces children's stress levels and challenges them to find tools to cope with their medical condition through interactive play.

The authors of this article stress that the results shown are based on both empirical experience and the ongoing feedback from medical staff, patients and their relatives. They are not the result of any form of scientific research.

\subsection{Training and Methodology}

Working in a very sensitive environment, RED NOSES develops and maintains high ethical and artistic quality standards in all its clown programs. The artist's work is preceded by rigorous training within the organization, mainly in its training platform - the International School of Humor-located in Vienna, but also through local workshops and exchange programs between partner organizations.

To become a RED NOSES clowndoctor, the candidate has to fulfil the ensuing entry requirements: a minimum age of 23 years; be a professional artist with a background preferably in the performing arts; and a clean police record. After 3-4 auditions, they enter a six-month trial training period, after which, the clown moves into the next training stage for one year.

The ongoing training in three main fields, namely artistic, medical and psychosocial studies for clowns, is given both at the beginner and advanced level. Roughly 16 workshops held per school year focus on different aspects of hospital clowning and are taught by internationally-renowned teachers. Some workshops include practical training in the hospital setting.

After talks and mutual agreements have been reached with the hospital management, the hospital writes an invitation, and a Memorandum of Understanding is signed. Thereafter, active 
cooperation is started with the hospital. Regular internal feedback sessions allow the hospital and the clowns to exchange information and evaluate the progress of the visits, plus the impact on the hospitalized children.

\subsection{Regular Visits to Pediatric Wards}

As a best practice, regular clowndoctor visits ("clown rounds") to pediatric hospital wards last between 3 to $5 \mathrm{~h}$ and are carried out by two artists, preferably, and when possible, always a male and a female. Depending on the audience, the clowndoctors make use of an array of artistic techniques that range from music and story-telling to circus art, pantomime, magic, improvisation, etc. The type of humor used is also adjusted to the target audience(s) and to their respective situation. Frequently, the clown mirrors the mood and type of humor expressed by the child as a way to start the interaction.

During their visits, the clowns move from bedside to bedside in several children's wards, from oncology to cardiology, transplant units, intensive care, neonatology, and others. When the clowndoctors enter the room, the child is often alone or with her/his parents. Without playmates or toys, the child is very much restricted in the normal forms of play and in the amount of play possibilities. Therefore, the clowndoctor assumes the role of the playmate and starts a game that opens up and creates an atmosphere of playfulness.

In an environment where the theme of play is lacking, clowns often use the situation of simply having the patient in a hospital room or having medical material and instruments at hand to initiate and engage in some form of play. They create humorous and amusing scenes, where medicines are magic pills, where a hospital bed is a space machine, a flying car or a magic carpet. By turning the hospital room into a space that favors play and by stimulating children's senses and capabilities, clowndoctors turn the hospital environment into a less scary and more humane place for them. All of the play is adapted to the condition of the child; hence, if the patient is limited to a bed and her/his movement is restricted, physical play is put aside and gives place to verbal play or simply "make believe" situations produced by the clowns. The goal is always to reduce the patient's anxiety level and to generate a better, more relaxed and calm atmosphere that can boost a child's recovery process.

The interaction between the clowndoctors and the children creates a supportive environment, during which children are fully included, giving them self-confidence and courage, an element fundamental to their wellbeing. In fact, encouraging and facilitating children's active participation in the programs and being sensitive to their condition is central to reducing their vulnerability and increasing their reaction. This interaction can also have a non-formal educational component, as the clowndoctor helps children to develop certain skills and understand the need for certain medical procedures, such as the need for taking medicines. Simultaneously, it provides a sense of "normality" through self-expressing activities that allow children to do what they do best-play!

Children's response to clowndoctors is generally very positive, as portrayed in several written letters from parents we have received and in written reports from our clowns. This response is so positive, that medical staff and family members request the clowns to be present in numerous medical procedures and other delicate moments, like in our special program, NOS!, described later 
in this article. Naturally, the predisposition to engage in some sort of playful activities varies greatly with the age group, it being easier to engage smaller children than teenagers. However, our experience has shown that even when it takes longer to engage the child, at some point, they respond to the clowns and start taking part in the interaction. From the moment they let the clowns in, a change in their mood is immediately noticeable, and children's attitudes towards certain medical procedures and staff can improve for the better. A nurse from St. Joseph Krankenhaus, "Josephinchen," (Children's General Hospital) in Berlin-Tempelhof said in a feedback session, "Their intervention with the patients was astonishing. Some even forgot that they were in the treatment room. And even for us, the medical staff, it's a good therapy. We work in a much better mood, and our work with the patients is easier".

A small-scale research project conducted in cooperation with our partner organization in Slovakia, at the Oncology Clinic for Children in Bratislava [3], showed that ČERVENÝ NOS Clowndoctor programs contributed to the improvement of the emotional mood of hospitalized children. The collection of data was done via individual questionnaires comprised of 10 questions to assess the following variables: mood, adaptability to hospital, importance of the clowndoctor program and impact of the performances. The questionnaire was presented to 38 respondents (16 children aged between 1.5 and 8 years; 16 children from 9 to 16 years of age; plus six mothers). In the case of pre-school age children, the parents responded to the questionnaires after consulting with the child. Older children answered the survey themselves. The parents responded to the questions specifically addressed to them. The answers were recorded by a psychologist.

Differences in the answers of younger and older children were expected, as their needs and reactions to hospitalization vary greatly. The answers of younger children show a higher frequency of positive evaluation in all questions than the responses by older children. For example, when questioned about the influence of clowndoctor visits, $93 \%$ of children aged between 1.5 and 8 years say that clowndoctor visits improve their mood and overall state of wellbeing, while that number decreases to $64 \%$ among children aged 9 to 16 . This can be related in part with older children's attitudes that perceive this kind of humor as being for young children and not for them anymore. The percentage of negative answers to the 10 questions presented was insignificant. From the results, patients and parents generally agree that the visits by the clowndoctors improve the mood in the room ( $91 \%-100 \%$ of the respondents) and can offer some practical solutions and tools to face problems common to hospitalized children.

In fact, through light-hearted play, professionally trained hospital clowns provide children in hospitals with coping strategies. According to RED NOSES International expert, Gary Edwards, there are five distinctions in child developmental stages that are relevant for clown work in hospital - infants, toddlers, pre-school children, school-aged children and young persons. Each stage requires specific artistic approaches to achieve the expected result of the visit (as described above). For example, to ease a toddler's experience in the hospital and reduce fear, the clowns often resort to some sort of play to distract the child. In this case, bubbles and post-procedure play can work very well. Role playing can be a powerful tool to divert the attention of toddlers, pre-school and school-aged children from certain medical procedures. It provides an alternative focus during the procedure, which will not be associated with a painful experience, but rather with a positive 
experience of interaction with the clown. Young persons are more hesitant to express their feelings of pain and do not want to be embarrassed. They also take more personally the stigma of being different and isolated from their friends. In this case, the clown is very attentive to respect young persons' privacy and always avoids being condescending during the interaction. It is equally very important to include these young adults in their treatment.

The clowns are also very successful in involving the child in the treatment process, which she/he does not usually understand and/or accept. Clowndoctors are very successful in conveying content that will be essential for treatment, especially for children with chronic diseases, such as the need of taking medicine or undergoing regular therapy. Therefore, children have something to look forward to, and while waiting for the next regular visit, they attempt tricks and are immersed in the world of play once again.

Feedback from hospitals and medical staff regarding the contribution and benefits of regular visits by professional clowndoctors to the wellbeing of children in the hospital has been equally tremendously positive. To maintain the high artistic and quality standards of the programs, these feedback sessions take place on a regular basis as per the Memorandum of Understanding with the hospital. They are put in writing by the clowns, reported back to the management of RED NOSES and are essential to assess the impact that clown visits have on the patients and to look for common areas for cooperation. This has resulted in an exponential increase of the number of children's wards and patients visited by RED NOSES clowndoctors. In 2013, we visited over 485,000 children in 187 hospitals in 11 countries. The success of the program is also translated in the number of requests to open a new program or to increase the number of visits to pediatric wards.

Regular Visits to Hospitals in the West Bank

Regular visits to pediatric wards, which have successfully been implemented throughout Europe, have also proven to be very successful in other areas of the world. A good example of best practices is the RED NOSES regular children's program in Palestine, implemented by our branch office in the West Bank [4].

Recognizing the needs of the population in the West Bank and the Gaza Strip, RED NOSES International and RED NOSES Palestine have put in place a regular program for children in hospitals, as the one described above in Section 2.2. This program follows the same approach as the one implemented by our partner organizations in Europe and New Zealand. Currently, these visits are being implemented in the four partner hospitals in the West Bank-Beit Jala Governmental Hospital (Figure 1), Ramallah Medical Complex, Hebron Governmental Hospital and Augusta Viktoria in Jerusalem - with incredibly positive feedback from patients, relatives and medical staff. The success of our program in the Palestinian territories demonstrates that hospital clown programs can be implemented everywhere in the world with the same positive results as the ones already proven in the West.

RED NOSES programs in the West Bank hospitals not only bring Palestinian children in the hospital a much needed smile and play opportunities, but they also help undermine the stress caused by the extremely aggravating endeavor of accessing health services. Regular visits to these four hospitals also present an element of stability in an area where family visits cannot be taken for 
granted. In a territory deeply affected by the restriction on the freedom of movement, due to the permit system in place in the Palestinian territories, "mothers below the age of 39 and fathers are the most frequently denied permits" [5]. This absence can intensify the feeling of insecurity and can induce further stress, discomfort and malaise, especially among children.

Figure 1. Regular children's program in Beit Jala Governmental Hospital.

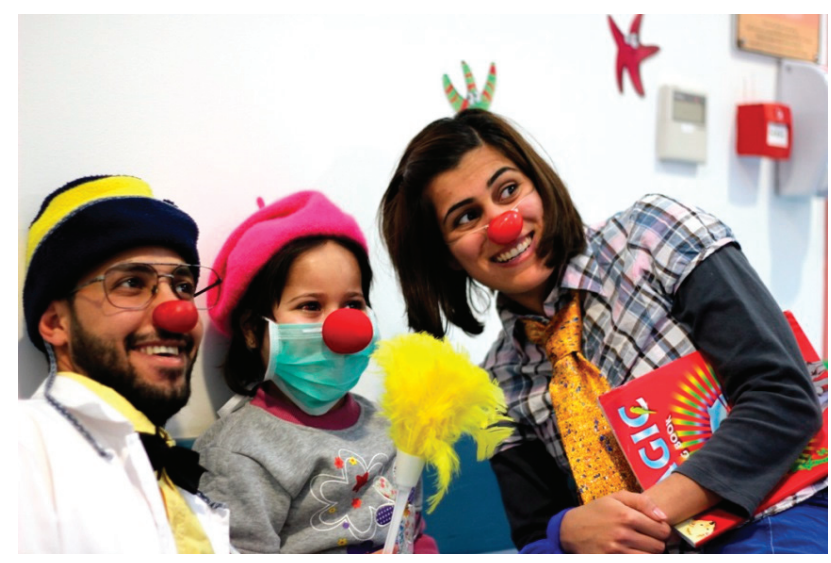

In addition, Palestinian children continue to register high levels of post-traumatic stress (PTS) and various mood and anxiety disorders, which render essential programs focusing on easing the stress caused by illness and the violence in their surroundings. According to UN agencies, $14.2 \%$ of kindergarten-aged children present indications of emotional stress [6] related to family violence (which tends to increase in cases where unemployment and poverty are present) and with the conflict (many children suffered or witnessed violence and/or injury, several types of ill-treatment and abuse, arrests, demolition of their houses, settler-related violence, etc.) [7]. By focusing on psychological wellbeing, RED NOSES programs help these children to cope with the stress caused by the violence in their surroundings, as clowndoctor performances provide a platform for children to handle daunting situations. Clowndoctors reach beyond the moment of interaction; they help build human capacity to deal with illness and disability. Through humor, clown work promotes critical thinking and encourages children's ability to understand their situation and to look for ways to challenge it.

Moreover, the implementation of this program helps the Palestinian health system to respond to several immediate challenges, including an epidemiological transition that is translated in an ever-increasing incidence of chronic and non-communicable diseases (NCDs) among Palestinian children [8]. With several patients having to cope with long stays at the hospital and eventual long processes of medical referrals for treatment outside of their area of residence or abroad, the psychological burden of these diseases cannot be overlooked.

RED NOSES visited over 11,500 Palestinian children in the West Bank in 2013. Half of the Palestinian population is under 16 years old, and according to the Palestinian Central Bureau of Statistics (PCBS), the percentage of children aged between $0-14$ years is $40.1 \%$ of the whole population (38\% in the West Bank and $43 \%$ in Gaza) [9]. 


\subsection{RED NOSES Special Programs}

\subsubsection{Caravan Orchestra: Empowering Children with Disabilities}

In line with Article 30 § 5.d. of the UN Convention on the Rights of Persons with Disabilities [10], RED NOSES recognizes the necessity for children with disabilities to participate in play, recreation and leisure.

2014 marks the second anniversary of the RED NOSES program, the Caravan Orchestra, based on the format from the CliniClowns Foundation in the Netherlands. This tailor-made musical theatre program is uniquely designed for children and youth with mental and multiple disabilities.

The performance: A group of three specially trained clowns travel from "oasis to oasis" visiting institutions for special education. They are looking for new musicians to join their orchestra, because music is their passion. The clowns quickly find what they are looking for: the children in the room. A treasure chest reveals keys that become musical instruments; the children's names are woven into highly personalized songs, and everything together results in a joint melody.

At the heart of everything, the child: For one week, they immerse themselves into the children's world and reach out to them, individually relating to their respective needs. During the workshop, the clowns concentrate on the receptiveness and emotional status of the participants, approaching them in a variety of holistic ways, with music, colorful requisites, innumerable sounds and, of course, the playful art of clowning. Every child reacts differently. Some participate immediately, clap and laugh, while the reactions of others are subtle. All of the senses of the children are stimulated, and their creativity emerges during this personal psychosocial intervention.

Through interactive play based on sensitivity and respect, the clowns use humor and laughter as valuable tools to encourage and empower this vulnerable group, whose self-esteem and self-confidence become enhanced, and a good state of wellbeing emerges. The fight against social stigmas and discrimination is promoted, enabling the individuals to participate and integrate better within the hospital environment and the community.

Having received good resonance in Austria, we now have the program running in four more of our eleven partner organizations in the Czech Republic, Hungary, Slovakia and Slovenia. In 2013, over 120 plays that included 880 children and youth with disabilities were performed.

A special team of five experienced clowns (three main + two in reserve) are given extra artistic training in musical instruments, sign language and improvisation in order to deal with the different disabilities of the target group. The training and the first three performances are overseen by the project leader [11].

\subsubsection{Circus Patientus: The Circus Has Been a Guest in Hospitals Since 2004}

The Circus Patientus program has its roots in the Czech Republic's ZDRAVOTNÍ KLAUN, RED NOSES International partner organization, which counts on the support of the Czech Chapter of the United Nations organization, the World Health Organization (WHO). The first hospital circus performance took place in the Czech Republic in 2004 and catered to young, long-term care patients in oncological and orthopedic units and pediatric and adolescent psychiatric facilities. 
All sick children who want to participate are welcome. The circus program is customized and rehearsed with children no matter what their physical state-in a cast, bedridden, with crutches - everything goes! Together with two RED NOSES clowns, the children convert the hospital room into a stage, where the children are transformed into artful magicians, dazzling artists, skilled unicycle riders and muscular weightlifters. At the end of the project week, the grand performance in front of doctors, nursing staff and family members is met with thunderous ovations.

The sick child is relieved of his or her passive role in the everyday hospital routine, even if their illness, concerns and disorders only temporarily fade into the background. As full attention is focused on their new skills, the young patients discover a new side to themselves. The round of applause boosts their self-confidence and the creative collaboration stimulates their enthusiasm and vitality.

Young long-term care patients in the Czech Republic, Austria (Figure 2), Slovakia, Slovenia and Lithuania are transformed into enthusiastic circus ring stars. In 2013, we brought the magic of performances to more than 2,200 children. In several cases, they were given the opportunity to create their own play script, exploring their abilities to the maximum and making them the stars of the show!

In the Czech Republic and Slovakia (Figure 3), our RED NOSES team even puts together a tent that literally brings "the circus into the hospital". Playfulness is triggered, and the magic of the circus tent transports the patients, relatives and medical staff to a world far away from the hospital reality, at least for some hours. Feedback from relatives and medical staff has been tremendously positive.

Figure 2. Performance of Circus Patientus in Austria.

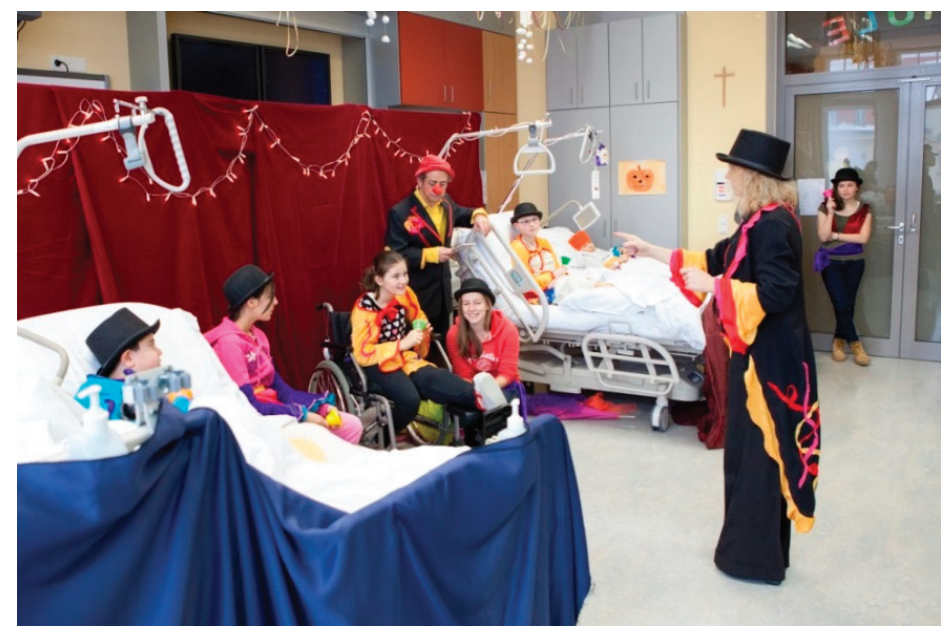


Figure 3. Performance of Circus Patientus in Slovakia.

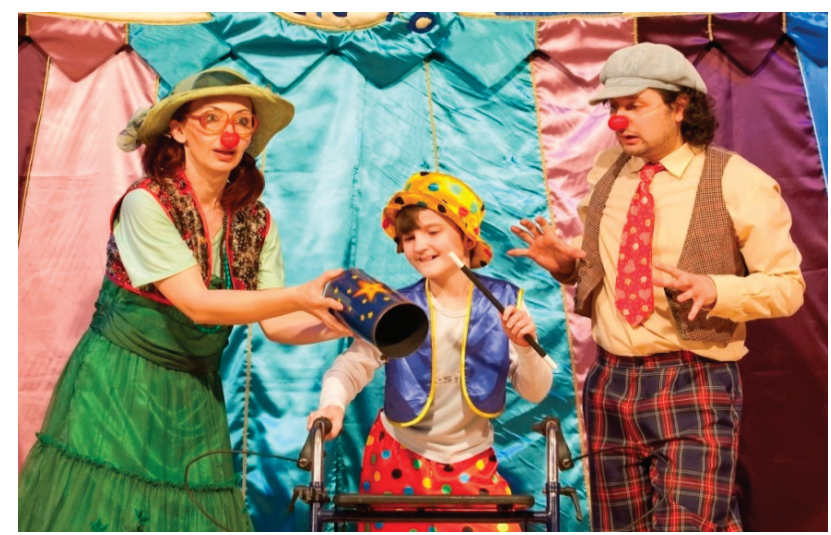

\subsubsection{NOS! (Na Operační Sál! (“To the Operation Theatre”))}

In 2013, another very successful Czech pilot program for humor intervention in surgery preparation-NOS! - started at the children's surgery department in University Hospital-Motol, Prague and shortly afterwards in the Ostrava-Poruba Hospital; and since 2014, in the Teaching Hospital Hradec Kralove (Figure 4A,B).

In this intervention, the clowns are the trigger for humor, which takes place in this environment that is normally not conducive to play in.

One experienced clowndoctor spends time with a child and the parents during preparations for an operation, assuaging their fears, anxiety and insecurities during these difficult moments through sensitive, humorous intervention. Under these specific conditions, a single clown can better exercise his or her artistic empathy. For the intervention, the clown identifies several stress moments - changing scrubs, coming into the department, entering the "staff only area", waking up in a new room - and replaces them with playfulness to help ease the stress of the patient.

The actual time the clown spends at the ward varies according to the number of children for surgery, so the visit can last between 4 to $6 \mathrm{~h}$. When children come back from surgery, most of them are still asleep, and the nurses insist that they sleep as long as possible, advising parents not to interrupt their sleep. When they do wake up, quite often, they have an adverse reaction to the anesthetics (crying, fits of anger). During these episodes, not even a mother's attention helps. The clown's role is usually to make it obvious to the parent that he or she is available to help with the child, but leaves it up to them to choose the appropriate moment. The child falls asleep and wakes up with the same clown and play taking place. A seamless overlap has occurred without the child ever noticing any interruption.

After an internal evaluation period of three months, a meeting was held in the hospitals with the relevant hospital staff. In all three hospitals, the reception of the project was very positive. This project requires close ties, cooperation and trust among the participating clowns and all staff members. In fact, the effect of the clown's presence at the ward seems to have achieved a subjective feeling of more "room," more calm, more relaxation and more fun. We also received 
several spontaneous and hugely positive feedback letters from parents, such as the mother of a small patient (name withheld) who said, "My son was crying and didn't want to swallow the oral anesthetic. He made such problems, I was so nervous. I was so happy that the clown was here and able to sooth his nerves, as well as mine! He really saved the situation!"

The project has, in the meantime, extended to medical facilities in Slovakia, where the clowns now accompany children into the surgery room for long, painful medical procedures. Last year, we performed 34 of these visits, during which RED NOSES clowns attended to 333 children.

Figure 4. Lukáš Houdek, a.k.a. RED NOSES, clown Dr. Ivan Motyka (Zdravotní Klaun, CZ) helps patients preparing for surgery.

A

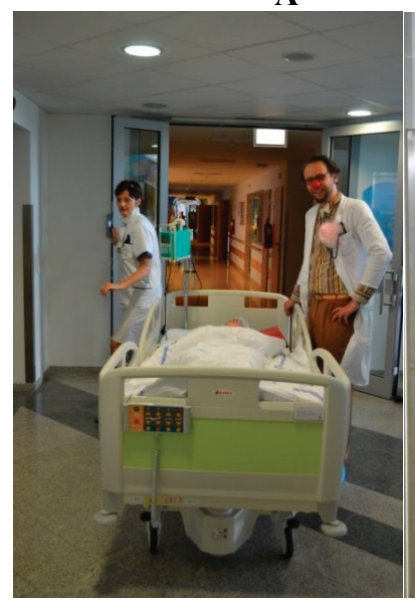

B

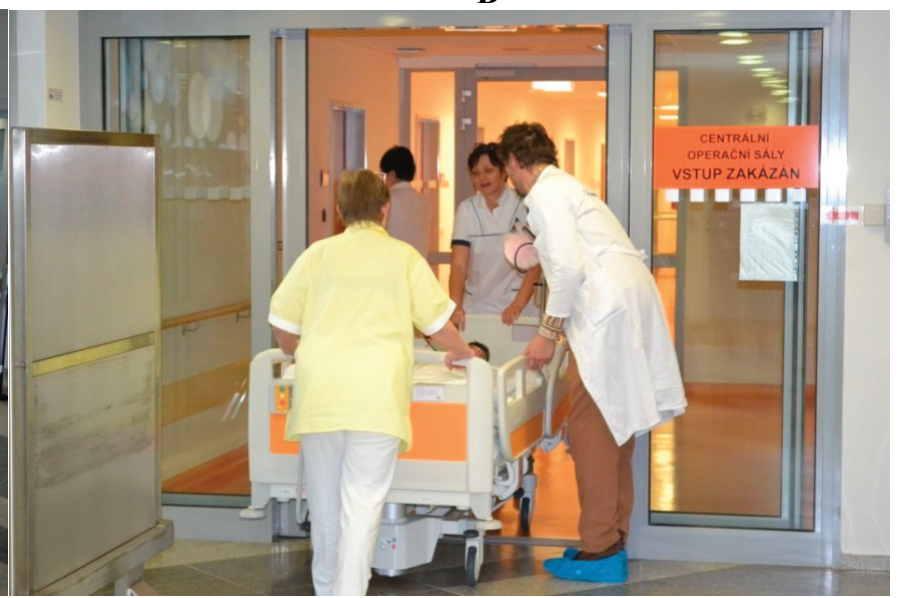

\subsubsection{Clown on Duty}

In 2010, RDEČI NOSKI in Slovenia began a project that has been in operation ever since: Clown on Duty. This project was started at the request of several nurses and is still very successful. Over a span of a few days, the clowns participate in the entire hospital routine, from A to Z: during medical treatments, such as drawing blood or taking X-rays, during boring waiting times, during preparatory procedures before an operation, etc. During this entire period, the clowndoctors are present around the clock for patients, just like physicians and the nursing staff. Their presence brings a sense of security and variety.

The project, which takes place once or twice a year, builds bridges between the hospital staff and the clowns. During the project, physicians and nursing staff can learn from the humorous interaction with patients, and the clowns gain new and important experience that helps them in the everyday hospital setting. The goal of this partnership is to facilitate exchange between artists and medical staff, but also to create a more humane and patient-friendly atmosphere in hospital wards. The immediate result of the clowns' presence is a lighter and more cheerful mood, a change that is beneficial for both patients and medical staff who deal with the burden of disease, pain and loss on a daily basis. 


\subsection{5. "Wake Up. Come Back to Us!": Visits at the Bedside of Pediatric Coma Patients}

Faced with craniocerebral trauma or other such life-threatening diagnosis, children in hospital need very specific neurological treatment and special care during rehabilitation.

To serve exactly this purpose, the "Budzik Klinik" ("Alarm Clock Clinic") in Warsaw opened its doors in summer, 2013. The first and most modern of its kind in Poland, the clinic specializes in free treatment and follow-up for young coma patients.

The hospital "Budzik Klinik" has 15 beds on three floors and provides an advanced medical infrastructure for affected children. An important part of the therapy is the fact that parents are always allowed to be present. The founder, Ewa Blaszczyk, actress and concerned mother, built the clinic with the help of her charitable foundation, FUNDACJA Ewy Błaszczyk "AKOGO?" and many generous donors and sponsors.

In addition to doctors, neurologists, physiotherapists and psychologists, the Polish RED NOSES organization, CZERWONE NOSKI, was also asked to be part of the treatment plan from the outset, because their presence is an important stimulus for comatose children. Clown work performed directly at the bedside is an important and powerful stimulus, not only for comatose children, but also for those who have come out of a coma and gone into rehabilitation. Therapists in the clinic involve the clowns in all of the stages of the recovery process.

RED NOSES has been visiting little patients in the "Budzik Klinik" on a regular basis since August, 2013, and a unique and highly successful project has developed.

Even if it seems that the children do not notice or respond to anything, the clowns contribute greatly to the waking up process with their sensitive, poetic and musical visits. They are valuable companions, especially when the little ones gradually regain consciousness.

Eight children have already woken up from being in a coma (a great success for the clinic). Additionally, even afterwards, RED NOSES clowns are still warmly welcomed by the little patients and their parents. The humorous interaction supports their rehabilitation and helps all those involved to endure and keep on going.

When the little patients finally leave the hospital, they see the clowns as close friends and are happy to stay in touch with them. They remain by their sides to accompany them on their journey back to life, giving them hope and courage.

\subsection{6. "We Have Slippers"}

Palliative medicine utilizes a multidisciplinary approach to patient care, relying on input at different levels from doctors, pharmacists, nurses, chaplains, social workers, psychologists and other health professionals. Together, they formulate a plan of care to relieve the suffering in a patient's life. The philosophy behind palliative care lies in holistically addressing physical, emotional, spiritual and social issues.

According to Gary Edwards, RED NOSES expert, tearing down the stigma in palliative care is one of the benefits of the RED NOSES children's program, "We have slippers," which he started in the Czech Republic in 2011. Children often do not understand the processes taking place around them when in palliative care. They do not understand their illness and the limitations and 
restrictions involved in their situation. They do not understand the reason why they are isolated and why the entire mood in the room is somber and sad; why everyone is quiet; why they cannot play. They often feel that it is their fault, that they are being punished, since they are not allowed to play. This common notion goes against the natural instinct of the child, who has the right to play in any situation. Children are very sensitive and can feel the atmosphere is daunting and stressful for their family members.

The clowns who carry out this program, which was developed together with a mobile hospice team, are specially trained in visiting the patient at home and dealing with the implications that are involved in such circumstances. The biggest problem to implementing this program is that there is a need for the parents to initiate and ask for it, since it is a very personalized form of intervention. The parents have to realize that the stimulus for playfulness is lacking, needs to be present and needs to be filled. The visit is therefore planned in close cooperation with the parents, as it has to be a more compassionate visit responding to human needs.

The clowns come into the house and initiate play, quite often in the context of a birthday party; or sometimes, the family just invites the children's friends over, and this works very well, giving it the feel of a real party.

However, the intervention is often a one-time visit when the clowns join a house call by the doctors. They drive in the same car to make sure that when the doctors are there, the clowns are also present. The duration of the visit always varies, as there needs to be space for some fun. This requires good cooperation with the doctors, who understand that they need to exercise a lot of patience, since it is not a quick house call.

Due to the success of the program for children, medical staff asked for it to also take place in palliative care for Czech adults.

\subsubsection{Emergency Smile}

In recognizing that opportunities for play, recreation and cultural activities can have a significant therapeutic and rehabilitative role in helping children to recover a sense of normality and joy after their experience of loss, dislocation and trauma, RED NOSES International created the "Emergency Smile" project in 2012. This program builds upon the previous international engagements of RED NOSES, including the disaster relief project in Kosovo's largest refugee camp in 1999 and the emergency response following the 2011 Christchurch earthquake in New Zealand.

The new program had its official debut in the summer of 2013 at a medical facility for tropical diseases in Akonolinga, Cameroon. In a pilot project initiated in partnership with Médecins Sans Frontières (MSF), RED NOSES sent a small team of clowns to raise awareness locally and contribute to managing the pain plan of patients with the stigmatized and neglected disease, Buruli ulcer. During their three-week long stay, the clown team visited the ward twice a day and took their juggling acts and funny songs to the dressing rooms, physiotherapy sessions and into the waiting room of the operating theatre. At the end of the trip, the clowns helped the children on the ward put on a play about early detection of the disease, conveying a clear message that the best treatment is found in the hospital (Figure 5). 
Through educational theatre, our clowndoctors actively worked to demystify this neglected tropical disease and to break away from the social stigmas that are associated with Buruli ulcer. For example, the clowns actively contributed to integrating a boy found with advanced Buruli ulcer in a rural area and who was abandoned by his family because of the disease. During the visit, the boy was amazed by the clowns, whom he followed everywhere. Because of his dedication, our team chose him to be their helper and assistant in the hospital throughout the RED NOSES stay. After our departure and in contacts with medical staff in Akonolinga, we were told that the boy was now a very confident boy, proud of his newly acquired status as "assistant" of the RED NOSES clowns. He was no longer the boy that was abandoned because of his disease, but rather the "clown helper". The presence of the clowns was a trigger that boosted his confidence and has, since then, helped to lift his spirits and to face the painful disease.

Figure 5. Final performance of "Emergency Smile" in Akonolinga, Cameroon.

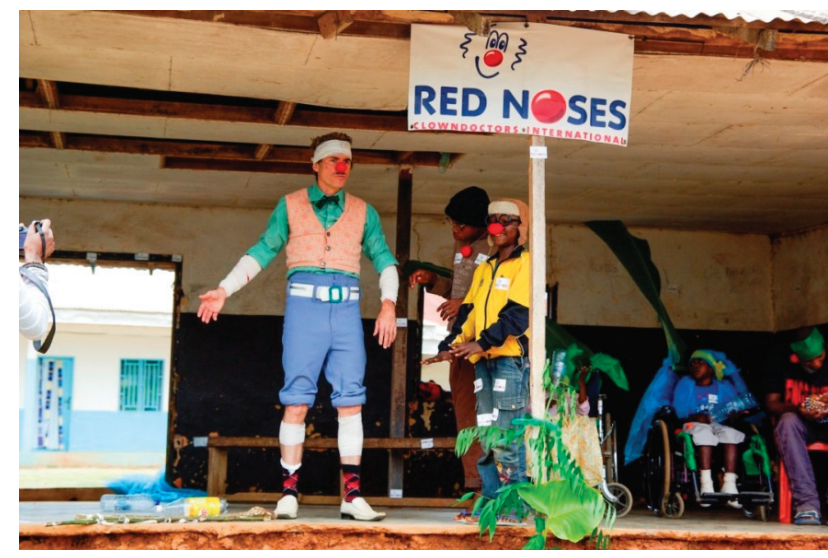

In addition, according to the feedback reports from the local medical staff, the impact of the RED NOSES visits on the patients' wellbeing was astonishing. Worth noticing is the positive resonance of the presence of the clowns in the treatment room while patients undergo the painful procedures of changing band aids. This process was described by the medical staff as very painful and traumatic, especially for small children. When the clowns were present during this procedure, the children were distracted by the cheerful figure of the clown that helped shift their attention from the procedure itself, with amazing results that impressed the medical staff to the point of having them ask for basic training in hospital clowning, in order to apply some of the successful tricks after the departure of the clowndoctors.

\section{Conclusions}

Psychologically, hospital clowning has proven essential in providing children with coping strategies and in contributing to raise their self-esteem, build up confidence and improve their social abilities. Through interactive play, RED NOSES clowndoctor performances support resilience, reduce patients' anxiety and seek to have a positive impact on the overall wellbeing of 
children suffering from ill health. Additionally, this patient-oriented care has a very positive impact on the parents and the way they deal with the health condition of their children.

The success of performances is linked not only to the high quality and specialized artistic training of the performing artists involved, but also to the interdisciplinary and cross-sectorial approach adopted in the implementation of hospital clowning programs - an approach that strengthens the linkages between culture, health and development.

Due to the positive resonance from patients and medical institutions, RED NOSES children's programs have greatly expanded throughout the years. RED NOSES is currently addressing the needs of a growing number of children, having visited in 2013 alone more than 485,000 children in 187 children's hospitals, in 11 countries. The groups of children visited by our clowndoctors have become increasingly heterogenic, thus requiring specific approaches to respond to their individual needs. The person-centered approach implemented by our clowndoctors has allowed us to reach out to children with diverse medical conditions, from diverse cultural and socio-economic backgrounds and in very different environments and countries. The result is that regardless of the environment and medical condition of these children, hospital clowning contributes to the improvement of their wellbeing and helps fight stigmas against children with disabilities.

\section{Acknowledgments}

We would like to thank the RED NOSES group, in particular our amazing artists who provided us with the necessary insights and practical experience in the hospital.

We express our gratitude to Monica Culen, Giora Seeliger and Gary Edwards for sharing their immense knowledge and expertise on humor in healthcare and the impacts of the several programs presented in this article to foster the wellbeing of children in hospital. To Natalie Porias and Eva Primavesi, thank you for all your support and help!

\section{Author Contributions}

Laura Anes and Marianne Obi conceptualized, wrote and edited the paper.

\section{Conflicts of Interest}

The authors declare no conflict of interest.

\section{References}

1. Stuckey, H.L.; Nobel, J. The connection between art, healing, and public health: A review of current literature. Am. J. Public Health 2010, 100, 254-263.

2. United Nations. United Nations Convention on the Rights of the Child, Article 31; New York, NY, USA, 1989. 
3. Hlivová, I. Mgr. Children's Oncology Clinic of the Children's Faculty Hospital and Polyclinic: Bratislava, Slovakia. In cooperation with the Office of the W.H.O. in Slovakia. Clinical Study of the Effects of RED NOSES Clowndoctors in the Children's Oncology Department of the Children's Faculty Hospital in Bratislava-Kramara (Unpublished), 2008.

4. Bundeskanzleramt, Sektion Kultur, Abt. EU-Kulturpolitik. Creative Europe Desk-Culture. Best Practice, EU-Programm Kultur (2007-2013); Gutenberg Werbering GmbH: Linz, Austria, 2014; pp. 68-71.

5. World Health Organization. Right to Health: Barriers to Health Access in the Occupied Palestinian Territory, 2011 and 2012. WHO Special Report; Geneva, Switzerland, 2013; Publication number: WHO-EM/OPT/004/E, 14.

6. World Health Organization, Report by Secretariat. Health Conditions in the Occupied Palestinian Territory, Including East Jerusalem, and in the Occupied Syrian Golan; Sixty-Fifth World Health Assembly; Geneva, Switzerland, 11 May 2012, Provisional agenda item 15, A65/27 Rev.1, P. 11.

7. UNICEF. Children Affected by Armed Conflict, Israel \& the State of Palestine. CAAC Bulletin, July 2013. Available online: http://www.unicef.org/oPt/UNICEF__State_of_Palestine_-_CAAC_bulletin_July_2013.pdf(accessed on 21 October 2014).

8. World Health Organization. Health conditions in the Occupied Palestinian Territory, Including East Jerusalem, and in the Occupied Syrian Golan. Sixty-Sixth World Health Assembly; Geneva, Switzerland, 17 May 2013, Provisional agenda item 20, A66/INF./3, P. 2.

9. Palestinian Central Bureau of Statistics (PCBS). Available online: http://www.pcbs.gov.ps/ (accessed on 10 June 2014).

10. United Nations. United Nations Convention on the Rights of Persons with Disabilities, Article $30 \S$ 5.d.; United Nations: New York, NY, USA, 2006.

11. For More Information on the Caravan Orchestra, Please View a Video on Our Website. Available online: http://www.rednoses.eu/red-noses-programs/caravan-orchestra/\#.U610o1O956Y (accessed on 21 October 2014). 


\title{
Pediatric Hospital: The Paradigms of Play in Brazil
}

\author{
Lino de Macedo, Gláucia Faria da Silva and Sandra Mutarelli Setúbal
}

Abstract: The role of play in Brazilian children's hospitals is highlighted, as well as the perspective of humanization in Brazil. Some aspects of our culture are crucial to understanding the importance of play considering our society. Sabara Children's Hospital ("Hospital Infantil Sabará") in Brazil is used particularly to discuss humanization. To understand the issue of play in Brazil, it is important to discuss hospitals in their social context, their history, current roles in children's care, humanization history and child development, according to the approaches of Piaget and Winnicott that are used in our culture.

Reprinted from Children. Cite as: de Macedo, L.; da Silva, G.F.; Setúbal, S.M. Pediatric Hospital: The Paradigms of Play in Brazil. Children 2015, 2, 66-77.

\section{Introduction}

Although hospitals are a recent institution in Brazil (less than 100 years), it is a fact that, nowadays, in our country, families use children's hospitals for childcare. Even more recent are the playrooms inside children's hospitals. The importance of play was recognized only in 2005 , by incorporating the law that obliges each hospital to install a playroom when it has children in-patients.

The presence of a playroom does not mean that play is happening. It will only occur if the hospital has a humanization culture. In Sabará Children's Hospital, the playroom is fully occupied with sick children exchanging feelings, experiences and ideas, while playing games, or painting, or listening to stories, according to the program designed for that day and hour.

\section{Results and Discussion}

\subsection{The Hospital: Social Context and the Present Moment}

Since the middle of the last century, the fundamental mark of these institutions has been linked to the original meaning of the word, hospital, which comes from the Latin, hospitium, the place where visitors were received. With the passing of time and the evolution of cities, the word hospice started to refer to establishments permanently occupied by poor, sick people, the incurable and the insane, and the name, hospital, indicated houses where sick people received temporary treatment.

In the book, History and Evolution of Hospitals in Brazil ("História e Evolução dos Hospitais no Brazil") [1], one can read that the healthcare in our country was precarious. The clinics were meant only for the high social classes, and the hospitals were designed for the poor. There were no trained professionals (nurses, doctors, assistants), and the struggle included a differentiation between medical and social care. There were no clinicians working together as a team. One must consider that there was one nurse for every 37,000 inhabitants. Nowadays, there are nearly 4 nurses for every 500 inhabitants. Only in 1944 did professors from Sao Paulo University reorganize the 
hospital system into something close to the system we have today, with clinicians working as a team on each a patient.

In recent years, technology has come to permeate our daily lives in an irreversible way. The whole of society has been affected: health, education, manufacturing, financial services and communication. In other words, new technologies allow for and require new ways of interacting with people.

With the difficulties with respect to the social differences in Brazil, the public hospital is a privileged place for the deposition of the symptoms of contemporary disease, which is much more than healthcare itself, but also psychosocial care. Families have been arriving with their demands and anguishes at the hospital. Therefore, one can find in the hospital medical knowledge combined with technology, but also difficulty during the discharging of patients and families. They need to cope with the hospital situation before they go home.

Raising a child, playing with a child and treating a child are really about expanding shared time, being together, looking, seeing and communicating and letting him/her cope with the processes he or she has been experiencing.

\subsection{Humanization}

The notion of comfort became important in 1928 in France. In the 1930s, the concept was extended to well-being. The principle of humanity appeared in 1949. "It is necessary to humanize hospitals" became a slogan [2]. Decades later, the word humanization became obsolete and was replaced by the term, quality. This term became important again in the 1980s and 1990s, with projects on the humanization of care. Nowadays, humanization is one concept used when a hospital is concerned with both health and psychosocial care [2].

Humanization policies entered onto the Brazilian scene in 2000. There was a nationwide push for the Unified Health System (Sistema Único de Saúde), redefining the concept of health as a political and social action, capable of creating not only healthcare, but also psychosocial care $[3,4]$.

It is our interest, therefore, to explore the relationship among clinicians, patients and their families as an open, continuous and essentially relational process. In Brazil, it is common to see entire families become affected to the point of dysfunction by a child's illness. Families can face illness in a way that can damage their perception of the disease, as well as the sick child's perception. It should be emphasized that, institutionally, it is possible to support one or the other stance when the whole staff is aware of this [5].

From an ethical perspective, human projects are not accomplished through actions, but are instead realizations of values. Values are neither subjective, nor objective, as they are constructed both individually and collectively. As human constructions, they are constantly changing. There is always a subjective moment that is objectified in an act that is trigged by values. Values are the most important human elements and not recognizing their fundamental role is a tragedy in the practice of medicine [6].

From this perspective, humanizing means not only making every day in hospitals lighter and more playful, but also taking a stance that targets, identifies, makes visible and respects the values of the patient and his or her family [7]. 


\subsection{The Child's Development According to Winnicott}

Donald Woods Winnicott (1896-1971) was a psychoanalyst and pediatrician at Paddington Green Children's Hospital, London, for over 40 years. His perspective on children's development differs from the classic trends of psychoanalysis in many aspects, keeping, nonetheless, its topicality and influence. We will outline the propositions about the formation of the self, a fundamental axis to think about play as a space for subjectivity, creativity and self-healing [8].

In psychoanalysis, it is known that the self is a structure that is organized little by little, from birth onwards. The baby is born with an inherited potential and characteristics that must be known and respected; for instance, a child might be quiet and sleepy or restless and hungry. The first weeks are difficult. It is the moment when mother and child need to get to know each other, and this familiarity will guide the rhythm of care, of sensations that are permitted or avoided, of body movements, of the tones of affection that prevail at every micro moment of care, made of endless sequences of presence, stimulation and absence.

In Winnicott's theory, dependence and inter-subjectivity are founding axes of the human psyche. Such inter-subjectivity, however, has strict rules that transpire in the concept of the sufficiently good mother. This is the mother who can modulate the needs of the care of her baby's self. From the baby's perspective, the sensorial stimulations, simultaneous or sparse, will form a "mantle" of well-being derived from her or his connection with the care. That (discomfort, cold, hunger, sleepiness) disappears when that other appears (milk, lulling, singing). This modulation will allow the psyche to come out with all its potential and begin the complex unit called the psychosoma.

If the first year of life goes well, the self will come out sustained by the environment that provided the adaptation for his or her maturation process without interruptions. The illusion process will go its course simultaneously with the slow and gradual beginning of frustration, until the initial omnipotence gives way to progressive contact with reality [9]. The union between maturation, care and development will slowly provide moments of gradual differentiation, accompanied by pleasure and anguish.

At this point, it is important to keep the sensation of the continuity of himself or herself and the trust in this continuity, moreover, when noticing, simultaneously: (1) the emergence of the mother as a person who sustains the baby with her body, her looks, her face; and (2) the emergence of himself or herself as a unit, connected and dependent on the mother. The mediation between the baby's initial omnipotence, the process of illusion and disillusion, which gives way to the real world, will be a task made easier by the transitional object.

The transitional object, therefore, will be the object that can keep the illusion of the continuity of the presence of the baby and parents, and at the same time, this same object will enable gradual and secure detachment of the child from his or her parents. This intermediate area born of the adaptation of the environment, of the trust in intersubjectivity, is called potential space, the space from which play will be born. Play will always be, for Winnicott, in childhood or in adult life, the way to restore trust in one's self and in the world as we experience it. 


\subsection{Being in the Hospital for a Child}

\subsubsection{Sickness}

Being hospitalized for children is an adverse situation in and of itself. It is something they did not want, and sometimes, it is felt as a tragedy. Hospitalization changes a child's life routine. They can collaborate, reject or resign, cry, become aggressive, depending on the capability of the clinicians to care for the sick child and of her or his family to cope with the hospital situation. In other words, getting sick and having to go to the hospital can be felt by the child as a threat. This is called the maladaptive cycle of threat, danger, fear, distress, pain, aversion and avoidance [10]. The child is afraid of being abandoned.

\subsubsection{Toxic Stress}

One of the factors that disturbs the healthy development of a small child, according to the Center on The Developing Child at Harvard University [11], is toxic stress. In a word, this stress refers to the marks left on the child by the adversity of negative experiences and which affect his or her development. It is known that, when a child feels threatened, its body responds by raising its heart rate, blood pressure and stress hormones (cortisol). According to the Center, the intensity, the duration and the repetition of situations that bear these responses may have damaging effects on learning, behavior and health throughout life. It is also known that the presence of adults participating, taking care of or avoiding these occurrences may prevent these damages. In other words, a disease, occasional or chronic, and the ways a child copes with it can cause toxic stress and influence the child's development negatively. How adults respond in these situations can mitigate the child's suffering and be favorable for the child's present and future.

There are two other forms of stress that are not toxic. These can be positive in the sense that every child's interaction with the external world is supposed to create a certain tension, and the outcome can be positive. If there is an obstacle, problem or interest, it requires an effort or a certain level of excitement for the response, and the cycle is closed. Then, the child can rest and move on to other things. Consequently, there are stresses (most of them) that are positive when they are favorable for the healthy development of the child. There is also tolerable stress, which refers to apprehensive situations, such as the loss of a dear person or the death of an animal. If the child can count on the positive help of an adult and overcomes this situation, the damaging effects are not permanent.

Let us consider that stress that is not positive, tolerable or toxic in and of itself. Rather, it depends on the ways or the sensitivity of the child's responses to the stimulations or the situations that produce them, as well as the individual perception of certain events and their consequences for the short, medium and long run. Perception is a complex concept, especially in childhood. The child's perception is deeply connected to its parents' perception and family narrations. In a children's hospital, two fields of intervention, which fundamentally connected and different, are opened:

- The perception and the impact of getting sick on parents (time perspective);

- The perception and the impact of getting sick on the child (reverberations). 
The perception of children includes their hypotheses about getting sick, the etiology and the evolution. Reality and fantasy interlace, forming a reality according to which the child responds to the world and to treatment. Thus, it is difficult to assert that there are children who are frailer and others who are more resilient to the same stressful occurrence or if the environment's response contributes to these characteristics. What matters, however, is that the former are the ones that get harmed the most, even more so if certain negative situations that cause suffering, fear or threats occur frequently. In this sense, toxic stress, little by little, produces a pattern of defense, resentment or fear in the face of several things and people, which has a repetitive and cumulative effect, affecting the child's mental, emotional and physical health for life. It is not by chance that these are the children who, as they become youngsters and adults, may experience health problems, drug abuse, depression and difficulties in succeeding socially, whether it is in school, at work, starting a new family or in their behavior generally as adult citizens [11].

What is applicable to the child is also valid for adults, their parents or guardians. Many of them are a positive reference to the child, because of the care and importance they give to them, because of the love they dedicate to them and that feeds the child's life and development. Nevertheless, there are others who often behave in a frail manner, commit abuse, are negligent, suffer from mental illness, use drugs and become violent and unable to take care for their child, because, in such cases or moments, they cannot or do not know how to look after themselves. It is not the case to deny them the right or the wish to have children, but to admit that they, the parents and children, need social and institutional support. One has to recognize that children, no matter who their parents are and what they can do for these children, belong to a society, are part of the world and express a moment in the cycle of life, one that needs to be recognized as a right and necessity to receive optimum standards in the possibilities of growth, not for themselves, but for all of us. Children, no matter who their parents are and what they can do for these children, are the future that we, as adults, must care for, protect and offer the best conditions for its existence.

Hence, when we refer to humanization, we will always be referring to play as a tool to help children to cope with hospital procedures that might be traumatic.

\subsection{Play in the Hospital}

"Everything seems very simple when it goes well" [12], says Winnicott. His wisdom overflows the limits of his writing's intention, allowing us to go beyond the quotation above for play.

"When a woman becomes a mother, she can be a mother in such a natural way, we should never interfere. She will not be able to fight for her rights, because she will not have an understanding of the real world. Everything she will know is that she has been wounded. The only difference is that the wound is not a broken bone or a cut in her arm, but the baby's mutilated personality. It is common that a mother may spend years of her life trying to heal this wound, when it was actually caused by us when, for no reason, we interfered in something that was so simple that it did not seem to be important at all" [12].

The development of psychism, humanization in its many perspectives, becoming sick, playing or the negative aspect of toxic stress, each phenomenon in its own way reopens the fundamental issue that permeates the construction of this work: intersubjectivity. Whether it is between parents and 
baby, staff and family, caregivers and child and, above all, in the countless forms of its absence, intersubjectivity does not only sustain and guide the essence of who we are, but participates customarily in the foundation of who we can become.

Back to Winnicott, in the early moments of the most essential intersubjective relation, a delicate area of sharing pleasure and trust gains consistency and sacredness between a mother and her baby. This area is called potential space, and it has the power to overcome one of the main risks of early development: the contact between the internal and the external world [13]. To have an idea of the relevance of this communication, countless severe psychopathological conditions are recognizable from this fracture: paranoia, delusion or hallucination represent, in a way, the overlapping of the internal world over the external one.

If psychopathology exemplifies the fracture, play represents the cure: in each moment a child plays, the possibility and the main tool to appease and weave links between the internal and the external perception, remakes moments of subjective reassurance.

"The essential characteristic of what I wish to communicate refers to play as an experience, always a creative experience, an experience of space-time continuity, a basic form of living" [13].

To Winnicott, there is a direct evolution of the transitional phenomena to play, from play to shared play and from this to cultural experiences. Thus, it can be observed that in the passage from intersubjectivity of the first months, the way toward the first organization as a separate self is paved. Such an experience initiates play as a necessary experience in the creation of this source area for playfulness, relationships and games, as well as the fruition of symbolic and cultural aspects [13].

Piaget considers the ludic relation of the child with objects (the mediators are internal and refer to what the child can and wants to do with them) [14]. For Piaget, as for Winnicott, what is considered as a preparation of the possibility of playing is the extreme dependence of the self on his or her immediate environment, this regarded as the basis for the building of the ego and, consequently, of the object (without the building of the ego, the self does not differentiate as a unit; as a phenomenon, when we observe a child, we see something similar to the symptoms of the autism spectrum).

Observing a small child playing is a fascinating experience. Let us consider a child interacting with objects. If the playing activities involve only the child and objects, it is a play exercise, according to Piaget [15]. These are repeating actions, which she or he knows how to do, for functional pleasure. It is the child who chooses the actions that are better for him or her. The child considers the object's functions and physical characteristics. What kind actions can we observe in this experience? Children can look at an object, beat, push, fill it up with things and then empty it again, smell, lick, produce sounds, squeeze, hide it from sight and then look at it again, turn around, emit sounds, etc. It is the child who, in an absorbed, focused way, chooses what, when and how to do this. This play exercise does not require a particular structure. The functional pleasure, the repetition of what the child wants to repeat, is enough.

It is important, at the hospital, that a child has opportunities to play this way. In this context, we observe that sometimes what pleases a child is drawing or painting a picture and, soon after, painting or drawing another, repeatedly. In these moments, it seems like the best thing for the child 
is to focus on the things she or he knows and likes to do. The child has the chance to decide what to do, at least in this situation, having some self-control over his or her life and interests.

Nevertheless, we can observe or promote another playful activity that is equally important. In this case, the source of the play, who moves it or promotes it, is an adult, who dances, clowns, sings, tells stories, proposes tasks or activities, starts conversations, laughs, shares something in common or just stays near. In such situations, the initiative belongs to the other, and the child interacts by saying or showing how and how much he or she likes the proposal. In this case, it is the child's relation with adults that is healing, and the objects or things used are merely a means to link them. Being passive, quiet and ignoring are situations experienced by hospitalized children in our country. If someone comes with a different, interesting proposal, which takes the child from the situation he/she is in, this can be very healing for that child.

At Sabará Children's Hospital, these two forms of promoting play for the small child are put in practice. There are objects, games and materials that children can choose to play with, relying only on themselves. There are also people - volunteers and hired professionals - who sing, clown, tell stories and carry on interesting activities. There are dogs to be touched and petted, dogs whose patience, presence and tolerance bring peace, joy and comfort to the children. It is important to know how to provide these different forms of ludic experiences. It is important to stimulate and enable, even within the limitations for which the child is in the hospital, so that the child can take initiative, search and decide what she or he knows and wants to do. It is important, also, that adults be present and likewise take initiative, make proposals, take away - in a playful and light manner - the child from that moment and situation she or he is in and lead him or her to another situation.

In other words, there are two situations: children can play with objects and assimilate them by themselves, or they can react, participate, follow or imitate external initiatives, which come from the external world, moreover when these can create or demonstrate nice and funny things to be seen or enjoyed. These two sources - the external, coming from the social aspect, and the internal, from the personal aspect - meet after the child is six or seven years of age, when the symbolic and exercise games become games with rules. In this case, the two aspects-personal and social- become inseparable. In fact, in this game structure, the rules and objectives are social, cultural and anthropological. It is about learning, and liking, to be subordinate to them and respecting them. This type of game also requires other people with whom to play; people who one depends on for the game to gain life experience and make sense of it; as well as people who are opponents and who one likes to defeat. From the personal point of view, in this game, it is the actions, the decisions and the choices made by each player that count. No one can play for another player. Hence, it is all about controlling procedures, perfecting forms of sharing the development of the game, consenting and respecting, but also knowing how to fight to achieve a good result in every game. In this structure, the institutional aspect and the context, which organize the inter-individual relations, are also very important. At Sabará Children's Hospital, the older children have access to these types of games; they can find them in the playroom, can challenge the volunteers that visit them in their rooms, or the waiting room, or in the moments preceding a surgery. 


\subsection{Therapeutic Toys}

This review will focus on Brazilian research abstracts regarding the use of therapeutic toys. Studies about hospital play can be read in the following articles [16-26].

For Angelo [26], the use of toys in hospitals is one of the resources that makes the child's experience easier and a valuable information instrument for the healthcare team. In her research, she observed that the therapeutic toy could help the hospitalized child to understand what is going on and what is being done to him or her.

Pinheiro, Lopes and Teixeira [27], in 1993, researched "the influence of toys in the humanization of the assistance of the nursery to the hospitalized child". Its use is complemented by materials related to the venipuncture therapy, favoring the orientations of the humanization of the assistance to the hospitalized child. Ten children participated in the research, who were evaluated before and after the orientation in the presence and in the absence of their mothers.

Medeiros, Matsumoto and Ribeiro [28] used the institutional therapeutic toy (brinquedo terapêutico institucional (BTI)) to prep relatives and five children of pre-school age who were about to receive intravenous puncture at an emergency room. The BTI was also used to understand the relatives' perception regarding this preparation. The toy, according to them, allowed the child to: know what to expect and how to participate in the intravenous puncture; understand its purpose; get involved in the situation; and manipulate the material and establish a relation of trust with the professional. Likewise, it allowed the relatives to acknowledge its benefit to the child's preparation and provide an important source of support and protection. As a conclusion, the authors proposed that the use of the BTI should be integrated with the nursery care provided to children in emergency facilities, assuring humanized, good-quality assistance.

Kiche and Almeida [29] used the therapeutic toy as a strategy of relief for pain and tension during the application of a surgical bandage in children. The objective was to compare the reactions expressed by the child during the application of the bandage before and after the emotional preparation with the institutional therapeutic toy (BTI). Thirty four children admitted for surgery in a public pediatric hospital participated in the research. The children's behavior and the measuring of pain were considered during the application of the bandage at two moments: before and after the use of the therapeutic toy. The results pointed out that greater adaptation and acceptance of the procedure became more frequent after the toy. The levels of pain also decreased after the use of the therapeutic toy. To them, the therapeutic toy became evident as an effective strategy in reducing the child's fear, tension and pain during the bandage procedure.

Conceição, Ribeiro, Borba, Ohara and Andrade [30] carried out a research study meant to understand the parents' perception and the use of the therapeutic toy in prepping the child for intravenous puncture in clinics. The data were collected through semi-structured interviews conducted with eight parents or children's guardians. The results showed that they approved of this preparation strategy and believed that it benefitted them with respect to knowledge of the procedure, reduced fear, calmed them down and promoted their safety, as well as that of the child, besides providing for a humanized and good quality nursery service for the child and his or her 
family. The importance of implementing the therapeutic toy in healthcare assistance to children in clinics and basic healthcare facilities is reaffirmed.

Fontes, Mondini, Moraes, Bachega and Maximino [31] carried out an exploratory study about the use of the therapeutic toy as a therapeutic resource in relieving the child's real and subconscious tensions related to hospitalization. The authors used an observational guideline, applied at two moments: the day before the surgery and the day of the surgery, immediately before its start. They used storytelling and a demonstration of the nurses' interventions on the toys (dolls) with equipment and materials normally used in hospitalization (gloves, surgical aprons, facial masks and surgical caps). Hence, to them, play favors the interaction of the child in the hospital environment, as well as the expression of the child's feelings and emotions.

We conclude this analysis of the place of play for the hospitalized child with the study of Weber [32], who researched "the influence of the ludic activity on the child's anxiety during the pre-surgery period in the clinic's surgical center". To evaluate the children's anxiety, she used the modified Yale Preoperative Anxiety Scale (mYPAS). This scale evaluates five masteries: activities, vocalization, emotional expression, apparent awakening state and interaction with relatives. In each mastery, the evaluator, observing the child's responses, chooses one of four possibilities, for each mastery, except for vocalization, with six alternatives. Cut-off points are defined, characterizing the positions with or without anxiety. Through this scale, 50 children, five to 12 years old, were evaluated. The children were divided into two groups. One of them, the recreation group, took part in ludic interventions in the playroom room. The other one, the control group, did not receive these interventions. The anxiety scale was applied at two moments: one immediate that is as soon as the children got to the clinic, and the other 15 minutes later. The results showed that, in the second evaluation, the children in the recreation group had their anxiety decreased, and the ones in the control group did not.

\section{Conclusions}

The importance of play was discussed from different points of view. This article considered Brazilian culture and the role of play as a cognitive apparatus, as a healing tool of potentially stressing experiences. There is play that dignifies the child as a human being, who requires specific actions when getting sick. Finally, we presented research about therapeutic play interventions in hospitals and clinics.

Highlighting the recreational, educational, clinical and therapeutic functions of play, its many and important functions were revealed [14]. It creates the basis to develop affectivity and intelligence. Human beings can be affected, but also can creatively affect the world around them. Affection is what affects us, but also what touches us.

At a glance:

- Humanization at the hospital implies values and practice that result from the commitment of all in favor of the well-being and the care of children as subjects with rights;

- Assuming a theoretical vision of the child's development and the place of play and playful activities is just as important as the practice and the technologies used for the treatment; 
- Stress, in the hospital context, is a variable to be considered by everyone, and play is an important way to mitigate it in favor of something more tolerable or even positive;

- There are practices at Sabará Children's Hospital that benefit the well-being of children, via play and playful activities, during their free time at the hospital;

- There is evidence from research carried out in Brazil that the use of toys benefits the child's emotional stability during hospitalization.

\section{Acknowledgments}

The authors offer their gratitude to José Luiz Setubal, Fátima Fernandes and Wagner Marujo (www.hospitalinfantilsabara.org.br) for the institutional support throughout the process of production of this article.

\section{Author Contributions}

Lino de Macedo: toxic stress, Piaget's concept of play, illness, therapeutic toys and the relationship between affectivity and intelligence on play. Gláucia Faria da Silva: hospital, humanization, Winnicott's concepts about child development and play, illness and the relationship between affectivity and intelligence on play. Sandra Mutarelli Setúbal: play practices at Sabará Hospital, humanization, therapeutic toys, critical reading and helpful suggestions.

\section{Conflicts of Interest}

The authors declare no conflict of interest.

\section{References}

1. Campos, E.S. História e Evolução dos Hospitais; EDUSP: São Paulo, Brazil, 1965 (In Portuguese).

2. Nardin, A. L'humanisation de L'hôpital. Mode D'emploi. Avaliable online: http://museeaphp.fr/wp-content/uploads/2013/10/Exposition-humanisation-DP.pdf (accessed on 6 August 2014).

3. Benevides, R.; Passos, E. Humanização na saúde: Um novo modismo? Interface-Comunicação Saúde e Educação 2005, 9, 389-394 (In Portuguese).

4. Benevides, R.; Passos, E. A humanização como dimensão pública das políticas de saúde. Ciência Saúde Coletiva 2005, 10, 561-571 (In Portuguese).

5. Cadernos Humaniza SUS—Atenção Básica. Available online: http://bvsms.saude.gov.br/bvs/ publicacoes/cadernos_humanizasus_atencao_basica.pdf (accessed on 6 March 2014). (In Portuguese).

6. Guillén, D.G. Procedente do I Congresso Internacional Humanidades \& Humanização em Saúde. In proceedings of Bioética e humanização, Faculdade de Medicina da Universidade de São Paulo, São Paulo, Brazil, 31 March-1 April 2014. Avaliable online: http://www.blucherproceedings.com.br/pdf/medicalproceedings/cihhs/AnaisCompletosCIHHS2014.pdf (accessed on 20 December 2014). (In Portuguese). 
7. Csikszentmihalyi, M. Paradigms of Play. In The Handbook of Child Life: A Guide for Pediatric Psychosocial Care; Thompson, R.H., Ed.; Charles C Thomas Pub: Springfield, IL, USA, 2009; p. 145.

8. Silva, G.F. Gravidez: Regressão e movimentos representacionais na perspectiva de Freud e Winnicott. M.Sc. Thesis, Instituto de Psicologia da Universidade de São Paulo, São Paulo, Brazil, 2007; p. 60. (In Portuguese).

9. Winnicott, D.W. Os Bebês e Suas Mães, 3rd ed.; Martins Fontes: São Paulo, Brazil, 2006; p. 11. (In Portuguese).

10. Mackenzie, A. Everybody Stay Calm: How to Support Your Young Child through Medical Tests and Procedures; Global Publishing Group: Mt Evelyn, Vic, Austrália, 2014.

11. Centro de Desenvolvimento Infantil da Universidade de Harvard. As Bases da Saúde Para a Vida Toda São Construídas na Primeira Infância. Avaliable online: http://www.developingchild.harvard.edu (accessed on 20 December 2014). (In Portuguese).

12. Winnicott, D.W. O Brincar e a Realidade; Imago Editora: Rio de Janeiro, Brazil, 1975; pp. 15, 75.

13. Guerra, V. Proferida na III Jornada de Psicanálise de crianças e Adolescentes: A clínica atual. In proceedings of A Importância dos Objetos no Processo de Simbolização, Sociedade Brazileira de Psicanálise de São Paulo, São Paulo, Brazil, 30-31 May 2014. (In Portuguese).

14. Piaget, J. Relações Entre a Afetividade e a Inteligência no Desenvolvimento Mental da Criança; Wak Editora: Rio de Janeiro, Brazil, 2014. (In Portuguese).

15. Piaget, J. A Formação do Símbolo na Criança: Imitação, Jogo e Sonho, Imagem e Representação; Editora LTC-Livros Técnicos e Científicos: Rio de Janeiro, Brazil, 1990. (In Portuguese).

16. Montiel, J.M.; Bartholomeu, D.; Cecato, J.F.; Martinelli, J.E.; Ferreira, P.P. Considerações sobre o brincar durante a recuperação de crianças hospitalizadas. Revista Inovação Tecnológica 2013, 3, 2 (In Portuguese).

17. Mitre, R.M.A.; Gomes, R. A promoção do brincar no contexto da hospitalização infantil como ação de saúde. Ciência Saúde Coletiva 2004, 9, 147-154 (In Portuguese).

18. Furtado, M.C. Brincar no hospital: Subsídios para o cuidado de enfermagem. Rev. Esc. Enf. USP 1999, 33, 364-369 (In Portuguese).

19. Motta, A.B.; Enumo, S.R.F. Brincar no hospital: Estratégia de enfrentamento da hospitalização infantil. Psicologia Estudo Maringá 2004, 9, 19-28 (In Portuguese).

20. Wiezzel, A.C.S.; Villela, F.C.B. A brinquedoteca e o brincar no hospital: Diálogo entre o lúdico e o terapêutico. Nucleus 2008, 5, 39-50 (In Portuguese).

21. Mello, C.O.; Goulart, C.M.T.; Ew, R.A.; Moreira, A.M.; Sperb, T.M. Brincar no hospital: Assunto para discutir e praticar. Psicol. Teor. Pesqui 1999, 15, 65-74 (In Portuguese).

22. Batista, C.; Mussini, V. O Lugar do Brincar no Hospital: O Faz-de-conta. Avaliable online: http://www.pucpr.br/eventos/educere/educere2007/anaisEvento/arquivos/CI-203-12.pdf (accessed on 20 December 2014). (In Portuguese).

23. Santos, L. Brinquedoteca-Uma Visão Internacional; Oliveira, V.B., Ed.; Editora Vozes: Petrópolis, Brazil, 2011. (In Portuguese). 
24. Motta, A.B.; e Enumo, S.R.F. Brincar no hospital: Câncer infantil e avaliação do enfrentamento da hospitalização. Psicologia Saúde Doenças 2002, 3, $23-41$ (In Portuguese).

25. Oliveira, R.S. A Importância do Brincar no Ambiente Hospitalar: Da Recreação ao Instrumento Terapêutico. Available online: http://psicologado.com/atuacao/psicologia-hospitalar/aimportancia-do-brincar-no-ambiente-hospitalar-da-recreacao-ao-instrumento-terapeutico (accessed on 20 June 2014).

26. Angelo, M. Brinquedo: Um caminho para a compreensão da criança hospitalizada. Rev. Esc. Enferm. USP 1985, 19, 213-223 (In Portuguese).

27. Pinheiro, M.C.D.; Lopes, G.T. A influência do brinquedo na humanização da assistência de enfermagem à criança hospitalizada. Revista brasileira de enfermagem 1993, 46, 117-131 (In Portuguese).

28. Medeiros, G.; Matsumoto, S.; Ribeiro, C.A.; de Borba, R.I.H. Brinquedo terapêutico no preparo da criança para punção venosa em pronto socorro. Acta Paulista Enfermagem 2009, 22, 909-915 (In Portuguese).

29. Kiche, M.T.; Almeida, F.A. Brinquedo terapêutico: Estratégia de alívio da dor e tensão durante o curativo cirúrgico em crianças. Acta Paul Enferm 2009, 22, 125-130 (In Portuguese).

30. Conceição, C.M.; Ribeiro, C.A.; de Borba, R.I.H.; Ohara, C.V.S.; Andrade, P.R. Brinquedo terapêutico no preparo da criança para punção venosa ambulatorial: Percepção dos pais e acompanhantes. Escola Anna Nery 2011, 15, 346-353 (In Portuguese).

31. Fontes, C.M.B.; Mondini, C.C.S.D.; Fernandes, M.C.A.; Bachega, M.I.; Patrisi, M.N. Utilização do brinquedo terapêutico na assistência à criança hospitalizada. Rev. bras. educ. Espec. 2010, 16, 95-106 (In Portuguese).

32. Weber, F.S. A influência da atividade lúdica sobre a ansiedade da criança durante o período pré-operatório no centro cirúrgico ambulatorial. J. Pediatria. Rio Janeiro. 2010, 86, 209-214 (In Portuguese). 


\title{
The Role of Play in Children's Palliative Care
}

\author{
Sue Boucher, Julia Downing and Rise Shemilt
}

\begin{abstract}
Play is the universal language of childhood and the time and opportunity to play is every child's right. The role of play as a vehicle for communication, a tool for distraction and its value in the holistic development of a normal child is without dispute. The role and value of play increase proportionately when a child is made more vulnerable through illness or disability. Despite this, providing time and opportunities to play can be overlooked or considered to be of little importance or relevance when the focus of the adult carers is the amelioration of clinical symptoms of the illness and on lessening the psychological impact the illness may have on the child. This paper outlines the role and the value of play as an integral component in the provision of palliative care for children with chronic, life-threatening and life-limiting conditions. It will show how providing appropriate equipment, sufficient time and relevant play opportunities not only improves the very sick child's psychological wellbeing, but also allows the child to cast aside the confines and restrictions imposed upon them by their illness and for a few golden moments to be nothing more than a child at play.
\end{abstract}

Reprinted from Children. Cite as: Boucher, S.; Downing, J.; Shemilt, R. The Role of Play in Children's Palliative Care. Children 2014, 1, 302-317.

\section{Introduction}

“The sky's awake so I'm awake and I have to play".

(Princess Anna from Disney's Frozen)

It is generally agreed that play is an important part of children's development, education and learning, and that play develops with the mind, and the mind develops with play [1-6]. Play is the language of children. Play is the "work" of children. Play is the way that children learn about their world, become competent at skills, learn to cooperate with others and gain mastery over their emotions. Play is what motivates children to get out of bed in the morning. Think of children and one thinks of play. Mention toys and one thinks of children. However, thoughts of very sick children or children with severe limitations or restrictions on their mobility, their stamina or their cognitive capacity do not as quickly turn to thoughts of toys and play. As responsible adults our overwhelming impulse when faced with a very sick and vulnerable child is to find ways to improve that child's health, take away distressing symptoms and to provide the most appropriate medications and therapies. It does not sit well with us that children suffer and die, but they do. It is estimated that globally around 18,000 children under the age of 5 years will die each day, a figure which equates to around 11 million children dying every year [7].

While more than $50 \%$ of these deaths are from preventable causes [7] there are still millions of children who will die this year or whose lives are threatened by diseases such as cancer, heart disease and genetic conditions. These children live with conditions which will shorten their lives 
and lead to their death either in childhood or early adulthood [8]. While still not universally accessible [9,10], all children with life-threatening and life-limiting conditions have the right to receive palliative care which aims to ameliorate the unpleasant symptoms of the illness or condition and improve the quality of life of the sick child and that child's family [10-13].

When a child is diagnosed with an illness or condition likely to considerably shorten their lifespan, there are many challenges as well as new and frightening experiences that both the child and the child's family will inevitably face. These experiences can and often do overwhelm the child, the parents and family members and all those close to the family. The provision of palliative care from the moment of diagnosis allows the "breathing space" for those who care most for the child to adjust and to continually readjust to their new reality.

"When my son was diagnosed I felt as if all my self-esteem had disappeared. I could not see my future, and I felt like my family was a freak show for everybody to look at. All I could think about was his death and thoughts of this preoccupied everything I did'. [14] (p. 7)

These words of a mother whose child was diagnosed with a life-limiting illness illustrate this feeling of devastation and loss of control. Palliative care providers walk the journey from diagnoses, through to the end-of-life and into bereavement along with the child and the child's family, providing appropriate and compassionate support whenever and wherever it is needed. However, despite the devastating consequences of a terminal diagnosis, the child continues to have all the unique and ever-evolving needs, desires and the rights of any other child [15]. The overwhelming urge and desire to play still exists, indeed, it could be argued that because of the benefits of play, these children have an even greater need to play than other children [6] as can be seen in the case study in Box 1 .

Box 1. Case Study.

Sunflower House Children's Hospice in Bloemfontein, South Africa is seldom without the sound of children playing and their noisy chatter and laughter. While the children cared for at this hospice all have an illness or condition that threatens or will likely shorten their lives, on this warm afternoon in December 2008 most looked remarkably robust and were engaged in exuberant play, both in and out of doors. I came across Lebo lying in a small, quiet room with just one bed. It was a room, I was told, often used by the sickest children-those whose deteriorating health prevented them from coping with the normal day-to-day activities of the hospice. It was also used at times for those nearing the end of life. Almost 7 years old, Lebo looked closer to 4; his stunted growth the result of congenital heart disease. His energy levels were depleted despite the oxygen being fed to him via a saturator. Any pain he had was well controlled but there was no mistaking the anxiety and sadness in his eyes as they followed me into the room. We did not share a common language but no words were needed for me to know that he would rather be playing with his friends. While he had managed to tear the paper wrapping off a gift he'd been given to reveal a plastic fishing rod with a handful of colourful fish, the stiff packaging had proven too much for Lebo so the toy lay still unopened on the bed. 
Releasing the toy for him and without words we began to play together. I pretended to be completely inept at catching the fish which made him smile. I clapped whenever he caught a fish, which delighted him even more. I hid the fish in the folds of the bedclothes and he found them again to raspy giggles. For a while we played together and Lebo smiled and laughed and clapped in delight. When I had to leave I was rewarded with the sweetest smile and a wave. Lebo died not long after my visit, an event not unexpected as he had fought to live almost every day of his short and life and had faced many difficulties, both social, emotional and physical. But for a few golden moments of time on that warm December day Lebo was able to be nothing more, and most certainly nothing less, than a child at play.

\section{Children's Rights and Play}

Article 23 of the UN Convention on the rights of the child [16] calls upon all parties to recognise that a mentally or physically disabled child should enjoy a full and decent life, in conditions which ensure dignity, promote self-reliance and facilitate the child's active participation in the community (p. 8). Article 31 of the same convention calls upon all parties to recognise the right of the child to rest and leisure, to engage in play and recreational activities appropriate to the age of the child and to participate freely in cultural life and the arts. Article 31 also calls upon all parties to respect and promote the right of the child to participate freely in cultural and artistic life and encourage the provision of appropriate and equal opportunities for cultural, artistic, recreational and leisure activity (p. 10).

The International Children's Palliative Care Network (ICPN), the only organisation working globally to champion the rights of life limited children, published a charter of rights of life limited and life threatened children [17]. The Charter states that, wherever possible, life limited and life threatened children be provided with opportunities to play, access leisure opportunities, interact with siblings and friends and participate in normal childhood activities.

\section{Palliative Care for Children}

Palliative care aims to optimise quality of life in the face of an ultimately terminal condition. The World Health Organization (WHO) defines palliative care for children as "the active total care of the child's body, mind and spirit, (which) also involves giving support to the family. It begins when illness is diagnosed, and continues regardless of whether or not a child receives treatment directed at the disease. Health providers must evaluate and alleviate a child's physical, psychological, and social distress" [18]. Palliative care is not a single intervention; it is a philosophy of care. It can be seen as a thread that weaves through the lives of all children with a life limiting illness, often alongside active interventions and treatment.

Palliative care for children is appropriate from the time of diagnosis, even when there is hope for a cure; it continues throughout the trajectory of the illness and, should no cure be possible, supports the child and family through death and into the bereavement period for as long as it is needed [18]. Children and young people with life-limiting or life-threatening conditions have distinctive palliative care needs, which differ significantly from those of adults [15,19]. For example, 
communication with children is often more challenging and their understanding of death and dying is not the same as that of adults [15].

Ideally, this care is provided by a multi-disciplinary team of professionals that could include doctors, nurses, psychologists, social workers, counsellors, physiotherapists, play therapists, music therapists, educators and any others, according to the specific and individual needs of each child and the resources available [20]. Members of this multi-disciplinary team undergo specific training in order to be effective in lessening any physical, social, psychological, emotional, cognitive or spiritual suffering the child and family members' may experience.

\subsection{Where is Palliative Care for Children Provided?}

Palliative care for children can be delivered in a diversity of settings, including a hospital, an out-patient clinic, an in-patient care unit, a purpose built children's hospice, a community centre, or in the child's own home [18]. The important thing in the provision of palliative care for children is that palliative care is a philosophy of care that should be provided wherever the child and their family are being cared for, and the model of care delivery will vary according to culture, resources and family preferences.

\subsection{Eligibility Criteria}

Eligibility criteria for children's palliative care differ widely according to the specific service required and geography. The stage of the illness will determine what level of palliative care is required while geography influences who is eligible to access available services. For example, in sub-Saharan Africa, most children accessing palliative care services have HIV and/or cancer [21,22], and the same is true for adults; in the United Kingdom, however, the breadth of the disease profile of children who can receive these services is expansive and very different from that of adults. Some children will need respite care and some long-term access to services, while others will have only a few days to live [23].

In order to help identify children in need of palliative care, the Association for Children's Palliative Care (now called Together for Short Lives) and the Royal College of Paediatrics and Child Health developed categories of children with life limiting and life-threatening illnesses [24,25]. The categories act as a guide, but the most important factor is not identifying which category fits a child but ensuring that the child has access to palliative care [22]. The four categories are: (1) life-threatening conditions for which curative treatment may be feasible but could fail; (2) conditions for which there may be long phases of intensive treatment aimed at prolonging life, but premature death is still possible; (3) progressive conditions for which there is no curative treatment; and (4) conditions that are not considered progressive but are characterised by severe neurological disability, which may cause the patient to deteriorate unpredictably [24].

\section{The Effect of a Life-Limiting Illness on a Child}

The effects of any chronic illness are likely to be pervasive, particularly if the illness threatens or will limit the life of the child. There is likely to be a significant amount of stress and anxiety 
experienced by the child. In addition, limitations due to illness often place obstacles in the way of normal development.

Apart from the very obvious physical effects that any chronic or life limiting illness has on the child, Goodman [26] lists common psychological problems experienced by children with chronic and life limiting illnesses to include the internalisation of problems leading to anxiety, depression, fear, hopelessness, helplessness, loss of control and frustration; the externalisation of problems which leads to aggression, noncompliance and withdrawal; somatic complaints such as pain and impaired functioning; self-concept issues manifesting in poor self-image and low self-esteem and social and educational difficulties such as academic and learning problems and decreased or deficient social competence.

Particular problems will be associated across different illnesses and for different reasons. For example, cognitive deficits are a possible complication for children who have had cranial radiation and for children who have had strokes.

How a child responds and ultimately adjusts to a diagnosis will differ according to a variety of factors, including the type of illness and the effect of the treatment on the child, the child's age, mental capacity and personality. Other factors influencing a child's response include:

- The degree to which the illness impairs the child's ability to continue with normal activities and functioning, e.g., a child with cancer may have sporadic school attendance thus impacting academic progress.

- The involvement of the brain, e.g., if there are learning problems and loss of social skills.

- The severity and the course of the illness.

- The child's view of death — as the illness progresses their fear of death may heighten

- The type of medical procedures and their experience in hospital

- The way the family functions and the effect of the illness on the family will influence the child. The child copes best when a family is cohesive, flexible, supportive, and communication is open and clear.

- The internal resources of the child pre-illness, for example how they cope in stressful situations.

- External resources and support systems: adequate outside support can have a positive effect on the child and family's adjustment and is related to personal, financial and geographic factors [26].

\section{The Needs of the Life-Limited Child}

"Food, toys and love are what we need to live." (4 year old child) [27] (p. 112)

"If kids are normal, not sick, they like to be treated special. But if kids have a disease, they wanted to be treated normal." (11 year old girl) [27] (p. 82)

The second of these two statements from children, recorded in the book "Armfuls of Time" [28] reflects the duality experienced by children with a chronic or life-limiting condition. Their longing for a normal life and to be treated as "normal" children while simultaneously coming to terms with the "abnormal" circumstances their illness or conditions have thrust upon them and their families. Sourkes makes the point that parents are faced with the difficult task of providing all the care and 
support required by the illness while making every effort to keep the child's life as normal as possible, which at times still includes the need for discipline and boundary setting. It could mean finding a way for the sick child to attend school whenever possible or providing opportunities for them to socialise with their friends. This, says Sourkes, fosters self-esteem and communicates a critical message to the child that while the illness may be abnormal, the child remains normal in their eyes [28].

Love, respect and dignity are just as important for children with a life limiting illness as for adults [29]. The University of Rochester Medical Center [29] suggests that the dying child has specific psychosocial needs which include: allowing the child to partake in age-appropriate activities and play; allowing the child to communicate openly and honestly, to express their fears and anger and to be listened to in a non-judgemental manner; ensuring the child has as much independence and control as is possible within the limits of their illness whilst respecting boundaries and age-appropriate limits; respecting the child's spiritual needs and allowing them to express these as appropriate according to their culture and background; and the need for reassurance that they are not alone, and that they will be missed by their loved ones when they die.

In their book on developmental and spiritual issues of dying children, Jones and Weisenfluh [30] contend that children facing life-limiting and life-threatening conditions have unique psychosocial and spiritual needs and those who provide care need to create interventions and models of support that will meet these needs. They make the point that after reaching a certain age or cognitive level children have the capacity for autonomy, choice, and thoughtful decision-making and should be included throughout the treatment process and in end-of-life decisions. At the same time, clinicians caring for dying children should remember that they continue to be children throughout the illness and dying process. Consequently it is important for these professionals to maintain an understanding of the developmental stages of children as defined by Piaget [31] and how these will in turn interact with the illness and the dying process.

Jones and Weisenfluh [30] state that one of the greatest needs of children with a life limiting illness is for those providing care to be honest and to tell them exactly what is happening to them. This approach allows the dying child a modicum of control and the opportunity to express their own choices. Questions the children may have include "Will you come with me?" "What does heaven look like?" "Can I bring my toys?" "Will my mom and dad be ok?" "Will it hurt?" "Who is God?" "Will you remember me?"

To be able to deal with these questions children need to have people caring for them who have a firm grasp of a child's cognitive abilities and of developmental stages in order to contextualise and provide appropriate responses to the questions they ask and concerns that they raise.

In summary, the dying child needs to participate in age appropriate activities that allow them to "just be children" while providing opportunities for them to experience a level of independence and control. They need to be provided with opportunities and the means by which to express their fears and anxieties and to communicate their questions and concerns about their own death in a non-threatening environment with carers who will respond appropriately. They need to participate in activities that will allow them to continue along physical, social, emotional and cognitive developmental pathways in order for them to reach their full potential, and despite their 
illness, they still need to be given boundaries, to learn self-control and how to best inhabit their own humanity.

\section{The Role of Play in the Provision of Children's Palliative Care}

\subsection{What is Play?}

Definitions on play abound, each of them differing in accordance with the primary focus of the definer. In the General comment No. 17 on Article 31 of the UN Convention on the Rights of the Child [32], the legal definition of play is recorded as:

"behaviour, activity, or processes initiated, controlled and structured by children themselves and it takes place whenever and wherever opportunities arise. Caregivers may contribute to the creation of environments in which it takes place, but play itself is non-compulsory, driven by intrinsic motivation and is undertaken for its own sake, rather than as a means to an end. It involves the exercise of autonomy, physical, mental or emotional activity, and has the potential to take infinite forms, either in groups or alone. These forms will change and be adapted throughout the course of childhood. The key characteristics of play are fun, uncertainty, challenge, flexibility and non-productivity. Together, these factors contribute to the enjoyment it produces and the consequent incentive to continue to play. While play is often considered non-essential, the Committee reaffirms that it is a fundamental and vital dimension of the pleasure of childhood, as well as an essential component of physical, social, cognitive, emotional and spiritual development." [32] (pp. 5-6)

Gray [33], defines play as a confluence of several characteristics which he distils to the following five:

1. Play is self-chosen and self-directed; players are always free to quit. Play is therefore what one wants to do at that moment and gives a feeling of liberty. Grey also makes the point that when adults play with children they should resist the urge to control the play as children may feel obliged to continue even when they do not wish to do so.

2. Play is activity in which means are more valued than end. The focus on the process and not the product of any play activity effectively removes any fear of failure. This also gives the player the freedom to experiment with new ways of doing things.

3. Play has structure, or rules, which are not dictated by physical necessity but emanate from the minds of the players. The child is willing to accept the rules of the game only because at any moment, he or she has the freedom to choose to leave it. In agreement with Vygotsky, who makes the point that the child's desire to play is so strong it becomes the motivating force for self-control [34], Grey contends that "the greatest of play's many values for our species lies in the learning of self-control... Everywhere, to live in human society, people must behave in accordance with conscious, shared mental conceptions of what is appropriate; and that is what children practice constantly in their play. In play, from their own desires, children practice the art of being human." 
4. Play is imaginative, non-literal, mentally removed in some way from "real" or "serious" life. It is "serious yet not serious, real yet not real. In play one enters a realm that is physically located in the real world, makes use of props in the real world, is often about the real world, is said by the players to be real, and yet in some way is mentally removed from the real world." The role of fantasy and imagination is central to most forms of play and is governed by rules within the minds of the players and not by the laws of nature. For example a broom can be a horse or, as in the game of chess, a particular shaped piece of wood can be a castle. Thus through play the child learns to take charge of the world and not simply respond passively to it. Children are also able to switch from being completely absorbed in the fantasy of the game, to returning to reality as needed - they are able to distinguish between real and pretend yet at times prefer to stay in the "magic" of the game as opposed to re-entering the "real world".

5. Play involves an active, alert, but non-stressed frame of mind. Grey asserts that this last characteristic follows naturally from the other four. Because of the very nature of play, the player is freed from the "strong drives and emotions that are experienced as pressure or stress." Some refer to this state of play as "flow" where attention is so attuned to the activity, there is reduced consciousness of self and time.

In Grey's opinion [33], the more fully an activity entails all of these characteristics, the more inclined most people are to refer to that activity as play, including the players themselves. He also notes that all of the characteristics describe the motivation or attitude that the player brings to the activity, rather than the activity itself.

Play is central to the life of the young child. It occupies most of his time between daily routines. It contributes to every single aspect of his development and lays the foundation for almost everything that he learns before he goes to school. Play is the means by which the child explores and masters his world and the non-verbal expression of his experience of reality [6].

\subsection{Understanding the Needs of the Dying Child through Play}

"Whoever wants to understand much must play much."

Gottfried Benn [35]

In her paper on the use of play therapy in paediatric palliative care, van Breeman tells us that in order to provide comprehensive care for the dying child, nurses can expand their role and offer support to the parents or caregivers, listen and reflect the child's hopes and fears expressed through the child's play, and facilitate the development of positive family relationships and healing during the dying journey [36].

van Breeman refers to McDonald and McIntyre's [37] assertion that the manner in which individuals gain knowledge and a sense of value from their lives is through the experiences of the body and the interpretation of those experiences by the mind. In a similar way to adults, children also seek to make sense of their experiences in living and dying. There is a widely held belief in palliative care that patients should be considered the ultimate experts on their own lives. 
van Breeman concludes that this includes children, who, regardless of their age, need to be given opportunities to share their history and incorporate it into their dying journey [36].

One of the most effective ways to allow this history telling is for those providing care to a dying patient to take the time to listen to their narrative. This provides the insight needed to experience what the person is feeling, how they want to be treated and how much they are ready to hear. These narratives are usually told via the spoken or written word. Children will however differ in their ability to use language to tell their story, due to their illness and/or stage of development, thus utilising play instead [36].

Play provides children with a safe and acceptable way to deal with the fallout from traumatic experiences. Trauma is "an impingement that occurs before the individual has developed mechanisms that make the unpredictable, predictable" [38] (p. 151). The devastating impact of a life threatening illness on the child qualifies as trauma. Winnicott, the first British paediatrician to become a psychoanalyst, stressed the importance for the young child of the preservation of a certain amount of illusion, and avoiding a sudden insistence on reality [39]. The child with a life-threatening illness faces the ultimate threat of loss of life and it is fair to say that in that moment of diagnoses, he or she loses a critical aspect of childhood.

In her book Armfuls of Time, Sourkes contends that "the overwhelming nature of the illness cannot be approached by reality alone. Paradoxically, the illusion afforded by play is what allows reality to be integrated. Through play, the child can advance and retreat, draw near and pull away from the intense core. These tentative forays allow the child to contain and master the experience." She goes on to say that the fantastical world of the child at play should not be seen as avoidance of the truth because "illusion is translucent, if not transparent, and thus reality shines through for both the child and the therapist even when not addressed directly by either" [27] (p. 6).

Sourkes reminds us that children are not inclined to play when there is evidence of developmental disorders, severe psychopathology, or deprivation. It is also not unusual for the trauma of a life-threatening illness to temporarily extinguish the child's capacity for play. However, within the context of psychotherapy, progress towards restoration can be seen when a child's play returns to its former level of animation.

Thus, for children with life-limiting illnesses, or for children who have experienced trauma and stress as a result of a life-threatening diagnosis, play is the most natural means by which they can offload aggression, come to terms with the trauma of illness and impending death and attempt to take control of their world. Through play the child expresses traumatic fixations, conflicts and hostilities. The child also uses play to relax tension and anxiety [6].

\subsection{Play Therapy in Children's Palliative Care}

"Through play a child is able to release pent-up feelings of anxiety, disappointment, fear, aggression, insecurity, and confusion. Bringing these feelings to the surface encourages the child to deal with them, learn to master them, or abandon them. Through symbolic representation, the child gains a sense of control over events that seem uncontrollable in reality. Often, children are unable to verbally express what they 
are feeling; thus, in play therapy, toys serve as children's words and play as their language." [40] (p. 240)

Whilst all children in palliative care have the need and right to play to express, explore and understand their experience and thoughts and feelings in relation to this, some children may additionally benefit from play therapy - a specific therapeutic intervention which uses play as the language through which the therapy takes place.

Based on a number of psychological theories, the use of play as a therapeutic intervention can be traced as far back as 1919. The works of Axline [41] and Oaklander [42] are probably the most significant to the growth of the discipline. There are two major approaches in play therapy, these being "Non-directive play therapy" and "Directive play therapy." It is common for today's practitioner to use a combination of both these approaches in accordance with the particular circumstances [43]. See Example 2. for Axline's Eight Basic Principles of Non-Directive Play Therapy.

Play therapy can be defined as a specific counselling approach "in which games, toys and mediums such as clay, drawings and paint are used to help a child or adolescent to express their emotions, thoughts, wishes and needs. It helps them to understand muddled feelings and upsetting events that they have not had the chance or the skills to sort out properly. Rather than having to explain what is troubling them, as adult therapy usually expects, children use play to communicate at their own level and at their own pace, without feeling interrogated or threatened" [45]. Much of current play therapy practice is based upon the work of Virginia Axline [41], who is credited with being the inventor of non-directive play therapy.

In the 1974 publication of her book, "Play Therapy" Axline [41] asserts that there is a frankness, and honesty, and a vividness in the way children state themselves in a play situation. Their feelings, attitudes, and thoughts emerge, unfold themselves, twist and turn and lose their sharp edges. The child learns to understand himself and others a little better and to extend emotional hospitality to all people more generously. Bit by bit, with extreme caution, the child externalizes that inner self and states it with increasing candour and sometimes with dramatic flair. He soon learns that in this playroom with this unusual adult he can let in and out the tide of his feelings and impulses. He can create his own world with these simple toys that lend themselves so well to projected identities. He can be his own architect and create his castles in the sand, and he can people his world with the folks of his own making. He can select and discard. He can create and destroy. He can build himself a mountain and climb safely to the top and cry out for all his world to hear, "I can build me a mountain or I can flatten it out. In here I am big!” [41] (Preface).

Box 2. Axline's Eight Basic Principles of Non-Directive Play Therapy [42].

The therapist:

- Must develop a warm and friendly relationship with the child.

- Accepts the child as she or he is.

- Establishes a feeling of permission in the relationship so that the child feels free to express his or her feelings completely. 
- Is alert to recognise the feelings the child is expressing and reflects these feelings back in such a manner that the child gains insight into his/her behaviour.

- Maintains a deep respect for the child's ability to solve his/her problems and gives the child the opportunity to do so. The responsibility to make choices and to institute change is the child's.

- Does not attempt to direct the child's actions or conversations in any manner. The child leads the way, the therapist follows.

- Does not hurry the therapy along. It is a gradual process and must be recognised as such by

the therapist.

- Only establishes those limitations necessary to anchor the therapy to the world of reality and to make the child aware of his/her responsibility in the relationship.

(Source www.playtherapy.org.uk [44])

During non-directive play therapy, the therapist will behave in ways that will convey to the child the security and opportunity to explore not only the room and the toys but himself in this experience and relationship

Children communicate through words, body language and play [15,41] and Sourkes [27] contends that when children are given free rein to play, they are able to communicate their fears, hopes and allow observers to gain a deeper understanding of their situation. Those with an understanding of play therapy are able to use play as the medium to develop a therapeutic relationship with the child which in turn allows discussion about death to be a normal part of a child's experience [36]. van Breeman cautions that learning to see and hear play should not be confused with playing with children. "Children's storytelling may occur using a sand tray, painting, dress-up, big-energy, drawing, and/or playing with archetypes. Children can express feelings about their family, how they view their illness, what they need to feel supported, how they want to live and who they need in their dying journey" [36] (p. 512).

\subsection{The Therapeutic Role of Play in Children's Palliative Care}

All children receiving palliative care need to play and whilst not all of them will need play therapy, the need for this type of therapeutic intervention will be higher within this more vulnerable population.

When considering the therapeutic role of play in children's palliative care we are again reminded of the duality of these children who have a strong need to feel normal while their illness or condition imposes many additional needs upon them thus making them feel "different" and "abnormal". Play has a role in responding to both the universal, but often overlooked, and the additional needs of these children. It does this by:

(a) Fulfilling the universal or basic needs of all children, including those in palliative care where the urge to play still exists. The role of play here is to support the developing mind of the child to learn about the world, to become competent at skills and master emotions. 
Play is a safe process in which the child takes control in expressing, exploring, experimenting and understanding their reality without failure and with the overall aim to master their experience.

(b) Fulfilling a specific psychosocial need existing in children in palliative care. The lived experience of a child in palliative care is characterised by stress, anxiety, obstacles to normal development, depression, fear, and loss of control, which in turn affects psychological, social and academic functioning. These children have additional needs to those of children not in palliative care such as the need for open and honest expression and communication with adults involved in their care, exploration and understanding of the dying process and involvement in end of life decisions.

While it is possible for unstructured play to adequately address both these needs, those who care for children in palliative care should be aware of when play therapy is indicated to allow a child the opportunity to express their fears and concerns.

The following case study from Sunflower Children's Hospice in Bloemfontein, South Africa and written up on the ICPCN website [46], demonstrates the therapeutic value of play in the context of children's palliative care.

A young girl of 14 years who had a name that meant "Unwanted" in South Sotho was admitted to Sunflower House Children's Hospice in Bloemfontein, South Africa. She was HIV infected and had advanced disease with severe malnutrition and depression. She did not make eye contact with the staff and sat outside on her own just gazing into space, unwilling to play with other children. Her family history showed she had been living with her grandmother after her mother died, and her father's whereabouts were unknown. An occupational therapy student spent time with her trying to get her interested in games and activities, without success at first. Another girl of her age tried to interact with her, also without success. The psychologist reported that she suffered from a very poor self-image and felt worthless; and said she just was waiting to die.

The occupational therapist (OT) then brought along two dolls, dressed alike, and the child became interested in these dolls, enjoying dressing them in different clothing and playing with their hair. Eventually she started to make up a story - telling the OT that the one doll was called by her own name and identifying why she felt depressed, sad and lonely-and that she had never felt loved and wanted. The other doll she spoke of as the child she would like to be-happy, loved and with a dream for a future as a nurse. Over the course of two weeks, she gradually spent more time with the "happy" doll and eventually gave the other doll to another child. Her attitude changed to match that of the doll she played with-she responded to hugs and would sit on a staff member's lap; she smiled and laughed with the other children; and she made friends with another young girl in the hospice. At the end she was very frail and could not keep any food down. Despite this, even on the day she died, she would insist on being amongst the other children in the garden, trying to eat whatever they ate, and she held her special doll in her hand, even when she lay dying. Needless to say, the doll was buried with her. 


\subsection{Recommendations Regarding Play in Children's Palliative Care}

The following recommendations will allow the child to access play to fulfil their universal needs as children and their additional needs on account of their life limiting illness or condition.

- An encouragement for those supporting the child to not overlook the need and right of the ill child to play and therefore to not overlook opportunities, time and equipment needed to facilitate this play;

- An awareness and appreciation within health, social care and related professions of the importance of play for children in palliative care, and their potential role in facilitating play and listening to the child's message as communicated through the play. Specific training for professionals regarding how to listen to the child through play could be useful here.

- Access to specialised play therapy interventions for those children who would benefit from such a provision.

\section{Conclusions}

A child receiving palliative care not only has the right but has an overwhelming need for time to be a child, to engage in childish pursuits such as developmentally appropriate play. The dying child needs activities that have no chance of failure as a way to balance the feelings of defeat and loss of mastery that comes with a diagnosis of a life-limiting illness. More than anything, these children need opportunities to communicate openly and honestly, to be enabled to express their very real fears or their feelings of anger. They need to know that there is someone on their care team that they can talk to about anything that concerns them, including about dying. Children without the necessary verbal skills, the maturity or the full comprehension of what they are experiencing only have the medium of play through which to communicate these anxieties and concerns. Those involved in their care need to have the skill to "listen" to what the child is telling them through their play and to respond appropriately.

The child with a life-limiting condition needs to be allowed as much independence and control as the illness allows. The loss of independence as the child's body succumbs to an illness can cause withdrawal and depression. As play is self-chosen, self-directed and the child has the authority to stop at any chosen time, it is one of the few activities that provides the sick child with a sense of control and some liberation from any restrictions imposed upon them by their illness. The spiritual needs of the child and their need for reassurance that they are not alone in the dying process can be addressed through play and play therapy. Concerns about what will happen to them when they die, what will happen to their family and whether they will be missed, if not expressed verbally, may surface when a child is given the opportunity to participate in therapeutic play with carefully chosen toys and objects.

The role of play and play therapy to not only provide a pleasurable distraction and temporary respite from painful procedures and unpleasant experiences that accompany any life-threatening or life-limiting illness, is of inestimable value. Allowing the sick child the opportunity to escape from the real world with all its emotional trauma and painful procedures into a world of their own making, a fantasy world where they are the masters of their universe and they decide what magical 
powers they possess is a gift that only play can provide. However, the ability for the child to find a voice with which to express his or her innermost anxieties, fears and concerns and have these addressed makes the provision of a safe place to play, suitable toys to play with and regular play times in the presence of adult/s who have an understanding of play therapy and the therapeutic value of play vital elements in the delivery of good palliative care for children.

\section{Acknowledgments}

The authors would like to thank all the children, parents and professionals with whom they have worked over the years and who have contributed to their understanding about the importance of play in children's palliative care.

\section{Author Contributions}

SB drafted the paper and RS and JD reviewed and amended the draft. All authors reviewed and agreed upon the final manuscript for submission.

\section{Conflicts of Interest}

The authors declare no conflict of interest.

\section{References}

1. Saracho, O.N.; Spodek, B. Children's play and early childhood education: Insights from history and theory. J. Educ. 1995, 177, 129-149.

2. Hughes, F.P. Children, Play and Development, 3rd ed.; Allyn and Bacon: Boston, MA, USA, 1999.

3. Hurwitz, S.C. To be successful—Let them play! Child Educ. 2002 79,101-102.

4. Smith, D. How play influences children's development at home and school. J. Phys. Educ. Recreat. Danc. 2002, 66, 19-23.

5. Tsao, L. How much do we know about the importance of play in child development? Child Educ. 2002, 78, 230-233.

6. Boucher, S.; Amery, J. Chapter 3: Play and Development. In Children's Palliative Care in Africa; Amery, J., Ed.; Oxford University Press: London, UK, 2009; pp. 37-78.

7. UNICEF. Millennium Development Goals; Goal: Reduce Mortality. Available online: http://www.unicef.org/mdg/childmortality.html (accessed on 24 June 2014).

8. Together for Short Lives. Available online: http://www.togetherforshortlives.org.uk (accessed on 24 June 2014).

9. Knapp, C.; Woodworth, L.; Wright, M.; Downing, J.; Drake, R.; Fowler-Kerry, S.; Hain, R.; Marston, J. Pediatric Palliative Care Provision Around the World: A Systematic Review. Pediatr. Blood Cancer 2011, 57, 361-368.

10. Connor, S.; Sepulveda Bermedo, M.C. Global Atlas of Palliative Care at the End of Life; Worldwide Palliative Care Alliance: London, UK, 2014.

11. Gwyther, L.; Brennan, F.; Harding, R. Advancing palliative care as a human right. J. Pain Symptom Manag. 2009, 38, 767-774. 
12. Marston, J.; Boucher, S.; Downing, J.; Nkosi, B.; Steel, B. International Children's Palliative Care Network: Working together to stop children suffering. Eur. J. Palliat. Care 2013, 20, 308-310.

13. Downing, J.; Boucher, S.; Nkosi, B.; Steel, B.; Marston, J. Transforming children's palliative care through the International Children's Palliative Care Network. Int. J. Palliat. Nurs. 2014, 20, 109-114.

14. interACT. There's No such Thing as a Silly Question. Very Special Kids in partnership with the Gandel Charitable Trust: Melbourne, Australia, 2007.

15. Amery, J. Chapter 1: Introduction. In Children's Palliative Care in Africa; Amery, J., Eds.; Oxford University Press: London, UK, 2009; pp. 37-78.

16. United Nations. The UN Convention on the Rights of the Child; UN: Geneva, Switzerland, 20 November 1989.

17. International Children's Palliative Care Network (ICPCN). The ICPCN Charter for the Rights for Life Limited and Life Threatened Children. ICPCN, South Africa 2008. Available online: http://www.icpen.org/icpen-charter/ (accessed on 13 June 2014).

18. World Health Organization (WHO). Effective Palliative Care for Children 2002. Available online: http://www.who.int/cancer/palliative/en/ (accessed on 13 June 2014).

19. Hain, R.D.; Jassal, S.S. Oxford Specialist Handbooks in Paediatrics: Paediatric Palliative Medicine; Oxford University Press: Oxford, UK, 2010.

20. Vickers, J.; Chrastek, J.; Place of care. In Oxford Textbook of Palliative Care for Children, 2nd ed.; Goldman, A., Hain, R., Liben, S., Eds.; Oxford University Press: Oxford, UK, 2012; pp. 391-401.

21. Downing, J.; Marston, J.; Boucher, S. Children's palliative care in Africa. Aust. J. Cancer Nurs. 2010, 11, 3-10.

22. Downing, J.; Marston, J.; Fleming, E. Children's Palliative Care: Considerations for a physical therapeutic environment. J. Palliat. Care 2014, 30, 116-124.

23. Hain, R.; Heckford, E.; McCulloch, R. Paediatric palliative medicine in the UK: Past, present, future. Arch. Dis. Child 2011, 97, 381-384.

24. Association for Children's Palliative Care (ACT); Royal College of Paediatrics and Child Health (RCPCH). In A Guide to the Development of Children's Palliative Care Services: Report of the Joint Working Party; ACT/RCPCH: Bristol, UK, 1997.

25. Wood, F.; Simpson, S.; Barnes, E.; Hain, R. Disease trajectories and ACT/ RCPCH categories in paediatric palliative care. Palliat. Med. 2010, 24, 796-806.

26. Goodman, R.F. Children with chronic illness: The interface of medicine and mental health. Child Study Cent. 2001, 5, 1-6.

27. Sourkes, B.M. Armfuls of Time: The Psychological Experience of the Child with a Life Threatening Illness; Routledge: London, UK, 1995.

28. Sourkes, B.; Frankel, L.; Brown, M.; Contro, N.; Benitz, W.; Case, C.; Good, J.; Jones, L.; Komejan, J.; Modderman-Marshall, J.; et al. Food, Toys and Love: Pediatric Palliative Care. Curr. Probl. Pediatr. Adolesc. Health Care 2005, 35, 350-386.

29. University of Rochester Medical Center. Health Encyclopedia. Psychosocial Needs of the Dying Child. Available online: http://www.urmc.rochester.edu/Encyclopedia/Content.aspx? ContentTypeID=90\&ContentID=P03055 (accessed on 13 June 2014). 
30. Jones, B.; Weisenfluh, S. Pediatric Palliative and End-of-Life Care: Developmental and Spiritual Issues of Dying Children. Smith Coll. Stud. Soc. Work 2003, 73, 423-443.

31. Piaget, J. Cognitive Development in Children: Piaget Development and learning. J. Res. Sci. Teach. 1964, 2, 176-186.

32. UN Committee on the Rights of the Child (CRC). General Comment No. 17 (2013) on the Right of the Child to Rest, Leisure, Play, Recreational Activities, Cultural Life and the Arts (art. 31), 17 April 2013. Available online: http://www.refworld.org/docid/51 ef 9 bcc $4 . h t m l$ (accessed on 14th June 2014).

33. Gray, P. Freedom to Learn. The Roles of Play and Curiosity as Foundations for Learning. Psychology Today 19 November 2008. Available online: http://www.psychologytoday. $\mathrm{com} / \mathrm{blog} /$ freedom-learn/200811/the-value-play-i-the-definition-play-gives-insights (accessed on 12 June 2014).

34. Vygotsky, L.S. Play and its role in the mental development of the child. In The Role of Play in Development; Cole, M. Ed.; Soviet developmental psychology: An anthology. Armonk, New York, NY, USA, 1933/1977; pp. 76-99.

35. Gottfried Benn Quotes. Available online: http://www.justquotes.com/authors/gottfried_benn/ 13766 (accessed on 29 June 2014).

36. Van Breeman, C. Using play therapy in paediatric palliative care: Listening to the story and caring for the body. Int. J. Palliat. Nurs. 2009, 15, 510-514.

37. McDonald, C.; McIntyre, M. Reinstating the marginalized body in nursing science: Epistemological privilege and the lived life. Nurs. Philos. 2001, 2, 234-239.

38. Palombo, J.; Bendicsen, HK.; Koch, B.J. Guide to Psychoanalytic Developmental Theories; Springer: New York, NY, USA, 2009.

39. Winnicott, D.W. Playing and Reality; Routledge: London, UK, 1971.

40. Landreth, G.L. Innovations in Play Therapy. Issues, Process, and Special Populations; Brunner-Routledge: New York, NY, USA, 2001.

41. Axline, V.M. Play Therapy; Ballantine Books: New York, NY, USA, 1974.

42. Oaklander, V. 1978 Windows to Our Children; Real People Press: Lafayette, CA, USA. Play Therapy International. Available online: http://www.playtherapy.org/AboutPlayTherapy/ AxlinePrinciples.htm (accessed on 14 June 2014).

43. Play Therapy International. How does therapeutic play work? Available online: http://www. playtherapy.org/playhowdoestpwork.html (accessed on 14 June 2014).

44. Play Therapy International; About Play Therapy; Available online: http://www. playtherapy.org/AboutPlayTherapy/AxlinePrinciples.htm (accessed on 14th June 2014).

45. Play Therapy South Africa. What is play therapy?; Available online: http://www. playtherapy.co.za/what_is_play_therapy.html (accessed on 15 June 2014).

46. International Children's Palliative Care Network (ICPCN). Available online: http://www.icpcn.org/information/childrens-stories/ (accessed on 24 June 2014). 

Chapter 3:

Restorative Powers of Play 



\title{
Children's Play Environment after a Disaster: The Great East Japan Earthquake
}

\author{
Isami Kinoshita and Helen Woolley
}

\begin{abstract}
The Great East Japan Earthquake of March 11, 2011, together with the subsequent tsunami and nuclear power station accident, damaged a wide area of land. Children who experienced these terrible disasters and the post-disaster situation are still suffering in mental, physical and social ways. Children's play is an activity that they undertake naturally and which can help them recover from such disasters. This paper addresses the role of play, adventure playgrounds and other play interventions, including play buses, for the health triangle, which addresses mental, physical and social issues of children after the disasters. These interventions were shown to be effective because children could express their stress. This included play for their mental health, different body movements for their physical health and communication with playworkers and new friends for restructuring their social health. These three aspects relate to and support each other within the health triangle. An increase in childhood obesity and lack of exercise is an additional health issue in Fukushima. For a balanced recovery within the health triangle, more play environments should be provided and some improved. A child's right to play should be implemented in the recovery stage after a disaster.
\end{abstract}

Reprinted from Children. Cite as: Kinoshita, I.; Woolley, H. Children's Play Environment after a Disaster: The Great East Japan Earthquake. Children 2015, 2, 39-62.

\section{Introduction}

The World Health Organisation (WHO) describes health as a "complete state of physical, mental and social well-being (WHO, 1948 [1]) and this definition has been explained by some as a health triangle (Jenty [2], Ireland [3]). This concept of a health triangle was suggested by Araska Middle School in 1997 [4], when a graph was used to show the relation between the three different dimensions of mental, physical and social health.

Post-Traumatic Stress Disorder (PTSD), which can occur after a traumatic event, is one expression of a person not being in a complete state of good health. The phenomena of PTSD is classified into three types; (1) Re-experiencing the traumatic event; (2) Avoiding reminders of the trauma and (3) Increased anxiety and emotional arousal (Saylor, 1993 [5], Okuyama, 1996, [6]). Post-traumatic stress disorder (PTSD) suffered by children as the result of a disaster has been discussed by authors such as Saylor (1993) [5], who suggest that the symptoms differ depending on factors such as gender and age.

Although PTSD was understood to be a health issue in many parts of the world, it was not recognised in Japan at the time of the Kobe earthquake in 1995. However, the importance of play was understood by playwork volunteers from Setagaya Play Park in Tokyo who created an adventure playground in Kobe. The adventure playground was criticized, mainly by adults, because there was such a contrast between the children's play and the sad, mourning atmosphere of people who had lost families, 
friends, houses and all their resources in the earthquake. At times in the adventure playground children played "earthquake play" for which the playworkers and the executive organization were strongly criticized.

After the Kobe Earthquake, PTSD was recognized in increasing numbers of patients and as a result the importance of children's mental health care was acknowledged. As one aspect of mental care in Kobe area, pediatric doctors advocated children's play as one aspect of mental care to help release their stress and prevent PTSD by bringing children back to increased levels of normality in their daily lives (Okuyama, 1996) [6].

The UNISDR reports that, "30-50 percent of fatalities arising from natural events are children. The main causes of mortality in children are usually the same conditions that cause morbidity in non-emergency settings — children are vulnerable but disaster risk reduction can help minimize the risks from hazards" [7]. Disaster risk reduction can be improved by the daily play activities of children which allow them to know their local environment and to develop their risk management capability. In the case of the Tohoku triple disaster, the evacuation activities of children varied depending on how well they knew their locality which had been developed and absorbed through play in their daily lives. The effectiveness of evacuation was further influenced by children's training for such events. This is epitomized in the famous story known as known the Miracle of Kamaishi (Katada, 2012) [8], where nearly all 3000 children from the elementary and junior high schools were saved because of their repeated training in tsunami evacuation drills. It was also reported that in different areas children survived by climbing to higher ground they were familiar with in their daily play (Appendix 1) [9].

However, what happened to children's health after the triple disaster? Drawing upon the medical experience of the Kobe earthquake, the main focus on children's health after the Tohoku disaster was the prevention of PTSD, including flashbacks of the disasters. To this end, the care program concentrated on sending counsellors to the area. Professional counsellors were the only people working with children to help minimize their experience of flashbacks. Initially, there was no public program to provide playgrounds and promote children's play for their health. One year after the disaster, children in temporary housing had little, if any, play space (Woolley and Kinoshita, 2014) [10]. Four important factors in support of children's play were identified: Space, People, Interventions and Time. Adventure playgrounds, mobile play buses and cars and indoor playgrounds were initiated in the disaster area by both the voluntary and private sectors.

The United Nations General Comment No.17 states the challenges to be addressed in the realization of article 31 of the CRC (Convention on the Right of the Child). This asserts children's right to play, the lack of recognition of the importance of play and recreation, resistance to children's use of public spaces, balancing risk and safety, pressure for educational achievement, overly structured and programed schedules, neglect of article 31 in development programs, a lack of investment in cultural and artistic opportunities for children, the growing role of electronic media and marketing and commercialization of play [11]. As Japan was the only industrialized country of the eight consulted about article 31, it could have been expected that Japan would implement all these assertions. It appears, from an overview of post disaster policies for the whole area, that such challenges of cultural and social context may appear clearly after the disasters had happened. However, as already mentioned, there were some interventions such as adventure playgrounds, 
mobile play busses and indoor playgrounds which have contributed to play opportunities for children after the disaster. Here we will explore the relationship between health and those interventions.

As Masten and Narayan (2012) described, "research on pre- and post-disaster interventions to promote resilience in young people and families in mass trauma situations is a top priority [12]". However, there is not enough scientific data on this research. Joy and Howard Osofsky researched the aftermath of the disaster Hurricane Katrina. They summarized that "to sensitively help with evacuations and return to normalcy, responders must also be trained to understand the culture and traditions of the affected communities [13]. NPO Japan Adventure Playgrounds Association has been trying to establish adventure playgrounds so that they can be sustained by the local community. Some have criticized that "Resilience-building interventions may be ineffective and perhaps even harmful [14]". Thus, obvious interventions should be used carefully and attention paid to possible, unintentional effects. As Japanese adventure playgrounds include a strategy of community involvement, this intervention is similar to a community building strategy, as discussed in the case of Katrina's Children (Joy and Howard Osbone, 2007) [15].

\section{Methodology}

This article will now explore how children's play is supported in different contexts through interventions such as adventure playgrounds, play buses and cars and indoor play facilities and how these have become part of the provision for children's healthcare between the Kobe earthquake in 1995 and the Tohoku triple disaster in 2011. The paper does not address issues of physical health in a quantitative way but focuses on qualitative aspects of mental and social health with some relationship to physical health [16]. This paper is not based on evidence from a purely medical perspective, rather it reports some aspects of how children's play environments relate to the health triangle; It does this by taking a qualitative approach in the form of informal conversations and more structured conversations over the period between 2011 and 2014. Some of these conversations were held between the first author and play work staff and some involved both authors. The observation and interview research by both authors were conducted in spring of 2012 and 2014. The first author conducted additional interviews by telephone and e-mail. The purpose of the process was to establish the meaning of play in the reconstruction strategy, where some intervention was needed for the betterment of children's health. This may be considered as action research involving a responsive and iterative semi-structured approach. All the people interviewed were keen for their opinions and experiences to be shared with others worldwide.

\section{Results and Discussion}

\subsection{Play in a Post Disaster Context}

There was a clear professional focus on mental health and PTSD in the post disaster area of Tohoku, which is of course important, but children also need to develop their resilience and ability to overcome stressful events. The care children might need can vary depending on their situation. For children experiencing trauma, support from a professional counsellor is important. Others with less severe symptoms can be supported in alternative ways. 
Children's play can offer benefits to all three domains of the health triangle, each of which relates to the others. A focus on social relationships might also remove children's feelings of anxiety and encourage them to engage with other people.

Children's play may also contribute to brain development (Schonkoff, 2000) [17]. Free play can have a very important meaning linking physical and mental health (Play England, 2009) [18], while playing and walking provide children with more physical activity than most other activities (Mackett, 2004) [19].

Children's play has a role in releasing stress and PTSD; "Play is essential to the social, emotional, cognitive, and physical well-being" (Mulligan, 2012) [20]. Additionally, "Play and sporting activities are one of the best ways for children to deal with stress." (Child to Child Trust, web-site) [21].

Lisul (2004) [22] explained that play was a coping strategy after a stressful event. In the case of the bombing in Yugoslavia in 1999, she reported that a special type of repetitive (traumatic) play often occurred which was compared with the usual (creative) play, at a primary school, in Novi Sad, which had been heavily damaged during the bombing. Lisul (2004) reported that, from observations of children aged 6 and 7 years old, 19 of 23 children had an active and positive attitude to the traumatic situation. Among these 19 children, 13 were playing. She described "Most of these plays were 'war games' full of fights and anger, but children were able to think of reasons for war and solutions that would stop it through games. In some of the play, children were observed showing some characteristics of traumatic play and they were very precise in pointing out and explaining this. This is very important, because traumatic war games increased some problems and fears, and the children's ability to find solutions helped in their recovery" (Lisul, 2004) [22].

This understanding of traumatic play can be used as a lens to explore some of the play experiences of children in Japan in the aftermath of the earthquake and tsunami. Traumatic play such as earthquake play and tsunami play were seen in the adventure playgrounds. However, a discussion is still taking place in Japan as to whether this is a good thing or not, with some victims claiming that the atmosphere should be serious, not playful and others thinking that this might remind children of the stressful events but help to prevent flashbacks and PTSD.

\subsection{Adventure Playgrounds and Conflict in a Post Disaster Context}

There is not enough understanding of the role of adventure playgrounds after a disaster, although adventure play-based therapy for children with PTSD has been advocated [23] (Tucker, 2014).

The first adventure playground at Emdrup in Copenhagen was created during wartime in 1943, where children might play war games in the debris. Prof. Sorensen observed that children liked mischievous play and building using scrap wood found on a building site (Hurtwood, 1968) [24]. Hurtwood summarized the meaning of the adventure playground as "children build order in the chaotic situation" and introduced the concept of adventure playgrounds to England. So, the role of an adventure playground for children after a disaster, can be as Lisul mentioned "finding solutions helped in their recovery".

Arvid Bengtson explained that an adventure playground is an essential outlet in this situation of stress (Bengtson, 1972) [25]. Children can get rid of their superfluous energy and aggression can be sublimated. An adventure playground under good supervision can provide a repression-free area 
where children can develop independence and learn to stand on their own feet. This is not only beneficial to their physical health but also to their psychological well-being.

Duttner (1969) [26] explains the role of play as a control of experience based on Jan Piaget's theory that assimilation and accommodation of the local environment contribute to knowledge, understanding and development of people. Specifically, Duttner (1969) suggested that playgrounds can be similar to adventure playgrounds having opportunities for assemblage and dis-assemblage, including old tires, scrap lumber (with edges rounded), rope, cable spools, bamboo poles, canvas and burlap sacks, blocks, automobile parts, old mattresses, chairs, cardboard cartons, indeed an endless list of parts [26]. Noren-Björn wrote that the meaning of play for mental development was also based on Piaget's theory and Lill Peller's play theory. She further explained the role of play as part of the social and physical development of a child, from her survey at both unsupervised and supervised playgrounds (play park, adventure playground). She clearly understood that there was a greater variety of play involving social and physical development in a playground where there were playworkers [27]. The impact of play and adventure playgrounds in relation to the health triangle is demonstrated in Table 1 compared to counselling which had been provided as a government program.

Table 1. Health triangle and tasks for anti PTSD.

\begin{tabular}{|c|c|c|c|}
\hline & $\begin{array}{l}\text { Conditions Required to } \\
\text { Support the Reduction of } \\
\text { PTSD * } 1\end{array}$ & Counselling *2 & Play, Adventure Playground *3 \\
\hline $\begin{array}{l}\text { Mental } \\
\text { health }\end{array}$ & $\begin{array}{l}\text { Daily task; } \\
\text { deal with everyday issues; } \\
\text { less stress; feeling safe; } \\
\text { balance in lives. }\end{array}$ & $\begin{array}{l}\text { In a case of serious PTSD, } \\
\text { need to be cared for by } \\
\text { counsellors, overcome by } \\
\text { talking over time. }\end{array}$ & $\begin{array}{l}\text { Emotional experience, } \\
\text { If not so severe, to prevent PTSD, } \\
\text { by overcoming } \\
\text { through expression in play. }\end{array}$ \\
\hline $\begin{array}{l}\text { Physical } \\
\text { Health }\end{array}$ & $\begin{array}{l}\text { Body condition rest, exercise } \\
\text { and nutrition; no harmful } \\
\text { substances; } \\
\text { no disease }\end{array}$ & $\begin{array}{l}\text { Body condition (physical } \\
\text { health) relates to mental } \\
\text { condition. }\end{array}$ & $\begin{array}{l}\text { Moving about, inspired by the situation, } \\
\text { releases stress and promotes physical } \\
\text { development. }\end{array}$ \\
\hline $\begin{array}{l}\text { Social } \\
\text { Health }\end{array}$ & $\begin{array}{l}\text { Make/keep friends; get along } \\
\text { well in society; communication; } \\
\text { feeling not alone; } \\
\text { sense of "I did it" (achievement). }\end{array}$ & $\begin{array}{l}\text { Trust with the counsellor, } \\
\text { and supporting volunteers. }\end{array}$ & $\begin{array}{l}\text { Playing with friends; } \\
\text { communication with friends, } \\
\text { playworkers and other adults in the } \\
\text { playground; } \\
\text { social life in the community }\end{array}$ \\
\hline
\end{tabular}

References: * 1 Jenty (Webpage, 2014) [2], Lisul (2004) [22], Ireland (Webpage, 2014) [3], *2 Okuyama (1965) [6], F.Saylor (1994) [5] *3 Shonkoff (2000) [17], Child to Child Trust (2014) [21], Tucker (2014) [23], Hurtwood (1968) [24], Bengtson (1972) [25], Dutner (1969) [26], Noren-Björn (1982) [27].

There is little evidence to prove the importance of play in children's development in the context of disasters. However, there was a Japanese government research report which demonstrated evidence that children who played in nature had more sense of justice than those who did not (MEXT, 2012) [28]. Therefore, the evidence is currently only partial. However, it may be considered that play is too general a term to identify its benefits in this type of situation and that what may be important is the type of play children undertake; there is little evidence as to whether traumatic play is positive or negative. It is possible to hypothesize that it may be a mixture of both, as was seen in the adventure playgrounds in the aftermath of the disaster and as is further discussed in the rest of the paper. 


\subsection{Kobe Earthquake and Adventure Playground}

The Great Hanshin Earthquake (Kobe Earthquake) occurred at 5:46 on January 17, 1995. It measured 6.8 on the moment magnitude scale and M 7.3 on the Japan Meteorological Agency (JMA) magnitude scale. Approximately, 6334 people died, three people are still missing and 43,792 people were injured. Kobe city was seriously damaged. This was the worst earthquake disaster in Japan since the Great Kanto Earthquake of 1923.

Because many volunteers came to help and support the disaster area in activities such as rescue, evacuation centre activities, building temporary houses, repairing damaged houses and reconstruction, "volunteer" and "Non-Profit Organization" became popular keywords in Japan and resulted in the establishment of the Non-Profit Organization (NPO) Act in 1998.

Hideaki Amano was the first playworker at Hanegi Play Park in Tokyo (Appendix 2) and he went to Kobe on January 25, 10 days after the catastrophe, as a representative volunteer from Setagaya Play-Park. He and the other playworkers from Setagaya started an adventure playground activity at the corner of the park in the Nagata ward. At that time, about 250 people were sheltering in the park. Amano and his colleagues of Setagaya Play Park worked at this adventure playground for 5 months. At that time, PTSD was not recognized and the impact of children's play was not understood by the people around the playground, rather it offended them. Indeed, the adults around the playground became angry, when the children played earthquake play. It is easy to understand how the adults became angry in such a situation because most people were mourning the loss of family members or friends, houses, other property and social networks. The contrast between these lost physical and social landscapes and the children's play landscape in the adventure playground might have been offensive to some of the adult victims.

However, children are different from adults. They do not have property. Even though they had lost family members and friends and experienced a great shock, they would play if others were playing. Gradually they could express their inner trauma through play over time. As Amano has stated, not only the consultants involved in the mental care of children, but also specific types of play environments were needed in the evacuation and recovery process after the disaster.

In a similar way that Lisul described in Yugoslavia, traumatic play was also seen here in Japan. At first, there were children who were irritated, exploring anger and being extremely aggressive. This was symptomatic of PTSD, type 3: increased anxiety and emotional arousal. The children who had shown the symptom type 2 : avoiding reminders of the trauma, which is probably considered to be not as serious, joined in play influenced by the other children. The symptom of type 1: re-experiencing the traumatic event was evidenced in earthquake play. At that time, Amano and the other playworkers, together with other adults around the playground, were not aware of PTSD.

Amano explained traumatic play and the impact of the adventure playground in children's recovery in the aftermath of the Tohoku disaster in a newspaper article. He describes the transformation of traumatic play to creative play over time:

"It was the amusement place of the child" where I placed myself by force with a blue sheet at one corner of the refugee tent area in a park. 
At every distribution of boiled rice, a queue of almost 100 meters is made. We played with a child while roaring with laughter just beside the line. Both the sufferers of the disaster and the volunteers looked dubiously at the scene of our playground while emergency relief was still needed. Victims gathered day by day, and "the amusement place of the child" was frowned on.

However, everywhere was a refugee tent village, and both the school grounds and the park were full, and the place where a child could play freely did not exist anywhere.

Adults came to talk about their experiences of suffering in the month after the disaster. I hoped that a day would come when a child would express such an experience. After two months it was expressed in play.

"Seismic intensity 12 3!" 6-7 children get on the handmade desk which they had made with plywood and they huddle and rise slowly. "Seismic intensity 67 !' The leg of the desk, where the children are, breaks and so they fall down flop. Ah! The shout of joy of the children rings through the air.

Children show scraps of wood and they scrunch up newspaper and place it in a bin. They set fire to the end of the paper and flames rise while they look up. "They are starting to burn! A town burns, a school burns! They pile up more scraps of wood while crying and create a roaring fire. "Ooh!' a cry of joy.

For the adults who suffered from the disaster, this scene was unpleasant. However, it was one month before even an adult came to talk. The child who does not have words to talk about what is in his heart only has play as a way of expressing themselves. "Seismic intensity 7!" they break the leg of the desk, and your mind tries to understand the huge, unreasonable experience that they can never accept that it is easier to "burn" a town than it is to build it again.

This play might result in a child getting over and accepting the event which had happened.

Play is not simply about killing time. The children who suffered from the disaster must get over it by themselves somehow. They run around and blow off stream. They have a long talk with friends. They change an event that sometimes involves a serious injury into play that they can accept. The children build their world and express themself and heal themself.

In an unprecedented disaster, a child is obviously a victim. It is good to let a counsellor enter the stricken area to care for their emotional well-being, but a child has power to heal themself. Therefore there should be enough places for play" [29].

(From part of the article written by Hideaki Amano, Power of Play Healing Children, the Kyodo News, March 14, 2011. Translated by the authors.).

\subsection{The Great East Japan Earthquake and Adventure Playground}

The Great East Japan Earthquake (Tohoku Disaster happened at 14:46 on March 11, 2011. Its moment magnitude was M. 9.0 which was the biggest one in the history of Japan. Most of the coastal area was damaged by the Tsunami. The height of the tsunami was more than $10 \mathrm{~m}$ and $40.1 \mathrm{~m}$ at its highest, depending on the geographic condition. By June 14, 2014, 18,502 people had lost their lives or were missing. More than 400,000 houses and buildings were partially or completely destroyed. The number of evacuees peaked at more than 400,000 people but by May 15, 2014 [30] this had reduced 
to 258,219 . The affected area was immense and included the coastal area of municipalities from north of Iwate prefecture to south of Chiba Prefecture, a distance of more than $500 \mathrm{~km}$.

The nuclear power station accident caused by the earthquake and tsunami, which resulted in a meltdown of three of the plant's six nuclear reactors, increased the influence and seriousness of the damage. This incident measured Level 7 on the International Nuclear Event Scale, which is the same level as that of the largest nuclear incident in the world: the Chernobyl Disaster in 1986 [24]. Because of radioactive contamination, people had to evacuate immediately although their houses were and still are undamaged by the earthquake and tsunami. The incident resulted in the evacuation of over a further 300,000 .

This triple disaster is unique in the recorded history of the world. Although it is now more than three years on, many people are still living in temporary houses and many young families have decided not to go back to their home town and the population of the municipalities which suffered from the disaster has been decreasing, with the younger generation particularly affected.

The NPO Japan Adventure Playgrounds Association (JAPA) started a project building an adventure playground in the disaster area after, learning from the experience of the Kobe Earthquake and recognizing the importance of supporting play in the recovery of children suffering from the disaster. JAPA looked across a wide area for a suitable place to build an adventure playground and found a place at Ohya district on a hillside behind Ohya primary school where people had evacuated from the lower coastal area in Kesennuma city.

Preparatory work started in April 2011 and the playworker from Hanegi Play Park was sent to this new location. His nickname was "Kanpei”. Hideaki Amano and other playworkers came to help build the playground but children who had been evacuated to the school also helped. It was quite difficult to distinguish whether they were working or playing. In this case, Hideaki Amano and the other playworkers developed communication processes to get agreement to build the playground with the people of the community, the people who had evacuated at the school and teachers of the school. Through this process, two land owners kindly offered the use of their hillside land for the adventure playground because the land was not being used. Although adults had heard about this playground, they did not understand it. Some said "there are many natural spaces around this mountain for children, why do we need to make such a playground?" However, when they watched children gradually recover their smile by working and playing while building the playground, the adults also recovered their smile. Someone said "what a wonderful thing it is, to be able to see the children's smiles".

This adventure playground was named "Asobi-ba” (Figure 1), which in Japanese means playground. It has been gradually recognized and supported by the local community. Kanpei played a great role in communicating with local people to get their trust. An event involving the local community and residents of the temporary houses in the school ground, demonstrated the very good and close relationship between adults and children. In such a way, the health triangle of mental, physical and social domains looked very positive and different from other temporary housing sites. 


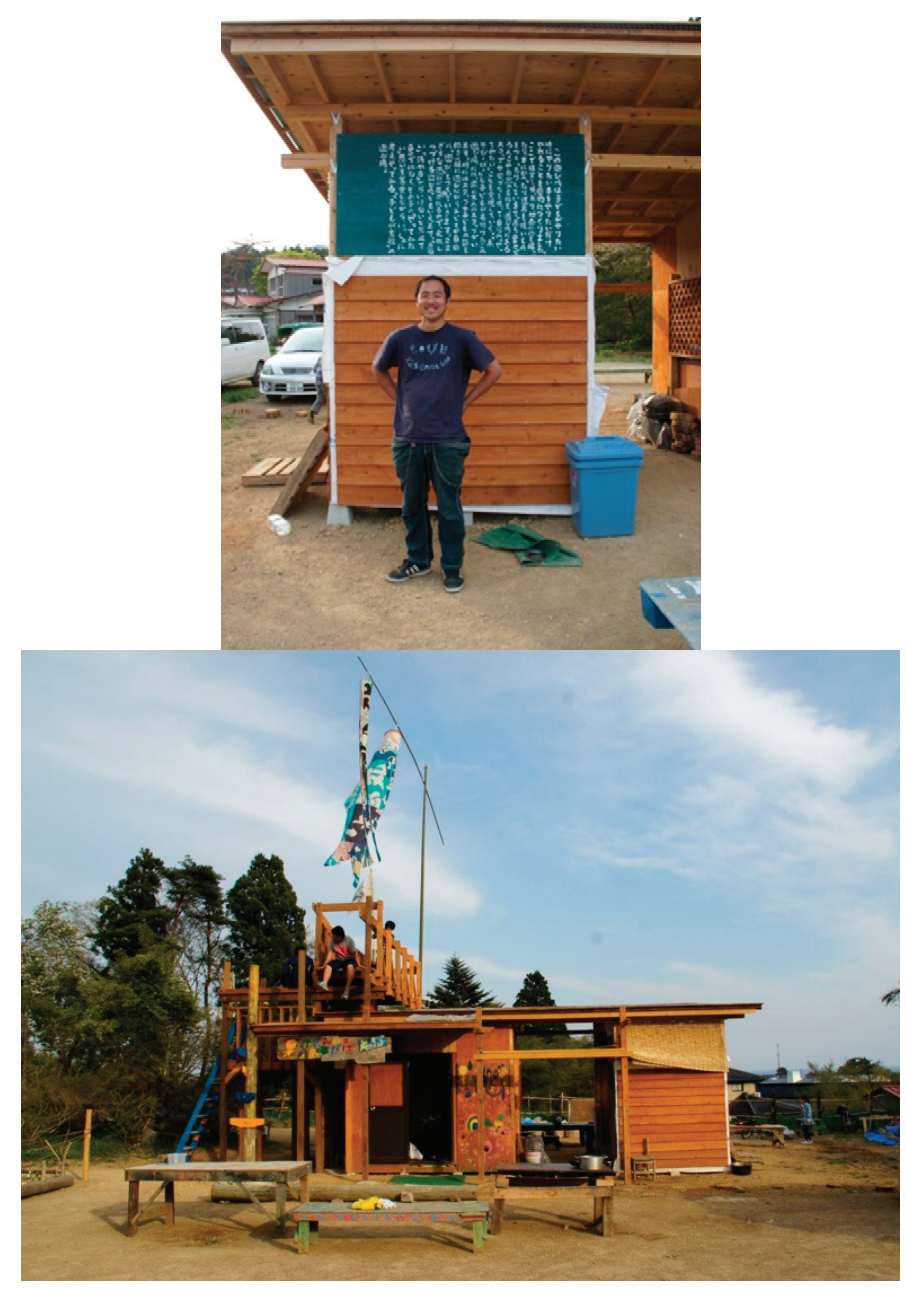

Figure 1. Adventure playground Asobi-ba in Kesenuma, playworker Kanpei (above).

Asobi-ba was mentioned in the mass media such as newspapers and television because it was attractive for the media to highlight what was going on in the disaster area. Media coverage increased the number of visitors to Asobi-ba. Among the visitors were those who were very impressed and wanted to build this type of adventure playground in their neighbourhood. After the initial success of the Ohya playground, adventure playgrounds and playground activities increased across the Tohoku area to about 25 as shown in Table 2.

Another playworker, nicknamed Buncha, came to support the adventure playground movement in other areas. In Koizumi district, again in Ishinomaki city, he helped with the building of another adventure playground. He also supported other areas if people wanted to build an adventure playground by consulting and helping during the initial building period. He also helped by training young playworkers. He responded to the question asking if there was tsunami play in children's play. 
Table 2. Adventure playgrounds in the Tohoku Area. (original data was given from Mr. Tsutom Sunaga to use with his permission. This shows the situation on July, 2012 which movement is growing.)

\begin{tabular}{|c|c|c|c|c|c|c|c|c|c|}
\hline \multicolumn{3}{|c|}{ Address } & \multirow{2}{*}{ № } & \multirow{2}{*}{ Name } & \multicolumn{4}{|c|}{ Management } & \multirow{2}{*}{$\begin{array}{l}\text { Organization } \\
\text { Type } \\
\end{array}$} \\
\hline Prefecture & Municipality & District & & & (1) & (2) & (3) & Opening Frequency & \\
\hline \multirow[t]{2}{*}{ Iwate } & Noda vilage & & 1 & Noda Primary School Playpark & $\circ$ & - & I & irregularly & $\mathrm{C}$ \\
\hline & Rikuzentakata & Kurosaki & 2 & Makibakko & $\circ$ & $\delta$ & - & - & $\mathrm{B}+\mathrm{D}$ \\
\hline \multirow[t]{24}{*}{ Miyagi } & Kesennuma & Motoyoshi & 3 & Asobiba & $\circ$ & $\delta$ & IV & 5 days /week & $\mathrm{E} \rightarrow \mathrm{B}$ \\
\hline & & Motoyoshi & 4 & Asobo-car & $\circ$ & $s$ & IV & irregularly & E \\
\hline & & Motoyoshi & 5 & Kurinoki Hiroba & $\circ$ & $\delta$ & IV & 4/week + holidays & $\mathrm{B}$ \\
\hline & $\begin{array}{l}\text { MinamiSanriku } \\
\text { town }\end{array}$ & Utatsu & 6 & Utatsu TengunoYama School & $\circ$ & - & III & $2 /$ week & A \\
\hline & Tome city & & 7 & Tome no Asobiba & $\circ$ & $\delta$ & $\mathrm{I}$ & irregularly & $\mathrm{A}+\mathrm{E}$ \\
\hline & Kurihara city & Kannari & 8 & HieJinja no Asobiba & $\circ$ & $\delta$ & I & irregularly & $\mathrm{A}+\mathrm{E}$ \\
\hline & Ishinomaki city & Kitakami & 9 & Nikkori Playpark & $\circ$ & $\delta$ & I & irregularly & A \\
\hline & & Kawakita & 10 & $\begin{array}{l}\text { Kamegamori Adventure } \\
\text { Playground }\end{array}$ & $\circ$ & $\delta$ & II & 1stSunday/monthly & B \\
\hline & & Ishinomaki & 11 & Playpark Yappesu & $\circ$ & $\delta$ & I & $1 /$ monthly & $\mathrm{C}$ \\
\hline & & Ishinomaki & 12 & Koganehama Chibikko Hiroba & $\circ$ & $\delta$ & III & every weekend & $\mathrm{D}$ \\
\hline & & Ishinomaki & 13 & $\begin{array}{l}\text { Ishinomaki Playpark in } \\
\text { Kaihoku school }\end{array}$ & $\circ$ & $\delta$ & I & 4th Sunday & $\mathrm{C}$ \\
\hline & & Ishinomaki & 14 & $\begin{array}{l}\text { Ishinomaki Playpark in } \\
\text { Sumiyoshi }\end{array}$ & $\circ$ & $\delta$ & I & Second Sunday & \\
\hline & & Ishinomaki & 15 & Minatoprimary schoool Asobiba & $\circ$ & - & I & irregularly & $\mathrm{A}$ \\
\hline & & Ishinomaki & 16 & Nikoniko Playpark & $\circ$ & - & I & $1 /$ monthly & $\mathrm{D}$ \\
\hline & Rifu town & & 17 & Rifu Playpark & () & $\delta$ & $\mathrm{I}$ & irregularly & A \\
\hline & Sendai city & Aoba ku & 18 & NishiKoenPlaypark & () & $\delta$ & IV & 3 or 4 times a week & $\mathrm{A}$ \\
\hline & & Wkabayashi ku & 19 & Furujiro playpark & () & $\delta$ & II & 1/monthly & A \\
\hline & & Wkabayashi ku & 20 & $\begin{array}{l}\text { KaiganKoen Adventure } \\
\text { playgrounda }\end{array}$ & $\bullet$ & $\delta$ & I & closed by disaster & \\
\hline & & Wkabayashi ku & 21 & Rokugo Asobiba & $\circ$ & $\delta$ & III & 1/weekly & $\mathrm{C}+\mathrm{E}$ \\
\hline & & Wkabayashi ku & 22 & Nipperia Asobiba & $\circ$ & $\delta$ & II & 1/weekly & \\
\hline & & Wkabayashi ku & 23 & Shichigo Asobiba & $\circ$ & $\delta$ & II & $1 /$ weekly & \\
\hline & & Wkabayashi ku & 24 & Arai2goKoen Asobiba & $\circ$ & $\delta$ & II & 1/weekly & \\
\hline & & Wkabayashi ku & 25 & KamiaraiKokaido Chibaihiro & $\circ$ & $\delta$ & $\mathrm{I}$ & $1 /$ weekly & \\
\hline & & Wkabayashi ku & 26 & $\begin{array}{l}\text { Playgroup at temporary houses } \\
\text { at the site for school }\end{array}$ & $\circ$ & - & III & $1 /$ weekly & $\mathrm{D}$ \\
\hline Yamagata & Yamagata city & & 27 & Yamagata Playpark & $\circ$ & $\delta$ & - & irregularly & A \\
\hline \multirow[t]{3}{*}{ Fukushima } & Minamisoma city & & 28 & Minna Republic & $\circ$ & $\delta$ & - & Irregularly & $\mathrm{C}$ \\
\hline & Date city & & 29 & planning & is & - & - & - & A \\
\hline & Fukushima city & Iizaka & 30 & Moniwa Adventure playground & $\circ$ & - & - & 2-4 days/week & A \\
\hline \multicolumn{10}{|c|}{ Sources: NPO Japan Adventure Playgrounds Association } \\
\hline \multicolumn{10}{|c|}{ [index (1): starting time] @): from before the disaster $\bullet$ closed by disaster $\circ:$ started after the disaster is: planning } \\
\hline \multicolumn{10}{|c|}{ [index (2): visiting play car $1 \cdot \operatorname{car} 2$ ] $\delta:$ visiting [index (3): opening times (at moment July 1, 2012)] I : less than $10 、$ II : 10 49、III: 50 99 、IV: over 100} \\
\hline $\begin{array}{l}\text { [index organ } \\
\text { Outside, E: ] }\end{array}$ & $\begin{array}{l}\text { nization type]: A: } 1 \\
\text { Network organiza }\end{array}$ & $\begin{array}{l}\text { local group, B: Ne } \\
\text { tion in Japan, F: S }\end{array}$ & & $\begin{array}{l}\text { uhood Community, C: Network o } \\
\text { /Universities }\end{array}$ & & & & ons, D: Volunteer Organ & zation from \\
\hline
\end{tabular}


"Tsunami play was seen often at Asobi-ba. With a handmade equipment slide, a child gliding from the top plays the part of the tsunami. A child standing below is drenched, and may die or not, and at the side another child is positioned in the role of announcing "a major tsunami warning is announced". They all survived on this occasion. Hideaki Amano (who sometimes came from Tokyo to support us as the headquarters of the adventure playgrounds network JAPA), said that the big slide had been made with tsunami play in mind. In the summer time, children played by flushing water, brought from a keg, from the top of the slide, as tsunami play. There was another child who was frightened feeling the reality of the Tsunami by watching this play. Then I told the children to stop this tsunami play. We (the playworkers at Asobi-ba) have never made the kids play tsunami play. However, another adventure playground organization said that they had tried to involve children in tsunami play. They had tried to use a blue sheet and balls to imitate a tsunami. At Asobi-ba, we let children decide by themselves whether to play tsunami play or not. There is a discussion whether it is good or not for play-workers to introduce this kind of tsunami play for children so that they can release their stress and trauma."

An earthquake disaster might make children violent just after it had happened. But it was observed that these children at the playground gradually recovered their tenderness again over time.

When the kid's hideout play got popular among the children at Asoi-ba, they always took items such as water, food, radio and flashlight or torch. They would say: "Tsunami may come again. In that case, we evacuate to here. Here is surely a safe place."

This highlights traumatic play and its role in helping children overcome trauma and in preventing flashbacks. The interview with Buncha and Kanpei demonstrates that playworkers know the children who frequently used the adventure playgrounds and their different backgrounds. Children changed through communication with the playworkers and other children.

Following the Kobe earthquake, Okuyama (1996) [6] described that children's play relating to their frightening experience or slight regression was a behaviour to protect them from their uneasiness. Then, she concluded that it was very important to create an environment in which children felt safe and protected by the people close to them. For that, the adults surrounding the children should be stable. If they were not and were uneasy, or sometimes angry, resulting in conflict or fighting, then children's mental condition could deteriorate. For that reason, she argued the importance of supporting both children and their parents to help release their stress and uneasiness. For children themselves, she advocated the importance of a playground, so that they could deal with their stress and uneasiness by themselves. She analyzed that children expressed feelings of uneasiness and their anger through the process of play. She stated that sometimes in their play the symptoms of PTSD, such as: re-experiencing the traumatic event, avoiding reminders of the trauma and increased anxiety and emotional arousal were sometimes exhibited. However, communication and sharing experience with friends would help to calm the situation in the knowledge that other children had experienced and felt similar things. From her research after the Kobe disaster, she realized that it was very important to open a playground to help children recover their emotional balance, as well as enabling them to restart school and preschool sooner. This was similar to the experience described by Hideaki Amano. In the case of Asobi-ba in Kesennuma after the Tohoku disaster, Kanpei had explained that listening to children and their communication with playworkers had also been important and in their care they 
gradually opened up and talked. This enabled him to gradually get to know their family. In turn, those families who came to learn of their children's play through communicating with playworkers, also recovered their calm voice and attitude. However, some children, especially those visiting the playground every day, exhibited signs of stress at home. In this way, the role of the playworker could have been extended to that of a social worker. So, it looked as if the role of the playworker may extend to being a social worker organizing social health. Where adventure playgrounds had been supported by the local community, communication with them also had a positive impact on the children where they felt protected and able to recover their emotional balance.

When we asked Buncha if there had been an improvement in the understanding of children's play through the Asobi-ba and other adventure playground activities, he responded:

"Here, people think, of course, it is ordinary for children to play but they also think now that children cannot win in the competition of education if they are doing ordinary things. (As UN CRC committee commented that children did not have enough time to play as a result of the competitive educational system in Japan.) In the Kesennuma area there was a traditional approach to childcare which was called Yama (Forest) Gakko (School) and which involved teaching children through playing in the forest. However, this traditional method of education had been disappearing, because increasingly it was thought that it did not contribute to success in educational competitiveness. There was no thought of educational competition after the earthquake and tsunami disasters, and therefore children could have the opportunity to play with energy. This was the situation in Asobi-ba and was very much appreciated by the people. Adults had not had enough time to think about children's needs."

Asobi-ba was established by the management of the NPO Japanese Adventure Playground Association (JAPA) which meant it was initiated from outside the local community. However, the management of this playground was undertaken by the local community from the summer of 2012 .

One specific characteristic of Japanese adventure playgrounds is that the playground is sustained by the local community. As already mentioned, Lady Hurtwood described that the main dissenting opinion to an adventure playground concerned the perceived disorder and in some countries this is hidden from the outside by a fence. However, in Japan there is no fence around an adventure playground: it is visibly open and also invisibly open to everyone. As a common finding among about 400 adventure playground, this characteristic is often seen as a specific feature in Japanese adventure playgrounds. In Table 2, there are many cases of adventure playgrounds sustained by the local community, which have been supported by or linked with an organization from outside and these are indicated in organisation types $\mathrm{A}+\mathrm{E}$ or all organisation types $\mathrm{E}$.

As a new adventure playground, Makibakko at Rikuzentakata is a good example to show how the local community sustained the playground. This playground was opened in the summer of 2012 and was initiated by a mother who had visited Asobi-ba. She was a member of a child rearing group at Rikuzentakata city, and she wanted to have an adventure playground at the centre of the city. However, the town centre was totally destroyed by the tsunami and the ground level had sunk by about $1 \mathrm{~m}$ as a result of the earthquake. The hill side for housing was limited and therefore she found some land that had been abandoned for cultivation in her parents' village. At first she was worried 
that the area was very rural and that there were only four children in the village. The first author gave advice to her that the adventure playground should not have the same landscape as Asobi-ba. She could make an adventure playground in the local style of farming, inviting her colleagues in the child rearing group from the whole city. She was encouraged by this advice and opened the playground. Another key person Mr. Koizumi was also involved in this and he travelled from Tokyo making a personal sacrifice to help. Perhaps, it was remarkable that the older people of this community were delighted with this project and they took part in the process of building play equipment (Figure 2), a cooking kiln, and making a name board. It looked as though the playground was for three generations. Such a positive social situation contributes to the health triangle.

\subsection{Play Car-Mobile Play}

Sendai is a major capital city in northern Japan and has three adventure playgrounds. Kaigannkoen Adventure Playground was the largest of these but had suffered badly from the tsunami. The playworker there, Akio Nemoto, survived the tsunami by climbing to the top of the play equipment, which, in turn, stood on top of a mound. Together, with some village people who had evacuated to this playground, they survived. In this coastal area of Sendai city, the surrounding land is flat; therefore, the mound of $15 \mathrm{~m}$ was the highest point and indeed the only elevated piece of land in this area. As the tsunami approached, Akio wanted to be the last to leave after he had made other people evacuate from the playground. However, some old people arrived there after being evacuated from their village and climbed to the top of the mound to escape the tsunami. Akio helped the old people get warm from the cold air and snow by covering them with blue sheets and other material with which the adventure playground was equipped. Finally, they were rescued by helicopter after the mound had been surrounded by water. This demonstrated that the adventure playground might serve as a base for evacuation because survival play is familiar to an adventure playground and the relevant materials are likely to be available.

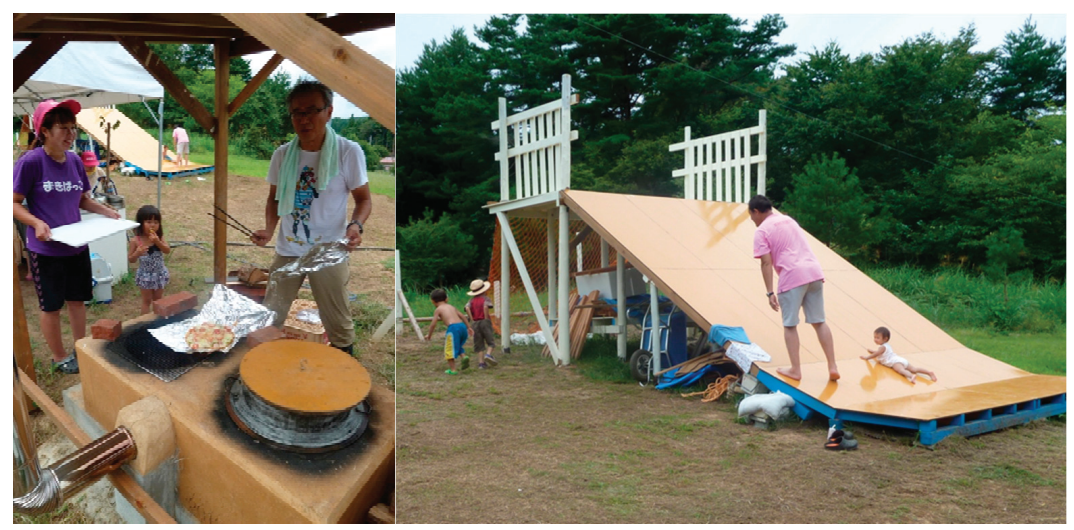

Figure 2. Adventure playground built by the village community "Makibakko".

This experience was shocking for Akio, but he started play work activity by visiting the evacuation locations after just a few days of rest. The NPO Japanese Adventure Playground Association 
coordinated support to send play cars which were donated by private companies. One of two was used in Sendai while the other was used by Buncha to visit different sites to provide adventure playground activities supporting other activities initiated by local people.

The area of the disaster was widespread and there were enormous numbers of temporary housing sites: 260,000 people were still living in temporary houses three years after the disaster. The requirements for children's play were not considered in the environment of these sites. Around the pre-fabricated houses, asphalt or gravel covers the surface and is occupied by many car parking places. Some sites have a volunteer play program but most sites hold these activities inside in a meeting room, not outside. It is proposed that in such circumstances, four key factors affecting play — space, people, intervention and time - should be considered for the betterment of children's environments (Woolley and Kinoshita, 2014) [10].

One of the interventions to support children's play in the temporary housing areas is play buses. Kirby provides mobile play facilities from a play bus and he has been visiting the disaster area from Tokyo two or three times every month since the disaster. He has mainly visited the area in Ishinomaki city. Ishinomaki city has a population of about 150,000 and is a local core city in the coastal area in the northern part of Miyagi prefecture. In Ishinomaki, Mr. Shibata had started play activities, using the name Rainbow Crayon, from the evacuation stage just after the earthquake and after temporary housing had been provided. He has been visiting these sites every day to support play activities for children. However, there are about 150 temporary housing sites, and it is difficult to cover the entire area. Kirby has been supporting his activities by brining play materials and playworkers to sites by bus (Figure 3). At first, their activity took place around the temporary houses using the tarmac spaces in between car parking places in front of gathering places. In some locations, it was difficult for the residents of temporary houses to understand the importance of this activity. The residents wanted to stay quiet and claimed that sometimes children made a noise. The playworkers sought to develop the residents' understanding and gradually the residents changed their attitude to support their activity by watching children playing. Now, not only children from the temporary housing site but also children from the surrounding area come when mobile play is happening. Here, the playworker fulfils a role similar to a community worker by connecting adults with children.

There is an episode reported by Kirby about 6 months after the disaster when the play car visited a site in Ishinomaki city. A 4 year old girl came to the play car with her mother tied to her hand. When she saw other children were playing and having fun, gradually this little girl became involved and concentrated on playing with other children. Her mother was very surprised by this because this girl had not gone further than 5 metres from her side; she was always touching or following her mother closely after the disaster, which might be understood as a symptom of PTSD type 2: regression. This episode demonstrates how the play supported by the play car contributed to recovering the child's health. 


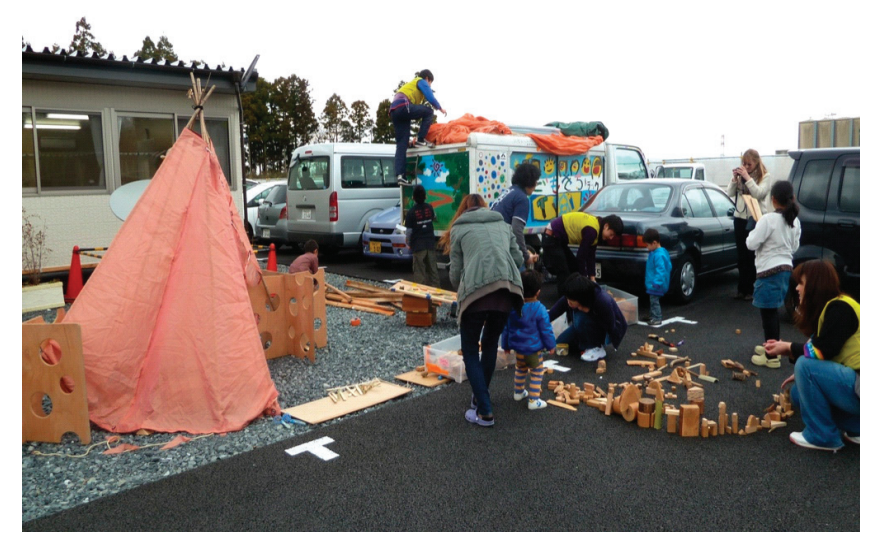

Figure 3. Mobile play truck at a temporary housing site.

Social health for children can include not only being with each other but also being with adults. The playworker Kirby has established contact with citizen movement networks of the young generation which might be a new way of creating community and incubating activities such as social businesses. Through these contacts, Kirby has also collaborated with other organizations running the Koganehama adventure playground. He has coordinated a street party project and mini city project as big events for children to gather in the town centre. Kirby's activity shows that the role of playworker and mobile play can connect different stakeholders to support a child's right to play and their play environments.

\subsection{Fukushima and Indoor Playground}

A more serious and ongoing concern is children's environments in the Fukushima Prefecture. The area suffered radioactive contamination which spread from the power plant to the northwest (Figure 4). Young families were evacuated from the prefecture and the population suddenly declined after the disaster.

At the time, statements from the government about radiation levels were confusing for parents and resulted in fear and concern for the future of their children.

The data about radiation levels which the government and media reported for a while after the accident was measured $7 \mathrm{~m}$ from the ground level, well above the height of adults. Then, it changed to radiation measurements at $1 \mathrm{~m}$ above ground level. However, this is a standard which relates to the height of an adult. A small child's body is nearer to the ground than $1 \mathrm{~m}$ where the radiation is higher and therefore children were not considered separately.

Even at a low dose, many were uncertain as to whether children should be allowed or forbidden from outdoor activities. Some parents adopted the defensive measure of restricting their children's outdoor activities to reduce their exposure to radioactivity. However, when outdoor activity is restricted, the development of a child's mind and body may be affected [31]. Adults worry about health impairments caused by radioactivity and children's growth, growth because of the control on 
outdoor activities. The parents of small children in Fukushima continue to be faced with this great dilemma.

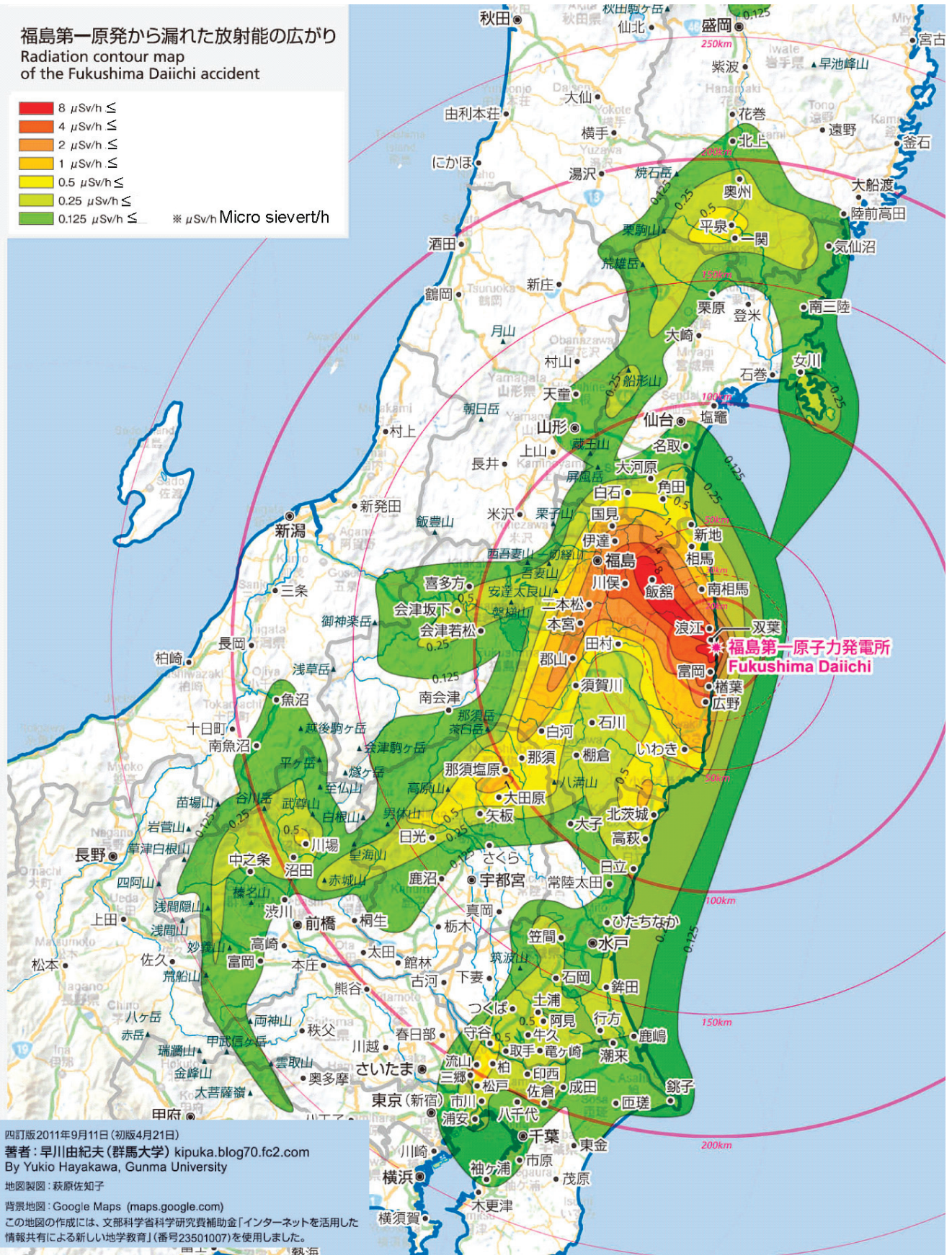

Figure 4. Radiation contour map of the Fukushima Daiichi Accident. This is arranged from the map made by Yukio Hayakawa with his permission (2012.3.15). 
The obesity of children increased noticeably in Fukushima Prefecture after the disaster (Figure 5). The ratio of children whose weight was $20 \%$ more than the standard was higher than the national average [32]. Fukushima was the top highest for obesity for $6,7,10,13,15$, and 17 year old children. Also, Miyagi and Iwate prefectures, both affected by the earthquake and tsunami, were located in the higher classes of obesity. This demonstrates that children in the disaster area have increased body weights and this may be because of a lack of physical activity since the disaster. This is particularly the situation in Fukushima prefecture where there has been a restriction on being outdoors because of radiation contamination and where children's obesity has increased since the disaster. However, obesity and trauma might have no relationship, because the numbers of children who suffered from the tsunami were limited in Fukushima to the coastal area, and most children inland were visibly not harmed.
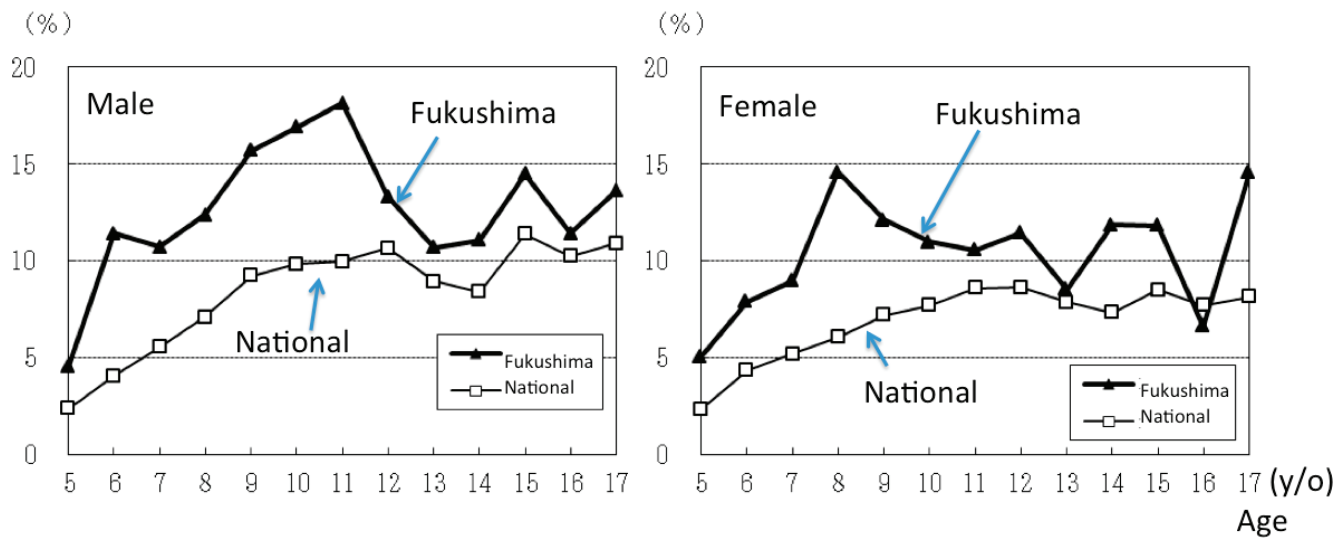

The Ratio of Obesity by Age, in Fukushima Prefecture compared with National level Source: Fukushima Prefecture Statistics ed. Report of the survey by school health statistics in 2012

Figure 5. The difference of the ratio of obesity by age in Fukushima prefecture. (This is arranged from the original graph made by the department of statistics of Fukushima prefecture with the permission to use.)

In Fukushima Prefecture, there has been a restriction on outdoor activity. In 2012, there were 132 public schools with this restriction reducing to 56 schools in 2013 (Nikkei News, 2013) [33]. However, there are still many parents who restrict their children from playing outdoors.

Paediatric Doctor, Shintaro Kikuchi, opened a temporary indoor playground in the summer holidays in 2011. Initially, he had tried talking to local government and private companies but with limited success. Finally, the local supermarket offered the use of a supermarket building which was closed and the city of Korriyama promised to give support with a financial subsidy. In this way, the first indoor playground "PEP Kids" opened on December 23, 2011 (Figure 6). In this indoor space, there is a sand play area of $70 \mathrm{~m}^{2}$ an activity zone for running, play equipment for physical movement and a cooking room. About 1000-1600 children use this daily. There are 6-8 staff in this indoor playground supervising and supporting children's play. 
Then, Fukushima prefecture set up a project to support local governments to develop indoor playgrounds from 2012. The number increased to 64 indoor playgrounds in the Fukushima Prefecture by May 2014 (Figure 7). The facilities are mostly equipped by the agent handling Scandinavian play equipment. Therefore, each playground is not as different from each other as they might be. Staff provide some supervision but mostly they are not trained playworkers.

Mr. Hiroyuki Yoshino, concerned about the issue of radioactive influence on children, organized the Children and Fukushima Network. He and his colleagues in the network have been sending children from Fukushima to safer, greener places outside of Fukushima. This network extended to connect with Japanese citizen organizations supporting children at Chernobyl which developed after the Chernobyl disaster of April 26, 1986.

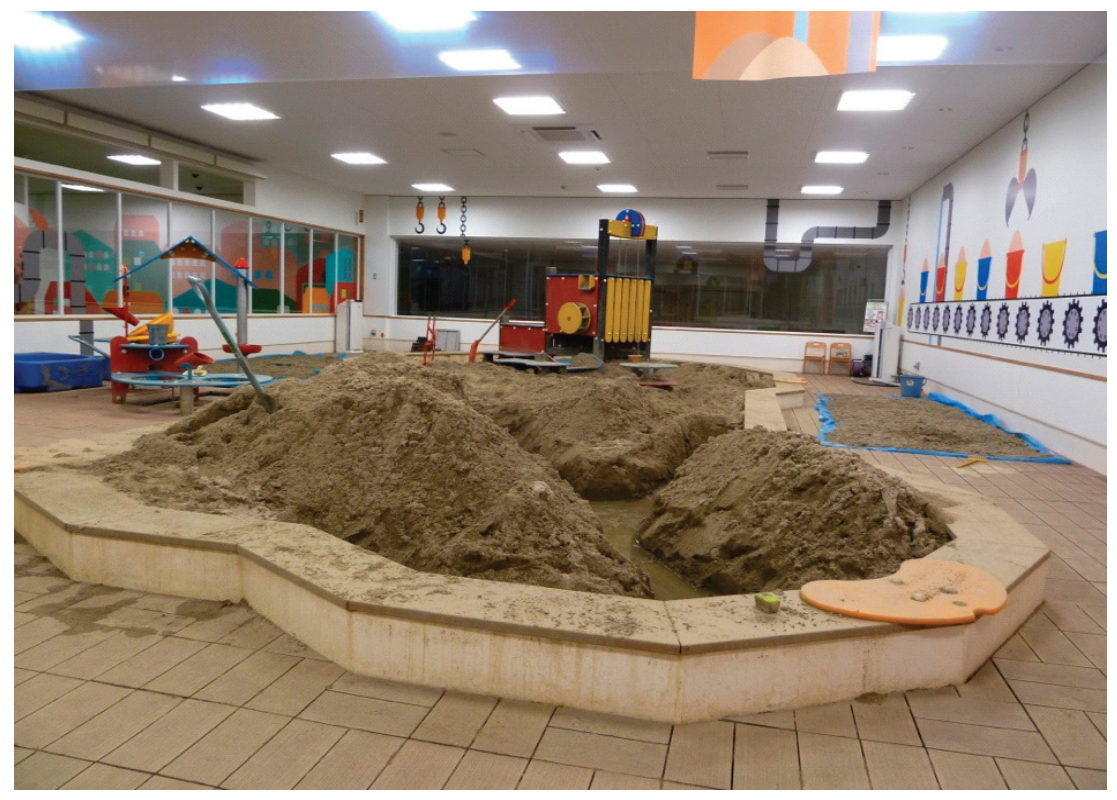

Figure 6. Indoor playground "PEP Kids" in Kooriyama city.

There was no clear information about which level of radiation was safe for children when the Fukushima Daiichi Nuclear Power Station accident happened in 2011. Initially, the government announced $20 \mathrm{mSv} /$ year as the maximum safe standard level but this was criticized strongly by the public, and the government responded by changing the level to $1 \mathrm{mSv} / \mathrm{year}$ (MEXT, 2011) [34]. This means that the aerial dose rate of $0.23 \mu \mathrm{Sv} / \mathrm{h}$ over $8 \mathrm{~h}$ every day became the standard for outdoors. There were many places in Fukushima, where the dose rate in the air was over $0.23 \mu \mathrm{Sv} / \mathrm{h}$. For the standard level to be $20 \mathrm{mSv} / \mathrm{year}$, the air dose rate would be $3.8 \mu \mathrm{Sv} / \mathrm{h}$ over $8 \mathrm{~h}$ every day outdoors. This standard was applied to decontamination workers and in deciding zoning categories for the areas where people would be allowed to live. This demonstrates that a double standard and there has been no agreement on safe levels of radiation. A young boy of 14 years old who was evacuated from Namie town, close to the nuclear power station, commented: 
"Even the scientists said different things about which level is safe, depending on their viewpoint, for or against nuclear power stations. Please come here, scientists from both sides to have a battle or discussion in front of us, then we will decide it by ourselves." (Children's Summit Sendai, 2011) (Appendix 3) [35] is might be the real opinion of children and parents who have children in the contaminated area. There are many different opinions from scientists about the impact of lower radiation levels on children's bodies. The general public has not been able to assess meaningfully the risks and as a result has lost trust in the scientists (Appendix 4) [36].

The Location of Indoor Playgrounds

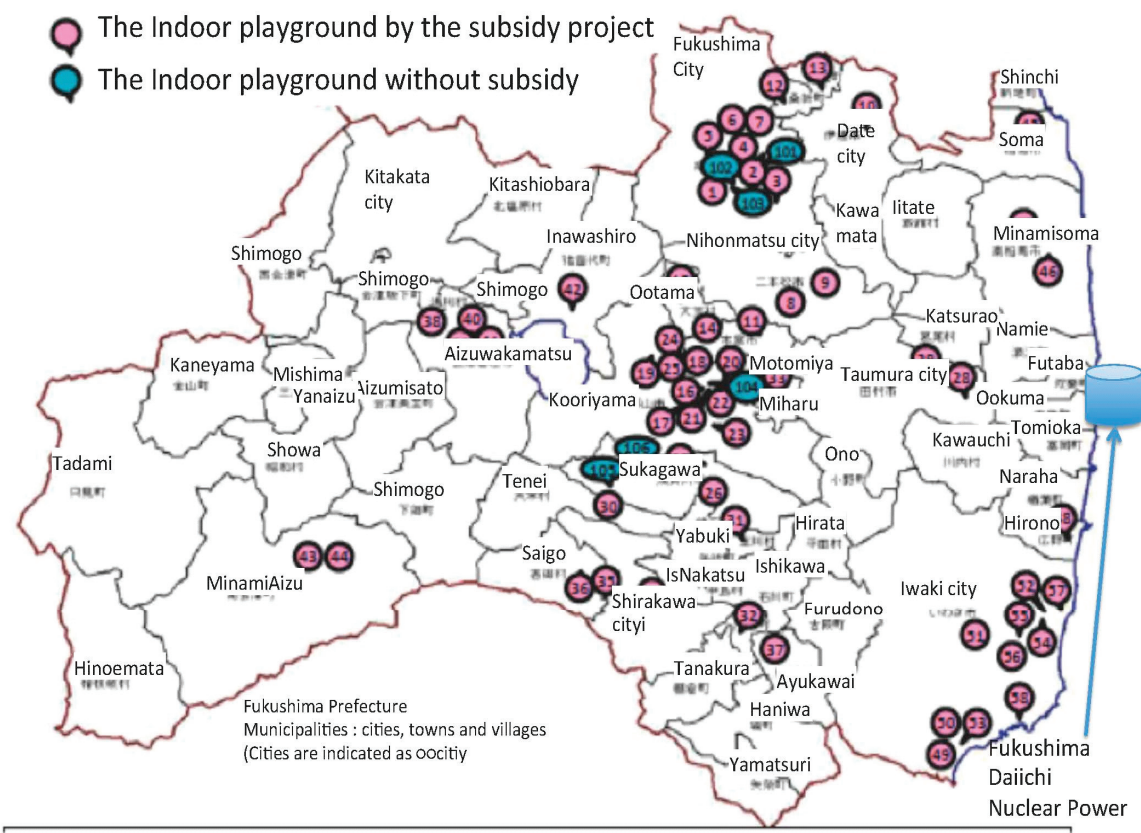

Figure 7. The location of Indoor Playgrounds in Fukushima Prefecture (source: Fukushima Prefecture 2014.4.7, This is arranged from the original map made by the department of Child Rearing Support of Fukushima prefecture with the permission to use.).

Therefore, contacts with the citizen groups and organizations in Chernobyl who had been supporting children enabled Yoshino and other colleagues to identify the importance of a "sanatorium" where children could stay in a safe, uncontaminated and green environment, allowing their natural metabolism to normalize [37-39]. As a result, they started a program, using their network of organizations, to send children temporarily to such locations.

In Fukushima Prefecture, decontamination work has been ongoing since the disaster and, now, in most municipalities, radiation levels in the air are much reduced. The prefecture has established a strategy to support children's play outdoors, recognizing that they cannot solve the issue of the increasing obesity only by providing indoor playgrounds. However, there are still many parents who 
restrict children's outdoor play. The government has decontaminated many residential areas but, over time, higher levels of caesium have accumulated in several locations. Though the government has guaranteed the level of radiation that is safe by their measurements, there may be locations where higher levels of caesium exist and where children should be protected from its effects. Yoshino's group and other organizations are focusing on measuring the radiation outdoors in residential areas to show more detailed data on maps so that children and their parents will be able to know where the "hot spots" are located.

In consideration of the physical domain of the health triangle in the context of Fukushima, there may be a dilemma between the impact of radiation and the promotion of outdoor play against increased obesity. However, addressing the social domain, the network of citizen and local government organizations, and professionals, including scientists with reliable data, should be encouraged to create children's safer and healthier play environments. Fukushima Prefecture has started now to promote the adventure playground as a model of collaboration with local organizations.

It is now possible to establish the impact of the adventure playgrounds and other interventions implemented since the disaster, based on the research and discussions, using the model of the health triangle as can be seen in Table 3.

Table 3. Impact of interventions such as adventure playgrounds in children's play in a post disaster context in Japan.

\begin{tabular}{ll}
\hline & $\begin{array}{l}\text { Adventure Playgrounds and Other Interventions Promoting } \\
\text { Children's Play in Post Disaster Context }\end{array}$ \\
\hline Mental & $\begin{array}{l}\text { Expression of emotions through play: } \\
\text { feeling accepted; } \\
\text { communication with friends or playworkers to release stress and the feeling of uneasiness; } \\
\text { body movement to release stress and to make positive influences to mental condition [40]. }\end{array}$ \\
\hline Physical & $\begin{array}{l}\text { Moving about; } \\
\text { different types of play result in whole body } \\
\text { Health }\end{array}$ \\
& $\begin{array}{l}\text { Mavement to promote physical development [41]. } \\
\text { Social }\end{array}$ \\
Health & $\begin{array}{l}\text { Sharing experiences with others in the same peer group; } \\
\text { Improved well-being resulting from safe play space such as } \\
\text { adventure playgrounds or indoor play spaces in Fukushima; }\end{array}$ \\
& $\begin{array}{l}\text { Improved social interaction within a community involving not only } \\
\text { children but also their parents and other residents. }\end{array}$ \\
\hline
\end{tabular}

\section{Conclusions}

It is now increasingly recognized that the mental health of children in a post disaster context may involve Post-Traumatic Stress Disorder (PTSD). However, its relationship with physical and social health should be considered. Children's play has a very important impact on the health triangle. The CRC general comment No.17 on Article 31 stated that, there are many barriers to supporting play in Japan. This prevailing culture of not supporting children's play appeared clearly in the post disaster 
context, for example at the evacuation centre and at temporary housing sites where children were restricted from playing freely.

It has been demonstrated that adventure playgrounds have an important role in helping children to release mental stress through their play. However, this needs further research to explore this more. In this research, earthquake play and tsunami play were often seen in the adventure playgrounds. Such play might be an expression of children overcoming shocking events of which, on their own, they did not understand the meaning. This is a hypothesis which merits further investigation. Through play, children might recover both physical health and social health with friends. So, the image of children recovering their smile by playing as they used to before the disaster has helped adults to understand the meaning of play. From such experience and sympathy, there are people who have been encouraged to build other adventure playgrounds in their own residential area. As a result, adventure playgrounds have developed in the disaster area. The involvement of local communities has been a feature in sustaining these developments. Further discussion about the use and integration of the health triangle may help communities develop effective health strategies.

Nevertheless, the increase in children's obesity after the disaster in the Fukushima Prefecture demonstrates that the area may not be healthy for children. Most did not understand the importance of play and this was expressed in the restrictions on children's play at the evacuation stage and, later, in the lack of outdoor play spaces at the temporary housing sites. Fukushima Prefecture has promoted indoor playgrounds and this might be considered appropriate at a time of radiation contamination. After de-contamination, the development of children's outdoor adventure playgrounds, mobile play supported by interventions such as play buses and play cars and various other approaches for increasing the opportunity for children to play should be given more consideration than they have been.

\section{Acknowledgments}

Special thanks to Hideaki Amano, Tsutom Sunaga (Buncha), Akio Nemoto, Shunichi Kanbayahshi (Kanpei), Satoru Hoshino (Kirby), Shigeki Shibata, Shintaro Kikuchi, Hiroyuki Yoshino, Shigeki Shibata, Etsuko Takahashi, Emiko Mashiko, Narumi Kumasawa, Shinichiro Nitta, Hiromi Matsumura, the Association for Children's Environments, Japan Adventure Playgrounds Network (JAPN, Nihon Boken Asobiba Dukuri Kyokai), the department of Child Rearing Support of Fukushima prefecture and other people who contributed to share their experiences and very important and useful information concerning this paper. We are also grateful to the Daiwa Anglo-Japanese Foundation and the Japan Society for the Promotion of Science who funded the visits to Japan of the second author.

\section{Appendix}

\section{Children that Survived the Tsunami}

In the case of Togura Primary School and Secondary School in Minami Sanriku Town, children were evacuated from the public evacuation place to climb up the hills and survived. (From the research done in the April 2011 by the author). On the contrary, in the case of Ookawa primary school 
in Ishinomaki, while 34 children died, tragically 74 children died, because of the teachers' error of judgment. Though, some children climbed up the mountain themselves and those who were able to do so survived.

\section{Adventure Playground Movement in Japan}

Adventure playgrounds first started in 1943 in Emdrup in Denmark, with landscape architect C.TH. Sørensen being their lead developer. This type of adventure playground was subsequently introduced by Mr. and Mrs. Ohmura in Japan, through the book "Planning for Play" written by Lady Allen of Hurtwood and translated and published in Japanese in 1973. After several experiments opening adventure playground activities, in the International Year of the Child in 1979, Setagaya ward decided on a memorial project, to build a permanent adventure playground in one corner of Hanegi District Park. This type of adventure playground was called a Play Park and was extended to four parks in Setagaya ward and then eventually all over Japan. Nowadays, there are about 400 organizations across Japan who are running adventure playgrounds including the non-permanent style, such as activities on every weekend for instance (IPA Japan, 2013) [41]. For networking purposes, the Japan Adventure Playgrounds Association was established in 2003 and supports the play activities in the disaster area.

\section{Children and Youth Forum at the Disaster Area $=$ Kodomo Mirai Jin Summit}

At the Kodomo Miraijin Summit held on September 4, 2011, where Isami Kinoshita attended and talked with the 55 children gathered from the disaster area. This Summit was held by the support of Deutsches Kinderhilfswerk e.V. and its report was available also in English [34].

\section{Discussion about the Safer Level of Radiation Affection}

Currently, the linear no-threshold model has been used but there are still many discussions. As the reason for the safer level is not clear, it is said by many scientists and governmental officers that there has not been enough evidence or epidemiologic data about the impacts to the human body from lower radiation. In Japan, with the historical events of Hiroshima and Nagasaki, some data has been produced from epidemiologic long term research conducted by US and Japan, which was called ABCC. However, a major setback has been that the data is not open so that the others can check the safety levels [35].

\section{Author Contributions}

These authors contributed equally to this work. Yes but led by Isami Kinoshita.

\section{Conflicts of Interest}

The authors declare no conflict of interests. 


\section{References}

1. WHO. Definition of Health. Available online: http://www.who.int/about/definition/ en/print.html (accessed on 14 June 2014).

2. Jeanty, Jacquelyn, Description of Health Triangle, eHow web-site watched in 14 June 2014. Available online: http://www.ehow.com/about_5206047_description-health-triangle.html (accessed on 14 June 2014).

3. Ireland, Kay, Can Stress Affect Your Health Triangle? Available online: http://healthyliving. azcentral.com/can-stress-affect-health-triangle-7063.html (accessed on 28 June 2014).

4. Schumacher, C.; Hansen, M.A.; Ingle, D.E.; Middaugh, J.P.; Mehrkens, H.L.; Green, T. 1995 Alaska Youth Risk Behavior Survey (YRBS) (1997 Update). Available online: http://www.epi.hss.state.ak.us/pubs/yrbs/yrbs_toc.htm (accessed on 28 June 2014).

5. Saylor, C.F. Children and Disaster; Saylor, C.F., Ed.; Plenum Press: New York, NY, USA, 1993; pp. 1-237.

6. Okuyama, M. Recovery from Earthquake for Children (in Japanese). Available online: http://www.blog.crn.or.jp/lab/06/15.html (accessed on 1 July 2014).

7. Disaster risk management for health: Child health. Available online: http://www.unisdr.org/we/ inform/publications/19992 (accessed on 14 June 2014).

8. Katada, T. Surviving Power for Children (in Japanese). Froebel publisher, 2012, and TV program. Available online: http://pf.nhk-ep.co.jp/detail/1693 (accessed on 1 September 2012).

9. Tragedy by tsunami disaster at Okawa primary school in Ishinomaki (in Japanese). Available online: http://memory.ever.jp/tsunami/higeki_okawa.html (accessed on 25 April 2014).

10. Woolley, H.; Kinoshita, I. Space, People, Interventions and Time (SPIT): A model for understanding children's outdoor play in post-disaster contexts based on a case study from the triple disaster area of Tohoku in North-East Japan. Child. Soc. 2014, doi:10.1111/chso.12072.

11. United Nations Committee on the Rights of the Child. General comment No. 17 (2013) on the right of the child to rest, leisure, play, recreational activities, cultural life and the arts (art. 31). Available online: http://www.refworld.org/docid/51ef9bcc4.html (accessed on 14 August 2014).

12. Masten, A.S. Narayan, A.J. Child development in the context of disaster, war, and terrorism: Pathways of risk and resilience. Annu. Rev. Psychol. 2012, 63, 227-257.

13. Osofsky, H.J.; Osofsky, J.D. Hurricane Katrina and the Gulf oil spill: Lessons learned. Psychiatr. Clin. North Am. 2013, 36, 371-383.

14. Bonanno, G.A.; Westphal, M.; Mancini, A.D. Resilience to loss and potential trauma. Annu. Rev. Clin. Psychol. 2011, 7, 511-535.

15. Osofsky, J.D.; Osofsky, H.J.; Harris, W.W. Katrina's children: Social policy considerations for children in disasters social policy report. Available online: http://files.eric.ed.gov/fulltext/ED521702.pdf (accessed on 14 August 2014).

16. Shannon, M.P.; Lonigan, C.J.; Finch, A.J., Jr.; Taylor, C.M. Children exposed to disaster: I. Epidemiology of post-traumatic symptoms and symptom profiles. J. Am. Acad. Child. Adolesc. Psychiatr. 1994, 33, 80-93. 
17. Institute of Medicine, Committee on Integrating the Science of Early Childhood Development. Board on children, youth and families. In From Neurons to Neighborhoods: The Science of Early Childhood Development; Shonkoff, J.P., Phillips, D.A., Eds.; National Academies Press: Washington, DC, USA, 2000.

18. Play England, Play and Health: Making the links, Policy Briefing 3, 2008. Available online: http://www.playengland.org.uk/media/120486/play-and-health-policy-brief-03.pdf (accessed on 1 July 2014).

19. Mackett, R.L. Making children's lives more active. Available online: http://discovery.ucl.ac.uk/ 1346/1/2004_39.pdf (accessed on 14 August 2014).

20. Milteer, R.M.; Ginsburg, K.R.; Council on Communications and Media Committee on Psychosocial Aspects of Child and Family Health; Mulligan, D.A. The importance of play in promoting healthy child development and maintaining strong parent-child bond: Focus on children in poverty. Pediatrics 2012, 129, e204-e213.

21. Child to Child Trust. Helping Children and Adults Cope with Natural Disasters. Available online: http://www.child-to-child.org.uk (accessed on 6 June 2014).

22. Lisul, I. Play as a coping strategy during a time of bombing and destruction. In The Child's Right to Play; Clements, R.L., Fiorentino, L., Eds.; Greenwood Publishing Group: Westport, CT, USA, 2004; pp. 55-61.

23. Tucker, J. Kids with PTSD find help through adventure-based therapy. Available online: http://www.sfgate.com/bayarea/article/Kids-with-PTSD-find-help-through-adventure-based5436668.php_(accessed on 1 June 2014).

24. Lady Allen of Hurtwood. Planning for Play; Translated in Japanese by Mr. and Mrs. Ohmura; Kajima Publisher: Tokyo, Japan, 1973; pp. 1-144.

25. Bengtsson, A. Crosby lockwood; In Adventure Playgrounds; in Japanese translated by Ohmura, K. and Ohmura, S; Kajima publisher: Tokyo, Japan, 1974; p. 78.

26. Duttner, R. Design for Play; The MIT press: Cambridge, MA, USA, 1969: p. 45.

27. Noren-Byorn, E. The Impossible Playground; Human Kinetics: Champaign, IL, USA, 1982; pp. 1-224.

28. MEXT, Life- and Nature Experience Raise the Mind of Children in Japan, Mid Term Report (in Japanese). Available online: http://www.mext.go.jp/b_menu/shingi/old_chukyo/old_ gakushu_index/toushin/1315191.htm (accessed on 14 June 2014).

29. Amano, H. Power of Play Healing Children; the Kyodo News: Tokyo, Japan, March 14, 2011.

30. Aftermath of the 2011 Tōhoku earthquake and tsunami. Available online: http://en.wikipedia.org/wiki/Aftermath_of_the_2011_T\%C5\%8Dhoku_earthquake_and_tsunami (accessed on June 25 2014).

31. MEXT. Outline of the school health statistics in Japan, 2013 (in Japanese). Available online: http://www.mext.go.jp/b_menu/toukei/chousa05/hoken/kekka/k_detail/1345146.htm (accessed on 25 June 2014). 
32. MEXT. Research report about children's physical strength, athletic capability, and other exercises in Japan, 2013 (in Japanese). Available online: http://www.mext.go.jp/a_menu/ sports/kodomo/zencyo/1342657.htm (accessed on 1 June 2014). Those data are available online: http://www.e-stat.go.jp/SG1/toukeidb/GH07010201Forward.do (accessed on 1 June 2014).

33. Nikkei Newspaper, 2013.12.13 (in Japanese). Available online: http:/www.nikkei.com/article/ DGXNASDG13042_T11C13A2CC1000/ (accessed on 1 June 2014).

34. Safety standard of radiation (in Japanese). Available online: http://www.jaea.go.jp/04/turuga/ mext-monju/safety/safe-ri06.htm (accessed on 1 June 2014).

35. Kodomo Miraijin Summit Executive Committee. Kodomo Miraijin Summit Report, 2012 (in Japanese). Available online: http://kikaku-blog.p-kai.com/?eid=975921 (accessed on 1 June 2014).

36. Imanaka, T. Exposure of lower radiation and the risk of cancer (in Japanese). Available online: http://www.rri.kyoto-u.ac.jp/NSRG/etc/Kagaku2005-09.pdf (accessed on 1 June 2014).

37. Agency for Toxic Substances and Disease Registry. Available online: http://www.atsdr.cdc.gov/ (accessed on 1 June 2014).

38. U.S. Department of health and human services, Toxicological profile for cesium, 2004. Available online: http://www.atsdr.cdc.gov/toxprofiles/tp157.pdf (accessed on 1 June 2014).

39. Chernobyl: Consequences of the Catastrophe for People and the Environment (in Japanese). Available online: https://docs.google.com/document/d/1v9zYzyxFgpR0B9rPLM16aNrJWmgBs V7s_1tDVRHrlVI/edit (accessed on 1 June 2014)

40. Senda, M. Child and Play (in Japanese). Iwanami Publisher: Tokyo, Japan, 1992.

41. From the IPA Japan (in Japanese). Available online: http://www.ipa-japan.org/asobiba/modules/ news/article.php?storyid=221 (accessed on 1 June 2014). 


\title{
Restoration of Traditional Children's Play in Iranian Nomadic Societies (Case Study of Kohgilouyeh and Boyer Ahmad)
}

\section{Laleh Taheri and Golshan Chahian}

\begin{abstract}
This article aims to provide an insight into play as an important aspect of children's lives in an under-studied area of Iran. Our observations focus on the province of Kohgilouyeh and Boyer Ahmad with its ancient nomadic cultures. Through first-hand knowledge and lived experiences, supplemented by available literature, we seek to look at children's games in the frame of culture change, exploring their relationship with children's health and wellbeing. Play, as in every region in the world, conveys and reflects the dominant culture and teaches the values of the society in which the children live in the here and now and in which they will have to function as adults. Yet, types of play are not static. They develop alongside social, political and economic changes and embrace new forms emerging from modern lifestyles. The latter sometimes come into conflict with and challenge the local culture and traditional types of play, which are based on the lives and histories of the indigenous peoples and local communities. A sample of traditional tribal forms of play is analyzed for their health, entertainment and fun aspects. Such play allows children to prepare for life's realities, in particular for a life of cooperation. By contrast, whilst also providing children with tools and skills for the needs of modern life, new types of play focus more on competition and individualism. This divergence expressed in different types of play widens the generation gap and contributes to alienation. The shift from a collective to individualistic lifestyle thus has an unsettling impact on the community and impacts on the emotional and physical wellbeing of children. We will describe types of play and their role in the holistic development of nomadic children, as well as the impact of modernization and social change, including sedentarization. The article will highlight some consequences of the demise of indigenous play, through observation and analytical comparison of children's play in three generations. Based on the insights gained, the authors offer recommendations on how to restore traditional play and games through redesigning them to be capable of adaptation to changes in lifestyles.
\end{abstract}

Reprinted from Children. Cite as: Taheri, L.; Chahian, G. Restoration of Traditional Children's Play in Iranian Nomadic Societies (Case Study of Kohgilouyeh and Boyer Ahmad). Children 2015, 2, 211-227.

\section{Introduction}

Recent years have seen the transformation from a traditional society to a modern one for a large part of indigenous nomadic people. Loeffler observed that they are "changing basically the structure of their traditional way of life" alongside "changes in traditional subsistence economy" [1]. The expansion of networking through media has changed many aspects of human lifestyles and habits, especially for parts of the nomadic peoples who have become sedentarized. For both people who 
have continued a customary lifestyle of mobility or have settled in villages far from urban influences and electricity, traditional systems are still prevalent.

Nationally, while the percentage of migratory indigenous nomadic population has declined from some $50 \%$ to around $2 \%$, their absolute number has changed little, vacillating around $1.2-1.5$ million. Even large-scale and well-funded national programs of sedentarization [2] have made no dent in this number.

In fact, due to well-established ecological (carrying capacity) and social (governance system and customary laws) reasons, the surplus population of nomads has always migrated out to rural and urban areas, guarding against the stress of overpopulation.

It is to be expected that these societal changes also bring about new forms of play, replacing traditional games with new ones. This understanding is reflected in the United Nations Convention on the Rights of the Child (UNCRC) and has been incorporated in General Comment No. 17 (2013) on Article 31 [3]:

"Children reproduce, transform, create and transmit culture through their own imaginative play, songs, dance, animation, stories, painting, games, street theatre, puppetry, festivals, and so on. As they gain understanding of the cultural and artistic life around them from adult and peer relationships, they translate and adapt its meaning through their own generational experience. Through engagement with their peers, children create and transmit their own language, games, secret worlds, fantasies and other cultural knowledge."

In this study, we use the term "play" (baazi in Luri and Persian) interchangeably [4], both to mean games (structured) and free play (spontaneous, unstructured). Games played in an indigenous and traditional culture are tied to the values of that culture. Whether or not the games that are contrary to the tradition of a society become suitable replacements for traditional games is to be investigated in this paper. Kohgilouyeh and Boyer Ahmad province in Iran was chosen as a focus, because in this province, the acceleration of sedentarization has been more severe than in most other regions of the country. Hence, it provides a microcosm for observing the impact of modernization on children's behavior in play and consequently in health changes. This province has a deep-rooted nomadic culture, and though many of the nomadic communities have become settled, there are still parts of the tribes that have remained migratory and therefore more traditional.

Among the settled population, the traditional children's games unique to the Kohgilouyeh and Boyer Ahmad region are gradually disappearing and are being replaced with more generic modern alternatives. We outline the benefits of the old games, many of which could be adapted to suit current lifestyles whilst retaining their spirit of cooperation.

\subsection{Methodology}

Opportunities, as well as challenges, of conducting ethnographic research were highlighted by Friedl, who conducted such research between 1965 and 1994 during eight visits to this tribal region (and spending altogether six years in the village of Deh Koh). She wrote: “...although more than half the population of Iran is under the age of fifteen, few psychologists, educators, and social scientists actually focus on the development, not to speak of the culture, of children...Literature on 
children is scarce. One can start research anywhere on any topic concerning children, and be a pioneer." Because children "tend to clam up in the presence of strangers, and they play in hard-to-observe places and rarely with adults, let alone a relative stranger like me" [5], reflecting an indigenous perspective in this paper is invaluable.

This article aims to highlight the importance of the conservation and revival of traditional and local games. We explain the local culture of the area and the role that traditional games play in the development of children's physical and mental health [6], as well as their practical and social skills. To this end, we compare and contrast the games of three generations of some members of Kohgilouyeh and Boyer Ahmad tribes in the province.

The indicator of the benefits of games for children's physical and mental health will be the number and kind of social skills children learn in those games. As this piece of work was unfunded and relied on participants' own, scarce resources, the research tools that might have been employed in a fully-fledged research study were not available to the team. This is why, regarding the first and third generations, the social skills achieved were assessed through a process of reflection, observation and informal discussions. In the second generation, informal discussions were supplemented by the researchers' own experiences and observations as a second generation nomad. In all generations, participant observation and informal focus group discussions were the primary participatory methods used.

\subsection{Research History}

Many anthropologists have discussed the re-emergence of local games. For example, Ghaffari (2005) [7], an expert in the culture of Kohgilouyeh and Boyer Ahmad, recorded the traditional games of the province. However, up to now, no scientific research has been conducted about the importance of these games and their impact on the health of the children of this province. Our work seeks to provide a first step in this direction, and it is hoped that it will prompt a wider, empirical research study to be conducted in the near future. What distinguishes our emphasis from other approaches is the consideration of social skills in relation to the physical health and mental health aspects of children's play.

\section{The Theoretical Basis of the Research}

\subsection{Child Health, Play and Social Skills}

Children need particular attention. Social participation by children is very important to their wellbeing and health (Hart, 1997) [8]. UNICEF believes that children's participation in matters related to them from a very early age helps to protect them in a number of ways: against being involved in deviant activities, getting hurt and being dominated. Their participation contributes to the raising of a generation that feels responsible for and respects their own and others' rights. UNICEF argues that keeping children at the margins creates a dangerous situation for them. When children are not involved in decision-making processes and in opportunities to act constructively in matters that affect their lives, they do not have the appropriate vital abilities and skills when they grow up (Kamkar, 2003) [9]. 
This social growth consists of an acquired harmonious collection of social skills and behaviors, which enables individuals to establish good mutual relations with other people, to develop positive responses and to avoid behaviors that have negative consequences. It helps children acquire skills, such as cooperation, responsibility, empathy, self-control and independence, which are important aspects of growth (Gallahue and Ozmun, 1997) [10].

A significant part of a child's life consists of play and activities discovering the surrounding world. Learning through play is one of the most effective methods of fostering social skills. Play is the child's world and the focus of its concentration. Through play, children acquire ongoing information about themselves, their bodies and their movements. Many of the basic emotional concepts children develop have their roots in their free and happy world of play (Gallahue and Ozmun, 1997) [10].

Play teaches children to have proper relationships with others: it establishes what "normal" behavior is and promotes cooperation and participation in group activities. The child learns that if $\mathrm{s}$ /he has some rights, others should have rights as well. To a large extent, a child's life in society depends on this relation and activity (Sheikh, 2003) [11].

Experts in developmental theories argue that employing appropriate programs corresponding to the physical and psychological characteristics of human beings, especially during childhood and adolescence, support physical and mental health. Through these processes, individuals are being prepared to live and grow in a social environment (Bellucci, 1980) [12].

James and Prout (1990) [13] believe that children's play is an important part of their lives. All children are born and grow up in a specific society. Each of these societies consists of individuals who share legal, political and economic structures. An important part of children's development is to acquire an understanding of these structures. Therefore, when they grow up, they will be able to fit into this social framework. Vygotsky too emphasizes that play has an important part to play in children's growth, impacting on the development of both cognition and emotional/social development. The role that children play in their games shows their social and cultural position. Through play, children acquire the tools and concepts connected to their culture (Vygotsky, 1976, 1978) $[14,15]$.

Our discussion up to now shows the important role of play in learning social skills and the physical and mental wellbeing of children. In our analysis, the degree of learning social skills through play has been chosen as an index of the physical and mental health of three generations of children in this province.

It must be recognized that in many countries around the world, and for different reasons, there has been a decline in children's access to play opportunities [16]. Gray concludes that "the decline in play may be the factor that has most directly caused the decline in children's mental health" and that "restoring children's free play is not only the best gift we could give our children, it is also an essential gift if we want them to grow up to be psychologically healthy and emotionally competent adults" [17]. 


\subsection{Generation}

The concept of generation is ambiguous; separating one generation from the next is a difficult task. In this study, there was limited potential for entering the discourse on "generation". We are addressing three generations of "children" in this province (see below). We acknowledge the fact that the greater the gap between generations, the lesser is the understanding of one generation by the other (Panahi, 2004) [18]. Our division of three generations is based on the kind of game they play or played and the attitudes of children towards these games.

- The first generation includes primarily the children of communities who have been nomadic, as well as those who have settled in villages. Since the 1980 s, in some villages closer to cities, television started to make inroads with the spread of electricity. In those areas where a mobile way of life has persisted, this generation of children is still spending their free time playing unique and specific local and traditional games.

- The second generation's childhood (ca. 1980-1990) coincides with the arrival of computer games to the area, but before these became popular and widespread. This generation spent most of their time playing group games and a limited amount of time on computer games. The group games of this generation, such as football, hop-scotch, haft sang, dodgeball, etc., were becoming more generic. An important factor in this is the expansion in the means of communication especially through radio and television, which helped disseminate games that are not specific to a certain area or culture.

- The third generation (after 1990) grew up at a time when computer games became widespread and access to the Internet and online games became available. By then, traditional games were largely forgotten by this generation, and the way games are seen has changed in comparison with the two other generations.

Although the games themselves had changed from the first to the second generation, the goals of the games did not change. The games of the second generation were still social and group oriented. However, a marked generational gap can be observed in the differences between the third and first and second generations.

\subsection{About Kohgilouyeh and Boyer Ahmad Province}

\subsubsection{Geography}

Kohgilouyeh and Boyer Ahmad province is located in southwestern Iran within the Zagros mountain range. It is over 16,000 square $\mathrm{km}$ in size and includes eight townships; Boyer Ahmad, Kohgilouyeh, Gachsaran, Dena, Bahmaee, Bashtbavee, Charam and the provincial capital Yasuj. Kohgilouyeh and Boyer Ahmad is known as the "province of four seasons" because of its variable climate and seasonal changes in temperature. This seasonal weather pattern has affected the lifestyle of local people (Ghaffari, 2011) [19] and also the types of play in which children engage. 


\subsubsection{Culture and Social Position}

The provincial dialect is Lori, which is part of the southwestern language group, with the grammar related to Middle-Persian. People of Kohgilouyeh and Boyer Ahmad are nomadic by origin, and the province has hosted Boyer Ahmad, Bahmaee, Tayebi, Bashtbavee, Doshmanziari and Charam tribal confederacies (Ghaffari, 2011) [19]. The lives of nomadic communities are closely tied with nature, and the main source of their livelihood is nomadic pastoralism. Nomads often migrate in large groups of at least "nomadic camps" (maal), and the nomadic communities have had specific governance systems; these have broken down or been weakened over the past few decades. This weakening of the tribal systems has resulted in the fragmentation of socio-political frameworks and management arrangements, which used to govern a community as an independent unit. This, alongside numerous other causes, has led to major changes in the lifestyle of the inhabitants of Kohgilouyeh and Boyer Ahmad. One of the most obvious aspects of this upheaval was the large-scale sedentarization of nomadic communities in this region.

Currently, the nomadic population of Kohgilouyeh and Boyer Ahmad can be categorized by their lifestyle as follows:

(i) Migrating camps or "tent-holds" (nomadic households) using traditional means of migration by draft animals, on foot or by car. They practice nomadic pastoralism, but supplement natural rangeland feed with purchased, or sometimes grown, fodder. Living in tents, with challenging environmental conditions, competition with local sedentary populations or occasionally other tribes, and living in harsh mountains meant that individuals in each tribal unit have had to learn to support each other and to have responsibility for each other. It has created a sense of identity in which concepts such as loneliness, alienation or individualism did not exist (Taheri, 2006) [20].

Children from their early years onwards have had to accept some responsibility, according to their age and gender. They learn directly from their daily lives about responsibility and cooperation. For example, very young children are supposed to feed, graze and water chicken, chicks, goat kids and lambs. This is at once a kind of work and a kind of play. Instead of hugging toys, they hug such animals. Therefore, animals play an important role in the lives of these people, and children learn this important fact. Thus, nomadic children, from an early age and through work and play, learn how to enter life in the future when they grow up.

(ii) Sedentarized nomads residing in villages. The change in lifestyle from nomadic to sedentary meant their livelihood was now more reliant upon farming and semi-sedentary animal husbandry.

Although the traditional nomadic culture still exists in parts, as media and other facilities become more accessible in the villages, this culture is starting to diminish.

(iii) Sedentarized nomads residing in cities. These are mainly migrants from villages looking for work. Their employment tends to be less agriculturally based and more in line with that of other city workers, including in the service industries. 


\section{Findings and Discussion}

\subsection{Traditional Local Games (The First Generation Games)}

This study took as a sample 33 traditional local games of the Kohgilouyeh and Boyer Ahmad province; of these, nine were chosen to be discussed (see Table 1). From the latter, two are considered in some detail below. The remaining seven, mostly boys' games, are then listed. Girls would also participate in these games, though we acknowledge that future studies will need to pay special attention to gender and explore girls' changing play and any impact, positive or negative, on their health.

\subsubsection{General Game Rules}

Some of the goals and effects of these native games are highlighted in Table 2; many of them demonstrate a spirit of cooperation. Since the rules for designating the "Salaar" (game master), electing the game starter and picking team mates are the same for all group games, we begin by describing them in general.

\section{Designating the Salaar and Picking Team Mates}

At the beginning of each game, two of the oldest players are elected as Salaar. The remaining players pair up and decide upon nicknames for themselves. Each pair then puts their arm around one another's shoulders and introduces themselves to the Salaar by giving the two nicknames (without telling which nickname belongs to which player) and saying the word "sherr".

One of the Salaars replies by saying either "Andaresh venei gei kol" ("It is up to the tail-less cow"), "Sherr be der" (torn to pieces) or "Andar" (come in). Next, one of the players asks "Do you want the Lion or the Tiger?" and the Salaar chooses one of the nicknames. Whichever of the pair it belongs to is the person that joins their team; this will continue until all of the players have been chosen.

In this way, players are chosen anonymously, and none of the children are humiliated by always being the last one to be picked. This increases the self-confidence of children, which is an important factor in their mental wellbeing.

\section{Starting the Game}

There are several methods to ensure equal chances for either team to start the game: "Gendi o Qero", "Hali", "Tar o Khoshk":

Gendi o Qero: in this method, the two Salaars secretly take on the names "Gendi" (meaning lentil in the local dialect) and "Qero" (a type of weed growing in lentil fields). They then go to the youngest person and ask "Gendi bexowse yaa Qero?" (Should the lentil sleep or the weed?). If the answer is "Gendi bexowse" (the lentil should sleep), "Qero" is permitted to start the game with his team and vice versa. 
The reason for using "Gendi" and "Qero" is that when harvesting lentils, there are Qero weeds amongst the lentils that should be pulled out before cooking. This has become a metaphor for picking and sorting. This method both values the decisions of the youngest and provides an equal chance for both parties to start the game.

\section{Ending the Game}

A team in the winning position can stop the game at any time; to end it in other ways requires an agreement between the teams. This teaches children to play fairly. Therefore, the child learns to respect other people's rights in a practical manner and through play.

\subsubsection{Description of Two Sample Games}

\section{Qale Tu and Baving Baazi (Family Life and Wedding Game)}

In this game, usually played by the children of an extended family or nomadic camp (maal), children play out the ordinary life of a family. It usually ends with an imaginary wedding.

Players gather together and build small houses or tents. Each person acts as a family member. To begin with, the children make dolls, farming tools and kitchenware to simulate real life. Young girls usually use the dolls they have made themselves as the bride and groom. The dolls are mainly made of wood and have movable limbs. Girls make them dresses and folk costumes, put colorful cloths in their hands and act out folk dances with them. These dances are an inseparable part of the culture. All of the usual professions within society are played out. At the end of the game, the eldest girl in the group stands in the middle of a circle formed by the other children who sing her questions, which she answers in a "call and response" format song.

\section{Kel Kela Bard (Stone Throwing Game)}

To play this game, players divide into two teams and stand 20-30 meters apart. Each team places five stones on the ground. The stone closest to the other team is called the "frontier", representing the commander in war. First, it is agreed who is starting the game. If Team A starts, each team member is allowed to throw one stone at the frontier. Until the frontier is hit, no one is allowed to aim for other stones. As soon as the frontier is hit, aiming for the remaining four stones is allowed. If any of the stones is hit, the player is allowed to throw again. 


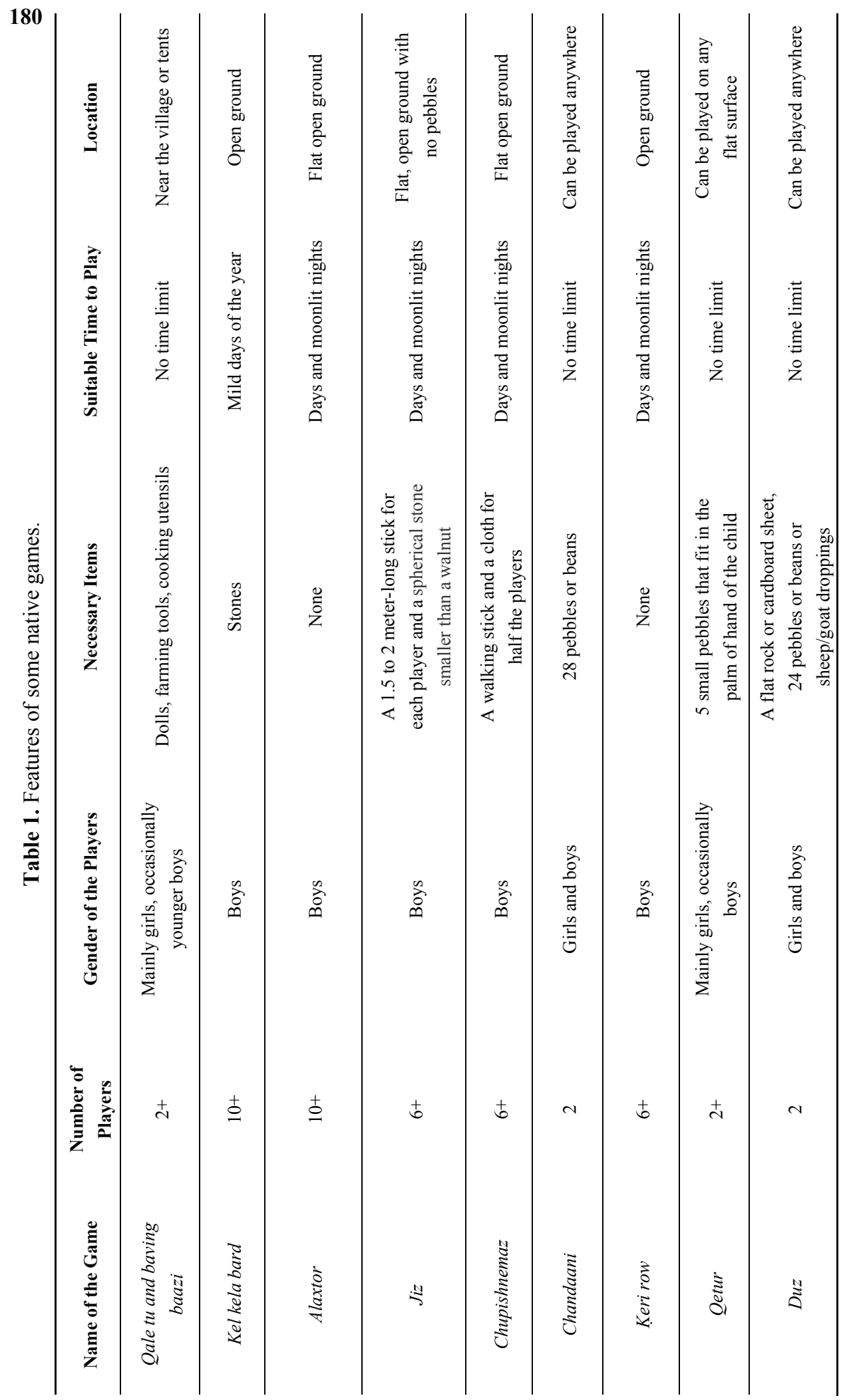




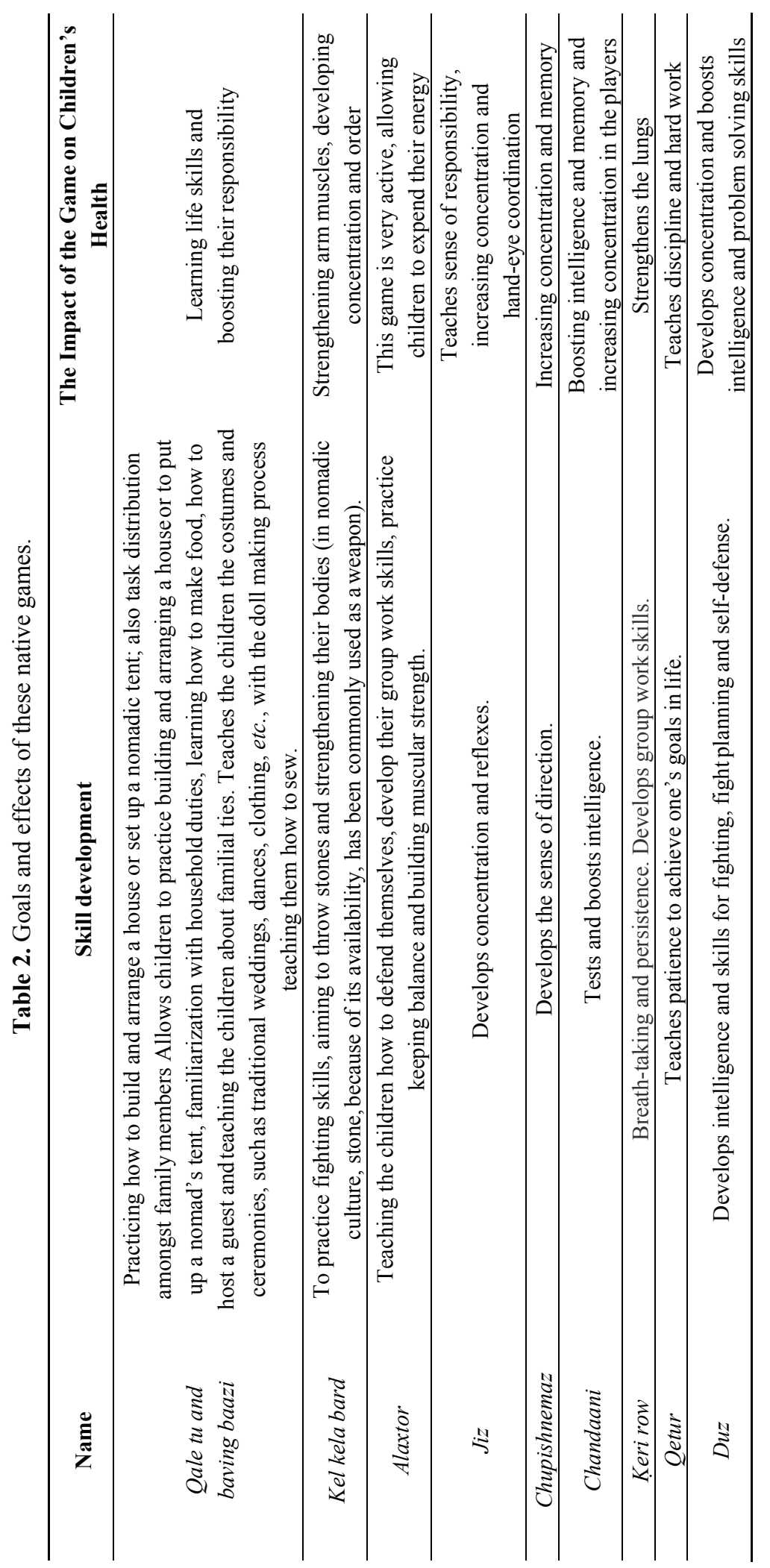




\subsubsection{Classification of the Traditional Games}

Based on our examination, we can classify traditional games according to time (some games are only played at specific times), gender, how physical or cerebral they are and if they are accompanied by songs.

Time: Ti-ti marrow and xenaatapak, in moonlight; uhala zokch, in spring and when the earth is damp.

People/tent-holds were living in tents, and the area where children play can be overseen by adults. In villages, people are relatives. This creates a situation in which children can play safely, in moonlight, outdoors. In fact, these night games are only played during moonlight or around the houses. We recognize that nowadays, in some places, children are not allowed outdoors at night. Yet, such play is beneficial for children's health and well-being such as not being afraid of the dark.

Cerebral games: dooz, chandaani, kus, peshkelagar, kedu.

Physical activity games, mainly played by boys: alaxtor, jiz gorna doval, band sare leng.

Games accompanied by singing: qalah tu va bavig baazi, aqa donba, qelong sarhadi.

\subsubsection{The Characteristics of Traditional Games}

The traditional games have developed over time to teach life skills and prepare children for the future. This results in the holistic development of children (including emotional, psychological, physical, social, cognitive, perceptual and moral development).

- These games require no special equipment; thus, they are accessible and affordable for all children regardless of family background and wealth.

- All of the children are equal within the games with the emphasis being on participation.

- The joy and happiness of the players remain whether they win or lose the game.

- Playing in the open air and interacting with the environment, attention to natural elements and dedicating some games to the elements such as rain, develops a sense of responsibility and cooperation, teaches discipline and respect for each other and for nature, prevents selfishness, boosts physical abilities and develops concentration.

Through having identified as an indicator the learning of social skills and their effects on children's physical and mental health and wellbeing, it can be said that the games of Kohgilouyeh and Boyer Ahmad rank qualitatively high in this indicator.

\subsection{The Games of the Second Generation}

The children of this generation are usually raised in towns and villages. Their childhood coincides with the time that television and radio were becoming widespread and computers began to become available. A gap between parents and children begins to become apparent in this generation, with traditional cultures no longer passed on by parents to the next generation. Nor are teachers and the media aware of the importance of conserving the traditional games. 
The reasons for this break in the cultural pathway are numerous and beyond the scope of this study.

The children of this generation learn their games from friends and classmates at kindergarten and school; they are greatly influenced by new ideas seen and heard on broadcast media. Therefore, old culturally-specific games start to fade away and are replaced by more general national and globally-available games (these findings are based on observations of the first author of this article, herself a child from the second generation, as well as on interviews with other individuals from the same generation).

Some tent-holds/households do pass down the traditional games to their second generation, but overall, fewer traditional local games are being played in comparison with games played everywhere in Iran. However, because the national games are usually based on traditional culture, in these games at least, there are still some connections to the traditional games. The introduced international and foreign games, on the other hand, have no links with Iranian culture.

Group games, played outdoors, are still popular with this generation. Computer games were not as complex and sophisticated in the past and not as appealing to children as they are today, resulting in less time spent playing them.

Since communities were stronger in the past, there was better supervision over the neighborhood, and the streets were safe places for children to play. Based on the first author's observations and interviews, the beneficial effects of these games remain evident in the generation.

The positive aspects of collective games in terms of furthering children's physical and mental health remain also true for this generation.

Since the culturally-rooted traditional games began to fall out of favor with this generation, people became gradually separated from their cultural roots. The games of this generation are not as adept at aiding the development of life skills. For example, Luri singing is being replaced by singing in Persian (the national language, taught exclusively in schools). Therefore, knowledge about the common vocabulary of the local language has been declining. At this time, we therefore witness a kind of social alienation and the beginning of the lack of identity of today's youth in relation to their local culture and skills. Therefore, it could be said that the games of this generation are contributing much less to improving children's health than the ones being played by the first generation.

\subsection{The Games of the Third Generation}

Like increasing numbers of children around the world, the children of this generation spend much of their leisure time online, including playing computer games. They rarely play offline group games of any kind; it is only during school breaks that some of these group games can be observed.

Within this generation, there is much less time dedicated to group games in comparison to solitary games. The loss of traditional games in this generation could result from a desire of the young people to adopt what they see as a modern lifestyle with new trends and a new popular culture. This is compounded by the lack of adequate space to play, changes in attitudes towards the aim of games (their spirit now is competitive rather than inclusive and cooperative) 
and also the increased availability of computer games. Such new forms of play also prepare children for future working life, which increasingly includes work with new forms of technological communication tools. The impact of these rapid changes on both genders of children, and changing parental attitudes, is not yet well understood and requires further exploration.

The scarcity of space for traditional games, different points of view about the goals of games, increased access to computer games and the lack of transmission of one generation's games to the next are all reasons for a lack of interest in traditional games in this generation. With the fast growth of computer science, computer games have begun to occupy the main part of children's play. These games have taken the place of collective and other traditional games. On the positive side, these games can increase the imaginative power of children. The child places him/herself in the atmosphere of the game; in their imagination, they consider themselves to be the main champion. In these games, there is a need for speed and fast reaction; therefore, they increase the speed of their hand-eye coordination. One can also teach various educational subjects by these means. Some of these games can be used to fill the leisure time of children. Computer games also have some negative aspects: they can make children agitated; children sit in front of the computer for a long time, and this can have negative consequences for their health (e.g., eyesight, posture). Through reduced physical activity, the child encounters physical damage, including obesity.

The negative aspect of obesity in Iran has been researched by a growing number of scholars, such as Hemati et al., who wrote: "Unhealthy lifestyle, especially excess time spent on watching TV, may cause obesity in Yasuj [the capital of Kohgilouyeh and Boyer Ahmad] adolescents.” [21]. Others have focused on environmental factors in Iran [22], which are described by Tamjydtash (2011) [23] as follows:

"Increased weight may reduce the level of the child's activity. This will affect the child's participation in recreational activities. The increased weight may create problems in terms of acquiring experiences in the general development of the child and will reduce the child's access to social recreation or play with other children. At the same time, a child's bodily condition can be an important factor of the child not being socially acceptable."

In addition to these damages, some children who play online games excessively may lose direct interaction and cooperation with other children. On occasion, their education is also negatively affected. Excessive engagement in such games can damage a child's emotional relations with parents and other members of their families; this in turn creates and deepens the generational gap and lack of connection between children and parents.

In the authors' view, modern, mainly computer, games, in terms of social skills, occupy a much lower place on the scale of health indicators compared with traditional games. 


\section{Concluding Observations}

\subsection{Comparing Generations}

In the first and second generations, the goal of the games played is defending oneself, one's tent-hold/household and their belongings, whereas in the third generation, the goal is to demonstrate superiority over playmates. This results in the loss of self-esteem of the loser.

In traditional games, the financial background of a child's family has no effect on the type of games available. The players have a sense of kinship towards each other, whereas third generation games often require expensive equipment, such as game consoles, which many cannot afford, thus broadening the "digital divide". This can bring about a sense of selfishness evident in some children's behavior.

More systematic research is necessary to determine whether violence is increasing in the games of the third generation, in comparison with traditional games, which may have been played in a more or less violent society.

In traditional games, singing is suitable to local culture, while the songs in computer games are suitable to the culture of the society making the game, which occasionally are in contradiction with the local culture. The gender aspects of these changes require further study.

Computer games can sometimes be at odds with cultural values, for instance the way women are depicted can be very different from traditional norms. The potential effects of empowering girls through new forms of play and therefore changing their knowledge levels, status, etc., have yet to be explored. Traditional culture in a given area is an old-established factor, and tensions can arise if changes happen suddenly.

Traditional games prepare children for their future social life by becoming more responsible, being able to communicate well with others and learning traditions from the generations before. Computer games, on the other hand, foster new skills, including communication skills, relevant for today's educational and employment requirements, but are often based on different values.

Our overall conclusion is that the games of the third generation have different, and arguably reduced, social skills compared with first and second generation games.

\subsection{Concluding Remarks}

Our paper highlights the fact that traditional games drawn from the culture of a people play an important role in teaching social skills to children and in preparing them for their future life. The positive impact of this learning on the health (physical and mental) of nomadic and rural children in Kohgilouyeh and Boyer Ahmad can be observed. Through the passage of time, children have become more interested in modern forms of games. There has been a tendency of children to distance themselves from the traditional play and culture of their people. The effect of these changes on children's physical and mental wellbeing is vastly under-documented and deserves further study. 


\subsection{Recommendations}

To address some of the issues identified, the authors suggest several measures to be considered and implemented:

- The family, a child's first playmates, should be familiarized with traditional games in order that they can pass these down to the next generation.

- Organizations such as national TV channels, education departments and other relevant bodies have a role to play in transmitting traditional games.

- Traditional games could be included in sport/physical education in schools. Empowering and upskilling teachers is one of the best ways to teach native games.

- Traditional games should be recognized as part of cultural heritage, and the Cultural Heritage Organization (Office of the President of the Republic) should take more actions towards conserving these games.

- Children today live in different circumstances; neighborhoods have changed and there is less space to play. Therefore, updating or adapting traditional games could support their revival and preservation.

- Competitions could be organized that focus on local traditional games and revive those no longer played.

- Since many of the traditional games require large areas of safe, open ground, local parks specifically designed with these games in mind should be created to provide the necessary play space.

\section{Acknowledgments}

Acknowledgements go to Ute Navidi for her critical observations. Thanks are also extended to the anonymous referees for their detailed feedback on the first draft of this article.

\section{Author Contributions}

The authors conceived of and co-wrote this article.

\section{Conflicts of Interests}

The authors declare no conflict of interest.

\section{References and Notes}

1. Loeffler, RL. Recent Economic Changes in Boir Ahmad: Regional growth without development. Iran. Stud. 1976, 9, 266-287.

2. Shahshahani, S. The tribal schools of Iran: Sedentarisation through education. In Contemporary Society, Tribal Studies; Pfeffer, G., Behera, D.K., Eds.; Concept Publishing Company: New Delhi, India, 2002. 
3. For the Full Text of the General Comment 17. Available online: www2.ohchr.org/ english/bodies/crc/docs/GC/CRC-C-GC-17_en.doc (accessed on 3 March 2015).

4. This definition of play therefore departs, to some degree, from that adopted by the UN Committee on the Rights of the Child (see fn3): "Children's play is any behaviour, activity or process initiated, controlled and structured by children themselves; it takes place whenever and wherever opportunities arise. Caregivers may contribute to the creation of environments in which play takes place, but play itself is non-compulsory, driven by intrinsic motivation and undertaken for its own sake, rather than as a means to an end. Play involves the exercise of autonomy, physical, mental or emotional activity, and has the potential to take infinite forms, either in groups or alone. These forms will change and be adapted throughout the course of childhood. The key characteristics of play are fun, uncertainty, challenge, flexibility and non-productivity. Together, these factors contribute to the enjoyment it produces and the consequent incentive to continue to play. While play is often considered non-essential, the Committee reaffirms that it is a fundamental and vital dimension of the pleasure of childhood, as well as an essential component of physical, social, cognitive, emotional and spiritual development".

5. Friedl, E. Children of Deh Koh: Young Life in an Iranian Village; Syracuse University Press: New York, NY, USA, 1997.

6. The most commonly quoted definition of health is that formalized by the World Health Organization (WHO) over half a century ago; "a complete state of physical, mental and social well-being, and not merely the absence of disease or infirmity." WHO. Preamble to the Constitution of the World Health Organization as adopted by the International Health Conference, New York, 19-22 June 1946, and entered into force on 7 April 1948. Our definition of health is wider and akin to that of Aboriginal Australians which incorporates community health and spiritual well-being as core aspects. "...Health does not just mean the physical well-being of the individual but refers to the social, emotional, spiritual and cultural well-being of the whole community. This is a whole of life view and includes the cyclical concept of life-death-life". National Health and Medical Research Council. Promoting the health of Indigenous Australians. A review of infrastructure support for Aboriginal and Torres Strait Islander health advancement. Final report and recommendations. Canberra: NHMRC, 1996: part 2: 4.

7. Ghaffari, Y. Ghaffari recorded traditional tribal games, many of which were played by men. In Traditional games of Kohgilouyeh. Ravayat: Tehran, Iran, 1995 (In Persian).

8. Hart, R. Children's Participation. The Theory and Practice of Involving Young Citizens in Community Development and Environmental Care; Earthscan Publications: London, UK, 1997.

9. Kamkar, M. A review over UNICEF function on children's participation. Available online: http://en.journals.sid.ir/ViewPaper.aspx?ID=50821 (accessed on 5 March 2015) (In Persian).

10. Gallahue, D.L.; Ozmun, J.C. Understanding Motor Development of Infants, Children, Adolescents, Adults; Plenum Press: New York, NY, USA, 1997; pp. 195-210. 
11. Sheikh, M.; Bagherzadeh, F.; Yousefi, S. Effect on motor development in selected school games in third-year female students in Tehran district 5. Olymp. Mag. 2003, 23, 77-87.

12. Bellucci, A. Examination of the Relationship between Motor Function, IQ and Adaptive Behavior in Educable Intellectually Disabled Children Aged 7-9 in the City of Nishapur. Master Thesis, Faculty of Humanities, Tarbiat Modarres University, Tehran, Iran, 2000.

13. James, A.; Prout, A. Constructing and Reconstructing Childhood; Falmer: Basingstoke, UK, 1990.

14. Vygotsky, L.S. Mind in Society; Harvard University Press: Cambridge, MA, USA, 1978.

15. Vygotsky, L.S.; Bruner, J.S.; Jolly, A.; Sylva, K. (Eds.) Play and Its Role in the Mental Development of the Child; Basic Books: New York, NY, USA, 1976.

16. International Play Association. Available online: www.ipaworld.org (accessed on 3 March 2015).

17. Gray P. The decline of play and the rise of psychopathology in children and adolescents. Am. J. Play 2011, 3, 443-463.

18. Panahi, M.H. The generation gap in Iran and its impact on education. Soc. Sci. Q. 2004, 27, 1-41 (In Persian).

19. Ghaffari, Y. Weddings and Their Change in Kohgilouyeh and Boyer Ahmad; The Mana: Isfahan, Iran, 2011.

20. Taheri, M. Criminal Matters in Nomadic Tribes. Master Thesis, University of Orumieh (Urmia), Orumieh, Iran, 2006.

21. Hemati, A.; Moghadasi, M.; Aziz, F. Association among lifestyle status and body mass index in Yasuj adolescents. Int. J. Curr. Res. Aca. Rev. 2014, 2, 19-24.

22. Kelishadi, R.; Hashemi Pour, M.; Sarraf-Zadegan, N.; Sadry, G.H.; Ansari, R.; Alikhassy, H.; Bashardoust, N. Obesity and associated modifiable environmental factors in Iranian adolescents: Isfahan Healthy Heart Program-Heart Health Promotion from Childhood. Pediatr. Int. 2003, 45, 435-442.

23. Tamjydtash, E. Comparative analysis of games and social impact of computer games on children's development. Peivand J. 2011, 385, 38-41 (In Persian). 
MDPI AG

Klybeckstrasse 64

4057 Basel, Switzerland

Tel. +41616837734

Fax +41 613028918

http://www.mdpi.com/

Children Editorial Office

E-mail: children@mdpi.com

http://www.mdpi.com/journal/children 



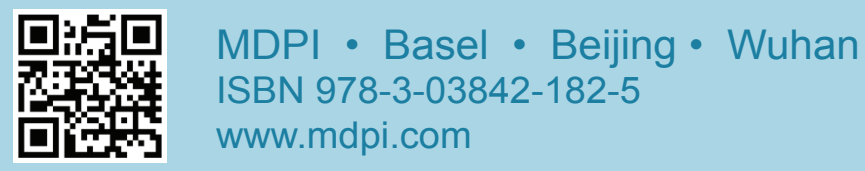

